\title{
Haemostatic variation in subjects with atherothrombotic risk : modulation by dietary fish oil
}

Citation for published version (APA):

Vanschoonbeek, K. (2007). Haemostatic variation in subjects with atherothrombotic risk : modulation by dietary fish oil. [Doctoral Thesis, Maastricht University]. Maastricht University. https://doi.org/10.26481/dis.20071213kv

Document status and date:

Published: 01/01/2007

DOI:

10.26481/dis.20071213kv

Document Version:

Publisher's PDF, also known as Version of record

\section{Please check the document version of this publication:}

- A submitted manuscript is the version of the article upon submission and before peer-review. There can be important differences between the submitted version and the official published version of record.

People interested in the research are advised to contact the author for the final version of the publication, or visit the DOI to the publisher's website.

- The final author version and the galley proof are versions of the publication after peer review.

- The final published version features the final layout of the paper including the volume, issue and page numbers.

Link to publication

\footnotetext{
General rights rights.

- You may freely distribute the URL identifying the publication in the public portal. please follow below link for the End User Agreement:

www.umlib.nl/taverne-license

Take down policy

If you believe that this document breaches copyright please contact us at:

repository@maastrichtuniversity.nl

providing details and we will investigate your claim.
}

Copyright and moral rights for the publications made accessible in the public portal are retained by the authors and/or other copyright owners and it is a condition of accessing publications that users recognise and abide by the legal requirements associated with these

- Users may download and print one copy of any publication from the public portal for the purpose of private study or research.

- You may not further distribute the material or use it for any profit-making activity or commercial gain

If the publication is distributed under the terms of Article $25 \mathrm{fa}$ of the Dutch Copyright Act, indicated by the "Taverne" license above, 


\title{
HAEMOSTATIC VARIATION IN SUBJECTS WITH
} ATHEROTHROMBOTIC RISK

\author{
Modulation by dietary fish oil
}



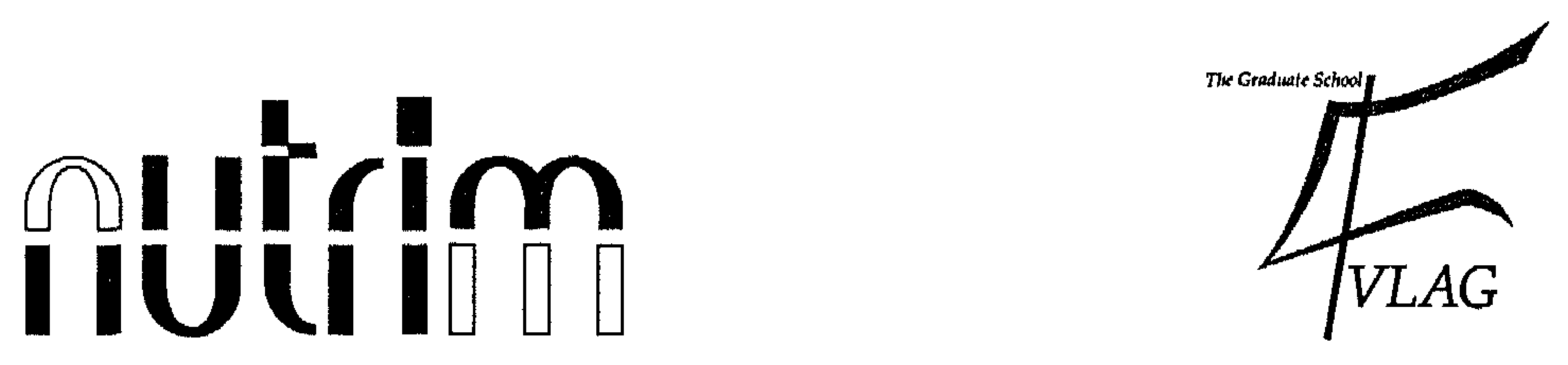

The studies presented in this thesis were performed within the Nutrition and Toxicology Research Institute Maastricht (NUTRIM), which participates in the Graduate School VLAG (Food Technology, Agrobiotechnology, Nutrition and Health Sciences) accredited by the Royal Netherlands Academy of Arts and Sciences.

Cover design: Marie-Louise Poelmans \& Kristof Vanschoonbeek

Layout: Kristof Vanschoonbeek

Printed by: Drukkerij Martens, Alken

(C) Kristof Vanschoonbeek, 2007

ISBN: 978-90-9022530-2 


\title{
HAEMOSTATIC VARIATION IN SUBJECTS WITH \\ ATHEROTHROMBOTIC RISK
}

\section{Modulation by dietary fish oil}

\author{
PROEFSCHRIFT \\ ter verkrijging van de graad van doctor \\ aan de Universiteit Maastricht, \\ op gezag van de Rector Magnificus, \\ Prof. mr. G.P.M.F. Mols \\ volgens het besluit van het College van Decanen, \\ in het openbaar te verdedigen \\ op donderdag 13 december 2007 om 14:00 uur
}

door

Kristof Vanschoonbeek

geboren te Hasselt op 3 januari 1973 


\section{Promotor}

Prof. dr. ir. W.H.M. Saris

\section{Co-promotores}

Dr. J.W.M. Heemskerk

Dr. M.P.M. de Maat (Erasmus MC Rotterdam)

\section{Beoordelingscommissic}

Prof. dr. C.D.A. Stehouwer (voorzitter)

Prof. dr. H. ten Cate

Dr. C. Kluft (TNO Leiden)

Prof. dr. E.C.M. Mariman

Prof. dr. ir. R.P. Mensink

The research described in this thesis was supported by a grant from the Netherlands Organization for Scientific Research (ZonMw, programme Nutrition and Chronic Diseases).

Financial support by Numico Research B.V. for the publication of this thesis is gratefully acknowledged. 


\section{CONTENTS}

$\begin{array}{lll}\text { Chapter } 1 & \text { General introduction } & 7\end{array}$

Chapter $2 \quad$ Fish oil consumption and reduction of arterial disease 27

Chapter $3 \quad$ Thrombin-induced hyperactivity of platelets of young stroke 39 patients

Chapter 4 Initiating and potentiating role of platelets in tissue factorinduced thrombin generation in the presence of plasma: subject-dependent variation in thrombogram characteristics

Chapter 5 Variable hypocoagulant effect of fish oil intake in man: modulation of fibrinogen level and thrombin generation

Chapter 6 Plasma triacylglycerol and coagulation factor concentrations predict the anticoagulant effect of dietary fish oil in overweight subjects

Chapter $7 \quad$ Anticoagulant effect of dietary fish oil in hyperlipidemia: a study of hepatic mRNA expression in APOE2 knock-in mice

Chapter $8 \quad$ General discussion

Summary

Samenvatting

Dankwoord 


\section{Chapter 1}

General introduction 


\section{BIOSYNTHESIS AND FUNCTION OF n-6 AND n-3 POLYUNSATURATED FATTY ACIDS}

Lipids are a major source of metabolic energy and provide essential material for the formation of cell membranes. Most lipids contain polyunsaturated fatty acids (PUFA), which are characterized by two or more double carbon-carbon bonds, appearing in nonconjugated strings. The position of the first double bond, as counted from the methyl end of the carbon chain, determines the biosynthetic class of PUFA. Major fatty acid classes are $n-3, n-6$, and $n-9$, where the first methyl-terminal double bond is located between carbon atoms 3-4, 6-7, and 9-10, respectively. Because in mammals carbon chain elongation and desaturation of fatty acids proceeds starting from the carboxyterminal end, these classes are retained during biochemical fatty acid processing (1). Accordingly, the so-called essential fatty acids linoleic acid (18:2 $n-6)$ and $\alpha$-linolenic acid (18:3n-3) must be acquired by dietary means. In various tissues, linoleic acid is converted into arachidonic acid (20:4 n-6), while $\alpha$-linolenic acid is the precursor of eicosapentaenoic acid (20:5 n-3) and docosahexaenoic acid (22:6n-3). Fish, marine mammals and seafood from cold waters are especially rich in the n-3 PUFA, eicosapentaenoic and docosahexaenoic acid, originating from consumed microscopic algae and plankton (2). In its natural form, the n-3 PUFA are accumulated in fish oil, being esterified in triacylglycerol. However, since unpurified fish oil can be contaminated with lipophilic organic chemicals (3), most commercially available preparations contain purified free fatty acids or ethyl esters.

The longer chain (C16-C22) fatty acids are essential structural components of all cell membranes, being incorporated into phospholipids and sphingomyeline. Both n-6 and n3 PUFA increase the fluidity of membranes, the membrane permeability for hydrophobic metabolites, electrical signal transduction, activity of membrane-bound receptors and enzymes, and many other membrane properties (4). Notably, the polyunsaturated C20 fatty acids are precursors of the bioactive eicosanoids, which have biological regulatory functions in cell-cell communication, i.e. the prostaglandins, thromboxanes and leukotrienes (5). The major precursor of eicosanoids is arachidonic acid (20:4 n-6), while eicosapentaenoic acid forms structurally similar eicosanoids but with often reduced biological activity.

The interest in fish oil as an n-3 PUFA nutritional component with possible antithrombotic effect arose in the mid-1970s. It was observed that Greenland Inuits, consuming high amounts of fatty fish, had a tendency of prolonged bleeding and a low incidence of cardiovascular disease (6). Since then, epidemiological observations have pointed to a clear association between fish oil consumption and reduced risk of coronary heart disease $(7,8)$. A variety of action mechanisms of the antithrombotic effect of fish oil have been proposed, namely reduction in platelet activation, lowering of the plasma concentrations of triglycerides and one or more (vitamin K-dependent) coagulation factors, and/or decrease in vascular tone (8). However, at least several of these effects are weak or vary from study to study. So far, little efforts have been made to explain this effect variation. 
General introduction

\section{PLATELET ACTIVATION AND THE PROCOAGULANT RESPONSE}

\section{Haemostasis and thrombosis}

The flow of blood through the vascular system is ensured by a balanced system of interactions between blood cells, plasma proteins and the endothelial-coated vessel wall. Damage of the vessel wall or blood stasis can result in significant disturbances of this balance, and lead to haemostasis or thrombosis. Under these conditions, a solid thrombus is formed as the result of two processes, assembly of a platelet plug and stabilization of this plug due to coagulation (9). Although usually described in a stepwise manner, these two haemostatic processes are known to occur in parallel, at least in reconstituted blood systems $(10,11)$. The more delayed process of fibrinolysis will dissolve the formed thrombus.

\section{Platelet functions}

Although being small anucleated cells, blood platelets express a high density of adhesion and signaling receptors on their membrane surface. Following vessel wall injury, platelets use these receptors to adhere to subendothelial matrix components, and then become activated via multiple signaling pathways. Specific platelet reactions include shape change (loose of discoid shape and pseudopod formation), secretion of granular constituents (e.g. autocrine agents), release of prostaglandins and thromboxanes, and surface changes of integrins leading to enhanced adhesiveness. These reactions contribute all to the formation of multi-platelet aggregates, which can develop into a vaso-occlusive thrombus (proaggregatory response).

Activated platelets have a different function in haemostasis and thrombosis, in that they can stimulate the coagulation process (procoagulant response) (12). Our laboratory and other laboratories have shown that a population of activated platelets develop profound surface changes, by which coagulation factors can bind with increased affinity to the platelet plasma membrane $(13,14)$. A key process in this conversion is the externalization of the amino-phospholipids, phosphatidyl serine (PS) and phosphatidyl ethanolamine (PE) (15). In resting platelets, these phospholipids are kept in the inner leaflet of the plasma membrane by an aminophospholipid translocase (16). However, in activated platelets experiencing a prolonged increase in cytosolic $\mathrm{Ca}^{2+}$ concentration, scrambling of the phospholipids over both sides of the plasma membrane is provoked, leading to expression of PS and PE at the outer membrane surface. The biochemical identity of the so-called scramblase activity is still unclear (17). The exposure of PS and PE greatly accelerates the activation of coagulation factors (see below). However, it has also been recognized that these phospholipids are perhaps not sufficient to explain the procoagulant function of platelets (18). Both non-stimulated and stimulated platelets produce microparticles (19-21), which provide another way of interaction with the coagulation system, because these microparticles also have a coagulation-promoting activity. 
Chapter 1

\section{Platelet (ant)agonists implicated in the procoagulant response}

This thesis concentrates on the procoagulant rather than the proaggregatory function of platelets. Therefore, a brief introduction is given of current knowledge of the platelet receptors and their signaling pathways involved in the procoagulant response (Table $\mathbf{1}$ ).

Table 1: Agents and signalling pathways involved in the procoagulant response of human platelets.

\begin{tabular}{|c|c|c|c|c|}
\hline Agonist/ligand & Receptor & Copies $^{2}$ & $\begin{array}{l}\text { Signaling } \\
\text { pathway }\end{array}$ & $\begin{array}{l}\text { Procoagulant } \\
\text { activity }^{3}\end{array}$ \\
\hline $\mathrm{PGL}_{2}$ & IP & & $\mathrm{Gs} / \mathrm{AC}$ & $\cdots$ \\
\hline $\mathrm{PGE}_{1}$ & EP & & $\mathrm{Gs} / \mathrm{AC}$ & - \\
\hline$v W F$ & GPIb-V-IX & 25000 & $14-3-3 \zeta$ & 0 \\
\hline Fibrinogen, vWF & $\alpha \operatorname{llb} \beta 3$ & 80000 & Sre & + \\
\hline Epinephrine & $\alpha 2 \mathrm{~A}$ & & $\mathrm{Gz} / \mathrm{AC} \downarrow$ & 0 \\
\hline ATP & $\mathrm{P} 2 \mathrm{X}_{1}$ & 130 & $\mathrm{Ca}^{2+}$ & 0 \\
\hline \multirow[t]{2}{*}{ ADP } & $\mathrm{P}_{2} \mathrm{Y}_{1}$ & 1000 & $\mathrm{Gq} / \mathrm{PLC}-\beta$ & 0 \\
\hline & $\mathrm{P} 2 \mathrm{Y}_{12}$ & 1000 & $\mathrm{Gi} / \mathrm{AC} \downarrow$ & + \\
\hline \multirow[t]{2}{*}{$\mathrm{TxA}_{2}(\mathrm{U} 46619)$} & $\operatorname{TP} \beta$ & & $\mathrm{Gi} / \mathrm{AC} \downarrow$ & 0 \\
\hline & $\mathrm{TP} \alpha$ & & $\mathrm{Gq} / \mathrm{PLC}-\beta$ & $?$ \\
\hline \multirow[t]{2}{*}{ Thrombin (SFLLRN ${ }^{4}$ ) } & PAR-1 & & $\mathrm{Gq} / \mathrm{PLC}-\beta$ & ++ \\
\hline & PAR-4 & & $\mathrm{Gq} / \mathrm{PLC}-\beta$ & + \\
\hline \multirow[t]{2}{*}{ Collagen (convulxin ${ }^{4}$ ) } & GPVI & 2000 & $\mathrm{FcR} \gamma / \mathrm{PLC}-\gamma 2$ & ++ \\
\hline & $\alpha 2 \beta 1$ & 4000 & Src & 0 \\
\hline Ionomycin / thapsigargin & - & - & $\mathrm{Ca}^{2+}$ & ++ \\
\hline
\end{tabular}

For details, see text.

${ }^{2}$ Global indications of receptor numbers per platelet (copies) are taken from (133).

${ }^{3}$ Symbols: - - suppression; 0 not involved; + enhancement; + + stimulation.

${ }^{4}$ SFLLRN and convulxin act only on PAR-1 and GPVI, respectively.

Endothelial-derived prostaglandin $\mathrm{I}_{2}\left(P G I_{2}\right.$, prostacyclin) and also non-endothelial prostaglandin $\mathrm{E}_{1}\left(P G E_{l}\right)$ bind to the IP and $\mathrm{EP}$ receptors on the platelet surface, respectively. Both prostaglandins act by coupling their receptor to the Gs protein, which activates adenylate cyclase (AC) (22). As a result, cyclic AMP is formed and protein kinase $\mathrm{A}$ is activated, which phosphorylates many platelet signaling proteins. This protein kinase suppresses the elevation in intracellular $\mathrm{Ca}^{2+}$ concentration in platelets (23), which is one of the key events required for generating platelet procoagulant activity (24). Both prostaglandins thus suppress the procoagulant response and other platelet reactions.

The platelet surface is particularly rich in receptors for adhesive proteins, by which platelets bind to the damaged vessel or to each other (9). Platelets adhere via glycoprotein (GP)Ib-V-IX, in a shear-dependent way, to von Willebrand factor $(\nu W F)$, immobilized in the vessel wall or present in plasma. Interaction of vWF with GPIb-V- 
IX causes a small activating signal via $14-3-3 \zeta$ protein (25), but this does not lead to procoagulant activity (26). The most abundant protein on the platelet surface is integrin $\alpha I I b \beta b 3$ (GPIIb-IIla). A conformation change of this integrin is required (inside-out signaling) to allow its binding to VWF and to fibrinogen. Platelet aggregates then form by multiple platelet interactions with fibrinogen and VWF $(27,28)$. Fibrinogen binding can cause signal transduction (outside-in signaling), mediated via protein tyrosine kinases of the Src kinase and focal adhesion kinase families (29). This does not result in PS exposure (30), but stimulates the formation of microparticles that are also active in coagulation (21).

The hormone epinephrine stimulates platelets via the $\alpha_{2 \mathrm{~A}}$ receptors, which couple to the $\mathrm{Gz}$ protein, which inhibits AC (31). Procoagulant effects of this signaling route are not described. Activated platelets produce a number of autocrine substances, which cause signaling and, hence, may contribute to the procoagulant responses. In particular, these are the dense body constituents, ATP and ADP, and the eicosanoids, prostaglandin $\mathrm{H}_{2}$ $\left(\mathrm{PGH}_{2}\right)$ and thromboxane $\mathrm{A}_{2}\left(\mathrm{TxA}_{2}\right)$ (32).

Released $A T P$ stimulates the $\mathrm{P} 2 \mathrm{X}_{1}$ receptor on the platelet surface, which is a receptoroperated ion channel causing a small, transient $\mathrm{Ca}^{2+}$ influx $(33,34)$. Autocrine $A D P$ is a key agonist for platelet aggregation, but also plays a role in the procoagulant response. Platelets express two different purinergic receptors for ADP, the $P 2 Y_{1}$ and $P 2 Y_{12}$ receptors. The first one mediates shape change and initiation of aggregation, while the second one completes this response $(35,36)$. $\mathrm{P} 2 \mathrm{Y}_{1}$ is coupled to $\mathrm{Gq}$, which activates the phosphoinositide-specific phospholipase C (PLC)- $\beta$ (37). Like other PLC- $\beta$ stimulating agonists $\left(\mathrm{TxA}_{2}\right.$ and thrombin), phosphatidylinositol 4,5-biphosphate $\left(\mathrm{PIP}_{2}\right)$, present in the plasma membrane, is cleaved into inositol triphosphate $\left(\mathrm{InsP}_{3}\right)$ and diacylglycerol (DAG). Ins $\mathrm{P}_{3}$ activates a $\mathrm{Ca}^{2+}$ channel in the endoplasmatic reticulum, and mobilizes $\mathrm{Ca}^{2++}$ from stores to the cytosol. This in turn triggers store-regulated $\mathrm{Ca}^{2+}$ influx channels, resulting in an influx of extracellular $\mathrm{Ca}^{2+}$ into the platelet (38). The other second messenger, DAG, triggers the translocation of inactive protein kinase $\mathrm{C}$ (PKC) from cytosol to membrane (39). Activated $\mathrm{PKC}$ in the presence of increased $\mathrm{Ca}^{2+}$ contributes to platelet secretion and aggregation. Stimulation of $\mathrm{P}_{2} \mathrm{Y}_{1}$ does not result in procoagulant activity, putatively because of the number of these receptors is small and the $\mathrm{Ca}^{2+}$ signal is only moderate (24).

In contrast, $\mathrm{P} 2 \mathrm{Y}_{12}$ is a Gi-protein coupled receptor, which inhibits $\mathrm{AC}$, thereby reducing the cyclic AMP level and enhancing the $\mathrm{Ca}^{2+}$ signal generation $(36,40)$. Furthermore, $\mathrm{P}_{2} \mathrm{Y}_{12}$ activates the phosphoinositide 3-kinase pathway via $\mathrm{Gi}$, which not only is implicated in thrombus stability, but also contribute to the $\mathrm{Ca}^{2+}$ signal $(41,42)$. Once activated, this receptor enhances the platelet procoagulant response $(43,44)$.

Prostaglandin $\mathrm{H}_{2}\left(\mathrm{PGH}_{2}\right)$ and thromboxane $\mathrm{A}_{2}\left(T x \mathrm{~A}_{2}\right)$ are formed in activated platelets, following the cleavage of arachidonic acid from membrane phospholipids by cytosolic phospholipase $\mathrm{A}_{2}$ (45). Arachidonic acid is converted to $\mathrm{PGH}_{2}$ and $\mathrm{TxA}_{2}$ by the cyclooxygenase-thromboxane synthase complex (target of aspirin). These instable autocrine eicosanoids diffuse through the plasma membrane and activate other platelets via their thromboxane prostanoid receptors, $\mathrm{TP} \alpha$ and $\mathrm{TP} \beta$ (46). While $\mathrm{TP} \alpha$ is a Gq- 
coupled receptor causing small $\mathrm{Ca}^{2+}$ responses via PLC- $\beta$, there are indications that TP $\beta$ is coupled to $\mathrm{Gi}(47)$. The TP receptors can also be stimulated by the stable $\mathrm{TxA}_{2}$ analogue, U46619 (48).

The coagulation product thrombin is a strong platelet agonist. Human platelets express two thrombin-cleavable protease-activated receptors (PAR-1 and PAR-4) in relatively high amounts (49). The majority of thrombin-evoked responses is due to PAR-1, which is cleaved by low thrombin concentrations, whereas PAR-4 only signals at high thrombin concentrations $(50,51)$. Thrombin-induced cleavage of PAR-1 and PAR-4 is followed by receptor coupling to $\mathrm{Gq}$ and subsequent stimulation of PLC- $\beta(37,52,53)$. Although thrombin is a potent agonist in causing platelet secretion and aggregation, it elicits a transient, spiking $\mathrm{Ca}^{2+}$ response in platelets (54). This can explain why thrombin alone is only weakly active in causing PS exposure and stimulating prothrombinase activity (55-57). Specific peptides, such as SFLLRN for PAR-1, can be used to activate the thrombin receptors separately.

Platelets express at least two receptors for collagen, the signaling receptor GPVI and the adhesive receptor, integrin $\alpha 2 \beta 1$ (GPla-IIa) (58). Both receptors synergize in plateletcollagen interaction, in such a way that either GPVI or $\alpha 2 \beta 1$ first binds to collagen, after which the other receptor becomes engaged $(59,60)$. GPVI is member of the immunoglobulin family of receptors, which by cross-linking induces tyrosine phosphorylation of the immunoreceptor tyrosine-based activation motif (ITAM) on the $\mathrm{Fc}$ receptor $\gamma$-chain by Src kinases $(61,62)$. Subsequent binding and activation of the non-receptor tyrosine kinase Syk results in phosphorylation/activation of PLC- $\gamma 2$, which mediates a persistent increase in $\mathrm{Ca}^{2+}$ concentration $(63,64)$. Integrin $\alpha 2 \beta 1$ basically supports this activation pathway $(65,66)$. Platelet GPVI activation, e.g. as stimulated by the specific ligand convulxin, is a good trigger of the procoagulant response $(60,66)$. Early reports have indicated that the combination of collagen and thrombin effectively stimulates platelet procoagulant activity $(67,68)$.

Other platelet-activating compounds causing PS exposure are the $\mathrm{Ca}^{2+}$-ionophore, ionomycin (69), and the inhibitor of the sarcoendoplasmic reticulum $\mathrm{Ca}^{2+}$ ATPases, thapsigargin, both giving rise to prolonged $\mathrm{Ca}^{2+}$ elevation in the platelet cytosol (70).

\section{COAGULATION CASCADE}

Coagulation of plasma to form a fibrin network involves a cascade of proteolytic reactions, in which inactive zymogens are converted into active enzymes (serine proteases) by selective peptide bond cleavages (71). Most coagulation factors are synthesized in the liver as inactive zymogens, and require post-ribosomal modifications for proper functioning. The coagulation factors, prothrombin, factors VII, IX, X, and the anti-coagulant factors protein $\mathrm{C}$ and protein $\mathrm{S}$, contain $\mathrm{N}$-terminal $\gamma$-carboxyglutamate (Gla) residues, which are carboxylated post-translationally by a hepatic vitamin $\mathrm{K}$ dependent carboxylase (72). These are known as vitamin K-dependent factors. The Gla residues are necessary for $\mathrm{Ca}^{2+}$-dependent binding to the negatively charged surface, e.g. of PS-exposing platelets. Other coagulation factors, such as factors V and VIII, 
function as non-enzymatic cofactors, which increase the catalytic efficiency of activated factor X and IX, respectively (73).

Historically, a distinction is made between the intrinsic and extrinsic coagulation pathways, initiated by foreign substances (contact activation) and native tissue factor, respectively $(71,74,75)$. The modern concept of coagulation emphasises on cooperative rather than separate roles for these two coagulation pathways (76). As shown in Figure 1 , two phases are usually distinguished. In the initiation phase, tissue factor, either blood-borne or of vascular origin, forms a complex with traces of activated factor VII (factor VIIa). This binding facilitates further formation of factor VIIa $(77,78)$. The complex of tissue factor and factor VIIa then activates traces of factors IX and X, which in turn ensure the activation of small amounts of other coagulation factors, including thrombin (10).

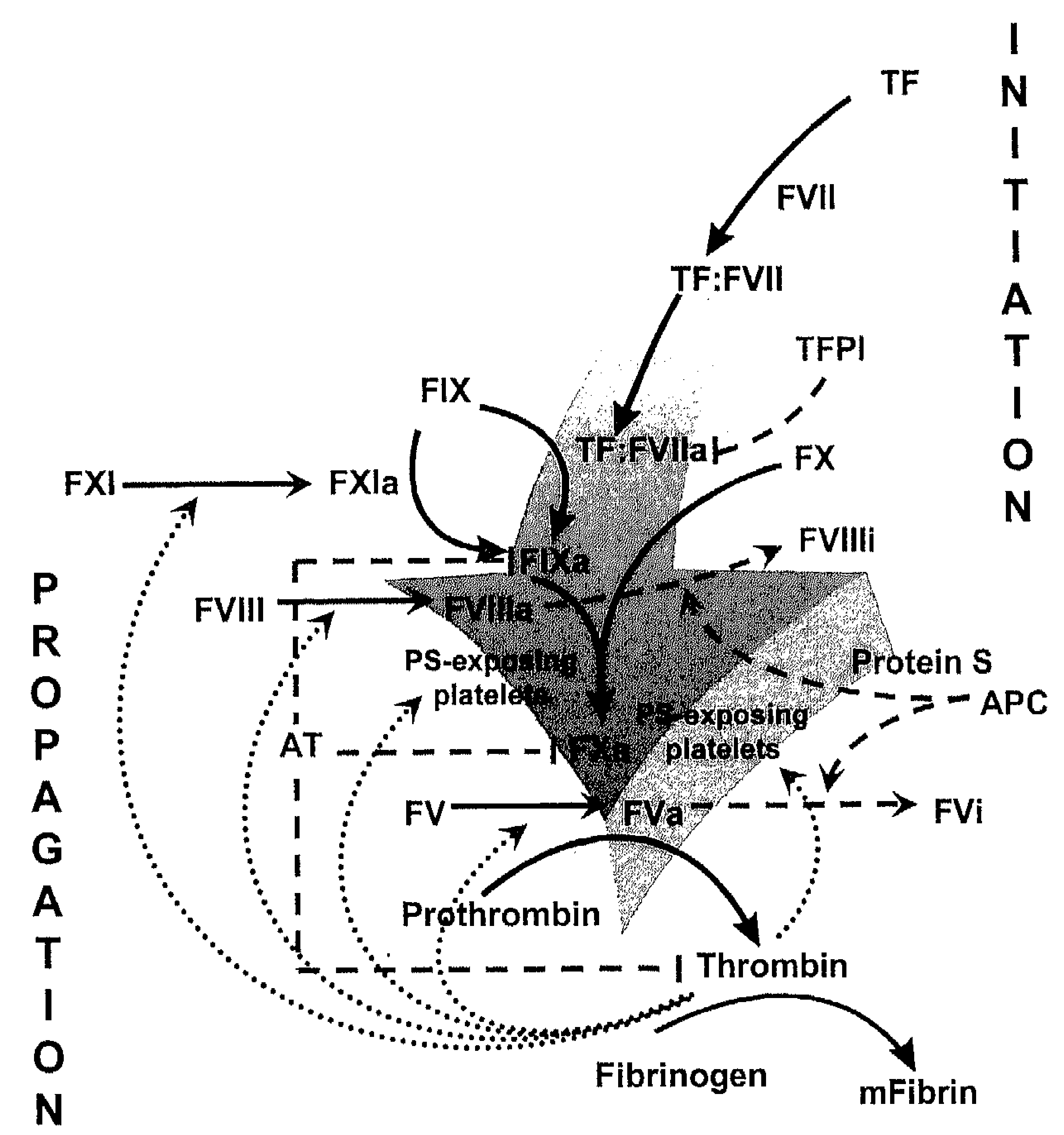

Figure 1. Schematic overview of the initiation and propagation phases of blood coagulation. For details, see text. Solid arrows point to activation, dotted arrows indicate positive feedback, and striped arrows represent inhibition. Abbreviations: APC, activated protein $\mathrm{C} ; \mathrm{AT}$, antithrombin; mFibrin, fibrin monomers; PS, phosphatidylserine; TF, tissue factor; TFPI, tissue factor pathway inhibitor. 
The propagation phase is supposed to start when activated forms of many coagulation factors are present, particularly due to the proteolytic activity of first thrombin traces $(79,80)$. For instance, thrombin will activate factors V, VIII, XI and XIII. In the presence of negatively charged phospholipids (provided by activated platelets) and $\mathrm{Ca}^{2+}$, the tenase complex is formed, which consists of factors VIIIa and IXa, and rapidly converts factor $\mathrm{X}$ into factor $\mathrm{Xa}$. Also, under the same conditions, the prothrombinase complex is formed, which consists of factors $\mathrm{Va}$ and $\mathrm{Xa}$, and enhances the conversion of prothrombin into thrombin. Together, both complexes, active on a procoagulant phospholipid surface, generate a burst of thrombin, which is a key enzyme in haemostasis (81). The propagation phase is continued in a way independently of tissue factor by factor XIa, which activates factor IX to form new tenase complexes with factor VIIIa (82). Thrombin formed is responsible for the conversion of fibrinogen into fibrin monomers. These monomers are cross-linked into a fibrin network by factor XIIIa, which becomes visible as a macroscopic fibrin clot.

The plasma further contains anticoagulant and fibrinolytic mechanisms, which likely function to restrict clot formation both spatially and temporally. Antithrombin provides a potent inhibitor of thrombin and factor $\mathrm{Xa}$, thereby suppressing the generation of these activated factors, in a way stimulated by heparin or heparin-like molecules (83). Other thrombin inhibitors present in plasma include the protease inhibitor, $\alpha 2$-macroglobuline (84). Tissue factor pathway inhibitor (TFPI), present in plasma and stored in platelets, inhibits the complex of tissue factor and factor VIIa with and without factor Xa (85). Thrombin bound to thrombomodulin converts protein $\mathrm{C}$ into the anticoagulant form, activated protein $\mathrm{C}$ (APC). The APC, together with its cofactor protein $S$, cleaves and inactivates factor $\mathrm{Va}$ and VIIla into inactive forms $(86,87)$.

The fibrinolytic system, dissolving fibrin clots, is activated by endothelial-derived tissue-type plasminogen activator (t-PA) that converts plasminogen to the active plasmin, which can cleave fibrin fibers. Fibrinolysis is inhibited by plasminogen activator inhibitor-1 (PAI-1), which is also released from endothelial cells and controls $\mathrm{t}-\mathrm{PA}$. Excess of thrombin can also inhibit fibrinolysis by activating thrombin activatable fibrinolysis inhibitor (TAFI), which makes fibrin less susceptible to plasmin (88).

\section{TRANSPORT OF BLOOD LIPIDS}

Fatty acids and lipids require amphipathic vehicles for their transport in the blood stream. Free fatty acids are transported bound to albumin, which is a liver-derived plasma protein. In contrast, fatty acids esterified in triglycerides or sterols esters are transported in the blood in the form of various types of lipoprotein particles, which differ in their content of proteins and lipids (Table 2). Triglycerides are packaged with cholesterol and apolipoproteins into chylomicrons, which are transported via the lymphatic system (89). In blood plasma, chylomicrons acquire apolipoprotein $\mathrm{E}$ and other apolipoproteins from high density lipoproteins (HDL). Once transported to adipose and muscle tissues, chylomicrons hydrolyze their triglycerides into fatty acid and glycerol by apolipoprotein C-II-dependent activation of lipoprotein lipase (90). 


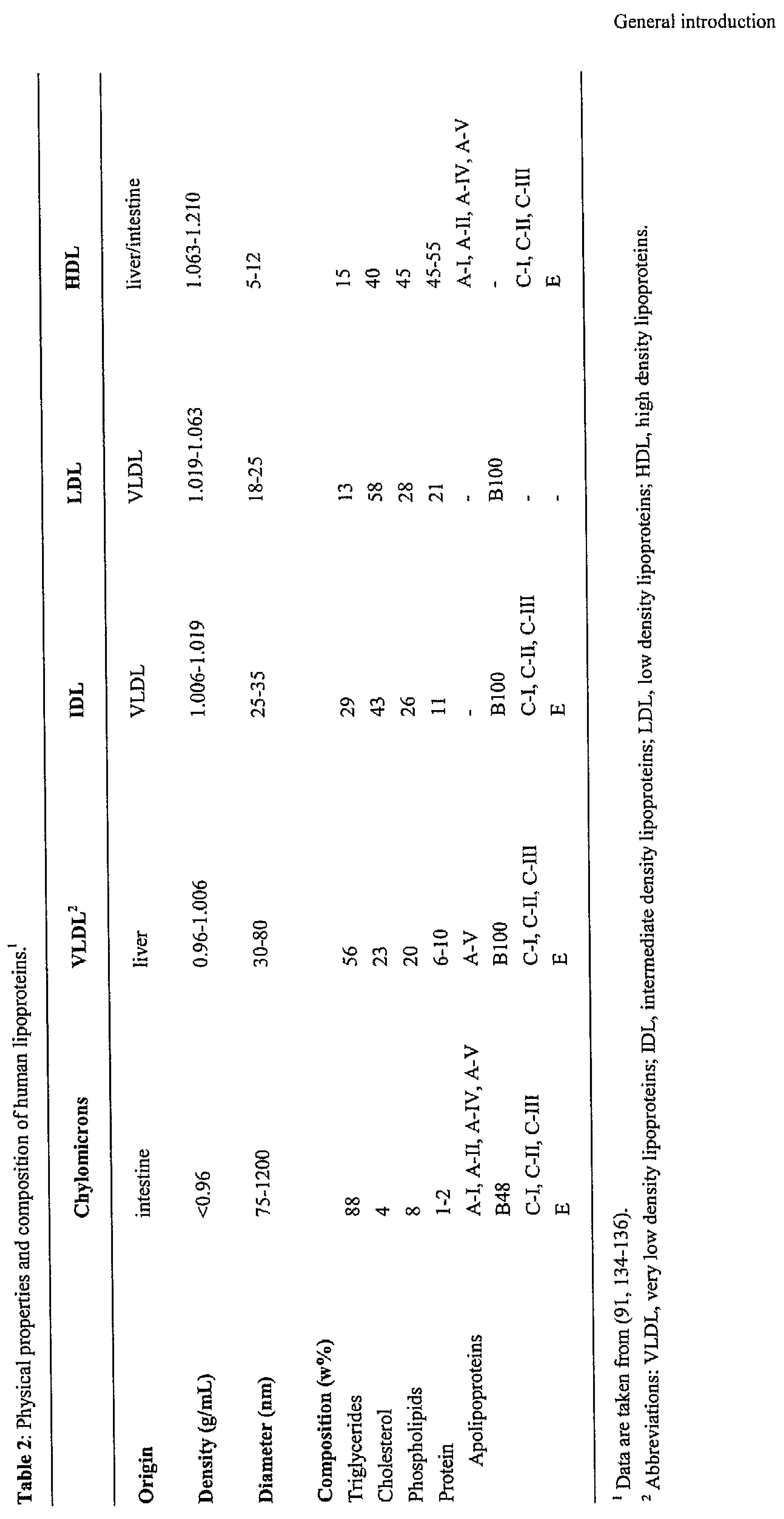


The liver removes chylomicron remnants after recognition of the apolipoprotein $\mathrm{E}$ component via low density lipoprotein (LDL) receptor members. The residual cholesterol associates with apolipoprotein B100 and is repackaged for transport in very low density lipoproteins ( $V L D L)$ particles, together with triglycerides and apolipoproteins (91). In adipose and muscle tissues, endothelial lipoprotein lipase has a similar function in depleting triglycerides from VLDL. Intermediate density lipoproteins (IDL) are then formed, which are taken up by the liver for reprocessing, or transform to LDL particles at further triglyceride depletion $(92,93)$.

$L D L$ particles form the main transport vehicle of (esterified) cholesterol and make up more than half of the total lipoprotein content in plasma. After recognition of the apolipoprotein B100, LDL particles are absorbed by the liver and other tissues. Particularly macrophages and other scavenger cells actively remove LDL particles from the bloodstream, thereby deposing cholesterol in the inner walls of blood vessels. This eventually leads to the development of a cholesterol-rich fatty streak, which may progress to an atherogenic plaque (94). $H D L$, which is produced in the liver and intestine, acquires cholesterol from cell membranes and transfers cholesteryl esters to VLDL and LDL particles $(95,96)$. HDL returns to the liver where cholesterol is removed and excreted as bile acids into the gall bladder (97).

Plasma concentrations of lipoproteins are established risk factors for atherothrombosis. Increased triglycerides and (small dense) LDL particles, in combination with reduced HDL particles, are associated with an atherogenic lipoprotein profile (98).

\section{ATHEROTHROMBOTIC DISORDERS}

Platelets are implicated in arterial thrombotic disorders, affecting the coronary, cerebral and peripheral circulation. In large vessels, thrombus formation of platelets often is a consequence of atherosclerosis, particularly by rupturing or denudation of atherosclerotic plaques (99). Atherosclerosis starts by chronic minimal injury of the vessel wall by oxidized LDL (100). It is thought that endothelial cells then release mediators that modulate vascular tone, augment platelet and leukocyte adhesion, enhance platelet activity and coagulation, and promote apoptosis (101). Monocytes thus migrate into the vascular intima and differentiate into macrophages (102). Uptake of oxidized LDL by macrophages results in transformation into so-called foam cells, which form fatty streaks. Foam cells secrete chemokines and mitogens, thereby recruiting more macrophages and promoting smooth muscle cell migration and proliferation into the intima (103). Plaque growth progresses as long as the mitogenic process persists. The narrowing of the vessel lumen results in turbulent blood flow through the area of stenosis, with sudden intimal disruption or plaque rupture. Thrombus formation immediately occurs, because plaques are greatly enriched in thrombogenic components such as fibrinogen, collagen and tissue factor $(104,105)$. Anti-platelet medication (aspirin, P2Y inhibitors) is commonly used to suppress thrombotic process in atherosclerotic arteries, but this may also influence plaque progression (106).

Atherosclerosis is considered to develop over several decades and is promoted by 
smoking, obesity, hypertension, hyperlipidemia and diabetes. These risk factors are quite common in Western communities: obesity affects over $50 \%$ of the adult population of the USA and diabetes affects up to $7 \%$ of the population in Western communities. Nowadays, atherosclerosis is the leading cause of morbidity and mortality in Europe, North America and Japan, with lifetime risks of developing coronary artery disease exceeding $30-40 \%(107,108)$.

\section{GENETIC POLYMORPHISMS OF PLATELETS AND COAGULATION FACTORS AS DETERMINANTS OF THROMBOTIC RISK}

Evidence is accumulating that individuals vary considerably in their susceptibility for developing cardiovascular disease. This variation can be explained by differences in genetic and environmental factors, and by different interactions between these factors. Genetic variations may thus contribute to disease predisposition, and life-style factors such as nutrition, e.g. controlling gene expression, may result in risk increase (109-111). In recent years, several variations in haemostatic genes have been linked to cardiovascular events. An extended overview of genetic polymorphisms and their association with venous and arterial thrombosis is presented in $(112,113)$. Here, only polymorphisms that are relevant to this thesis will be introduced (Table 3).

Some polymorphic platelet antigens have been implicated in atherothrombosis. These include genetic variants of integrins $\alpha$ IIb $\beta 3$ (GPIIb-IIIa) and $\alpha 2 \beta 1$ (GPIa-IIa). In the integrin $\beta 3$ (GPIIIa) gene, the $\mathrm{Pl}^{\mathrm{A} 2}$ (HPA-1b) allele is associated with an increased sensitivity to platelet aggregation stimulated by various agonists (114). In the gene of integrin $\alpha 2$ (GPIa), a synonymous polymorphism has been identified at nucleotide 807 . The $807 \mathrm{~T}$ allele correlates with an increased platelet surface density of $\alpha 2 \beta 1$ and with an increased rate of platelet adhesion to type I collagen $(115,116)$.

With respect to coagulation factors, the factor $\mathrm{V}$ Leiden polymorphism is associated with resistance to APC-induced cleavage of factor $\mathrm{Va}$ (117). This $\mathrm{G}$ to $\mathrm{A}$ transition at nucleotide 1691 results in persistent factor $V a$ activity which, in homozygous individuals, results in an 80-fold increased risk for venous thrombosis $(118,119)$. Another polymorphism of the factor $\mathrm{V}$ gene is the $\mathrm{A}$ to $\mathrm{G}$ transition at nucleotide 4070 . This polymorphism, together with several others, is known as the HR2 haplotype (120, 121). This haplotype increases the thrombosis risk in patients who also have the factor $\mathrm{V}$ Leiden variant $(122,123)$. In the prothrombin gene, a $\mathrm{G}$ to $\mathrm{A}$ transition in the 3'untranslated region at nucleotide 20210 is associated with increased plasma concentrations of prothrombin and with risk of venous thrombosis $(124,125)$. Furthermore, in prothrombin, the A to $G$ transition at the intronic nucleotide 19911 influences splicing efficiency and associates with increased plasma prothrombin concentrations $(126,127)$.

High plasma fibrinogen concentrations have been associated with occlusive vascular disorders $(128,129)$. For the fibrinogen $\beta$ gene, transitions are described for promotor nucleotides $-854(\mathrm{G} / \mathrm{A}),-455(\mathrm{G} / \mathrm{A})$ and $-148(\mathrm{C} / \mathrm{T})$. These polymorphic sites influence the binding of transcription factors and associate with increased fibrinogen expression 
Chapter 1

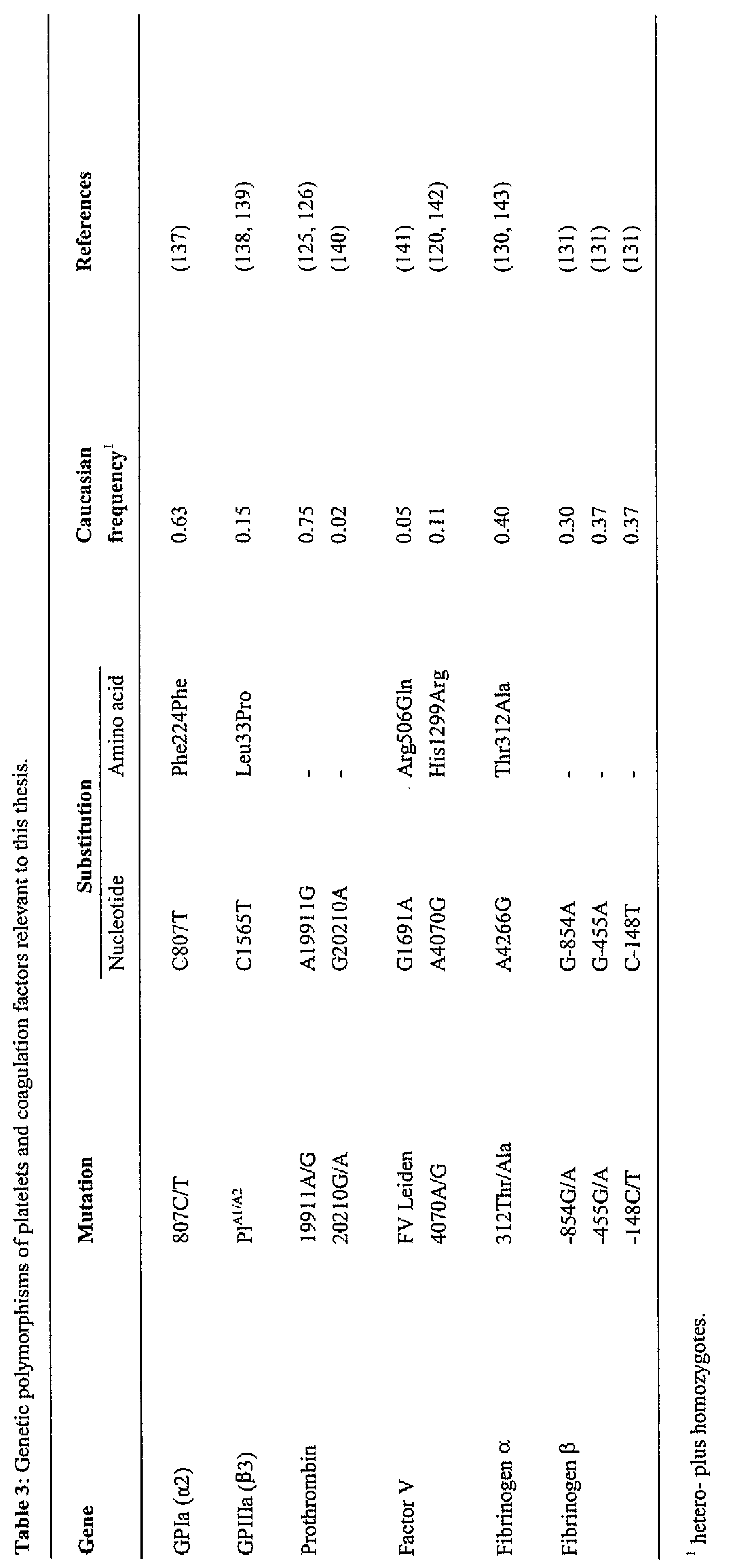


$(131,132)$. Furthermore, the T312A polymorphism of the fibrinogen $\alpha$ chain occurs in a region involved in factor XIII-dependent cross-linking of fibrin monomers. This may alter fibrin cross-linking, and result in unstable fibrin clots unstable that are more susceptible to embolization (130).

The various, sometimes weak, published effects of fish (oil) consumption on haemostatic factors, in combination with the high inter-individual variation of these effects, may suggest that multiple, variable genes are involved in the (cardioprotective) response to dietary fish. Accordingly, the hypothesis in this thesis is that variation in several haemostatic genes contributes to the variable, subject-dependent effects of fish oil. At least several of the haemostatic factors influenced by dietary fish oil are established risk factors of cardiovascular disease. Moreover, of the same factors, genetic variations are known with higher prevalence in patients with this disease. This raises the intriguing possibility that alleles of these genes are subjected to (different) diet-induced control, although it is likely that other genetic variations will be involved as well. In this thesis, we studied the possibility that the hypocoagulant effect of n-3 PUFA is sensitive to gene-environmental interactions which, in turn, contribute to the variable outcome of fish-oil intervention studies.

\section{OUTLINE OF THIS THESIS}

Chapter 2 starts from the observation that published studies on the atherothrombotic risk-reducing effects of dietary fish oil are variable in outcome. It is postulated that inter-individual variability in haemostatic factors contributes to the risk of thrombosis, and that dietary fish oil changes these factors in a subject-dependent way. The study described in chapter 3 investigates the contribution of inter-individual variability in the signal-transducing state of platelets from healthy subjects and patients at risk. In chapter 4, the thrombogram measurement of thrombin generation is used to study the inter-relationship of platelet activation and coagulation in human platelet-rich plasma. The importance of inter-subject variation in thrombin generation is determined for both platelet and coagulation parameters. This knowledge is used in chapters 5 and $\mathbf{6}$, where the effect of fish oil-derived n-3 PUFA is studied on coagulation factors, plasma lipids and thrombin generation profile. Intervention studies have been performed with two groups of subjects at risk, i.e. overweight volunteers and patients with type 2 diabetes and a tendency to hypertriglyceridemia. A main question is whether the anticoagulant effect of n-3 PUFA contains subject-dependent and specific genetic components. This work has led to the finding of a subject-dependent relation between levels of plasma lipids and coagulation factors. The mouse study of chapter 7 focuses on the liver as a diet-sensitive organ, controlling the overall composition of plasma. Transgenic ApoE2 knock-in mice are used as a model of hyperlipoproteinemia to study the effects of n-3 and n-6 PUFA on hepatic gene expression and on plasma coagulant activity. Also, possible modulation of the (post)translational processing, which may alter hepatic secretion quantitatively or qualitatively, has been checked. Chapter 8 takes the main conclusions into a broader perspective. 


\section{REFERENCES}

1. Hornstra G. The significance of fish and fish-oil enriched food for prevention and therapy of ischaemic cardiovascular disease. In: The Role of Fats in Human Nutrition (Vergroesen AJ and Crawford MA, Eds) Academic Press, New York. 1989: 152-235.

2. Berge JP, Barnathan $G$. Fatty acids from lipids of marine organisms: molecular biodiversity, roles as biomarkers, biologically active compounds, and economical aspects. Adv Biochem Eng Biotechnol. 2005; 96: 49-125.

3. Jacobs MN, Covaci A, Gheorghe A, Schepens P. Time trend investigation of PCBs, PBDEs, and organochlorine pesticides in selected n-3 polyunsaturated fatty acid rich dietary fish oil and vegetable oil supplements; nutritional relevance for human essential n-3 fatty acid requirements. J Agric Food Chem. 2004; 52: 1780-8.

4. Bezard J, Blond JP, Bernard A, Clouet P. The metabolism and availability of essential fatty acids in animal and human tissues. Reprod Nutr Dev. 1994; 34: 539-68.

5. Baker RR. The eicosanoids: a historical overview. Clin Biochem. 1990; 23:455-8.

6. Bang HO, Dyerberg J, Nielsen AB. Plasma lipid and lipoprotein pattern in Greenlandic west-coast Eskimos. Lancet. 1971; i: 1143-5.

7. Hu FB, Cho E, Rexrode KM, Albert CM, Manson JE. Fish and long-chain $\omega 3$ fatty acid intake and risk of coronary heart disease and total mortality in diabetic women. Circulation. 2003; 107: 1852-7.

8. Kris-Etherton PM, Harris WS, Appel LJ. Fish consumption, fish oil, omega-3 fatty acids, and cardiovascular disease. Circulation. 2002; 106: 2747-57.

9. Ruggeri ZM. Platelets in atherothrombosis. Nat Med. 2002; 8: 1227-34.

10. Mann KG, Butenas $S$, Brummel $K$. The dynamics of thrombin formation. Arterioscler Thromb Vasc Biol. 2003; 23: 17-25.

11. Hemker HC, Beguin S. Phenotyping the clotting system. Thromb Haemost. 2000; 84: 747-51.

12. Heemskerk JW, Kuijpers MJ, Munnix IC, Siljander PR. Platelet collagen receptors and coagulation. A characteristic platelet response as possible target for antithrombotic treatment. Trends Cardiovasc Med. $2005 ; 15: 86-92$.

13. Hoffman M. Remodeling the blood coagulation cascade. J Thromb Thrombolysis. 2003; 16: 17-20.

14. Zwaal RF, Schroit AJ. Pathophysiologic implications of membrane phospholipid asymmetry in blood cells. Blood. 1997; 89: 1121-32.

15. Bevers EM, Comfurius P, Zwaal RFA. Platelet procoagulant activity: physiological significance and mechanisms of exposure. Blood Rev. 1991; 5: 146-54.

16. Williamson P, Bevers EM, Smeets EF, Comfurius P, Schlegel RA, Zwaal RF. Continuous analysis of the mechanism of activated transbilayer lipid movement in platelets. Biochemistry. 1995; 34: 10448-55.

17. Heemskerk JWM, Bevers EM, Lindhout T. Platelet activation and blood coagulation. Thromb Haemost. 2002; 88: 186-93.

18. Monroe DM, Hoffman M, Roberts HR. Platelets and thrombin generation. Arterioscler Thromb Vasc Biol. 2002; 22: 1381-9.

19. Solum NO. Procoagulant expression in platelets and defects leading to clinical disorders. Arterioscler Thromb Vasc Biol. 1999; 19: 2841-6.

20. Garcia BA, Smalley DM, Cho H, Shabanowitz J, Ley K, Hunt DF. The platelet microparticle proteome. $J$ Proteome Res. 2005; 4: 1516-21.

21. Cauwenberghs S, Feijge MA, Harper AG, Sage SO, Curvers J, Heemskerk JW. Shedding of procoagulant microparticles from unstimulated platelets by integrin-mediated destabilization of actin cytoskeleton. FEBS Lett. 2006; 580: 5313-20.

22. Nakagawa $O$, Tanaka I, Usui $T$, Harada $M$, Sasaki $Y$, Itoh $H$, Yoshimasa $T$, Namba $T$, Narumiya $S$, Nakao K. Molecular cloning of human prostacyclin receptor cDNA and its gene expression in the cardiovascular system. Circulation. 1994; 90: 1643-7.

23. den Dekker E, Gorter G, Heemskerk JW, Akkerman JW. Development of platelet inhibition by cAMP during megakaryocytopoiesis. J Biol Chem. 2002; 277; 29321-9.

24. Hcemskerk JWM. Calcium and platelets. In: The Molecular Basis of Calcium Action in Biology and Medicine (Pochet, R, Donato, R, Haiech, J, Heinzmann, C and Gerke, V, eds), Kluwer Acad Publ, The Hague (the Netherlands), 2000: 45-71.

25. Clemetson KJ, Clemetson JM. Platelet receptor signalling. Hematol J. 2004; 5 Suppl 3: S159-63. 
26. Briede JJ, Wielders SJ, Heemskerk JW, Baruch D, Hemker HC, Lindhout T. von Willebrand factor stimulates thrombin-induced exposure of procoagulant phospholipids on the surface of fibrin-adherent platelets. J Thromb Haemost. 2003; 1: 559-65.

27. Ruggeri ZM, Dent JA, Saldivar E. Contribution of distinct adhesive interactions to platelet aggregation in flowing blood. Blood. 1999; 94: 172-8.

28. Huizinga EG, Tsuji S, Romijn RA, Schiphorst ME, de Groot PG, Sixma JJ, Gros P. Structures of glycoprotein Ib $\alpha$ and its complex with von Willebrand factor AI domain. Science. 2002; 297: 1176-9.

29. Shattil SJ, Kashiwagi H, Pampori N. Integrin signaling: the platelet paradigm. Blood. 1998; 91: 264557.

30. Heemskerk JW, Vuist WM, Feijge MA, Reutelingsperger CP, Lindhout $T$. Collagen but not fibrinogen surfaces induce bleb formation, exposure of phosphatidylserine, and procoagulant activity of adherent platelets: evidence for regulation by protein tyrosine kinase-dependent $\mathrm{Ca} 2+$ responses. Blood. 1997; 90: 2615-25.

31. Brass LF, Manning DR, Cichowski K, Abrams CS. Signaling through G proteins in platelets: to the integrins and beyond. Thromb Haemost. 1997; 78: 581-9.

32. Rendu F, Brohard-Bohn B. The platelet release reaction: granules' constituents, secretion and functions. Platelets. 2001; 12: 261-73.

33. Mahaut-Smith MP, Ennion SJ, Rolf MG, Evans RJ. ADP is not an agonist at P2X(1) receptors: evidence for separate receptors stimulated by ATP and ADP on human platelets. Br J Pharmacol. 2000; 131: 10814.

34. Oury C, Kuijpers MJ, Toth-Zsamboki E, Bonnefoy A, Danloy S, Vreys I, Feijge MAH, De Vos R, Vermylen $\mathrm{J}$, et al. Overexpression of the platelet $\mathrm{P} 2 \mathrm{X}_{1}$ ion channel in transgenic mice generates a novel prothrombotic phenotype. Blood. 2003; 101: 3969-76.

35. Gachet C. ADP receptors of platelets and their inhibition. Thromb Haemost. 2001; 86: 222-32.

36. Kunapuli SP, Dorsam RT, Kim S, Quinton TM. Platelet purinergic receptors. Curr Opin Pharmacol. 2003; 3: 175-80.

37. Offermanns $\mathrm{S}$, Toombs $\mathrm{CF}, \mathrm{Hu} \mathrm{YH}$, Simon MI. Defective platelet activation in $\mathrm{G}$ alpha(q)-deficient mice. Nature. 1997; 389: 183-6.

38. Rosado JA, Sage SO. The ERK cascade, a new pathway involved in the activation of store-mediated calcium entry in human platelets. Trends Cardiovasc Med. 2002; 12: 229-34.

39. Berridge MJ. Inositol trisphosphate and calcium signalling. Nature. 1993; 361:315-25.

40. Keularts IM, van Gorp RM, Feijge MAH, Vuist WM, Heemskerk JWM. $\alpha 2 A$-adrenergic receptor stimulation potentiates calcium release in platelets by modulating cAMP levels. J Biol Chem. 2000; 275: 1763-72.

41. Dangelmaier C, Jin J, Smith JB, Kunapuli SP. Potentiation of thromboxane $A_{2}$-induced platelet secretion by Gi signaling through the phosphoinositide-3 kinase pathway. Thromb Haemost. 2001; 85: 341-8.

42. Cosemans J, Munnix I, Wetzker R, Heller R, Jackson S, Heemskerk J. Continuous signaling via PI3K isoforms $\{$ beta\} and \{gamma\} is required for platelet ADP receptor function in dynamic thrombus stabilization. Blood. 2006.

43. Léon C, Ravanat C, Freund M, Cazenave JP, Gachet C. Differential involvement of the $P 2 Y_{1}$ and $P 2 Y_{12}$ receptors in platelet procoagulant activity. Arterioscler Thromb Vasc Biol. 2003; 23: $1941-7$.

44. Van der Meijden PEJ, Feijge MAH, Giesen PL, Huijberts M, van Raak LP, Heemskerk JWM. Platelet $\mathrm{P} 2 \mathrm{Y}_{12}$ receptors enhance signalling towards procoagulant activity and thrombin generation. A study with healthy subjects and patients at thrombotic risk. Thromb Haemost. 2005; 93: 1128-36.

45. Narumiya S, Sugimoto $Y$, Ushikubi F. Prostanoid receptors: structures, properties, and functions. Physiol Rev. 1999; 79: 1193-226.

46. Li Z, Zhang G, Le Breton GC, Gao X, Malik AB, Du X. Two waves of platelet secretion induced by thromboxane $A_{2}$ receptor and a critical role for phosphoinositide 3-kinases. J Biol Chem. 2003; 278: 30725-31.

47. Jantzen HM, Milstone DS, Gousset L, Conley PB, Mortensen RM. Impaired activation of murine platelets lacking Gai2. J Clin Invest. 2001; 108: 477-83.

48. Kattelman EJ, Venton DL, Le Breton GC. Characterization of U46619 binding in unactivated, intact human platelets and determination of binding site affinities of four TXA2/PGH2 receptor antagonists (13-APA, BM 13.177, ONO 3708 and SQ 29,548). Thromb Res. 1986; 41: 471-81.

49. Coughlin SR. Thrombin signalling and protease-activated receptors. Nature. 2000; 407: 258-64. 
Chapter 1

50. Shapiro MJ, Weiss EJ, Faruqi TR, Coughlin SR. Protease-activated receptors 1 and 4 are shut off with distinct kinetics after activation by thrombin. J Biol Chem. 2000; 275: 25216-21.

51. Covic L, Gresser AL, Kuliopulos A. Biphasic kinetics of activation and signaling for PAR1 and PAR4 thrombin receptors in platelets. Biochemistry. 2000; 39: 5458-67.

52. Brass LF, Hoxie JA, Manning DR. Signaling through $G$ proteins and $G$ protein-coupled receptors during platelet activation. Thromb Haemost. 1993; 70: 217-23.

53. Vu TK, Wheaton VI, Hung DT, Charo I, Coughlin SR. Domains specifying thrombin-receptor interaction. Nature. 1991; 353:674-7.

54. Heemskerk JWM, Feijge MAH, Henneman L, Rosing J, Hemker HC. The $\mathrm{Ca}^{2+}$-mobilizing potency of alpha-thrombin and thrombin-receptor-activating peptide on human platelets: concentration and time effects of thrombin-induced $\mathrm{Ca}^{2+}$ signaling. Eur J Biochem. 1997; 249: 547-55.

55. Andersen H, Greenberg DL, Fujikawa K, Xu W, Chung DW, Davie EW. Protease-activated receptor 1 is the primary mediator of thrombin-stimulated platelet procoagulant activity. Proc Natl Acad Sci USA. 1999; 96: 11189-893.

56. Keuren JF, Wielders SJ, Ulrichts H, Hackeng T, Heemskerk JWM, Deckmyn H, Bevers EM, Lindhout T. Synergistic effect of thrombin on collagen-induced platelet procoagulant activity is mediated through protease-activated receptor-1. Arterioscler Thromb Vasc Biol. 2005; 25: 1499-505.

57. Heemskerk JWM, Siljander PRM, Bevers EM, Farndale RW, Lindhout T. Receptors and signalling mechanisms in the procoagulant response of platelets. Platelets. 2000; 11:301-6.

58. Nieswandt B, Watson SP. Platelet-collagen interaction: is GPVI the central receptor? Blood. 2003; 102: $449-61$.

59. Auger JM, Kuijpers MJ, Senis YA, Watson SP, Heemskerk JW. Adhesion of human and mouse platelets to collagen under shear: a unifying model. Faseb J. 2005; 19: 825-7.

60. Siljander PR, Munnix IC, Smethurst PA, Deckmyn H, Lindhout T, Ouwehand WH, Farndale RW, Heemskerk JW. Platelet receptor interplay regulates collagen-induced thrombus formation in flowing human blood. Blood. 2004; 103: 1333-41.

61. Quek LS, Pasquet JM, Hers I, Cornall R, Knight G, Barnes M, Hibbs ML, Dunn AR, Lowell CA, Watson SP. Fyn and Lyn phosphorylate the Fe receptor gamma chain downstream of glycoprotein VI in murine platelets, and Lyn regulates a novel feedback pathway. Blood. 2000; 96: 4246-53.

62. Gibbins JM, Okuma M, Fandale R, Barnes M, Watson SP. Glycoprotein VI is the collagen receptor in platelets which underlies tyrosine phosphorylation of the Fc receptor gamma-chain. FEBS Lett. 1997; 413: 255-9.

63. Jackson SP, Nesbitt WS, Kulkarni S. Signaling events underlying thrombus formation. J Thromb Haemost. 2003; 1: 1602-12.

64. Munnix IC, Strehl A, Kuijpers MJ, Auger JM, van der Meijden PE, van Zandvoort MA, oude Egbrink MG, Nieswandt B, Heemskerk JW. The glycoprotein VI-phospholipase Cgamma2 signaling pathway controls thrombus formation induced by collagen and tissue factor in vitro and in vivo. Arterioscler Thromb Vasc Biol. 2005; 25: 2673-8.

65. Lecut C, Schoolmeester A, Kuijpers MJ, Broers JL, van Zandvoort MA, Vanhoorelbeke K, Deckmyn H, Jandrot-Perrus M, Heemskerk JW. Principal role of glycoprotein VI in alpha2betal and alphallbbeta3 activation during collagen-induced thrombus formation. Arterioscler Thromb Vasc Biol. 2004; 24: 1727 33.

66. Kuijpers MJ, Schulte V, Bergmeier W, Lindhout T, Brakebusch C, Offermanns S, Fassler R, Heemskerk JW, Nieswandt B. Complementary roles of glycoprotein VI and alpha2betal integrin in collageninduced thrombus formation in flowing whole blood ex vivo. Faseb J. 2003; 17: 685-7.

67. Bevers EM, Comfurius $\mathrm{P}, \mathrm{Zwaal}$ RF. Changes in membrane phospholipid distribution during platelet activation. Biochim Biophys Acta. 1983; 736: 57-66.

68. Thiagarajan P, Tait JF. Binding of annexin V/placental anticoagulant protein I to platelets. Evidence for phosphatidylserine exposure in the procoagulant response of activated platelets. J Biol Chem. 1990; 265: 17420-3.

69. Hargreaves PG, Jenner S, Merritt JE, Sage SO, Farndale RW. Ionomycin-stimulated arachidonic acid release in human platelets: a role for protein kinase $\mathrm{C}$ and tyrosine phosphorylation. Thromb Haemost. 1996; 76: 248-52.

70. Smeets EF, Heemskerk JW, Comfurius P, Bevers EM, Zwaal RF. Thapsigargin amplifies the platelet procoagulant response caused by thrombin. Thromb Haemost. 1993; 70: 1024-9.

71. Furie B, Furie BC. The molecular basis of blood coagulation. Cell. 1988; 53: 505-18. 
72. Vermeer C. Gamma-carboxyglutamate-containing proteins and the vitamin K-dependent carboxylase. Biochem J. 1990; 266: 625-36.

73. Kane WH, Davie EW. Blood coagulation factors V and VIII: structural and functional similarities and their relationship to hemorrhagic and thrombotic disorders. Blood. 1988; 71: 539-55.

74. Davie EW. Biochemical and molecular aspects of the coagulation cascade. Thromb Haemost. 1995; 74: $1-6$.

75. Furie B, Furie BC. Molecular and cellular biology of blood coagulation. N Engl J Med. 1992; 326: 8006.

76. Dahlbäck B. Blood coagulation. Lancet. 2000; 355: 1627-32.

77. Nemerson $Y$. Tissue factor: then and now. Thromb Haemost. 1995; 74: 180-4.

78. Giesen PL, Rauch U, Bohrmann B, Kling D, Roque M, Fallon JT, Badimon JJ, Himber J, Riederer MA, Nemerson Y. Blood-borne tissue factor: another view of thrombosis. Proc Natl Acad Sci USA. 1999; 96: $2311-5$.

79. Brummel KE, Paradis SG, Butenas S, Mann KG. Thrombin functions during tissue factor-induced blood coagulation. Blood. 2002; 100: 148-52.

80. Butenas $S$, van 't Veer C, Mann KG. Evaluation of the initiation phase of blood coagulation using ultrasensitive assays for serine proteases. J Biol Chem. 1997; 272:21527-33.

81. Hemker HC, Kessels H. Feedback mechanisms in coagulation. Haemostasis. 1991; 21: 189-96.

82. Wielders SJ, Beguin S, Hemker HC, Lindhout T. Factor XI-dependent reciprocal thrombin generation consolidates blood coagulation when tissue factor is not available. Arterioscler Thromb Vasc Biol. 2004; 24: $1138-42$.

83. Hemker HC, Beguin S. Mode of action of heparin and related drugs. Semin Thromb Hemost. 1991; 17 Suppl 1:29-34.

84. Hemker HC, Wielders S, Kessels $\mathrm{H}$, Beguin S. Continuous registration of thrombin generation in plasma, its use for the determination of the thrombin potential. Thromb Haemost. 1993; 70: 617-24.

85. Lindhout T, Franssen J, Willems G. Kinetics of the inhibition of tissue factor-factor VIla by tissue factor pathway inhibitor. Thromb Haemost. 1995; 74: 910-5.

86. Kalafatis $M$, Rand MD, Mann KG. The mechanism of inactivation of human factor $V$ and human factor Va by activated protein C. J Biol Chem. 1994; 269: 31869-80.

87. Nicolaes GA, Thomassen MC, Tans G, Rosing J, Hemker HC. Effect of activated protein C on thrombin generation and on the thrombin potential in plasma of normal and APC-resistant individuals. Blood Coagul Fibrinolysis. 1997; 8: 28-38.

88. Von dem Borne PA, Bajzar L, Meijers JC, Nesheim ME, Bouma BN. Thrombin-mediated activation of factor XI results in a thrombin-activatable fibrinolysis inhibitor-dependent inhibition of fibrinolysis. J Clin Invest. 1997; 99: 2323-7.

89. Hussain MM. A proposed model for the assembly of chylomicrons. Atherosclerosis. 2000; 148: 1-15.

90. Olivecrona G, Olivecrona T. Triglyceride lipases and atherosclerosis. Curr Opin Lipidol, 1995; 6: 291305 .

91. Ginsberg HN. Lipoprotein physiology. Endocrinol Metab Clin North Am. 1998; 27: 503-19.

92. Thyberg J, Calara F, Dimayuga P, Nilsson J, Regnstrom J. Role of caveolae in cholesterol transport in arterial smooth muscle cells exposed to lipoproteins in vitro and in vivo. Lab Invest. 1998; 78: 825-37.

93. Marzetta CA, Foster DM, Brunzell JD. Conversion of plasma VLDL and IDL precursors into various LDL subpopulations using density gradient ultracentrifugation. J Lipid Res. 1990; 31: 975-84.

94. Conway EM. Angiogenesis: a link to thrombosis in athero-thrombotic disease. Pathophysiol Haemost Thromb. 2003; 33:241-8.

95. Speijer H, Groener JE, van Ramshorst E, van Tol A. Different locations of cholesteryl ester transfer protein and phospholipid transfer protein activities in plasma. Atherosclerosis. 1991; 90: 159-68.

96. Tall AR. Plasma cholesteryl ester transfer protein. J Lipid Res. 1993; 34: 1255-74.

97. Oram JF, Yokoyama S. Apolipoprotein-mediated removal of cellular cholesterol and phospholipids. J Lipid Res. 1996; 37: 2473-91.

98. Dobiasova M, Raslova K, Rauchova H, Vohnout B, Ptackova K, Frohlich J. Atherogenic lipoprotein profile in families with and without history of early myocardial infarction. Physiol Res. 2001; 50: 1-8.

99. Gawaz M. Platelets in the onset of atherosclerosis. Blood Cells Mol Dis. 2006; 36: 206-10.

100. Kadar A, Glasz T. Development of atherosclerosis and plaque biology. Cardiovasc Surg. 2001; 9: 109 21. 
Chapter 1

101. Durand E, Scoazec A, Lafont A, Boddaert J, Al Hajzen A, Addad F, Mirshahi M, Desnos M, Tedgui A, Mallat $Z$. In vivo induction of endothelial apoptosis leads to vessel thrombosis and endothelial denudation: a clue to the understanding of the mechanisms of thrombotic plaque erosion. Circulation. 2004; 109: 2503-6.

102. Schober A, Bernhagen J, Thiele M, Zeiffer U, Knarren S, Roller M, Bucala R, Weber C. Stabilization of atherosclerotic plaques by blockade of macrophage migration inhibitory factor after vascular injury in apolipoprotein E-deficient mice. Circulation. 2004; 109: 380-5.

103. Takahashi K, Takeya M, Sakashita N. Multifunctional roles of macrophages in the development and progression of atherosclerosis in humans and experimental animals. Med Electron Microsc. 2002; 35: 179-203.

104. Viles-Gonzalez JF, Badimon JJ. Atherothrombosis: the role of tissue factor. Int $\mathrm{J}$ Biochem Cell Biol. 2004; 36: 25-30.

105. Cosemans JM, Kuijpers MJ, Lecut C, Loubele ST, Heeneman S, Jandrot-Perrus M, Heemskerk JW. Contribution of platelet glycoprotein VI to the thrombogenic effect of collagens in fibrous atherosclerotic lesions. Atherosclerosis. 2005; 181: 19-27.

106. Gawaz M. Role of platelets in coronary thrombosis and reperfusion of ischemic myocardium. Cardiovasc Res. 2004; 61: 498-511.

107. Ross R. The pathogenesis of atherosclerosis: a perspective for the 1990s. Nature. 1993; 362: 801-9.

108. Drouet L. Atherothrombosis as a systemic disease. Cerebrovasc Dis. 2002; 13: S1-6.

109. Grant PJ. The genetics of atherothrombotic disorders: a clinician's view. J Thromb Haemost. 2003; 1: $138 \mathrm{I}-90$.

110. Humphries SE, Henry JA, Montgomery HE. Gene-environment interaction in the determination of levels of haemostatic variables involved in thrombosis and fibrinolysis. Blood Coagul Fibrinolysis. 1999; 10 Suppl 1: S17-21.

111. Puddu P, Cravero E, Puddu GM, Muscari A. Genes and atherosclerosis: at the origin of the predisposition. Int J Clin Pract. 2005; 59: 462-72.

112. Kottke-Marchant K. Genetic polymorphisms associated with venous and arterial thrombosis: an overview. Arch Pathol Lab Med. 2002; 126: 295-304.

113. Lane DA, Grant PJ. Role of hemostatic gene polymorphisms in venous and arterial thrombotic disease. Blood. 2000; 95: 1517-32.

114. Michelson AD, Furman MI, Goldschmidt-Clermont P, Mascelli MA, Hendrix C, Coleman L, Hamlington J, Barnard MR, Kickler T, et al. Platelet GP IIIa Pl(A) polymorphisms display different sensitivities to agonists. Circulation. 2000; 101: 1013-8.

115. Kritzik M, Savage B, Nugent DJ, Santoso S, Ruggeri ZM, Kunicki TJ. Nucleotide polymorphisms in the alpha 2 gene define multiple alleles that are associated with differences in platelet alpha2 betal density. Blood. 1998; 92: 2382-8.

116. Kunicki TJ, Kritzik M, Annis DS, Nugent DJ. Hereditary variation in platelet integrin alpha 2 beta 1 density is associated with two silent polymorphisms in the alpha 2 gene coding sequence. Blood. 1997; 89: 1939-43.

117. Bertina RM, Koeleman BP, Koster T, Rosendaal FR, Dirven RJ, de Ronde H, van der Velden PA, Reitsma PH. Mutation in blood coagulation factor $\mathrm{V}$ associated with resistance to activated protein $\mathrm{C}$. Nature. 1994; 369: 64-7.

118. Castoldi E, Rosing J. Factor V Leiden: a disorder of factor $\mathrm{V}$ anticoagulant function. Curr Opin Hematol. 2004; 11: 176-81.

119. Nicolaes GA, Dahlback B. Factor V and thrombotic disease: description of a janus-faced protein. Arterioscler Thromb Vasc Biol. 2002; 22: 530-8.

120. Bernardi F, Faioni EM, Castoldi E, Lunghi B, Castaman G, Sacchi E, Mannucci PM. A factor V genetic component differing from factor $V \mathrm{R} 506 \mathrm{Q}$ contributes to the activated protein $\mathrm{C}$ resistance phenotype. Blood. 1997; 90: 1552-7.

121. Lunghi B, Iacoviello L, Gemmati D, Dilasio MG, Castoldi E, Pinotti M, Castaman G, Redaelli R, Mariani $G$, et al. Detection of new polymorphic markers in the factor $V$ gene: association with factor $V$ levels in plasma. Thromb Haemost. 1996; 75: 45-8.

122. Castaman G, Faioni EM, Tosetto A, Bernardi $F$. The factor $V$ HR2 haplotype and the risk of venous thrombosis: a meta-analysis. Haematologica. 2003; 88: 1182-9. 
123. Faioni EM, Franchi F, Bucciarelli P, Margaglione M, De Stefano V, Castaman G, Finazzi G, Mannucci PM. Coinheritance of the HR2 haplotype in the factor $V$ gene confers an increased risk of venous thromboembolism to carriers of factor V R506Q (factor V Leiden). Blood. 1999; 94: 3062-6.

124. Longstreth WT, Jr., Rosendaal FR, Siscovick DS, Vos HL, Schwartz SM, Psaty BM, Raghunathan TE, Koepsell TD, Reitsma PH. Risk of stroke in young women and two prothrombotic mutations: factor $\mathrm{V}$ Leiden and prothrombin gene variant (G20210A). Stroke. 1998; 29: 577-80.

125. Zivelin A, Rosenberg N, Faier S, Kornbrot N, Peretz H, Mannhalter C, Horellou MH, Seligsohn U. A single genetic origin for the common prothrombotic G20210A polymorphism in the prothrombin gene. Blood. 1998; 92: 1119-24.

126. Ceelie H, Bertina RM, van Hylckama Vlieg A, Rosendaal FR, Vos HL. Polymorphisms in the prothrombin gene and their association with plasma prothrombin levels. Thromb Haemost. 2001; 85: 1066-70.

127. von Ahsen N, Oellerich $M$. The intronic prothrombin $19911 \mathrm{~A}>\mathrm{G}$ polymorphism influences splicing efficiency and modulates effects of the $20210 \mathrm{G}>\mathrm{A}$ polymorphism on mRNA amount and expression in a stable reporter gene assay system. Blood. 2004; 103: 586-93.

128. Heinrich J, Balleisen L, Schulte H, Assmann G, van de Loo J. Fibrinogen and factor VII in the prediction of coronary risk. Results from the PROCAM study in healthy men. Arterioscler Thromb. 1994; 14: 54-9.

129. Lee AJ, Lowe GD, Woodward M, Tunstall-Pedoe H. Fibrinogen in relation to personal history of prevalent hypertension, diabetes, stroke, intermittent claudication, coronary heart disease, and family history: the Scottish Heart Health Study. Br Heart J. 1993; 69: 338-42.

130. Carter AM, Catto AJ, Kohler HP, Ariens RA, Stickland MH, Grant PJ. alpha-fibrinogen Thr312Ala polymorphism and venous thromboembolism. Blood. 2000; 96: 1177-9.

131. Behague I, Poirier O, Nicaud V, Evans A, Arveiler D, Luc G, Cambou JP, Scarabin PY, Bara L, et al. Beta fibrinogen gene polymorphisms are associated with plasma fibrinogen and coronary artery disease in patients with myocardial infarction. The ECTIM Study. Etude Cas-Temoins sur l'Infarctus du Myocarde. Circulation. 1996; 93: 440-9.

132. Humphries SE, Ye S, Talmud P, Bara L, Wilhelmsen L, Tiret L. European Atherosclerosis Research Study: genotype at the fibrinogen locus (G-455-A beta-gene) is associated with differences in plasma fibrinogen levels in young men and women from different regions in Europe. Evidence for gendergenotype-environment interaction. Arterioscler Thromb Vasc Biol. 1995; 15: 96-104.

133. Ruggeri ZM. Platelet-vessel wall interactions in flowing blood. In: Hemostasis and Thrombosis (Colman, R W, et al, eds), Lippincott, Philadelphia, PA, USA. 2001: 683-98.

134. Gotto AM, Pownall HJ, Havel RJ. Introduction to the plasma lipoproteins. Methods Enzymol. 1986; 128: 3-41.

135. O'Brien PJ, Alborn WE, Sloan JH, Ulmer M, Boodhoo A, Knierman MD, Schultze AE, Konrad RJ. The novel apolipoprotein A5 is present in human serum, is associated with VLDL, HDL, and chylomicrons, and circulates at very low concentrations compared with other apolipoproteins. Clin Chem. 2005; 51: 351-9.

136. van Dijk KW, Rensen PC, Voshol PJ, Havekes LM. The role and mode of action of apolipoproteins CIII and AV: synergistic actors in triglyceride metabolism? Curr Opin Lipidol. 2004; 15: $239-46$.

137. Carlsson LE, Santoso S, Spitzer C, Kessler C, Greinacher A. The alpha2 gene coding sequence T807/A873 of the platelet collagen receptor integrin alpha2betal might be a genetic risk factor for the development of stroke in younger patients. Blood. 1999; 93; 3583-6.

138. Newman PJ. Platelet alloantigens: cardiovascular as well as immunological risk factors? Lancet. 1997; 349:370-1.

139. Newman PJ, Derbes RS, Aster RH. The human platelet alloantigens, PIA1 and PIA2, are associated with a leucine33/proline33 amino acid polymorphism in membrane glycoprotein IIIa, and are distinguishable by DNA typing. J Clin Invest. 1989; 83: 1778-81.

140. Poort SR, Rosendaal FR, Reitsma PH, Bertina RM. A common genetic variation in the 3'-untranslated region of the prothrombin gene is associated with elevated plasma prothrombin levels and an increase in venous thrombosis. Blood. 1996; 88: 3698-703.

141. Zivelin A, Griffin JH, Xu X, Pabinger I, Samama M, Conard J, Brenner B, Eldor A, Seligsohn U. A single genetic origin for a common Caucasian risk factor for venous thrombosis. Blood. 1997; 89: 397402 . 
Chapter 1

142. Alhenc-Gelas M, Nicaud V, Gandrille S, van Dreden P, Amiral J, Aubry ML, Fiessinger JN, Emmerich $\mathrm{J}$, Aiach $\mathrm{M}$. The factor $\mathrm{V}$ gene $\mathrm{A} 4070 \mathrm{G}$ mutation and the risk of venous thrombosis. Thromb Haemost. 1999; 81: 193-7.

143. Baumann RE, Henschen AH. Human fibrinogen polymorphic site analysis by restriction endonuclease digestion and allele-specific polymerase chain reaction amplification: identification of polymorphisms at positions A alpha 312 and B beta 448. Blood. 1993; 82: 2117-24. 


\section{Chapter 2}

\section{Fish oil consumption and reduction of arterial disease}

Kristof Vanschoonbeek, Moniek P.M. de Maat and Johan W.M. Heemskerk

Journal of Nutrition, 2003; 133: 657-60 


\section{PURPOSE OF REVIEW}

Fish oil consumption may help to normalize the pre-thrombotic state and reduce arterial disease. This antithrombotic potential of fish oil, rich in $n-3$ polyunsaturated fatty acids (PUFA), has been attributed to a reduction in platelet activation, a lowering of plasma triglycerides and (vitamin $\mathrm{K}$-dependent) coagulation factors, and/or decrease in vascular tone. Most intervention studies show only moderate effects of n-3 PUFA on these haemostatic parameters. On the other hand, the usually small prolongation in bleeding time with fish oil does not appear to lead to bruising or haemorrhage, at least in healthy subjects. This contrasts to the increased bleeding risk accompanying the more prominent anti-haemostatic effects of antiplatelet and anticoagulant drugs. Here we propose that the beneficial effect of n-3 PUFA diet is related to down-regulation of the mutually positive interactions of platelet activation and coagulation. In addition, we consider the possibility that the dietary effect on haemostatic and lipid factors involves transcription regulation of multiple genes, perhaps in a subject-dependent way. 


\section{INTRODUCTION}

The interest in fish oil as a possible antithrombotic nutritional component arose in the mid-1970s with the observation that Greenland Inuits, consuming high amounts of fatty fish, had a tendency of prolonged bleeding and a low incidence of cardiovascular disease. It was realized that fish and other marine oils are typically enriched in the n-3 PUFA, eicosapentaenoic acid (20:5 n-3) and docosahexaenoic acid (22:6 n-3). High consumption of $\mathrm{n}-3$ PUFA ( $>5 \mathrm{~g}$ daily) was thus considered to be responsible for the low arterial disease (1), although it later appeared that also genetic factors can be involved. Epidemiological observations have pointed to a clear association between fish oil consumption and reduced risk of coronary heart disease, even with only two fish dishes per week (2). Early controlled intervention studies, e.g. with men who had recovered from myocardial infarction, also confirmed that regular intake of fatty fish or fish oil capsules reduced death from ischemic heart disease, although without clear effect on the incidence of reinfarction (3). Substantial research since has revealed a variety of changes in the haemostatic system, which can explain the antithrombotic potential of fish oil. Surprisingly, however, when reviewing the literature, many described effects of fish oil intervention on surrogate in-vitro endpoint measurements, such as haemostatic factors, are variable in outcome. This raises questions to the underlying causes and significance of the effect variation.

\section{MEMBRANE PHOSPHOLIPIDS, PLATELES AND BLEEDING TIME}

Dietary n-3 PUFA have an established influence on the composition of membrane phospholipids, which effect is already detectable at low fish-oil intake. Fish oil-derived $\mathrm{n}-3$ PUFA replace especially arachidonic acid $(20: 4 \mathrm{n}-6)$ in the structural phospholipids of platelets and vascular cells by eicosapentaenoate and docosahexaenoate. Since these PUFA are all cleaved from phospholipids by cytosolic phospholipase $A_{2}$, fish oil lowers the arachidonate production by the phospholipase and, thereby, the substrate level for cyclooxygenase and lipoxygenase. In platelets and vascular cells, dietary fish oil thereby reduces formation of the n-6 PUFA-derived prostaglandins and leukotrienes, although this effect is partly compensated for by formation of n-3 PUFA-derived homologues of these prostanoids (4). With respect to platelets, early work showed that the reduced formation of prostaglandin $\mathrm{H}_{2}$ /thromboxane $\mathrm{A}_{2}$ by fish oil via cyclooxygenase-1 (COX1) is physiologically significant, because the COX1 product of fish oil-derived eicosapentaenoate, thromboxane $A_{3}$, stimulated platelets in a less effective manner than thromboxane $A_{2}$, while the platelet-inhibiting effect of endothelial prostaglandin $I_{3}$ (derived from $n-3$ PUFA) was similar to that of prostaglandin $\mathrm{I}_{2}$ (derived from arachidonic acid) (5). Fish oil was therefore considered to influence the so-called thromboxane-prostaglandin balance controlling platelet activation in a favorable, i.e. less platelet-stimulatory way. However, later ex vivo model studies with rats indicated that the n-3 PUFA-derived prostanoids from the endothelium contributed no more than little to the suppression of platelet activation. 
Thus, at least in this animal model, it is unlikely that the antithrombotic potential of fish oil relies fully on an altered thromboxane-prostaglandin balance (6).

As reviewed by others (4, 7-9), many but not all human intervention studies indicate that fatty fish or fish oil intake reduces platelet activation (Table 1). This effect is mostly determined as reduced aggregation tendency of platelets (in vitro) or as reduced production of the platelet secretion product $\beta$-thromboglobulin (in vivo). It is mostly but not exclusively obtained under conditions where production of thromboxane $A_{2}$ is a rate-limiting step in the platelet-activation process. Typically, even at higher doses of $\mathrm{n}$ 3 PUFA ( $\geq 6$ g daily), only about half of the reviewed studies describes significant effects on platelet function. Accordingly, in spite of the firm evidence that dietary $n-3$ PUFA modify the phospholipid fatty acid composition and alter the platelet eicosanoid metabolism, these modifications are not accompanied by a proportionally reduced platelet activation (10). Together, these data indicate that the antithrombotic potential of fish oil is unlikely to result only from diminished thromboxane $A_{2}$ production by the platelets.

Table 1. Effects of $n-3$ PUFA intake from fish oil on haemostatic parameters in man. Review of data from published human intervention studies with n-3 PUFA, supplied as fatty fish or fish oil capsules. Dietary interventions were at indicated doses for at least 3 weeks. Numbers represent fractions of published studies with significant effect.

\begin{tabular}{|c|c|c|c|c|}
\hline \multirow[t]{2}{*}{ Dietary effect } & \multicolumn{3}{|c|}{ Dose of $n-3$ PUFA/day } & \multirow[t]{2}{*}{ References } \\
\hline & $<3 \mathrm{~g}$ & $3-6 \mathrm{~g}$ & $\geq 6 \mathrm{~g}$ & \\
\hline Reduced platelet function & $3 / 6$ & $11 / 15$ & $6 / 11$ & 1 \\
\hline Prolonged bleeding time & $3 / 7$ & $9 / 15$ & $7 / 11$ & 2 \\
\hline Reduced blood pressure & $4 / 5$ & $6 / 9$ & $4 / 6$ & 3 \\
\hline Reduction in triglycerides & $7 / 8$ & $23 / 26$ & $9 / 10$ & 4 \\
\hline Reduction in coagulation factors & $3 / 5$ & $3 / 13$ & $3 / 6$ & 5 \\
\hline Increased fibrinolysis & $1 / 3$ & $0 / 5$ & $1 / 2$ & 6 \\
\hline Increase in PAI-1 & $1 / 3$ & $3 / 9$ & $2 / 2$ & 7 \\
\hline
\end{tabular}

$'(11,12,14,25-27,30,37-57)$

${ }^{2}(11,12,14,22,25,27,29,38-42,46,47,49-52,54,55,58-64)$

${ }^{3}(22,32,42,44,49,58,59,61,63,65-68)$

${ }^{4}(12,14,17,19,22,25,27-29,37,38,40,42,44,48,49,51,52,56,57,59-64,66-76)$

${ }^{s}(17,19,22,28,29,38,40,46,47,49,51,61,64,67-69,71,73,74,77,78)$

${ }^{6}(14,19,28,51,71,73,78,79)$

${ }^{7}(17,19,28,29,38,44,51,71-74,78)$

Part of the published studies report of a significant prolongation in the bleeding time after supplementation of n-3 PUFA, whether or not in association with a reduced thromboxane formation or platelet function $(4,11)$. A prolonged bleeding time is compatible with the antithrombotic potential of n-3 PUFA. Combined administration of fish oil and aspirin administration resulted in a further prolongation of the bleeding 
time, whereas fish oil did not improve the aspirin-induced inhibition of platelet aggregation (12). This can be taken as another indication that fish oil and aspirin affect haemostasis via different mechanisms.

\section{BLOOD LIPIDS AND FIBRINOLYSIS}

One of the first demonstrated effects of fish oil (1), meanwhile confirmed in most reports, is a reduction in plasma triglycerides (13). This n-3 PUFA effect is particularly prominent in hypertriglyceridemic patients (14), and is explained by a reduced secretion of very low-density lipoproteins from the liver. As reviewed elsewhere $(8,13,15)$, there is no consistent effect of n-3 PUFA on total cholesterol level or cholesterol in lowdensity lipoproteins. In some studies, e.g. with hyperlipoproteinemic patients, even an adverse increase in cholesterol (total or low-density lipoprotein) was observed. It thus appears that fish oil only in part improves the lipid profile in blood and, thus, lowers only part of the risk factors of atherothrombosis.

Few studies have been carried out to investigate whether fish oil has a positive, increasing effect on fibrinolysis. Particular attention is paid to plasminogen activator inhibitor type 1 (PAI-1) activity. PAI-1 is a fibrinolysis inhibitor, which complexes with circulating tissue-type plasminogen activator and abolishes plasminogen activation and fibrin degradation. High PAI-1 levels associate with increased risk of arterial disease either causally or as a marker. As reviewed elsewhere (16), few authors reported that fish oil reduces PAI-1 activity, but the majority of the investigators showed significant increases in this factor. This increase, depending on the levels of other fibrinolysis parameters, would point to an higher rather than improved procoagulant state.

\section{COAGULATION AND RELATION TO PLATELET ACTIVATION}

Until recently, when global coagulation assays often lacked sensitivity, anticoagulant effects of fish oil were considered to be absent or small $(4,16)$. In some of the published human studies, fish oil however appeared to reduce the levels of one or more coagulation factors. This concerns moderate reduction of factors VII and X, each of which is implicated in thrombin formation (17-19). Both coagulation factors require vitamin K-dependent carboxylation for coagulant activity, which supports the notion that fish oil can interfere with vitamin $\mathrm{K}$ action. With the development of modern, sensitive assays this topic is receiving new attention. In recent diet studies with rats, it was found that n-3 PUFA reduced the levels of the vitamin K-dependent factors II and $\mathrm{X}$ to a degree that sensitive clotting assays were influenced (20). Particularly the process of tissue factor-induced thrombin generation, which is driven by the vitamin $\mathrm{K}$ dependent coagulation factors, was reduced after intervention with low doses of $n-3$ PUFA (21). In rat, this anticoagulant effect was not enlarged by vitamin $\mathrm{K}$ depletion and was accompanied by a lowering in factor V, which is vitamin $\mathrm{K}$-independent (6). Some human studies also report of reduced factor $\mathrm{V}$ activity with fish oil (17). Another factor that can be decreased in response to fish oil is fibrinogen (factor I), particularly in 
subjects with high baseline levels $(18,22)$. Fibrinogen, being an independent cardiovascular risk factor, is a vitamin $\mathrm{K}$-independent protein, which is required for both coagulant activity and platelet function. Thus, part of the literature points to an anticoagulant action of fish oil - although less potent than that of anticoagulant therapy -, which is partly independent of vitamin $\mathrm{K}$.

It is well established that the processes of platelet activation and coagulation are intimately linked and act mutually stimulatory (23). Activated platelets provide glycoproteins and a phosphatidylserine-containing outer membrane, at which coagulation factors assemble and become activated (Figure 1). In the presence of phosphatidylserine-exposing membranes, thrombin formation in plasma is potentiated by at least three magnitudes. Conversely, the thrombin that is generated is one of the most potent platelet agonists known. This positive interaction of platelet activation and coagulation can be quantified under physiological conditions by measuring the generation and inactivation of thrombin in platelet-rich plasma (24). As indicated in Figure 2, partial anticoagulant therapy with coumarin and partial platelet inhibition with aspirin have additive, suppressing effects on the thrombin generation, when measured with platelets and plasma. A similar, reduced and delayed generation of thrombin was also measured in plasma from healthy volunteers after a regular intake of n-3 PUFA (K. Vanschoonbeek, unpublished data, 2002). Together, this may illustrate that, with fish oil, the combination of a moderate antiplatelet and anticoagulant effect is more thrombo-protective than either effect alone (Figure 1).

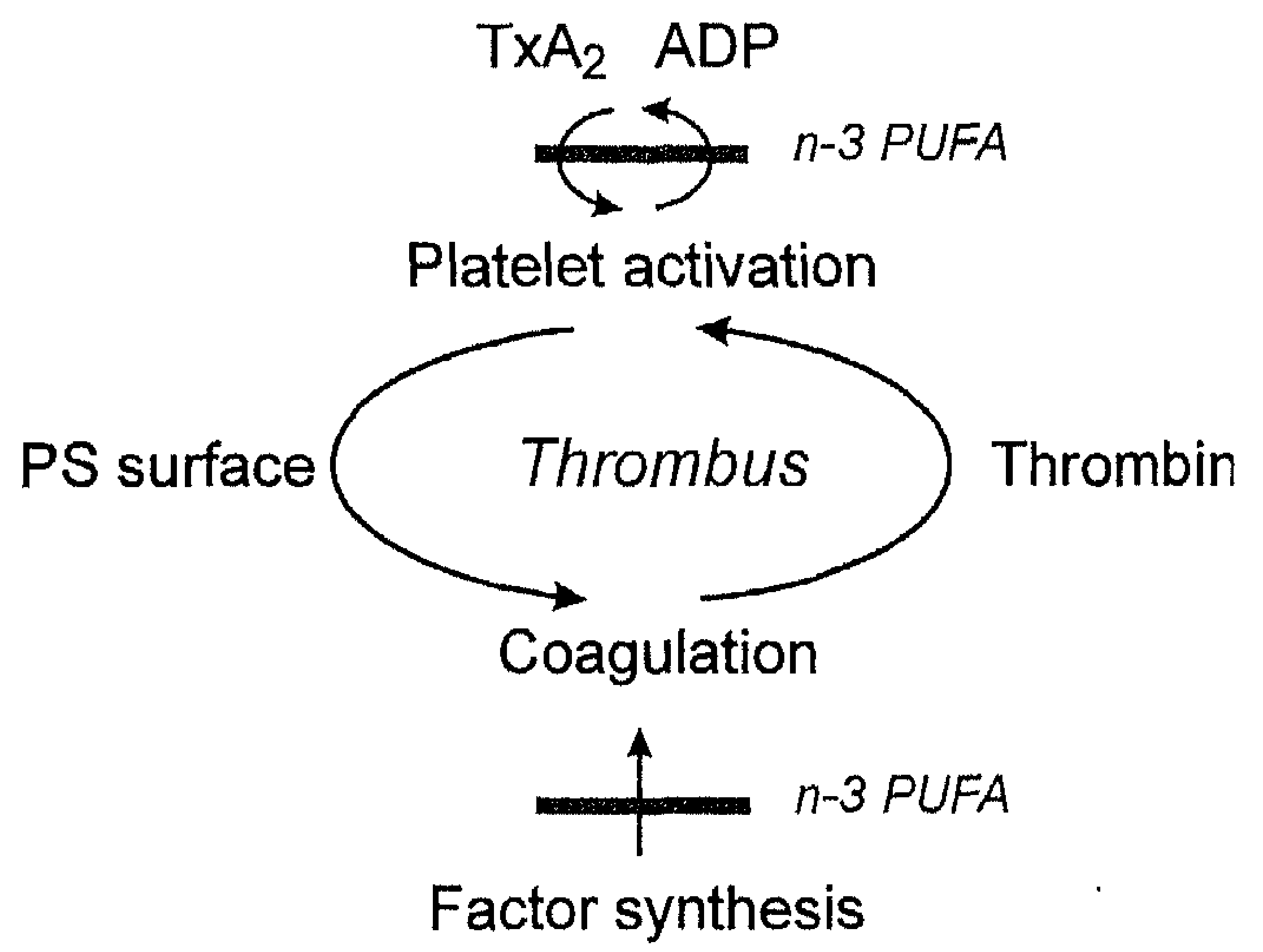

Figure 1. Positive interactions in thrombus formation of activated platelets, exposing procoagulant phosphatidylserine (PS) at their outer surface, and the coagulation process, generating platelet-activating thrombin. Fish oil diminishes platelet activation in part by lowering the arachidonate content of phospholipids and, thereby, the thromboxane ( $\left.\mathrm{TxA}_{2}\right)$ production. In addition, fish oil lowers coagulation factors levels, possibly by altered transcriptional activity in the liver. These two effects can add to reduce thrombus formation. 

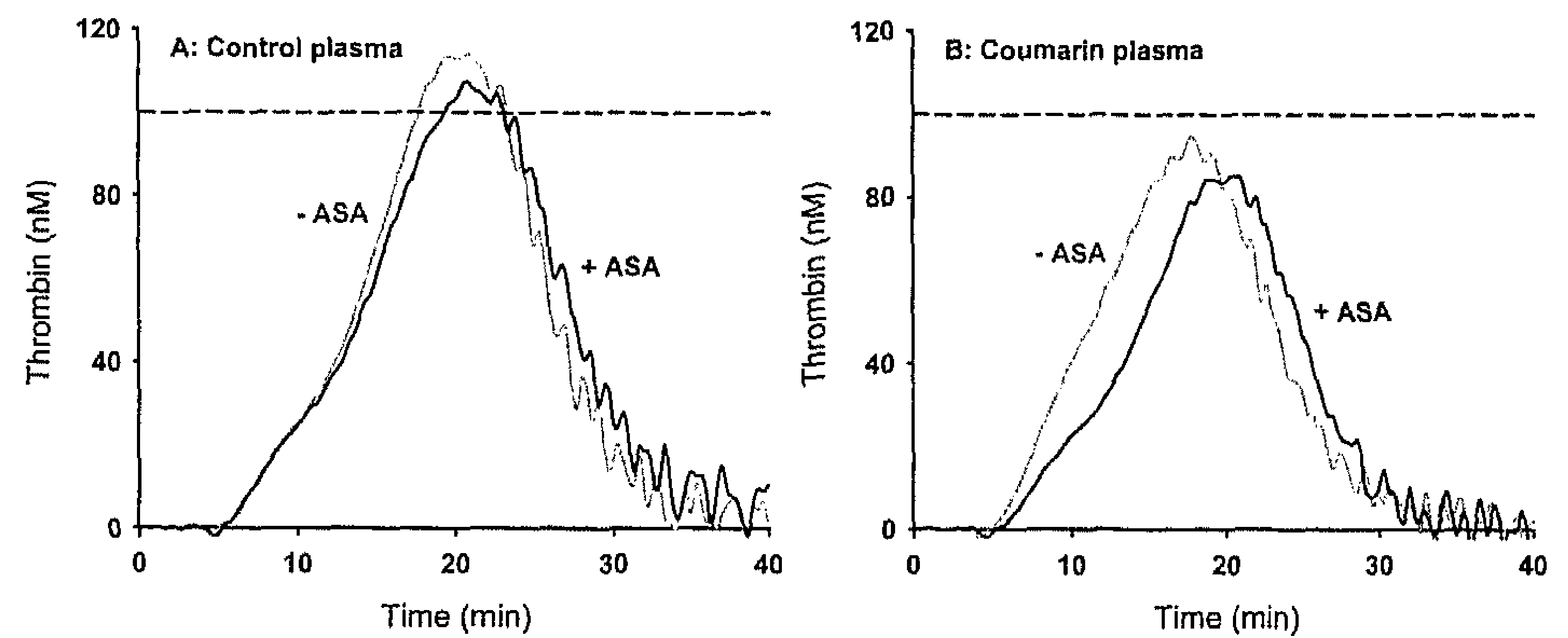

Figure 2. Additive effect of platelet inhibition and anticoagulant therapy on thrombin generation in plateletcontaining plasma. Platelet-rich plasma was triggered with recombinant tissue factor, and thrombin generation was followed in time from the cleavage of fluorescent thrombin substrate (24). Panel A: platelets were treated with aspirin (+ASA, black) or left untreated (-ASA, gray). Panel B: part of the control plasma was replaced by the plasma from a coumarin-treated patient (coumarin), as to give a final reduction in vitamin K-dependent coagulation factors of about $15 \%$. Note the decreased and prolonged peak of thrombin generation with ASA/coumarin.

\section{ADVERSE PHYSIOLOGICAL EFFECTS}

Successful antiplatelet and anticoagulant therapies are often accompanied by an increased risk of bleeding. Fish and fish oil supplements, mostly being well tolerated, have as main adverse side-effect mild gastrointestinal discomfort, appearing as a fishy aftertaste, belching, nausea, flatulence or loose stools. Published fish-oil intervention studies with healthy subjects do not provide indications for increased bleeding, even not after an intake of $6 \mathrm{~g}$ or more n-3 PUFA daily. Various papers explicitly mention absence of easy bruising or clinical signs of (postoperative) bleeding after fish oil application to patients with cardiovascular disease (25-27). Positive interactions between n-3 PUFA intake and oral anticoagulants have been monitored, but these appear to occur in the absence of clinically relevant bleeding (28). There is only an incidental report of a patient with minor nasal bleeding after a fish oil diet with concomitant anticoagulant therapy (29). In another study, fatal coagulapathy occurred in a patient after abdominal aortic aneurysm resection, but here a causal relationship of fish oil supplementation and the bleeding diathesis was reported to be uncertain (30). Only the Zutphen epidemiological study, investigating the association between fish consumption and stroke incidence in the Netherlands, concluded that large amounts of seafood may increase hemorrhagic subtypes of stroke, whereas only the consumption of small amounts of fish reduce the incidence of ischemic stroke (31). Vasodilatation is another reported effect - usually advantageous - of n-3 PUFA influencing the vascular system. However, a meta-analysis of clinical trials showed that the vasodilatating effect is most pronounced in hypertensive patients with no more than little effect on healthy 
normotensives (32). Thus, from the current literature, there seems to be little reason of concern for disadvantageous effects, at least when fish oil is not combined with anticoagulant treatment.

\section{VARIABLE TRANSCRIPTIONAL REGULATION}

As indicated, the usually mild and diverse thrombosis-reducing effects of n-3 PUFA intervention with respect to platelets, plasma lipid and coagulation factors show high inter-study variation. Some fish-oil effects, like changes in triglycerides, fibrinogen and other factors, seem to be most prominent in patients with increased basal values. Even within studies there is considerable variation in effects observed among individual subjects. Recent findings give an attractive explanation for the diverse and viable effects of n-3 PUFA on haemostatic and lipid factors, i.e. influence on gene expression. Feeding of fish oil to mice was found to down-regulate the hepatic mRNA level of sterol regulatory element-binding protein-1 (SREBP-1), which factor controls several lipogenic genes (33). Also in mice, n-3 PUFA suppress the endogenous peroxisome proliferator-activated receptor $\alpha(\operatorname{PPAR} \alpha)$, a ligand-activated transcription factor system (34), whereas oxidized n-3 PUFA rather activate PPAR $\alpha$ (35). It is also proposed that genetic polymorphisms of (haemostatic) factors associate with a variable, subject-dependent response to PUFA of genes coding for apolipoproteins (36). New research should indicate how important transcription factors and other regulatory elements are in mediating the fish oil response on the haemostatic system, e.g. regulation of hepatic secretion of triglycerides and (vitamin K-dependent) coagulation factors, and controlling the expression of platelet proteins. This can also reveal whether genetic components are involved in the subject-to-subject response variation to $n-3$ PUFA, such as polymorphisms in one or more haemostatic genes.

\section{Acknowledgments}

Due to space restrictions, only few citations could be included. We thank all authors in the field, apologizing for not having cited their work. 


\section{REFERENCES}

1. Bang HO, Dyerberg J, Nielsen AB. Plasma lipid and lipoprotein pattern in Greenlandic west-coast Eskimos. Lancet. 1971; i: 1143-5.

2. Kromhout D, Bosschieter EB, de Coulander CL. The inverse relation between fish consumption and 2year mortality from coronary heart disease. Lancet. 1987; i: 177-83.

3. Burr ML, Gilbert JF, Holliday RM, al. e. Effects of changes in fat, fish and fibre intakes on death and myocardial reinfarction; diet and reinfarction trial (DART). Lancet. 1989; i: 757-61.

4. Homstra G. The significance of fish and fish-oil enriched food for prevention and therapy of ischaemic cardiovascular disease. In: The Role of Fats in Human Nutrition (Vergroesen, E G, Ed) Academic Press, New York. 1989: 152-235.

5. Needleman P, Raz A, Minkes MS, Ferrendelli JA, Sprecher H. Triene prostaglandins, prostacyclin and thromboxane biosynthesis and unique biological properties. Proc Natl Acad Sci USA. 1979; 76: 944-8.

6. Nieuwenhuys CMA, Feijge MAH, Offermans RFG, Kester ADM, Hornstra G, Heemskerk JWM. Modulation of rat platelet activation by vessel wall-derived prostaglandin and platelet-derived thromboxane: effects of dietary fish oil on thromboxane-prostaglandin balance. Atherosclerosis. 2001; 154: $355-66$.

7. Kristensen SD, Schmidt EB, Dyerberg J. Dietary supplementation with n-3 polyunsaturated fatty acids and human platelet function: a review with particular emphasis on implications for cardiovascular disease. J Intern Med. 1989; 225: S141-50.

8. Malle E, Kostner GM. Effects of fish oil on lipid variables and platelet function indices. Prostagland Leukotr Essential Fatty Acids. 1993; 49: 645-63.

9. Chin JPF. Marine oils and cardiovascular reactivity. Prostagland Leukotr Essential Fatty Acids. 1994; 50: 211-22.

10. Heemskerk JWM, Vossen CRM, van Dam-Mieras MCA. Polyunsaturated fatty acids and function of platelets and endothelial cells. Curr Opin Lipidol. 1996; 7: 24-9.

11. Thorngren M, Shafi S, Born GV. Delay in primary haemostasis produced by a fish diet without change in local thromboxane $A_{2}$. Br J Haematol. 1984; 58: 567-78.

12. Harris WS, Rothrock DW, Fanning A, Inkeles SB, Goodnight SH, Jr., Illingworth DR, Connor WE. Fish oils in hypertriglyceridemia: a dose-response study. Am J Clin Nutr. 1990; 51: 399-406.

13. Harris WS. N-3 fatty acids and serum lipoproteins: human studies. Am J Clin Nutr. 1997; 65: 1645S$54 \mathrm{~S}$.

14. Zucker ML, Bilyeu DS, Helmkamp GM, Harris WS, Dujovne CA. Effects of dietary fish oil on platelet function and plasma lipids in hyperlipoproteinemic and normal subjects. Atherosclerosis. 1988; 73: 1322.

15. Leaf A, Weber PC. Cardiovascular effects of n-3 fatty acids. N Engl J Med, 1988; 318: 549-57.

16. Knapp HR. Dietary fatty acids in human thrombosis and hemostasis. Am J Clin Nutr. 1997; 65: 1687S$98 \mathrm{~S}$.

17. Oosthuizen W, Vorster HH, Jerling JC, Barnard HC, Smuts CM, Silvis N, Kruger A, Venter CS. Both fish oil and olive oil lowered plasma fibrinogen in women with high baseline fibrinogen levels. Thromb Haemost. 1994; 72: 557-62.

18. Shahar E, Folsom AR, Wu KK, Dennis BH, Shimakawa T, Conlan MG, Davis CE, Williams OD. Associations of fish intake and dietary $n-3$ polyunsaturated fatty acids with a hypocoagulable profile. The atherosclerosis risk in communities (ARIC) study. Arterioscler Thromb. 1993; 13: 1205-12.

19. Marckmann P, Bladbjerg EM, Jespersen J. Dietary fish oil (4 g daily) and cardiovascular risk markers in healthy men. Arterioscler Thromb Vasc Biol. 1997; 17: 3384-91.

20. Leray C, Wiesel ML, Freund M, Cazenave JP, Gachet C. Long-chain n-3 fatty acids specifically affect rat coagulation factors dependent on vitamin K. Arterioscler Thromb Vasc Biol, 2001; 21: 459-65.

21. Nieuwenhuys CMA, Béguin $\mathrm{S}$, Offermans RFG, Emeis JJ, Hornstra G, Heemskerk JWM. Hypocoagulant and lipid-lowering effects of dietary $n-3$ polyunsaturated fatty acids with unchanged platelet activation in rat. Arterioscler Thromb Vasc Biol. 1998; 18: 1480-9.

22. Haglund $O$, Wallin $R$, Luostarinen $R$, Saldeen $T$. Effects of a new fluid fish oil concentrate, Eskimo-3, on triglycerides, cholesterol, fibrinogen and blood pressure. J Intern Med. 1990; 227: 347-53.

23. Heemskerk JWM, Bevers EM, Lindhout T. Platelet activation and blood coagulation. Thromb Haemost. $2002 ; 88: 186-93$. 
24. Hemker HC, Giesen PLA, Ramjee M, Wagenvoord R, Béguin S. The thrombogram: monitoring thrombin generation in platelet rich plasma. Thromb Haemost. 2000; 83: 589-91.

25. Wojenski CM, Silver MJ, Walker J. Eicosapentaenoic acid ethyl ester as an antithrombotic agent: comparison to an extract of fish oil. Biochim Biophys Acta. 1991; 1081:33-8.

26. Roulet M, Frascarolo P, Pilet M, Chapuis G. Effects of intravenously infused fish oil on platelet fatty acid phospholipid composition and on platelet function in postoperative trauma. J Parent Enteral Nutr. 1997; 21:296-301.

27. De Caterina R, Giannessi D, Mazzone A, Bernini W, Lazzerini G, Maffei S, Cerri M, Salvatore L, Weksler B. Vascular prostacyclin is increased in patients ingesting omega-3 polyunsaturated fatty acids before coronary artery bypass graft surgery. Circulation. 1990; 82: 428-38.

28. Eritsland J, Arnesen H, Seljeflot I, Hostmark AT. Long-term metabolic effects of n-3 polyunsaturated fatty acids in patients with coronary artery disease. Am J Clin Nutr. 1995; 61: 831-6.

29. Smith P, Amesen H, Opstad T, Dahl KH, Eritsland J. Influence of highly concentrated n-3 fatty acids on serum lipids and hemostatic variables in survivors of myocardial infarction receiving either oral anticoagulants or matching placebo. Thromb Res. 1989; 53: 467-74.

30. Bowles MH, Klonis D, Plavac TG, Gonzales B, Francisco DA, Roberts RW, Boxberger GR, Poliner LR, Galichia JP. EPA in the prevention of restenosis post PTCA. Angiology. 1991; 42: 187-94.

31. Keli SO, Feskens EJ, Kromhout D. Fish consumption and risk of stroke. The Zutphen study. Stroke. 1994; 25: 328-32.

32. Morris MC, Sacks F, Rosner B. Does fish oil lower blood pressure? A meta-analysis of controlled trials. Circulation. 1993; 88: 523-33.

33. Kim HJ, Takahashi $M$, Ezaki $O$. Fish oil feeding decreases mature sterol regulatory element-binding protein 1 (SREBP-1) by down-regulation of SREBP-1 c mRNA in mouse liver. J Biol Chem. 1999; 274: 25892-8.

34. Takahashi M, Tsuboyama-Kasaoka N, Nakatani T, Ishii M, Tsutsumi S, Aburatani H, Ezaki O. Fish oil feeding allers liver gene expressions to defend against PPAR $\alpha$ activation and ROS production. Am J Physiol. 2002; 282: G338-G48.

35. Sethi S, Ziouzenkova O, Ni H, Wagner DD, Plutzky J, Mayadas TN. Oxidized $\omega-3$ fatty acids in fish oil inhibit leukocyte-endothelial interactions through activation of PPAR $\alpha$. Blood. 2002; 100: 1340-6.

36. Wallace AJ, Humphries SE, Fisher RM, Mann JI, Chisholm A, Sutherland WHF. Genetic factors associated with response of LDL subfractions to change in the nature of dietary fat. Atherosclerosis. 2000; 149: 387-94.

37. Demke DM, Peters GR, Linet OI, Metzler CM, Klott KA. Effects of a fish oil concentrate in patients with hypercholesterolemia. Atherosclerosis. 1988; 70: 73-80.

38. Freese R, Mutanen M. Alpha-linolenic acid and marine long-chain n-3 fatty acids differ only slightly in their effects on hemostatic factors in healthy subjects. Am J Clin Nutr. 1997; 66: 591-8.

39. Goodnight $\mathrm{SH}, \mathrm{J}_{\mathrm{r}}$, Harris WS, Connor WE. The effects of dietary omega 3 fatty acids on platelet composition and function in man: a prospective, controlled study. Blood. 1981; 58: 880-5.

40. Green D, Barreres L, Borensztajn J, Kaplan P, Reddy MN, Rovner R, Simon H. A double-blind, placebo-controlled trial of fish oil concentrate (MaxEpa) in stroke patients. Stroke. 1985; 16: 706-9.

41. Knapp HR, Reilly IA, Alessandrini P, FitzGerald GA. In vivo indexes of platelet and vascular function during fish-oil administration in patients with atherosclerosis. N Engl J Med. 1986; 314: 937-42.

42. Levinson PD, Iosiphidis AH, Saritelli AL, Herbert PN, Steiner M. Effects of $n-3$ fatty acids in essential hypertension. Am J Hypertens. 1990; 3: 754-60.

43. Li XL, Steiner M. Fish oil: a potent inhibitor of platelet adhesiveness. Blood. 1990; 76; 938-45.

44. Mehta J, Lawson D, Saldeen TJ. Reduction in plasminogen activator inhibitor-1 (PAI-1) with omega-3 polyunsaturated fatty acid (PUFA) intake. Am Heart J. 1988; 116: 1201-6.

45. Mori TA, Beilin LJ, Burke V, Morris J, Ritchie J. Interactions between dietary fat, fish, and fish oils and their effects on platelet function in men at risk of cardiovascular disease. Arterioscler Thromb Vase Biol. $1997 ; 17 ; 279-86$.

46. Nordoy A, Hatcher L, Goodnight S, Fitzgerald GA, Conner WE. Effects of dietary fat content, saturated fatty acids, and fish oil on eicosanoid production and hemostatic parameters in normal men. J Lab Clin Med. 1994; 123: 914-20.

47. Owens MR, Cave WT, Jr. Dietary fish lipids do not diminish platelet adhesion to subendothelium. Br J Haematol. 1990; 75: 82-5. 
48. Prisco D, Filippini M, Francalanci I, Paniccia R, Gensini GF, Serneri GG. Effect of $n-3$ fatty acid ethyl ester supplementation on fatty acid composition of the single platelet phospholipids and on platelet functions. Metabolism. 1995; 44: 562-9.

49. Rogers S, James KS, Butland BK, Etherington MD, O'Brien JR, Jones JG. Effects of a fish oil supplement on serum lipids, blood pressure, bleeding time, haemostatic and rheological variables. A double blind randomised controlled trial in healthy volunteers. Atherosclerosis. 1987; 63: 137-43.

50. Scheurlen M, Kirchner M, Clemens MR, Jaschonek K. Fish oil preparations rich in docosahexaenoic acid modify platelet responsiveness to prostaglandin-endoperoxide/thromboxane $\mathrm{A} 2$ receptor agonists. Biochem Pharmacol. 1993; 46: 245-9.

51. Schmidt EB, Varming K, Ernst E, Madsen P, Dyerberg J. Dose-response studies on the effect of $n-3$ polyunsaturated fatty acids on lipids and haemostasis. Thromb Haemost. 1990; 63: 1-5.

52. Silverman DI, Ware JA, Sacks FM, Pasternak RC. Comparison of the absorption and effect on platelet function of a single dose of n-3 fatty acids given as fish or fish oil. Am J Clin Nutr. 199l; 53: 1165-70.

53. Skeaff $\mathrm{CM}$, Holub BJ. The effect of fish oil consumption on platelet aggregation responses in washed human platelet suspensions. Thromb Res. 1988; 51: 105-15.

54. Thorngren M, Gustafson A. Effects of 11-week increases in dietary eicosapentaenoic acid on bleeding time, lipids, and platelet aggregation. Lancet. 1981;2: 1190-3.

55. Thorngren M, Gustafson A, Wohlfart G. Effects of acetylsalicylic acid on platelet aggregation before and during increase in dietary eicosapentaenoic acid. Haemostasis. 1983; 13: 244-7.

56. Tremoli E, Maderna P, Marangoni F, Colli S, Eligini S, Catalano I, Angeli MT, Pazzucconi F, Gianfranceschi $\mathrm{G}$, et al. Prolonged inhibition of platelet aggregation after n-3 fatty acid ethyl ester ingestion by healthy volunteers. Am $J$ Clin Nutr. 1995; 61: 607-13.

57. Turini ME, Powell WS, Behr SR, Holub BJ. Effects of a fish-oil and vegetable-oil formula on aggregation and ethanolamine-containing lysophospholipid generation in activated human platelets and on leukotriene production in stimulated neutrophils. Am J Clin Nutr. 1994; 60: 717-24.

58. Badalamenti S, Salerno F, Salmeron JM, Lorenzano E, Rimola A, Gines P, Jimenez W, Graziani G Arroyo $V$, et al. Lack of renal effects of fish oil administration in patients with advanced cirrhosis and impaired glomerular filtration. Hepatology, 1997; 25: 313-6.

59. Blonk MC, Bilo HJ, Nauta JJ, Popp Snijders C, Mulder C, Donker AJ. Dose-response effects of fish-oil supplementation in healthy volunteers. Am J Clin Nutr. 1990; 52: 120-7.

60. Clark WF, Parbtani A, Naylor CD, Levinton CM, Muirhead N, Spanner E, Huff MW, Philbrick DJ, Holub BJ. Fish oil in lupus nephritis: clinical findings and methodological implications. Kidney Int, 1993; 44: 75-86.

61. Cobiac L, Clifton PM, Abbey M, Belling GB, Nestel PJ. Lipid, lipoprotein, and hemostatic effects of fish vs fish-oil n-3 fatty acids in mildly hyperlipidemic males. Am J Clin Nutr. 1991; 53: 1210-6.

62. Hansen JB, Lyngmo V, Svensson B, Nordoy A. Inhibition of exercise-induced shortening of bleeding time by fish oil in familial hypercholesterolemia (type IIa). Arterioscler Thromb. 1993; 13: 98-104.

63. Mortensen JZ, Schmidt EB, Nielsen AH, Dyerberg J. The effect of N-6 and N-3 polyunsaturated fatty acids on hemostasis, blood lipids and blood pressure. Thromb Haemost. 1983; 50: 543-6.

64. Simons LA, Hickie JB, Balasubramaniam S. On the effects of dietary n-3 fatty acids (Maxepa) on plasma lipids and lipoproteins in patients with hyperlipidaemia. Atherosclerosis. 1985; 54: 75-88.

65. Appel LJ, Miller ERd, Seidler AJ, Whelton PK. Does supplementation of diet with 'fish oil' reduce blood pressure? A meta-analysis of controlled clinical trials. Arch Intern Med. 1993; 153: 1429-38.

66. Bruckner G, Webb P, Greenwell L, Chow C, Richardson D. Fish oil increases peripheral capillary blood cell velocity in humans. Atherosclerosis. 1987; 66: 237-45.

67. Flaten H, Hostmark AT, Kierulf P, Lystad E, Trygg K, Bjerkedal T, Osland A. Fish-oil concentrate: effects on variables related to cardiovascular disease. Am J Clin Nutr. 1990; 52: 300-6.

68. Gans RO, Bilo HJ, Weersink EG, Rauwerda JA, Fonk T, Popp Snijders C, Donker AJ. Fish oil supplementation in patients with stable claudication. Am J Surg. 1990; 160: 490-5.

69. Berrettini M, Parise P, Ricotta S, Iorio A, Peirone C, Nenci GG. Increased plasma levels of tissue factor pathway inhibitor (TFPI) after n-3 polyunsaturated fatty acids supplementation in patients with chronic atherosclerotic disease. Thromb Haemost. 1996; 75: 395-400.

70. Feskens EJ, Kromhout D. Epidemiologic studies on Eskimos and fish intake. Ann N Y Acad Sci. 1993; 683: 9-15.

71. Haglund O, Mehta JL, Saldeen T. Effects of fish oil on some parameters of fibrinolysis and lipoprotein(a) in healthy subjects. Am J Cardiol. 1994; 74: 189-92. 
Chapter 2

72. Hansen JB, Grimsgaard S, Nordøy A, Bønaa KH. Dietary Supplementation with Highly Purified Eicosapentaenoic Acid and Docosahexaenoic Acid Does Not Influence PAI-1 Activity. Thrombosis Research. 2000; 98: 123-32.

73. Prisco D, Paniccia R, Filippini M, Francalanci I, Bandinelli B, Comeglio P, Rostagno C, Abbate R, Neri Serneri GG. No changes in PAI-1 levels after four-month n-3 PUFA ethyl ester supplementation in healthy subjects. Thromb Res. 1994; 76: 237-44.

74. Sanders TA, Oakley FR, Miller GJ, Mitropoulos KA, Crook D, Oliver MF. Influence of n-6 versus n-3 polyunsaturated fatty acids in diets low in saturated fatty acids on plasma lipoproteins and hemostatic factors. Arterioscler Thromb Vasc Biol. 1997; 17: 3449-60.

75. Sorensen NS, Marckmann P, Hoy CE, van Duyvenvoorde W, Princen HM. Effect of fish-oil-enriched margarine on plasma lipids, low-density-lipoprotein particle composition, size, and susceptibility to oxidation. Am J Clin Nutr. 1998; 68: 235-41.

76. Svaneborg N, Moller JM, Schmidt EB, Varming K, Lervang HH, Dyerberg J. The acute effects of a single very high dose of $\mathrm{n}-3$ fatty acids on plasma lipids and lipoproteins in healthy subjects. Lipids. 1994; $29:$ : $45-7$.

77. Hostmark AT, Bjerkedal $\mathrm{T}$, Kjerulf $\mathrm{P}$, Flaten $\mathrm{H}$, Ulshagen $\mathrm{K}$. Fish oil and plasma fibrinogen. BMJ. 1988; 297: 180-1.

78. Moller JM, Svaneborg N, Lervang HH, Varming K, Madsen P, Dyerberg J, Schmidt EB. The acute effect of a single very high dose of $n-3$ fatty acids on coagulation and fibrinolysis. Thromb Res. 1992; 67: 569-77.

79. Brown AJ, Roberts DC. Fish and fish oil intake: effect on haematological variables related to cardiovascular disease. Thromb Res. 1991; 64: 169-78. 


\section{Chapter 3}

\section{Thrombin-induced hyperactivity of platelets of young stroke patients}

Kristof Vanschoonbeek, Marion A.H. Feijge, Karin Ansink, Jeffrey F.W. Keuren, Karly Hamulyák, H. Coenraad Hemker, Elisabeth C.M. van Pampus, Jan J. Lodder and Johan W.M. Heemskerk

Thrombosis and Haemostasis, 2002; 88: 931-37 


\begin{abstract}
Platelets are implicated in the development of premature arterial vascular diseases, ischemic stroke in particular. To investigate the activation tendency of platelets from such patients, we measured agonist-induced $\mathrm{Ca}^{2+}$ signal generation in fura-2-loaded platelets from 56 healthy volunteers, 26 young patients recuperating from stroke, and 20 patients with symptomatic peripheral arterial disease. In the presence of aspirin, the thrombin-induced $\mathrm{Ca}^{2+}$ response was increased for platelets from either patient group in comparison to platelets from control subjects $(P<0.04)$. A higher number of stroke patients had high-responsive platelets $(27 \%, 7 / 26)$ than of patients with peripheral arterial disease $(10 \%, 2 / 20)$ or healthy subjects $(4 \%, 2 / 56)$. In about half of the cases, a high thrombin-induced $\mathrm{Ca}^{2+}$ response was accompanied by increased thrombin-mediated procoagulant activity of the platelets. In a follow-up study, the thrombin-induced response was found to correlate strongly with only the response to protease-activated receptor 1 (PAR1) agonist $(r=0.91)$. It is concluded that a significant part of young patients with stroke have platelets with hyperactivity toward thrombin, which is not normalised by aspirin treatment. The subject-dependent variation in thrombin-induced signalling seems at least partially to be due to variation in PARl-mediated platelet activation.
\end{abstract}




\section{INTRODUCTION}

Cerebral infarction in young adults is an etiologically diverse disease, of which the underlying cause in individual cases often remains unknown $(1,2)$. Various lines of evidence suggest that increased platelet activation may be one of the risk factors for ischemic stroke. In a number of studies, the occurrence of a cerebrovascular accident appeared to be associated with increased platelet aggregation, as measured in platelet preparations ex vivo (3-7). Others have documented that circulating platelets from patients with arterial diseases may be increased in surface expression of activation markers, such as activated integrin $\alpha_{\mathrm{II}} \beta_{3}$ and P-selectin $(8,9)$. Large-scale intervention studies have shown that antiplatelet therapy is significantly though only partially efficacious in secondary prevention of ischemic stroke or transient ischemic attacks (1013). Increased levels of platelet release products, like $\beta$-thromboglobulin and platelet factor 4 , are reported to circulate in these patients (11). Evidence is arising that (combination) therapy with antagonists against the platelet purinergic receptors is at least as effective in reducing ischemic events as treatment with only aspirin $(14,15)$. A similar situation may exist for patients with peripheral arterial disease (PAD), another multifactorial vascular disease with high risk of thrombosis. Here, there is yet limited evidence for increased platelet activation (16). Nevertheless, also in this group of patients, antiplatelet therapy can result in partial risk reduction of new thrombotic events (15).

Upon platelet activation, agonist-induced generation of the second messenger, $\mathrm{Ca}^{2+}$, is an initial, integrative marker of the activation process. Generation of the $\mathrm{Ca}^{2+}$ signal is a prerequisite for the processes of shape change, secretion, thromboxane $A_{2}$ and ADP release, thrombus formation and the development of platelet procoagulant activity (17). In earlier work, we have established that platelets from healthy subjects exhibit a persistent inter-individual variability in their $\mathrm{Ca}^{2+}$ responses (18). This variation was typically unaltered after oral intake of aspirin or in-vitro application of aspirin to the platelets, suggesting it was thromboxane-independent $(18,19)$. Knowing that patients with platelets that are deficient in $\mathrm{Ca}^{2+}$ signal generation tend to have increased bleeding $(20,21)$, one can reason that increased $\mathrm{Ca}^{2+}$ mobilisation conversely leads to platelet hyperactivity. When persisting after aspirin intake, this might lead to disadvantageous consequences.

Here we determined the signal-transducing state of platelets from groups of young patients with ischemic stroke and patients with $\mathrm{PAD}$, and compared these with platelet signalling properties in healthy control subjects. We measured the rises in cytosolic $\left[\mathrm{Ca}^{2+}\right]_{\mathrm{i}}$ in the platelets in response to $\alpha$-thrombin and other agonists, and evaluated the effect of in-vitro addition of aspirin. In a second study with platelets from only healthy volunteers, we set to determine possible causes of the inter-individual variability in $\mathrm{Ca}^{2+}$ signal generation. Thrombin-evoked $\mathrm{Ca}^{2+}$ responses were therefore compared to responses elicited by the protease-activated receptor 1 (PAR1) of thrombin, SFLLRN, which only signals through the GTP-binding protein, $\mathrm{G}_{\mathrm{q}}$, and phospholipase C- $\beta$ (2224). 


\section{MATERIALS AND METHODS}

\section{Subjects}

Healthy, control subjects of the first study ( $n=56)$ had been free of medication for at least two weeks. Included young patients ( $n=26$, aged $<51$ years) had experienced an ischaemic stroke 3-12 months earlier, verified by computerised tomography or magnetic resonance imaging. Other included patients had symptomatic PAD $(n=20)$, confirmed by angiography, for at least two months. None of these subjects suffered from other cardiovascular diseases, hypertension, diabetes mellitus, hyperlipidaemia or obesity. The patients did not use anti-platelet medication other than aspirin (no nonsteroidal antiinflammatory agents, nitro-containing vasodilators, anticoagulants or platelet receptor drugs) (Table 1). Healthy subjects of the second study $(n=27)$ were also free of medication for two weeks; 13 of these individuals also participated in the first study. Experimental protocols were approved by the local Medical Ethics Committee.

Table 1: Baseline characteristics of healthy controls and patients with ischemic stroke or peripheral arterial disease (PAD).

\begin{tabular}{llll}
\hline & $\begin{array}{l}\text { Control } \\
(n=56)\end{array}$ & $\begin{array}{l}\text { Ischemic stroke } \\
(n=26)\end{array}$ & $\begin{array}{l}\text { PAD } \\
(n=20)\end{array}$ \\
\hline Age: & & & \\
$\quad 35$ & 44 & 43 \\
$\quad$ Median (y) & 31 & 45 & 45 \\
$\quad$ Range (y) & $22-57$ & $32-50$ & $25-56$ \\
Male (female) & $29(27)$ & $10(16)$ & $7(13)$ \\
& & & $12(8)$ \\
Non-smoking (smoking) & $46(10)$ & $16(10)$ & \\
& & & 7 \\
Medication: & 0 & 24 & 0 \\
$\quad$ Aspirin & 0 & 0 & 13 \\
Other anti-platelet & 0 & 19 & \\
Other than anti-platelet & 0 & & \\
\hline
\end{tabular}

\section{Materials}

Human $\alpha$-thrombin, ADP and apyrase were obtained from Sigma (St. Louis, MO, USA), while Horm-type collagen was from Nycomed (Munich, Germany). The PAR1 receptor agonist, SFLLRN, came from IHB (Academic Hospital Leiden, The Netherlands); fura-2 pentaacetoxy methyl ester was from Molecular Probes (Leiden, The Netherlands); lysine acetylsalicylate (aspirin) was from Genfarma (Maarssen, The Netherlands); and abciximab was obtained from Centocor (Leiden, The Netherlands). 
Convulxin was purified from snake venom as described (25). Purified bovine factors Va and $\mathrm{Xa}$ and prothrombin were obtained, as described before (26). High-Pure kit for isolation of genomic DNA was obtained from Roche Diagnostics (Mannheim, Germany). Taq1 and MspI restriction enzymes came from Gibco BRL (Breda, The Netherlands). DNA primers for PCR amplification were synthesized by Eurogentec (Liège, Belgium).

\section{Haematology}

Platelet count (in anticoagulated whole blood and plasma) and mean platelet volume were determined with a thrombocounter from Coulter Electronics (Luton, UK) using a standardised protocol.

\section{Blood cell isolation and $\left[\mathrm{Ca}^{2+}\right]_{i}$ measurements}

Blood was collected into $1 / 6$ volume of acid citrate dextrose $(80 \mathrm{mM}$ trisodium citrate, $52 \mathrm{mM}$ citric acid and $180 \mathrm{mM}$ glucose). Platelet-rich plasma was obtained by immediate centrifugation at $190 \mathrm{~g}$ for $15 \mathrm{~min}$. Buffy coats were collected for DNA analysis, where indicated. Platelets in plasma were loaded with fura-2 under strictly standardised conditions, as described before (18). Briefly, plasma was normalised to $3 \mathrm{x}$ $10^{8}$ platelets $/ \mathrm{ml}$ with autologous platelet-poor plasma. Incubation with $2.5 \mu \mathrm{M}$ fura- 2 pentaacetoxy methyl ester was during $45 \mathrm{~min}$ at $37^{\circ} \mathrm{C}$ in the presence of apyrase $(0.1$ unit ADPase $/ \mathrm{ml}$ ) and $100 \mu \mathrm{M}$ aspirin, unless indicated otherwise. Thereafter the platelets were centrifuged and washed in the presence of apyrase (0.1 unit ADPase $/ \mathrm{ml})$. The cells were resuspended in Hepes buffer, $\mathrm{pH} 7.45(136 \mathrm{mM} \mathrm{NaCl}, 2.7 \mathrm{mM} \mathrm{KCl}, 5$ $\mathrm{mM}$ Hepes, $2 \mathrm{mM} \mathrm{MgCl} 2,10 \mathrm{mM}$ glucose) containing $0.1 \%(\mathrm{w} / \mathrm{v})$ bovine serum albumin and apyrase $(0.1 \mathrm{unit} / \mathrm{ml})$ to a final concentration of $0.75 \times 10^{8}$ platelets $/ \mathrm{ml}$. Changes in $\left[\mathrm{Ca}^{2+}\right]_{i}$ were measured in duplicate at $37^{\circ} \mathrm{C}$ under continuous stirring by dual excitation fluorometry in an SLM-Aminco 8100 spectrofluorometer (SLM Instruments, Rochester NY, USA). Ratio values of fluorescence at 340 and $380 \mathrm{~nm}$ were converted to levels of $\left[\mathrm{Ca}^{2+}\right]_{\mathrm{i}}$, as described before (22). Fluorescence changes were measured upon stimulation of the platelets with $4 \mathrm{nM}$ thrombin, $15 \mu \mathrm{M}$ SFLLRN, $20 \mu \mathrm{M}$ ADP or 50 $\mathrm{ng} / \mathrm{ml}$ convulxin in the presence of $1 \mathrm{mM} \mathrm{CaCl}_{2}$.

\section{Prothrombinase measurements}

Platelet procoagulant activity was determined by measuring the rate of conversion of prothrombin to thrombin by the enzyme complex factor Xa-factor Va (samples of controls and patients in pairs). It was expressed as prothrombinase activity, basically as described elsewhere (26). Briefly, washed platelets $\left(1 \times 10^{7} / 0.5 \mathrm{ml}\right)$ in Hepes buffer $\mathrm{pH}$ 7.45 containing $1 \mathrm{mM} \mathrm{CaCl} 2$ were activated with $4 \mathrm{nM}$ thrombin and/or $50 \mathrm{nM}$ thapsigargin under stirring for $5 \mathrm{~min}\left(37^{\circ} \mathrm{C}\right)$. Samples of $25 \mu \mathrm{l}$ were added to $225 \mu \mathrm{l}$ of Hepes buffer $\mathrm{pH} 7.45$, supplemented with $0.5 \%(\mathrm{w} / \mathrm{v})$ bovine serum albumin, $3 \mathrm{mM}$ 
$\mathrm{CaCl}_{2}, 6 \mathrm{nM}$ factor $\mathrm{Va}$ and $3 \mathrm{nM}$ factor $\mathrm{Xa}$ (all final concentrations). Prothrombinase activity was started by the addition of $3.2 \mu \mathrm{M}$ prothrombin. This activity was linear in time from at least $30 \mathrm{~s}$ to $5 \mathrm{~min}$. At known time points, $25 \mu \mathrm{l}$ samples were transferred to $1 \mathrm{ml}$ of stopping buffer ( $120 \mathrm{mM} \mathrm{NaCl}, 50 \mathrm{mM}$ Tris- $\mathrm{HCl}$ and $2 \mathrm{mM}$ EDTA, pH 7.9). Thrombin was then measured colorimetrically at $405 \mathrm{~nm}$ with the chromogenic substrate $\mathrm{S} 2238$. The thrombin generation (nM thrombin formed $/ \mathrm{min} / 10^{7}$ platelets) was expressed as percentage of the maximal amount of thrombin generation, as measured with the same concentration of autologous, sonicated platelets. Prothrombinase activities were corrected for basal levels of thrombin formation measured with the unstimulated platelets.

\section{DNA isolation and determination of genetic polymorphisms}

Genomic DNA was isolated from leukocyte-rich buffy coats using the High-Pure kit from Roche Diagnostics. Genotypes were determined by a polymerase chain reaction (PCR) using the following nucleotide primer sets: 5'-TTCTGATTGCT GGACTTCTCTT-3' and 5'-TCTCTCCCCATGGCAAAGAG T-3' for the Pl' ${ }^{\mathrm{A}}$ genotypes of glycoprotein IIIa (27); 5'-GTGTTTAACTTGAACACATA T-3' and 5'ACCTTGCATATTGAATTGCT T-3' for 807C/T polymorphisms of glycoprotein Ia. The PCR amplification protocol for $\mathrm{Pl}^{\mathrm{A}}$ polymorphisms consisted of an initial denaturation segment of $94^{\circ} \mathrm{C}$ for $5 \mathrm{~min}$, followed by a 35-times repeated thermocycle $\left(94^{\circ} \mathrm{C}\right.$ for $60 \mathrm{~s}, 57^{\circ} \mathrm{C}$ for $45 \mathrm{~s}$ and $72^{\circ} \mathrm{C}$ for $60 \mathrm{~s}$ ) and an additional extension cycle at $72^{\circ} \mathrm{C}$ for $15 \mathrm{~min}$. The 266-bp fragment amplified by PCR was digested with MspI at $37^{\circ} \mathrm{C}$ for $90 \mathrm{~min}$. The protocol for $807 \mathrm{C} / \mathrm{T}$ consisted of an initial denaturation segment of $95^{\circ} \mathrm{C}$ for $5 \mathrm{~min}$, followed by a 30-times repeated temperature cycle $\left(95^{\circ} \mathrm{C}\right.$ for $30 \mathrm{~s}$, $50^{\circ} \mathrm{C}$ for $30 \mathrm{~s}$ and $72^{\circ} \mathrm{C}$ for $60 \mathrm{~s}$ ) and an additional extension cycle at $72^{\circ} \mathrm{C}$ for $7 \mathrm{~min}$. To distinguish between the two glycoprotein Ia alleles, the PCR product was digested with Taq1 restriction enzyme at $65^{\circ} \mathrm{C}$ for $15 \mathrm{~min}$ (28). Polymorphic genotypes were identified after electrophoresis of digestion products in ethidium bromide-stained agarose gels.

\section{Statistics}

Significance of differences between corresponding mean values compared to control groups was evaluated with a Mann-Whitney $U$ test (2-tailed). Correlations between parameters were determined using the Pearson correlation test. Tests were carried out with the statistical package for the social sciences (SPSS, Chicago, USA).

\section{RESULTS AND DISCUSSION}

\section{Increased thrombin-induced $\mathrm{Ca}^{2+}$ responses in patient platelets}

Platelet activation was determined from the $\mathrm{Ca}^{2+}$ responses of freshly isolated, washed 
platelets, which were loaded with fura-2 under standardised conditions (18). As the procedure is labour-intensive, measurements were initially carried out with a limited group of 56 healthy volunteers (median age 31 years), 26 young patients with stroke (median age 45 years) and 20 patients with PAD (median age 45 years). All three groups consisted of male and female subjects, of whom a substantial number was smoking (Table 1). Control subjects, being relatively young in age, were free of medication for at least two weeks. The included young stroke patients had experienced 3-12 months earlier a documented cerebrovascular infarction. The PAD patients were symptomatic for at least two months. None of the patients used other antiplatelet medication than aspirin.

Whole-blood platelet counts and mean platelet volume of the control subjects and patients were in the normal range (Table 2). The fura-2-loaded platelets were stimulated with sub-maximal doses of thrombin $(4 \mathrm{nM})$, thapsigargin $(100 \mathrm{nM}$, a specific inhibitor of sarco/endoplasmic reticulum $\mathrm{Ca}^{2+}$-ATPases), or fibrillar collagen $(5 \mu \mathrm{g} / \mathrm{ml}$, activating through the glycoprotein VI collagen receptor) in the presence $1 \mathrm{mM} \mathrm{CaCl}$. Initial rises in $\left[\mathrm{Ca}^{2+}\right]_{i}$ were determined as a reproducible, consistent parameter of platelet activation (relative method error of $4.1 \%$ and inter-individual coefficient of variance of $13.5 \%$ ) (18). In the platelets from control subjects, the thrombin-induced $\left[\mathrm{Ca}^{2+}\right]_{i}$ rises amounted to $548 \pm 98 \mathrm{nM}$ (mean $\pm \mathrm{SD}, n=56$ ). After in vitro incubation with $100 \mu \mathrm{M}$ aspirin (while loading the platelets with fura-2), these responses decreased with $8.7 \pm 16.9 \%$ to $505 \pm 103 \mathrm{nM}$ (Table 2). This aspirin treatment is sufficient to completely abolish thromboxane $\mathrm{A}_{2}$ formation by the platelets, similarly as does a single oral dose of 500 $m g$ aspirin $(18,19)$. In the platelets from patients with ischemic stroke, the thrombininduced rises in $\left[\mathrm{Ca}^{2+}\right]_{\mathrm{i}}$ were on average high, i.e. $593 \pm 152 \mathrm{nM}$ (mean $\pm \mathrm{SD}, n=26$, $P=0.45$ compared to controls). After aspirin treatment this response remained essentially unchanged, amounting to $600 \pm 149 \mathrm{nM}$ (Table 2). This lack of effect of aspirin was expected, because 24 out of 26 stroke patients used aspirin at a regular base (Table 1). With aspirin, the thrombin-induced response was significantly higher in the platelets from stroke patients than in control platelets $(P=0.003)$. Similarly, the thrombin-induced $\mathrm{Ca}^{2+}$ response of (aspirin-treated) platelets from patients with PAD was increased, i.e. $557 \pm 125 \mathrm{nM}(n=20, P=0.04)$. Absolute fura- 2 fluorescence levels in the platelets from healthy subjects and patient groups were similar, indicating that the different measurement data were not due to unequal loading of the probe (data not shown). Furthermore, in none of the subject groups there was a significant relation between platelet $\mathrm{Ca}^{2+}$ responses and subject age.

Considering that comparison of the thrombin-induced $\mathrm{Ca}^{2+}$ responses for these subjects is only relevant after aspirin treatment, normal values were set for this condition. To differentiate between control and patient values, we used the control data to set the normal range of thrombin-induced initial $\left[\mathrm{Ca}^{2+}\right]_{\mathrm{i}}$ rises at the mean $\pm 1.5 \mathrm{SD}$, i.e. 350 $660 \mathrm{nM}$ (Figure 1). Based on this criterion, 4\% (2/56) of the healthy subjects had platelets with high responsiveness towards thrombin. For the patients with stroke and PAD, these percentages were $27 \%(7 / 26)$ and 10\% (2/20), respectively. For neither patient group, the high $\mathrm{Ca}^{2+}$ responsiveness was related to sex (Figure 2A) or to 
Chapter 3

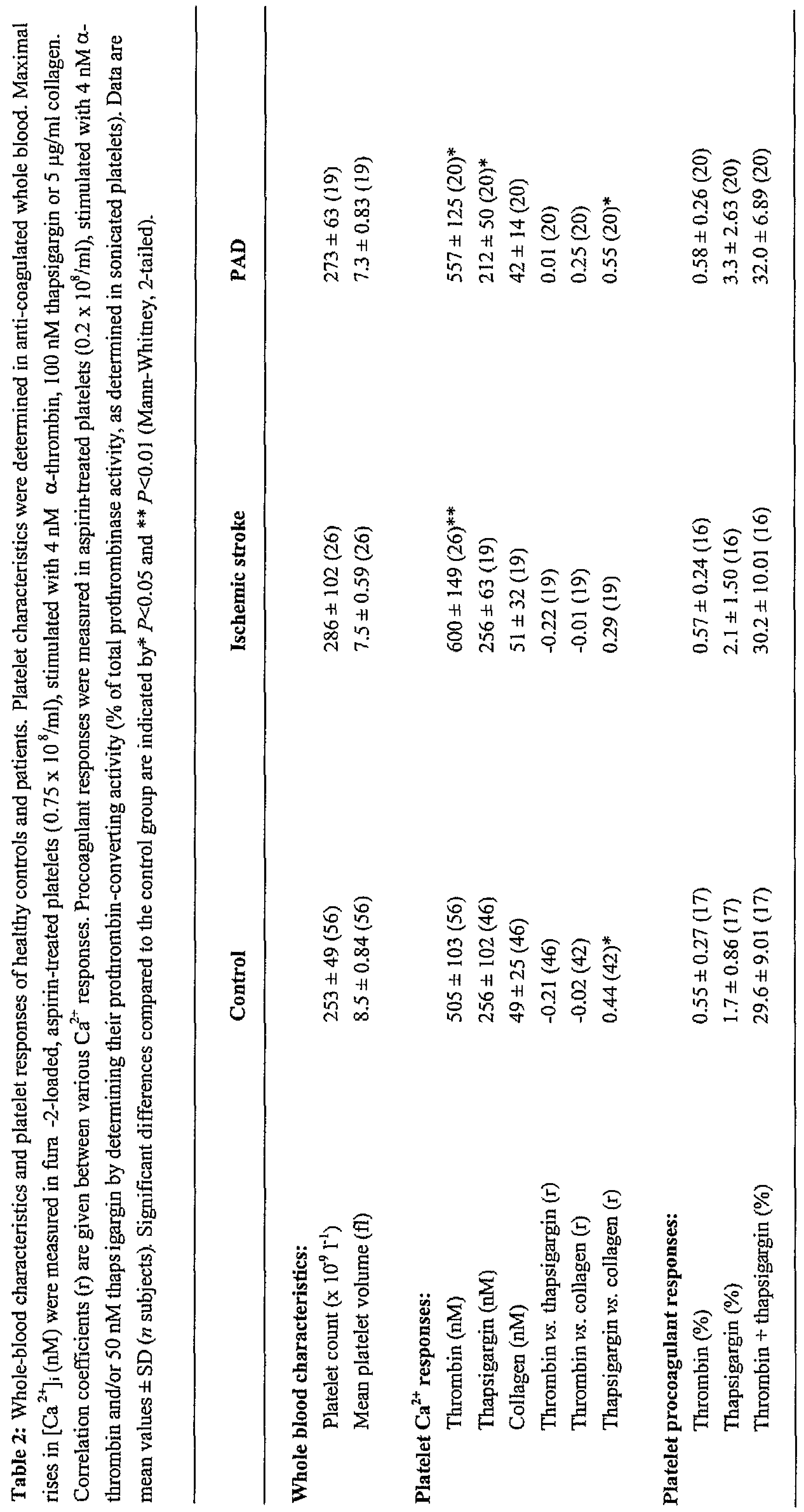




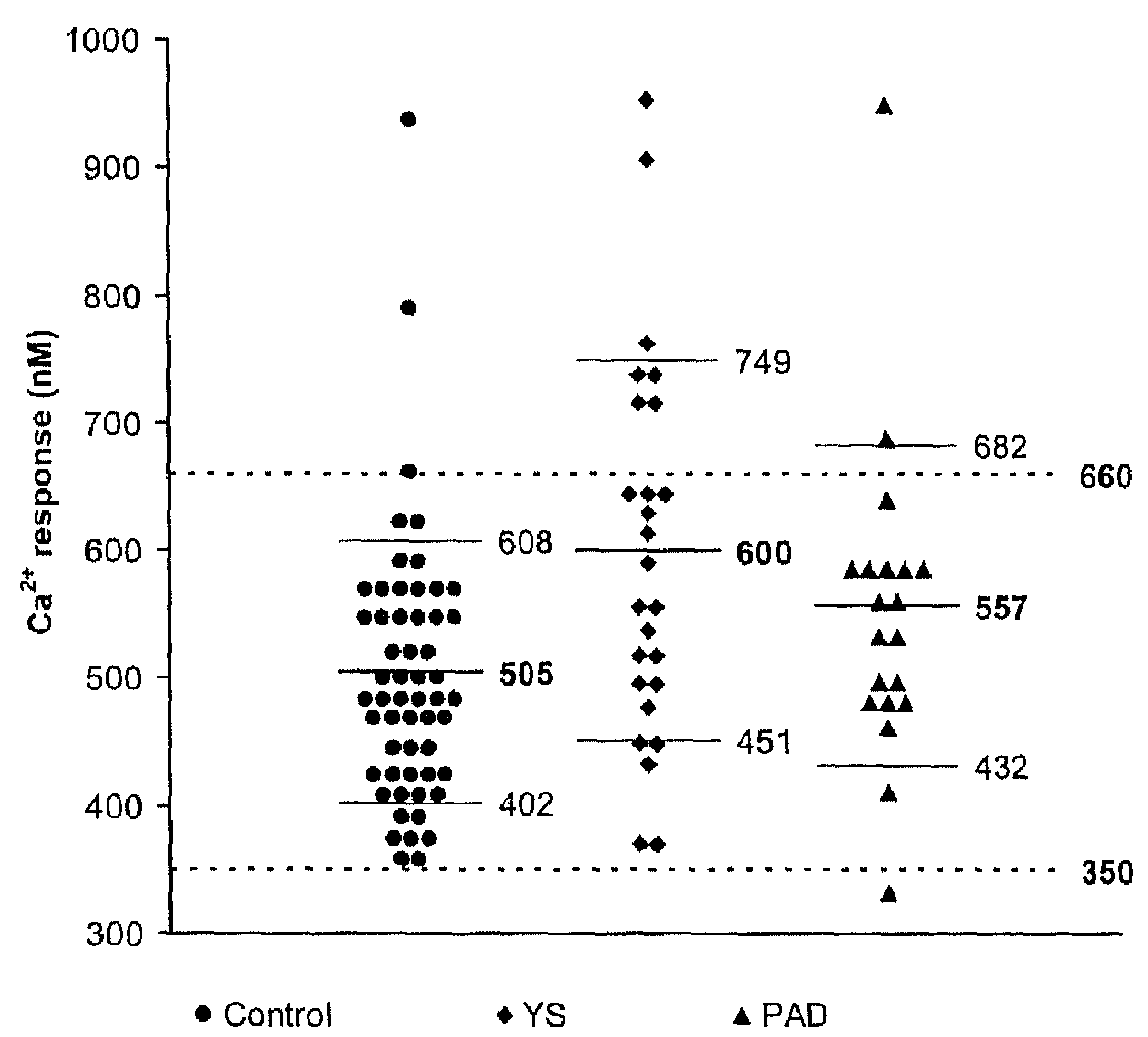

Figure 1. Thrombin-induced $\mathrm{Ca}^{2+}$ responses of aspirin-treated platelets from different healthy subjects (control), patients with ischemic stroke (IS) and patients with peripheral arterial disease (PAD). Fura-2-loaded platelets were stimulated with $4 \mathrm{nM}$ human $\alpha$-thrombin and $1 \mathrm{mM} \mathrm{CaCl}_{2}$ under stirring $\left(37^{\circ} \mathrm{C}\right)$.

smoking behaviour (Figure 2B). Thus, particularly in the group of stroke patients, a substantial number of individuals had platelets with high responses towards thrombin, even after aspirin treatment. Related literature data only concern measurements with platelets from patients with severe arteriosclerosis, where thrombin-induced $\mathrm{Ca}^{2+}$ responses were found to be decreased (29).

The increased $\mathrm{Ca}^{2+}$ responsiveness in patients with stroke and PAD was restricted to thrombin, and did not extend to other tested agonists (Table 2). Thus, aspirin-treated platelets from controls and stroke patients responded similarly to thapsigargin or collagen $(P>0.76)$. In case of the PAD group, the thapsigargin-evoked response was lower than for the control group $(P=0.03)$, while the collagen-evoked response was unaltered $(P=0.44)$. Significant relations between the $\mathrm{Ca}^{2+}$ responses were only detected between the thapsigargin- and collagen-induced responses (Table 2). Furthermore, the few individuals with high $\mathrm{Ca}^{2+}$ responses to thapsigargin or collagen (> mean $+1.5 \mathrm{SD}$ ) did not show high responses to thrombin (data not shown). This compares well to the earlier conclusion that, in healthy volunteers, the platelet $\mathrm{Ca}^{2+}$ signals induced by thapsigargin and collagen are determined by other factors (e.g. relative expression of sarco/endoplasmic reticulum $\mathrm{Ca}^{2+}$-ATPases) than the thrombin-induced signal (18). 
A

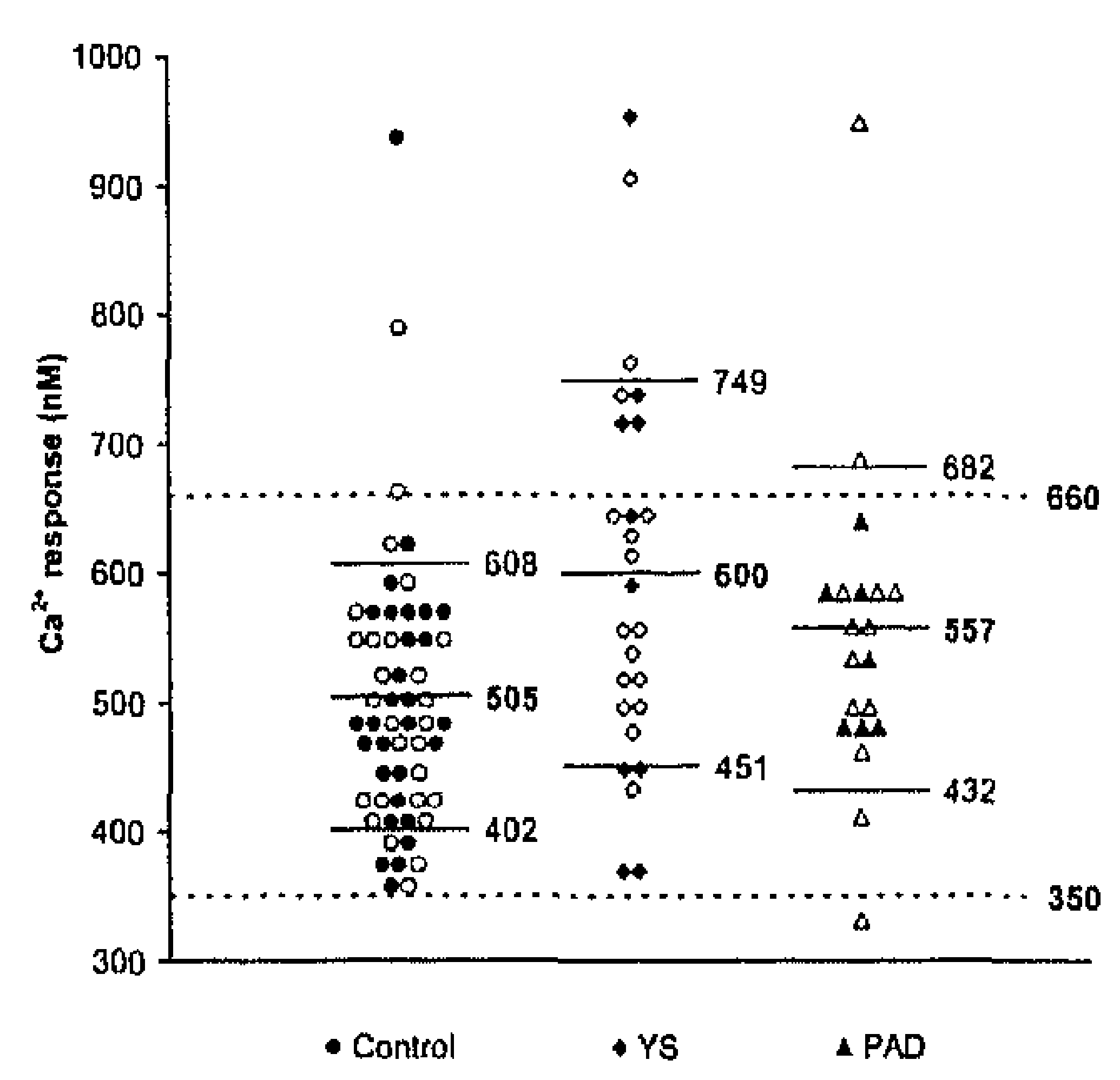

B

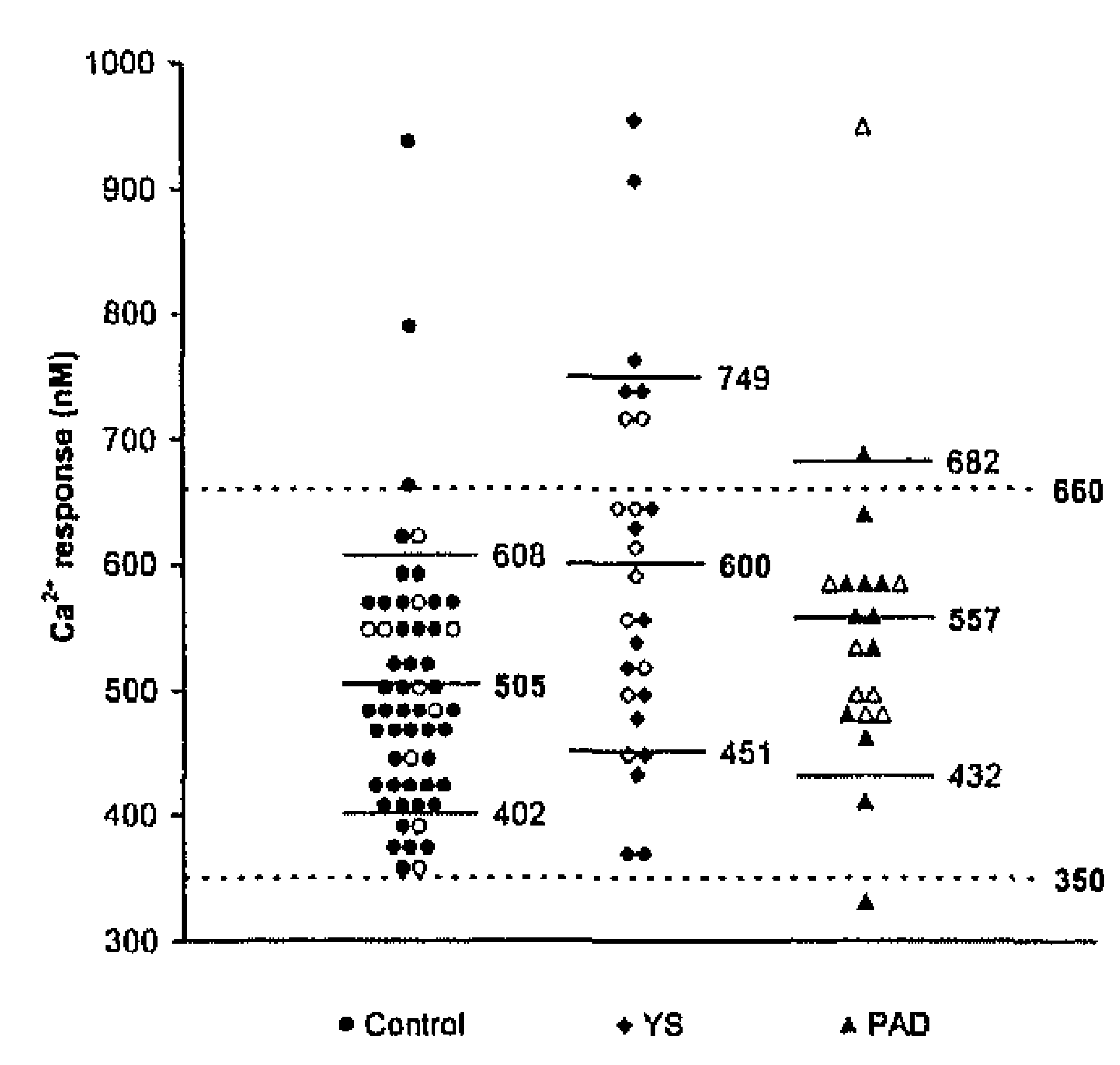

Figure 2. Thrombin-induced $\mathrm{Ca}^{2+}$ responses of aspirin-treated platelets from healthy subjects and patients with ischemic stroke (IS) or peripheral arterial disease (PAD). Data correspond to those of Figure 1, but are separated according to sex in panel A (closed symbols, male; open symbols, female), or to smoking behaviour in panel B (closed symbols, non-smoking; open symbols, smoking). $P$ values of differences between males and females for controls, IS and PAD patients are $0.88,0.96$ and 0.84 , respectively. $P$ values of differences between smoking and non-smoking for these groups are $0.62,0.87$ and 0.94 , respectively.

Thrombin greatly stimulates the procoagulant activity of platelets, when added together with other a strong agonist like thapsigargin (30). For platelets from controls and patients, we determined the prothrombinase activity following stimulation with thrombin and/or thapsigargin. Only the combination of these agonists resulted in appreciable prothrombin-converting activity (Table 2). There were no significant differences in prothrombinase activity between the platelets from control subjects and patient groups. However, for platelets from patients with high thrombin-induced $\mathrm{Ca}^{2+}$ responses, the prothrombinase activity with thrombin/thapsigargin was also relatively high, $37.6 \pm 7.1 \%$ (mean $\pm \mathrm{SD}, n=6$ ), in comparison to the averaged value of the normal-responding control group, $29.6 \pm 9.0 \%$. For the platelets from 6 analysed patients with high $\mathrm{Ca}^{2+}$ responses, 3 patients also showed high prothrombinase activity $(>40 \%)$. Thus, although the numbers are small, in a substantial part of the subjects with a high thrombin-evoked $\mathrm{Ca}^{2+}$ response, this was accompanied by a high thrombindependent procoagulant response.

\section{Involvement of $P A R 1$ in variable, subject-dependent $\mathrm{Ca}^{2+}$ response with thrombin}

To evaluate the significance of the variable thrombin-induced $\mathrm{Ca}^{2+}$ response, we subsequently studied the platelets from a different group of 27 healthy subjects in more detail. These volunteers had a median age of 25 years ( 9 males and 18 females). None of them had recently used medication, and 4 were smoking. Rises in $\left[\mathrm{Ca}^{2+}\right]_{\mathrm{i}}$ in the fura2-loaded, aspirin-treated platelets were measured upon activation with sub-maximal 
doses of thrombin, the PAR1 ligand SFLLRN, ADP and convulxin. The latter agent is a potent activator of the glycoprotein VI collagen receptor $(31,32)$. The $\mathrm{Ca}^{2+}$ responses were determined by two outcome values: the initial, maximal increase in $\left[\mathrm{Ca}^{2+}\right]_{\mathrm{i}}$ and the time integral of the total increase in $\left[\mathrm{Ca}^{2+}\right]_{i}$ (i.e. the area under the $\left[\mathrm{Ca}^{2+}\right]_{i}$ curve). The latter parameter is an adequate measure of the total $\mathrm{Ca}^{2+}$-mobilising potency (CMP) of an agonist representative of the whole process of platelet activation (22).

Following activation of the platelets with thrombin ( $4 \mathrm{nM})$, SFLLRN (15 $\mu \mathrm{M})$, ADP (20 $\mu \mathrm{M})$ or convulxin $(50 \mathrm{ng} / \mathrm{ml})$, initial $\left[\mathrm{Ca}^{2+}\right]_{\mathrm{i}}$ peaks were determined of $559 \pm 130,423 \pm$ $102,231 \pm 54$ and $537 \pm 121 \mathrm{nM}$, respectively (mean $\pm \mathrm{SD}, n=27$ ). The corresponding $\mathrm{CMP}$ values were $35.4 \pm 8.0,12.5 \pm 3.2,5.98 \pm 1.62$ and $56.2 \pm 10.3 \mu \mathrm{M} \cdot \mathrm{s}$, respectively. These data compare well to earlier CMP values for thrombin and ADP (22). When analysing the data of individual subjects, it appeared that the $\left[\mathrm{Ca}^{2+}\right]_{\mathrm{i}}$ peak values of thrombin and SFLLRN were strongly correlated (Figure 3A, $P<0.01$ ), but not those of thrombin and ADP (Figure 3B) or convulxin (Figure 3C). A similar relation was found when comparing the CMP values with thrombin and SFLLRN. These data collectively suggest that, at least in this group of subjects, the variability in both the initial and longer-term $\mathrm{Ca}^{2+}$ responses to thrombin is determined by variable $\mathrm{Ca}^{2+}$ signal generation through PAR1.

Rendu and co-workers report that thrombin-evoked platelet dense granule release - i.e. a $\mathrm{Ca}^{2+}$-dependent process - is subject to inter-individual variability (33). This is in line with the variable, PAR1-dependent $\mathrm{Ca}^{2+}$-responsiveness observed here. These authors showed that platelets from subjects carrying the $\mathrm{P}^{\mathrm{A} 2}$ polymorphism of glycoprotein IIIa were relatively protected toward SFLLRN-induced activation in comparison to subjects homozygous for the $\mathrm{Pl}^{\mathrm{A} 1}$ allele. The $\mathrm{Pl}^{\Lambda 2}$ polymorphism, along with the silent $\mathrm{C} 807 \mathrm{~T}$ polymorphism of the gene for platelet glycoprotein Ia, is a possible risk factor in young stroke patients $(34,35)$. For the group of 27 healthy subjects, we compared the platelet $\mathrm{Ca}^{2+}$ responses to thrombin and SFLLRN according to these genotypes. Within this group, 17 individuals carried the $\mathrm{Pl}^{\mathrm{A} 2}$ polymorphism (4 homozygous) and 19 the $807 \mathrm{~T}$ polymorphism ( 6 homozygous). Initial $\mathrm{Ca}^{2+}$ responses with thrombin were $565 \pm 138$ and $547 \pm 120 \mathrm{nM}$ (mean $\pm \mathrm{SD}$ ) for the $\mathrm{Pl}^{\mathrm{A} 2}$ carriers and non-P $\mathrm{P}^{\mathrm{A} 2}$ carriers, respectively. The corresponding responses with SFLRRN were $427 \pm 115$ and $417 \pm 78 \mathrm{nM}$, respectively. The differences between platelets from carriers and non-carriers were statistically insignificant $(P=0.81)$. Neither significant were the differences in ADP- or convulxin-induced responses of carriers and non-carriers $(P>0.63)$. Similarly, $\mathrm{Ca}^{2+}$ responses induced by thrombin, SFLLRN or ADP were not significantly different between carriers and non-carriers of the 807T polymorphism $(P>0.58)$. However, the platelets from $807 \mathrm{~T}$ carriers had a lower response to convulxin than those from noncarriers, i.e. $500 \pm 111$ versus $625 \pm 101 \mathrm{nM}$ (mean $\pm \mathrm{SD}, P=0.008$ ). Since the $807 \mathrm{~T}$ polymorphism correlates with increased expression of the glycoprotein Ia/IIa collagen receptor (34), this might suggest that this expression somehow interferes with glycoprotein VI signalling as induced by convulxin, although we note that the power of this pilot study is too low to draw strong conclusions. 

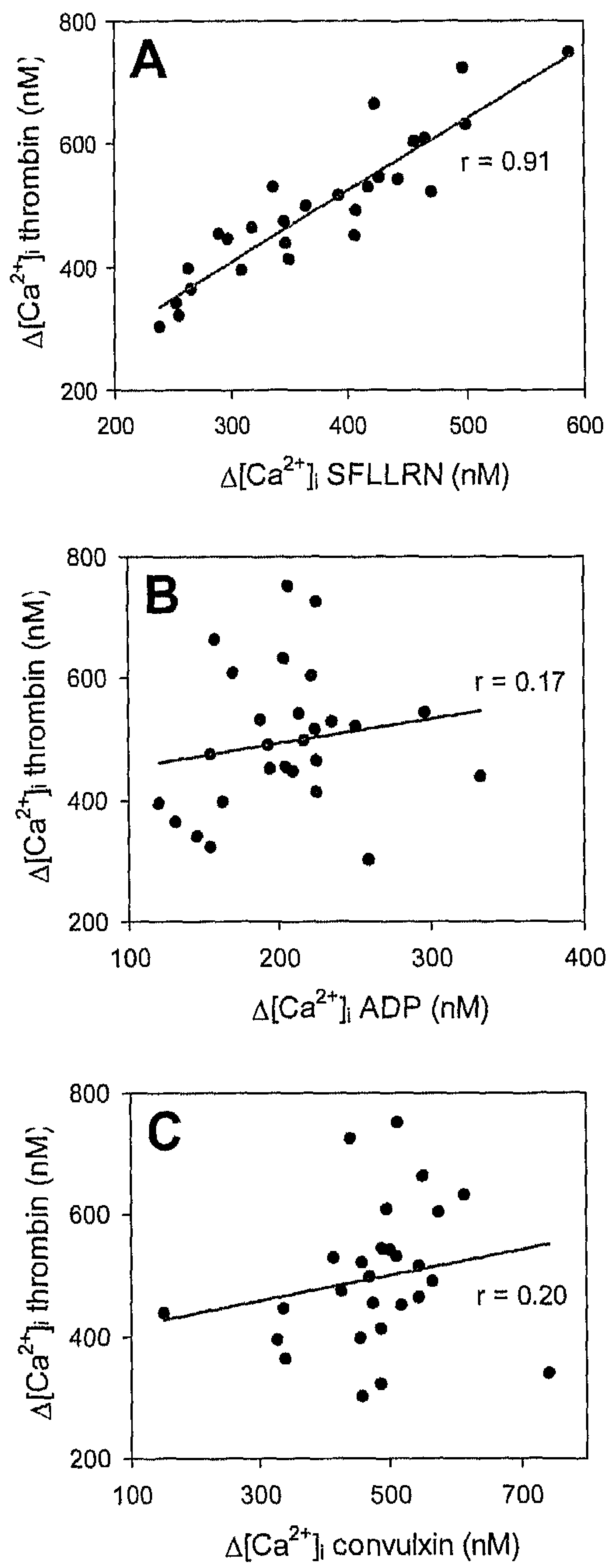

Figure 3. Correlations between agonist-induced $\mathrm{Ca}^{2+}$ responses of aspirin-treated platelets from healthy subjects. Fura-2-loaded platelets ( $n=27$ subjects) were stimulated with $\alpha$-thrombin $(4 \mathrm{nM})$, SFLLRN $(15 \mu \mathrm{M})$, ADP $(20 \mu \mathrm{M})$ or convulxin $(50 \mathrm{ng} / \mathrm{ml})$ in the presence of $1 \mathrm{mM} \mathrm{CaCl}_{2}$. Panels A-C relate per individual the initial $\left[\mathrm{Ca}^{2+}\right]_{i}$ peaks after stimulation of the platelets with: (A) thrombin versus SFLLRN $(r=0.91, P<0.01)$, (B) thrombin versus $\operatorname{ADP}(r=0.17),(C)$ thrombin versus convulxin $(r=0.20)$. 


\section{CONCLUSIONS}

The present data suggest that a considerable part of young patients with stroke, when monitored in the convalescent phase at least 3 months after the ischemic event, have platelets with increased $\mathrm{Ca}^{2+}$ responses to thrombin, that are occasionally accompanied by high thrombin-mediated procoagulant responses. These high responses persisted after in-vivo or in-vitro aspirin treatment and, thus, were independent of thromboxanemediated signalling events. This compares well with recent flow-cytometric measurements suggesting that increased platelet activation can be detected for up to three months after stroke (36). Our results cannot discriminate between an underlying prothrombotic state in the patients with high-responsive platelets and a possible causal relationship with the ischemic event.

Measurement of the platelet $\mathrm{Ca}^{2+}$ responses, as carried out here with relatively small numbers of subjects, is a labour-intensive test, requiring fresh blood samples. For largescale analysis, such functional measurement is preferentially be replaced by a structural test. Of interest thereby is the PAR1 expression, which receptor seems to determine the thrombin-induced response. There are recent clues that genetic variation in the PAR1 thrombin receptor may determine the thrombotic state. Arnaud et al (37) report of a frequent insertion polymorphism of PARl that may have a protective effect on venous thromboembolism in man. Nevertheless, our data provide direct support to the clinical finding that intervention with aspirin alone is only partly effective in secondary prevention of infarction (38).

\section{Acknowledgements}

We thank M. Lauman for accurate administrative support. This work was supported by the Profileringsfonds of the Academic Hospital of Maastricht. 


\section{REFERENCES}

1. Johnson CJ, Kittner SJ, McCarter RJ, Sloan MA, Stern BJ, Buchholz D, Price TR. Interrater reliability of an etiologic classification of ischaemic stroke. Stroke 1995; 26: 46-51.

2. Goldstein LB, Adams R, Becker K, Furberg CD, Gorelick PB, Hademenos G, Hill M, Howard G, Howard VJ, Jacobs B, Levine SR, Mosca L, Sacco RL, Sherman DG, Wolf P, del Zoppo GJ. Primary prevention of ischemic stroke. A statement for healthcare professionals from the stroke council of the American Heart Association. Circulation 2001; 103: 163-82.

3. Elwood PC, Renaud S, Sharp DS, Beswick AD, O'Brien JR, Yarnell JW. Ischaemic heart disease and platelet aggregation: the Caerphilly Collaborative Heart Disease Study. Circulation 1998; 83: 38-44.

4. Thaulow E, Erikssen J, Sandvik L, Stormorken H, Cohn PF. Blood platelet count and function are related to total and cardiovascular death in apparently healthy men. Circulation 1991; 84: 613-7.

5. Uchiyama S, Yamazaki M, Maruyama S, Handa M, Ikeda Y, Fukuyama M, Itagaki I. Shear-induced platelet aggregation in cerebral ischaemia. Stroke 1994; 25: 1547-51.

6. Iwamoto T, Kubo H, Takasaki M. Platelet activation in the cerebral circulation in different subtypes of ischaemic stroke and Binswanger's disease. Stroke 1995; 26: 52-6.

7. Konstantopoulos K, Grotta JC, Sills C, Wu KK, Hellums JD. Shear-induced platelet aggregation in normal subjects and stroke patients. Thromb Haemost 1995; 74: 1329-34.

8. Knight CJ, Panesar M, Wright C, Clarke D, Butowski PS, Patel D, Patrineli A, Fox K, Goodall AH. Altered platelet function detected by flow cytometry: effects of coronary arterial disease and age. Arterioscler Thromb Vasc Biol 1997; 17: 2044-53.

9. Bihour C, Durrieu-Ja's C, Macchi L, Poujol C, Coste P, Besse P, Nurden P, Nurden AT. Expression of markers of platelet activation and the interpatient variation in response to abciximab. Arterioscler Thromb Vasc Biol 1999; 19: 212-9.

10. Antiplatelet Trialists' Collaboration. Collaborative overview of randomised trials of antiplatelet therapy. Prevention of death, myocardial infarction, and stroke by prolonged antiplatelet therapy in various categories of patients. Br Med J 1994; 308: 81-106.

11. Del Zoppo GJ. The role of platelets in ischemic stroke. Neurology 1998; 51: S9-14.

12. Bednar MM, Gross CE. Antiplatelet therapy in acute cerebral ischemia. Stroke 1999; 30: 887-93.

13. Ringelstein EB, Nabavi D. Long-term prevention of ischaemic stroke recurrence. Thromb Res 2000;98: V83-96.

14. Hass WK, Easton JD, Adams HP, Pryse-Phillips W, Molony BA, Anderson S, Kamm B. A randomized trial comparing ticlopedine hydrochloride with aspirin for the prevention of stroke in high-risk patients. N Engl J Med 1989; 321: $501-7$.

15. CAPRIE Steering Committee. A randomised, blinded, trial of clopidogrel versus aspirin in patients at risk of ischaemic events (CAPRIE). Lancet 1996; 348, 1329-39.

16. Reininger $\mathrm{CB}$, Graf J, Reininger AJ, Spannag M, Steckmeier B, Schweiberer L. Increased platelet and coagulatory activity indicate ongoing thrombogenesis in peripheral arterial disease. Thromb Res 1996; 82: 523-32.

17. Heemskerk JWM. Calcium and platelets. In: The Molecular Basis of Calcium Action in Biology and Medicine (Pochet R, Donato R, Haiech J, Heinzmann C, Gerke V, eds), 2000, Kluwer Acad Publ, The Hague (the Netherlands), pp. 45-71.

18. Feijge MAH, van Pampus ECM, Lacabaratz-Porret $\mathrm{C}$, Hamulyák $\mathrm{K}$, Lévy-Toledano S, Enouf J, Heemskerk JWM. Inter-individual varability in $\mathrm{Ca}^{2+}$ signalling in platelets from healthy volunteers, relation with expression of endomembrane $\mathrm{Ca}^{2+}$-ATPases. $\mathrm{Br} \mathrm{J}$ Haematol 1998; 102: 850-9.

19. Feijge $\mathrm{MAH}$, Lacabaratz-Porret $\mathrm{C}$, van Pampus ECM, Hamulyák $\mathrm{K}$, Lévy-Toledano $\mathrm{S}$, Enouf $\mathrm{J}$, Heemskerk JWM. Contribution of thromboxane and endomembrane $\mathrm{Ca}^{2+}-\mathrm{ATPases}$ to variability in $\left[\mathrm{Ca}^{2+}\right]_{\mathrm{i}}$ signalling of platelets from healthy volunteers. Platelets 1998; 9: 179-83.

20. Rao AK, Kowalska MA, Disa J. Impaired cytoplasmic ionized calcium mobilization in inherited platelet secretion defects. Blood 1989: 74: 664-72.

21. Weiss $\mathrm{HJ}$, Lages B. Platelet prothrombinase activity and intracellular calcium responses in patients with storage pool deficiency, glycoprotein Ilb-IIIa deficiency, or impaired platelet coagulant activity. A comparison with Scott syndrome. Blood 1997; 89: 1599-1611.

22. Heemskerk JWM, Feijge MAH, Henneman $\mathrm{L}$, Rosing J, Hemker HC. The $\mathrm{Ca}^{2+}$-mobilizing potency of $\alpha$-thrombin and thrombin-receptor-activating peptide on human platelets. Eur J Biochem 1997; 249, 547-55. 
23. Offermanns S, Toombs CF, Hu YH, Simon MI. Defective platelet-activation in Gaq-deficient mice. Nature 1997; 389: 183-6.

24. Coughlin SR. Thrombin signalling and protease-activated receptors. Nature 2000; 407: 258-64.

25. Siljander P, Farndale RW, Feijge MAH, Comfurius P, Kos S, Bevers EM, Heemskerk JWM. Platelet adhesion enhances the glycoprotein VI-dependent procoagulant response: involvement of p38 MAP kinase and calpain. Arterioscler Thromb Vasc Biol 2001; 21:618-27.

26. Rosing J, van Rijn JLML, Bevers EM, van Dieijen G, Comfurius P, Zwaal RFA. The role of activated human platelets in prothrombin and factor X activation. Blood 1985; 65: 319-22.

27. Ridker PM, Hennekens CH, Schmitz C, Stampfer MJ, Lindpainter K. PIA1/A2 polymorphism of platelet glycoprotein IIla and risks of myocardial infarction, stroke and venous thrombosis. Lancet 1997; 349: 385-8.

28. Reiner AP, Aramaki KM, Teramura G, Gaur L. Analysis of the platelet glycoprotein Ia allele frequencies in three North American populations reveals genetic association between nucleotide $870 \mathrm{C} / \mathrm{T}$ and amino acid 505 Glu/Lys (HPA-5) dimorphisms. Thromb Haemost 1998; 80: 449-56.

29. Vicari AM, Monzani ML, Pellegatta F, Ronchi P, Galli L, Folli F. Platelet calcium homeostasis is abnormal in patients with severe arteriosclerosis. Arterioscler Thromb 1994; 14: 1420-4.

30. Smeets EF, Heemskerk JWM, Comfurius P, Bevers EM, Zwaal RFA. Thapsigargin amplifies the platelet procoagulant response caused by thrombin. Thromb Haemost 1993; 70: 1024-9.

31. Asselin J, Gibbins JM, Achison M, Lee YH, Morton LF, Farndale RW, Barnes MJ, Watson SP. A collagen-like peptide stimulates tyrosine phosphorylation of Syk and phospholipase $C \gamma 2$ in platelets independent of the integrin $\alpha_{2} \beta_{1}$. Blood 1997; 89: 1235-42.

32. Jandrot-Perrus $M$, Lagrue AH, Okuma M, Bon C. Adhesion and activation of human platelets induced by convulxin involve glycoprotein VI and integrin $\alpha_{2} \beta_{1}$. J Biol Chem 1997; 272: 27035-41.

33. Lasne D, Krenn M, Pingault V, Arnaud E, Fiessinger JN, Aiach M, Rendu F. Interdonor variability of platelet response to thrombin receptor activation, influence of $\mathrm{Pl}^{\mathrm{A} 2}$ polymorphism. $\mathrm{Br} \mathrm{J}$ Haematol 1997; 99: 801-7.

34. Carlsson LE, Santoso S, Spitzr C, Kessler C, Greinacher A. The $\alpha 2$ gene coding sequence T807/A873 of the platelet collagen receptor integrin $\alpha 2 \beta 1$ might be a genetic risk factor for the development of stroke in younger patients. Blood 1999; 93: 3583-6.

35. Hassan A, Markus HS. Genetics and ischaemic stroke. Brain 2000; 123: 1784-1812.

36. Meiklejohn DJ, Vickers MA, Morrison ER, Dijkhuisen R, Moore I, Urbaniak SJ, Greaves M. In vivo platelet activation in atherothrombotic stroke is not determined by polymorphisms of human platelet glycoprotein IIla or Ib. Br J Haematol 2001; 112: 621-31.

37. Arnaud E, Nicaud V, Poirier O, Rendu F, Alhenc Gelas $M$, Fiessinger $J N$, Emmerich J, Aiach $M$. Protective effect of a thrombin receptor (protease-activated receptor 1) gene polymorphism toward venous thromboembolism. Arterioscier Thromb Vasc Biol 2000; 20: 585-92.

38. Bates SM, Weitz JI. Prevention of activation of blood coagulation during acute coronary ischemic syndromes: beyond aspirin and heparin. Cardiovasc Res 1999; 41: 418-32. 


\section{Chapter 4}

Initiating and potentiating role of platelets in tissue factor-induced thrombin generation in the presence of plasma: subject-dependent variation in thrombogram characteristics

Kristof Vanschoonbeek, Marion A.H. Feijge, Roel J.W. van Kampen, Heidi Kenis, H. Coenraad Hemker, Peter L.A. Giesen and Johan W.M. Heemskerk

Journal of Thrombosis and Haemostasis, 2004; 2: 476-84 


\begin{abstract}
The haemostatic activity of plasma is determined by platelet activation and coagulation, which processes are mutually stimulatory. We studied this interaction by measuring the cleavage of fluorescent thrombin substrate in platelet-rich plasma (PRP), using the calibrated thrombogram method. In freshly isolated human plasma, thrombin formation triggered by tissue factor was fully dependent on the presence of platelets. It was abolished by annexin A5, indicating dependence on phosphatidylserine (PS) exposure at activated platelets. Comparison of plasmas from various subjects showed considerable inter-individual variation in total amount of thrombin generation, regardless of whether platelets or PS-containing phospholipids were present. Integrin $\alpha$ Ilb $\beta 3$ antagonists and ADP receptor blockage, but not aspirin, decreased the rate of thrombin generation (thrombin peak level) and extended the time of onset. Platelet inhibition with cAMPelevating agents decreased the thrombin-forming rate, but surprisingly shortened the onset time. Stimulation of platelets with agonists of Gi/q-coupled receptors and, to a larger extent, with collagen or $\mathrm{Ca}^{2+}$-ionophore increased the rate of thrombin generation and shortened its onset. In PRP from donors with low and high generation, platelet inhibitors and activators were similarly effective. Taken together, these results indicate that, in tissue factor-triggered PRP, PS exposure on activated platelets regulates both onset and rate of thrombin generation. However, coagulant activity rather than platelet activation determines the total amount of thrombin formed, i.e. the endogenous thrombin potential (ETP). Thus, kinetics of thrombin generation in PRP are controled by platelet inhibitors and agonists, but the process is in amount restricted by the subjectdependent variation in coagulation.
\end{abstract}




\section{INTRODUCTION}

Platelet activation and coagulation conjointly determine the haemostatic activity of plasma. Both processes are intimately related and thrombin is instrumental in each (1). Thrombin is efficiently and at high rate formed on platelets, which provide a surface for the binding of coagulation factors (reviewed in Refs. (2-4)). In an advanced stage of activation, platelets expose phosphatidylserine (PS) and other procoagulant phospholipids at their outer surface, at which the tenase and prothrombinase coagulant complexes assemble, forming factor Xa and thrombin, respectively. In addition, platelet integrin $\alpha \mathrm{IIb} \beta 3$ and glycoprotein $\mathrm{Ib}$ bind prothrombin and factor XI, respectively $(3,5)$. Sequential activation of the glycoprotein-bound factors can result in factor IX cleavage and, thereby, ensure sufficient factor IXa formation for prolonged coagulant activity, even when the tissue factor/factor VIIa complex - which triggers coagulation - has become inactivated. Other interactions between platelet activation and coagulation are the shedding of procoagulant, PS-exposing microvesicles from activated platelets (6), and the potent feed back of formed thrombin to propagate platelet and coagulant activation (7).

During recent years, evidence is accumulating that anti-platelet agents are effective in suppressing coagulation. Well-documented is the potent inhibitory effect of abciximab, tirofiban and other $\alpha \operatorname{IIb} \beta 3$ integrin antagonists on thrombin generation in plateletcontaining plasma (8-11). Other reports show that also blocking of glycoprotein Ib (1214) or of the $P 2 Y_{12} A D P$ receptor (15-17) affects the formation of thrombin. From these and other studies, the picture emerges of a complex pattern of multiple interactions between platelets and clotting factors, which is still poorly understood but is likely to change with the degree of platelet activation and the stage of the coagulation process. A manner to unravel these relationships is measurement of thrombin activity in coagulating platelet-rich plasma (PRP) or whole blood. In earlier work, thrombin generation was followed by sampling from the coagulating plasma or blood $(7,11)$. However, it is difficult to determine precise kinetics from such sampled, discontinuous measurements. Recently, a new fluorometric assay has been developed, where thrombin formation is continuously measured in the presence of fibrin clots in-situ without manual intervention $(18,19)$. This results in a so-called thrombogram, which gives information on both the thrombin-generating activity of plasma and the total, integrated activity of thrombin (thrombin-time integral or 'area-under-the-curve). The latter parameter reflects the total proteolytic activity of thrombin during the complete coagulation process, and is also referred to as the endogenous thrombin potential (ETP) (20). This method has opened new possibilities of study.

Here, we used the calibrated thrombogram method of continuous thrombin generation measurement to study the inter-relationship of platelet activation and coagulation in human PRP triggered with a low dose of tissue factor. We describe that the stimulating effect of platelets on thrombin formation particularly relies on PS exposure both in initial and sustained phases of coagulation. Furthermore, although the initial kinetics of thrombin generation are influenced by platelet activation or inhibition, we found that the 
activity of the coagulation system is a main determinant of inter-subject variation in thrombin generation.

\section{MATERIALS AND METHODS}

\section{Subjects}

Blood was drawn after full informed consent from 41 healthy, fasting volunteers, who were free of medication for at least two weeks ( 33 men and 8 women). For intra-subject variability analysis, blood was taken from 8 subjects ( 4 men and women) at three mornings in a period of three weeks.

\section{Materials}

The PAR-1 agonist peptide SFLLRN was purchased from Bachem (Bubendorf, Switzerland), abciximab (Reopro) was from Centocor (Leiden, The Netherlands). Human $\alpha$-thrombin, ADP, bovine serum albumin (BSA), MRS2179 and milrinone came from Sigma (St Louis, MO, USA), iloprost from Schering (Berlin, Germany), Hormtype collagen from Nycomed (Munich, Germany); AR-C69931MX was kindly provided by Astra-Zeneca (Charnwood, UK). Convulxin was purified from crude snake venom (21). Z-Gly-Gly-Arg aminomethyl coumarin (Z-GGR-AMC) came from Bachem (Bubendorf, Switzerland), acetylsalicylic acid (aspirin) from Lorex Synthelabo (Maarssen, The Netherlands), annexin A5 (annexin V) from Nexins Research (Hoeven, The Netherlands), and recombinant human tissue factor from Dade (Miami, FL, USA). Human thrombin calibrator and thrombogram software were supplied by Synapse (Maastricht, The Netherlands). Other chemicals were obtained from sources described before (22).

\section{Isolation of platelets and plasma}

Blood was drawn by venapuncture with a $1.2-\mathrm{mm}$ needle, dripping freely into $1 / 10$ volume of $129 \mathrm{mmol} \mathrm{L}^{-1}$ trisodium citrate. First $2.5 \mathrm{~mL}$ of blood were discarded. The blood was centrifuged at $260 \mathrm{~g}$ for $15 \mathrm{~min}$ to obtain platelet-rich plasma (PRP), and twice at $870 \mathrm{~g}$ for $10 \mathrm{~min}$ for platelet-free plasma (PFP). Platelet concentration was determined with a Beckman MicroDiff18 counter (Coulter Electronics, Luton, UK). PRP was normalised to $150 \times 10^{9}$ platelets $L^{-1}$ with autologous PFP.

\section{Thrombin generation measurement (calibrated thrombogram)}

Thrombin generation was continuously measured in freshly isolated human PRP and PFP, using the calibrated thrombogram method $(18,19)$. Briefly, triplicate samples of $80 \mu \mathrm{L}$ PRP $\left(150 \times 10^{9}\right.$ platelets $\left.\mathrm{L}^{-1}\right)$ were pipetted into wells of a 96 -wells plate (Immulon 2HB, Dynex Technologies, Chantilly, VA, USA), containing $20 \mu \mathrm{L}$ tissue 
factor $\left(3 \mathrm{pmol} \mathrm{L}^{-1}\right)$ in buffer A $\left(20 \mathrm{mmol} \mathrm{L}{ }^{-1}\right.$ Hepes, $140 \mathrm{mmol} \mathrm{L}^{-1} \mathrm{NaCl}, 5 \mathrm{mg} \mathrm{mL}^{-1}$ BSA, pH 7.35). Plates were inserted into a Fluoroskan Ascent well-plate reader (Thermolab Systems, Helsinki, Finland), and pre-heated to $37^{\circ} \mathrm{C}$ for $5 \mathrm{~min}$. Coagulation was started by automated addition of $20 \mu \mathrm{L}$ Z-GGR-AMC $\left(2.5 \mathrm{mmol} \mathrm{L}^{-1}\right)$, dissolved in buffer B (20 mmol L-1 Hepes, $0.1 \mathrm{~mol} \mathrm{~L}^{-1} \mathrm{CaCl}_{2}, 60 \mathrm{~g} \mathrm{~L}^{-1} \mathrm{BSA}, \mathrm{pH}$ 7.35). Plates were shaken for $10 \mathrm{~s}$ after substrate addition. Fluorescence accumulation from cleaved AMC was measured in-time at excitation and emission wavelengths of 390 and $460 \mathrm{~nm}$, respectively $\left(37^{\circ} \mathrm{C}\right)$. First-derivative curves of accumulation of fluorescence were converted into curves of nanomolar thrombin using human thrombin calibrator and thrombinoscope software correcting for non-linearity of fluorescence with AMC concentration, depletion of fluorescent substrate, and fluorescence accumulation due to $\alpha_{2}$-macroglobulin-bound thrombin $(18,23)$. When using PFP, coagulation was triggered with $5 \mathrm{pmol} \mathrm{\textrm {L } ^ { - 1 }}$ tissue factor and $4.0 \mu \mathrm{mol} \mathrm{L^{-1 }}$ phospholipid vesicles (PS : phosphatidylcholine : phosphatidylethanolamine, 1:3:1).

\section{Platelet activation and inactivation}

Normalised PRP was pre-incubated with platelet agonist or antagonist for 10 min while shaking. Controls were run with adequate vehicle. Where indicated, PRP was sonicated for $10 \mathrm{~min}(10 \mathrm{~s}$ on/off) at maximal range using a MSE Soniprep 150 Ultrasonic Disintegrator (Breda, The Netherlands).

\section{Statistics}

Intra- and inter-individual coefficients of variance were calculated as described (24). Pearson correlation test was used to determine correlations between parameters.

\section{RESULTS}

Thrombin generation in freshly isolated PRP relies on platelets, but is in amount limited by the coagulant activity of plasma

Thrombin generation was measured in citrated PRP from healthy subjects. Only freshly isolated PRP was used to prevent interference of microvesicles, which are shedding from platelets during storage even at room temperature. Using the thrombogram method, accumulation of fluorescence from cleaved Z-GGR-AMC was measured in real-time. Curves of nanomolar thrombin concentrations were obtained by parallel measurements of fluorescence provoked by the action of a calibrator with constant thrombin activity (19). With freshly isolated PFP, the addition of $\mathrm{CaCl}_{2}$ and a low dose of tissue factor $\left(0.5 \mathrm{pmol} \mathrm{L}^{-1}\right.$, low adherent phospholipids) did not result in measurable thrombin formation (Figure 1), such in agreement with earlier results obtained by sampling (7). In the presence of platelets, however, substantial amounts of thrombin were formed (Figure 1). In plasma from representative donors, initial rates of thrombin formation and peak levels increased linearly with the platelet count up to $20-75 \times 10^{9}$ 
platelets $\mathrm{L}^{-1}$; either parameter levelled off around $200 \times 10^{9}$ platelets $\mathrm{L}^{-1}$. The area under the curve, i.e. the endogenous thrombin potential (ETP), representing integrated thrombin activity, reached a maximum already at $35 \times 10^{9}$ platelets $\mathrm{L}^{-1}$. Apparently, at higher counts, the platelet number was still limiting for the rate of thrombin generation, but not for the total amount of thrombin formed. Note that platelet-fibrin clots were already formed at the start of thrombin formed.

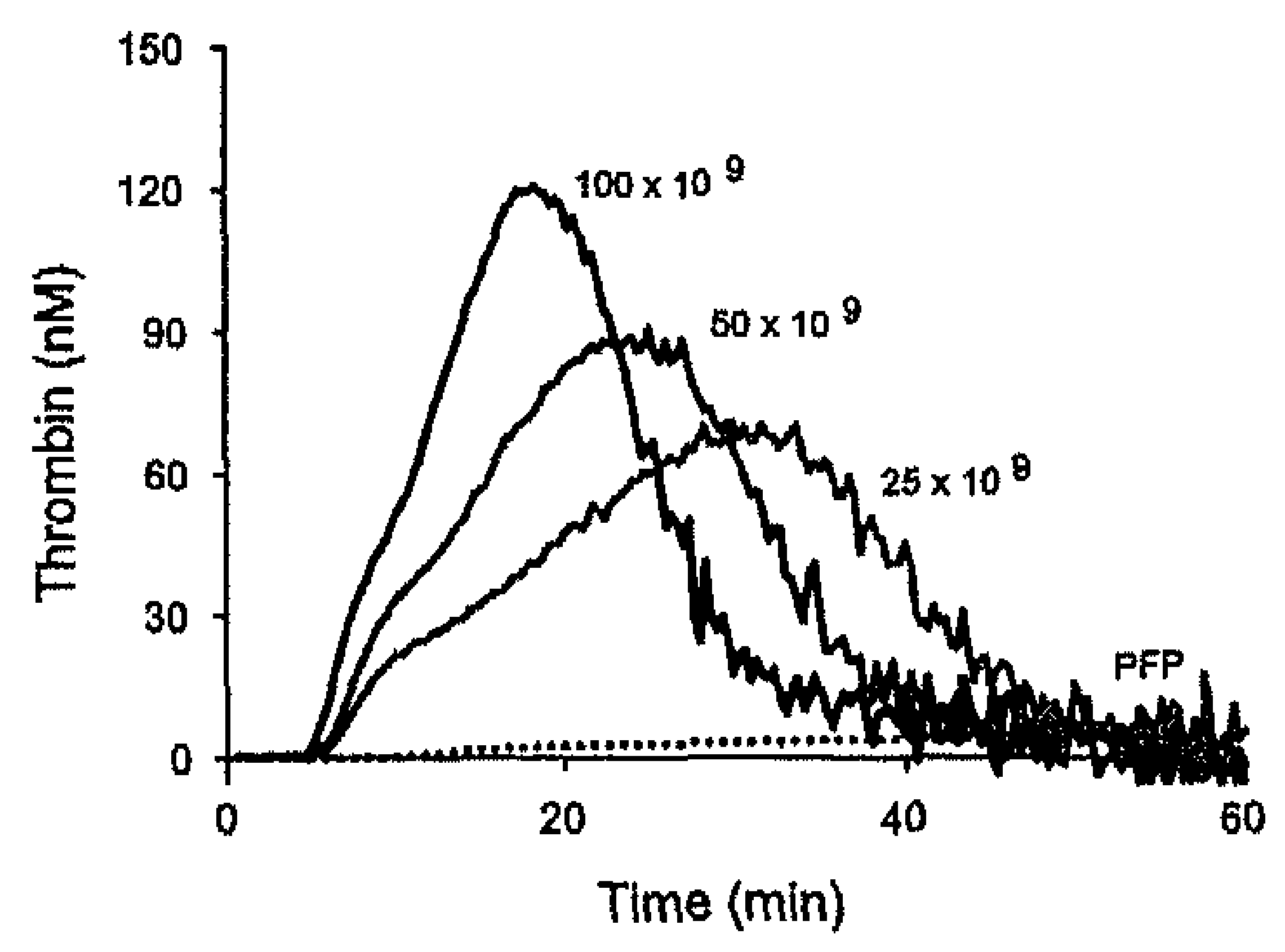

Figure 1. Effect of platelet concentration on tissue factor-induced thrombin generation in plasma. Citrated PFP or PRP $\left(25,50\right.$ or $100 \times 10^{9}$ platelets $\left.\mathrm{L}^{-1}\right)$ was recalcified and triggered with $0.5 \mathrm{pmol} \mathrm{L}^{-1}$ tissue factor. Thrombin generation was automatically measured with fluorescent Z-GGR-AMC substrate ( $\left.416 \mu \mathrm{mol} \mathrm{L} \mathrm{L}^{-1}\right)$, as described in materials and methods. Representative first-derivative curves of fluorescence accumulation are shown; thrombin values were determined with human thrombin calibrator.

For variability analysis, we compared thrombogram parameters (lag time, time to peak, peak level and ETP value) of normalized PRP from eight healthy subjects, who donated blood at three different occasions. Platelets from all subjects had normal aggregation responses with thrombin and ADP (not shown). At standard tissue factor concentration of $0.5 \mathrm{pmol} \mathrm{L}^{-1}$ and platelet count of $100 \times 10^{9} \mathrm{~L}^{-1}$, it appeared that PRP from some subjects consistently exhibited relatively high thrombin formation starting at an early time point (Figure 2A, at $5 \mathrm{~min}$ ), while PRP from other subjects gave lower and more delayed thrombin curves (Figure 2B).

In the absence of platelets, plasma (PFP) from all subjects did not give measurable fluorescence accumulation upon triggering with tissue factor. However, in the presence of PS-containing phospholipids, high thrombin formation was measured. At concentrations of $4 \mu \mathrm{mol} \mathrm{L} \mathrm{L}^{-1}$ phospholipids (20\% PS) and $5 \mathrm{pmol} \mathrm{L}^{-1}$ tissue factor, i.e. conditions where neither the phospholipid surface nor the coagulant trigger was ratelimiting, thrombin generation was rapidly initiated, starting after 2 min and peaking after 5 min. Plasmas from individuals with high thrombin peak levels in the presence of platelets (PRP) also gave high thrombin levels with phospholipid vesicles present (PFP + phospholipids) (Figure 2C). Plasmas from other donors exhibited low thrombograms in the presence of both platelets and phospholipids (Figure 2D). The intra-individual 

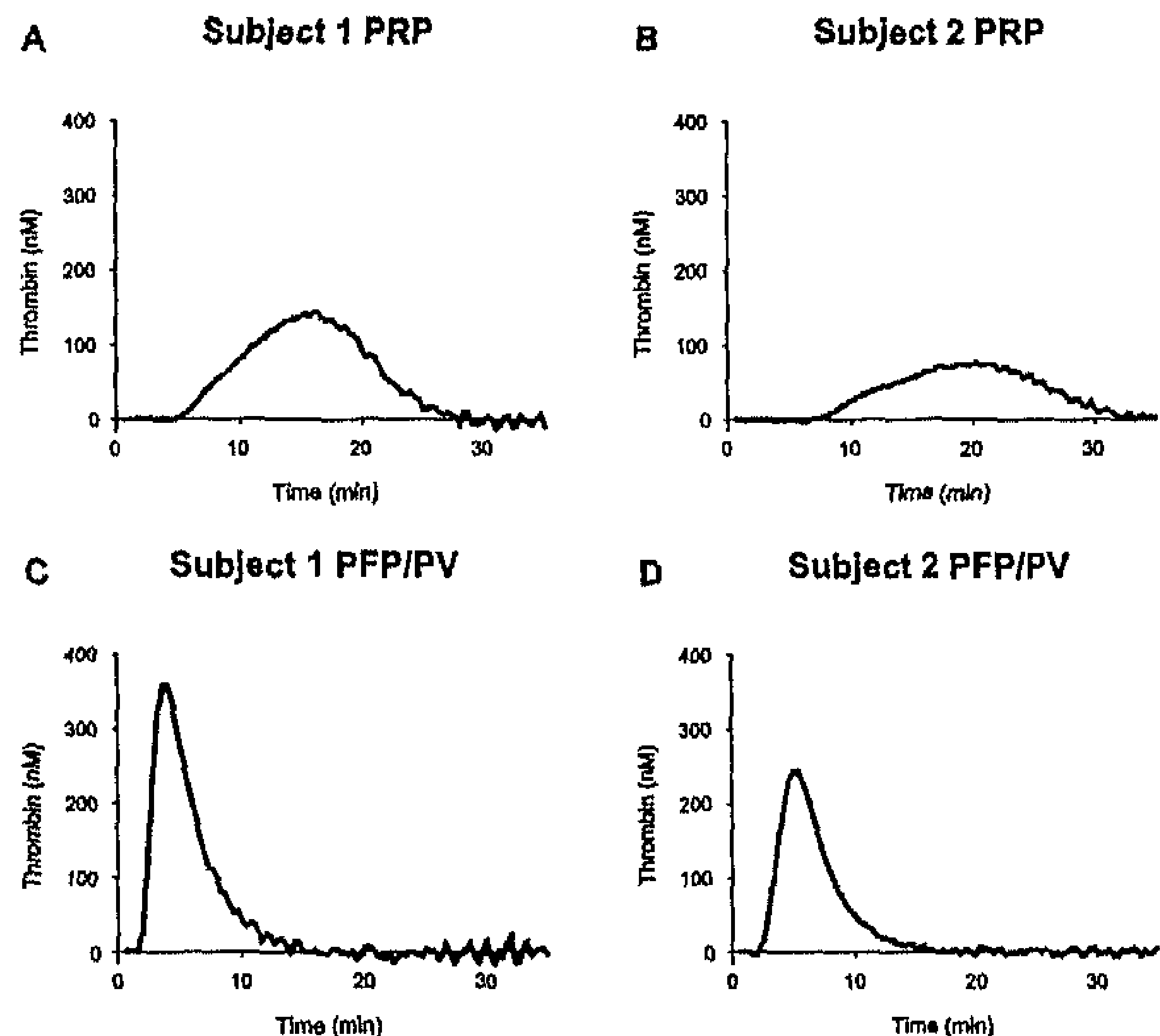

Figure 2. Variation in thrombin generation in plasma from various subjects. (A, B) Thrombin generation was induced with $0.5 \mathrm{pmol} \mathrm{L} \mathrm{L}^{-1}$ tissue factor in PRP containing $100 \times 10^{9}$ platelets $\mathrm{L}^{-1}$. (C, D) Thrombin generation was induced with 5 pmol $L^{-1}$ tissue factor in PFP with $4.0 \mu \mathrm{mol} \mathrm{L^{-1 }}$ phospholipid vesicles (PV). Thrombograms are given for plasma of subject 1 with relatively high thrombin generation $(A, C)$ and of subject 2 with low thrombin generation $(B, D)$.

variation in curves with PRP and PFP/phospholipids regarding peak time, maximal thrombin concentration and area under the curve (ETP) was low, i.e. variability coefficients ranging from $4-10 \%$ (Table 1). These values were close to the assay variability of approximately $5 \%$. In contrast, inter-individual variation in the curve parameters was higher, $11-29 \%$ for thrombograms with platelets and phospholipid vesicles (Table 1). This points to marked differences in thrombin-generating capacity between the plasmas from different subjects, regardless of the presence of platelets.

To further evaluate this, we compared the thrombograms with PRP and $\mathrm{PFP} /$ phospholipids from 41 subjects. Under standard conditions of platelets $\left(100 \times 10^{9} \mathrm{~L}\right.$ $\left.{ }^{1}\right)$, tissue factor $\left(0.5 \mathrm{pmol} \mathrm{L} \mathrm{L}^{-1}\right)$ and Z-GGR-AMC $\left(416 \mu \mathrm{mol} \mathrm{L^{-1 }}\right)$, the lag time of thrombin formation was on average $5.17 \pm 0.18 \mathrm{~min}$ (mean $\pm \mathrm{SD}, n=41$ ); the averaged thrombin peak level was $120 \pm 30 \mathrm{nmol} \mathrm{L}^{-1}$, while the ETP value was $1542 \pm 338$ nmol $\times$ min $L^{-1}$ (Figure 3A-B). In the presence of phospholipid vesicles, formed thrombin had an averaged peak level of $316 \pm 57 \mathrm{nmol} \mathrm{L}^{-1}$ with ETP of $1702 \pm 332$ nmol $\times$ min $L^{-1}$ (Figure 3C-D). Thus, in spite of the much lower thrombin peak levels seen in PRP (120 vs. $\left.316 \mathrm{nmol} \mathrm{L}^{-1}\right)$, the total amount of thrombin formed in the presence of platelets approached that with phospholipid vesicles $\left(91 \%\right.$ of $\left.1702 \mathrm{nmol} \times \operatorname{min~} \mathrm{L}^{-1}\right)$. Comparison of the thrombograms for PRP and PFP/phospholipids of each of the 41 subjects gave correlation coefficients of around $0.70(P<0.001)$ regarding thrombin peak and ETP levels (Figure 3E-F). Apparently, in the thrombograms with platelets present, thrombin peak and ETP values are mostly determined by variable, subjectdependent factors in coagulant activity rather than by variable platelet-related 
Table 1: Intra- and inter-individual variability coefficients in thrombin generation in the presence and absence of platelets. Thrombin generation was triggered with tissue factor in PRP $\left(100 \times 10^{9}\right.$ platelets $\left.\mathrm{L}^{-1}\right)$ from 8 healthy volunteers, who donated blood at three different occasions. For conditions, see Figure 2 . Thrombin

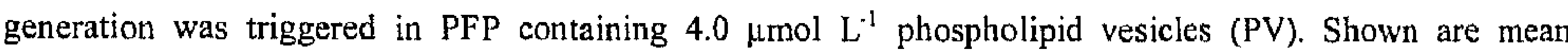
values $\pm \mathrm{SD}(n=8)$ of calibrated thrombogram parameters and inter-individual coefficients of variation (CV).

\begin{tabular}{|c|c|c|c|}
\hline & Value & Intra-CV & Inter-CV \\
\hline \multicolumn{4}{|l|}{$P R P$} \\
\hline Time to peak (min) & $20 \pm 2.1$ & 4.1 & 10.5 \\
\hline Peak height (nmol L $\mathrm{L}^{-1}$ ) & $144 \pm 31$ & 9.8 & 21.9 \\
\hline $\operatorname{ETP}\left(n \operatorname{mol} \times \min L^{-1}\right)$ & $1693 \pm 344$ & 8.3 & 29.2 \\
\hline \multicolumn{4}{|l|}{$P F P / P V$} \\
\hline Time to peak (min) & $4 \pm 0.5$ & 4.8 & 12.8 \\
\hline Peak height (nmol L-1) & $370 \pm 80$ & 4.9 & 21.5 \\
\hline $\operatorname{ETP}\left(n \operatorname{mol} \times \min L^{-1}\right)$ & $1593 \pm 441$ & 4.5 & 28.2 \\
\hline
\end{tabular}

properties. In other words, the thrombin generation in PRP, though being fully dependent on platelets, is restricted in rate and extent by variable, subject-dependent coagulant activity of the plasma.

Thrombin generation in $P R P$ requires $P S$ exposure on activated platelets and is differently influenced by cAMP elevation or integrin blockage

The early onset of thrombin formation in plasma with PS-containing phospholipid vesicles suggested that the availability of PS was a limiting factor in the platelet experiments. This was confirmed by addition to PRP of the PS-scavenging protein annexin A5 to PRP. Already at a low concentration of $1 \mu \mathrm{g} \mathrm{mL}^{-1}$ annexin A5, thrombin generation was delayed to $30 \mathrm{~min}$ and thereafter remained low (Figure 4A). Surface appearance of PS at (thrombin-)activated platelets can thus determine both onset and amount of thrombin generation. Thrombin generation in PRP was similarly abolished by a low dose of $0.1 \mathrm{U} / \mathrm{mL}$ unfractionated heparin (data not shown).

Reverter et al. have shown that cAMP-elevating agonists suppress the thrombin-forming process in reconstituted PRP (8). This could be confirmed in thrombograms run with PRP preincubated with high concentrations of iloprost and $\mathrm{PGE}_{1}\left(1\right.$ and $10 \mu \mathrm{mol} \mathrm{L} \mathrm{L}^{-1}$, respectively) (Figure 4B). These agents reduced peak level and total extent (ETP) of thrombin formation with $71-76 \%$ and $60-76 \%$, respectively (Table 2). Surprisingly, however, they shortened the onset of thrombin formation and the time to peak with 0.5 1.0 and 5-10 min, respectively (Figure 4B). ${ }^{1}$ Similar effects were seen with type-3 phosphodiesterase inhibitors like milrinone, which also elevate cAMP. In contrast, the type-5 phosphodiesterase inhibitor dipyridamole, raising cGMP, was without effect (Table 2).

\footnotetext{
${ }^{1}$ Note that thrombin generation in PRP was sensitive to dilution, pH and solvents like ethanol and DMSO. Controls were therefore run with adequate vehicle.
} 
A

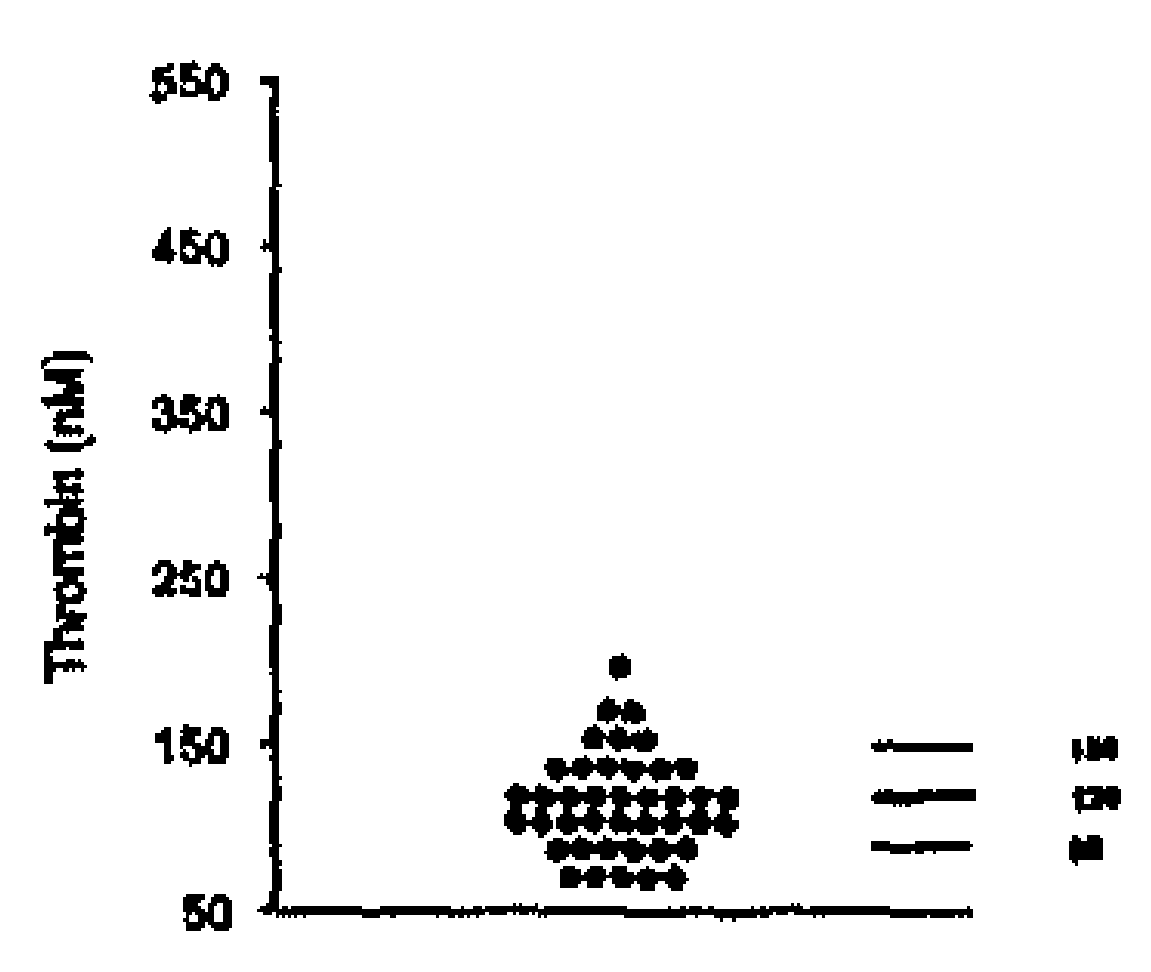

C

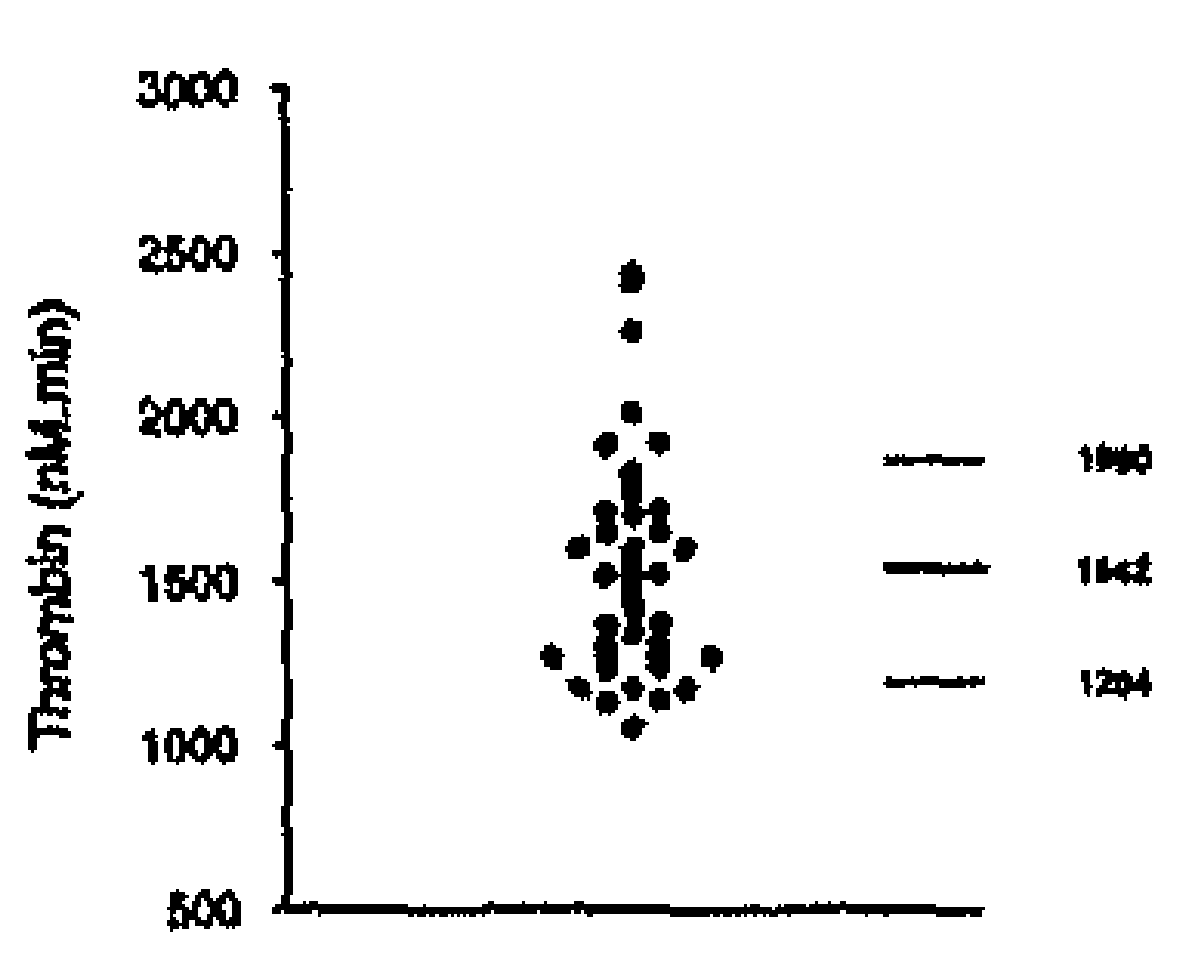

B Ponk lovel PFPIPV
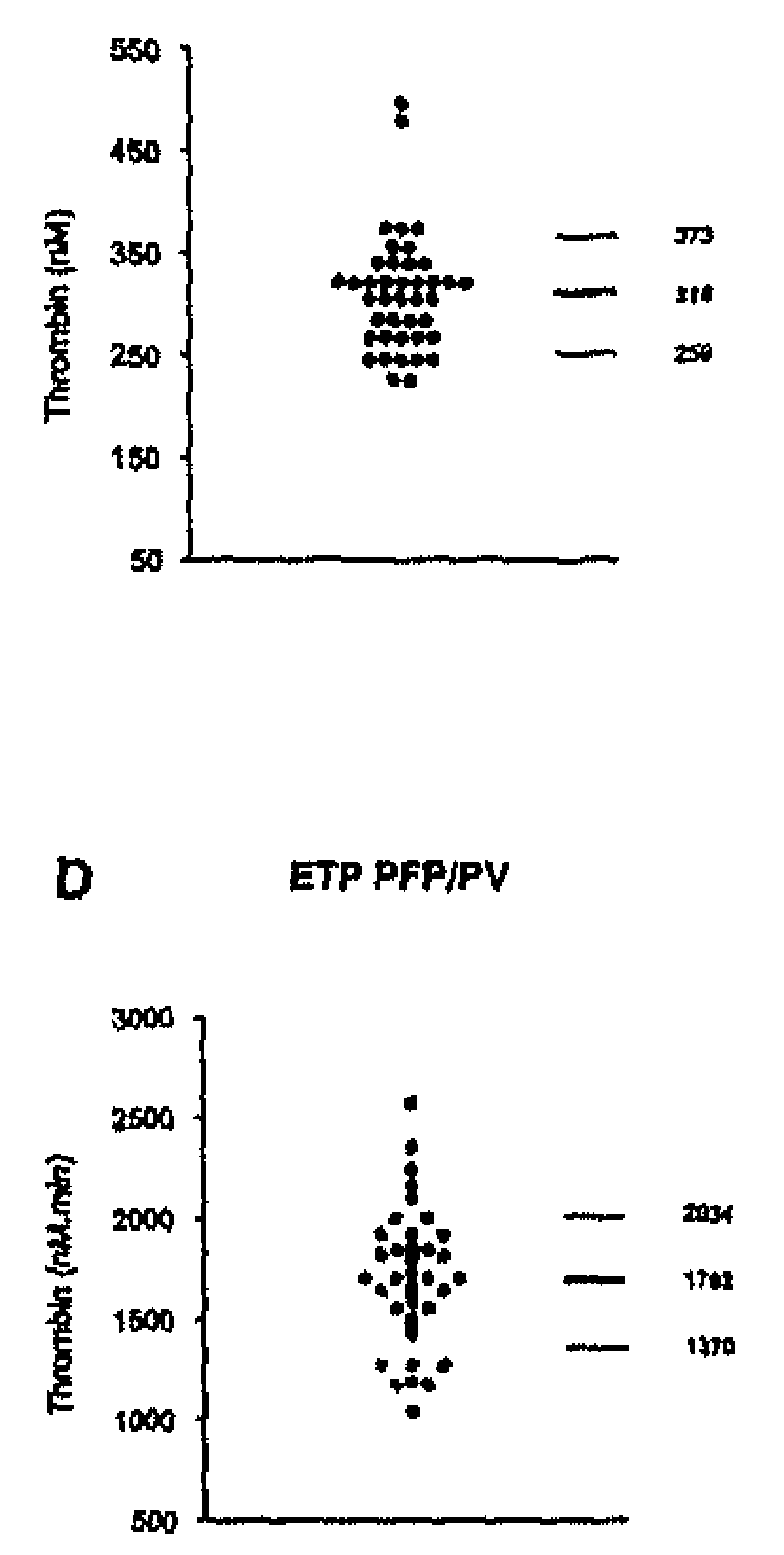

E Poak levol

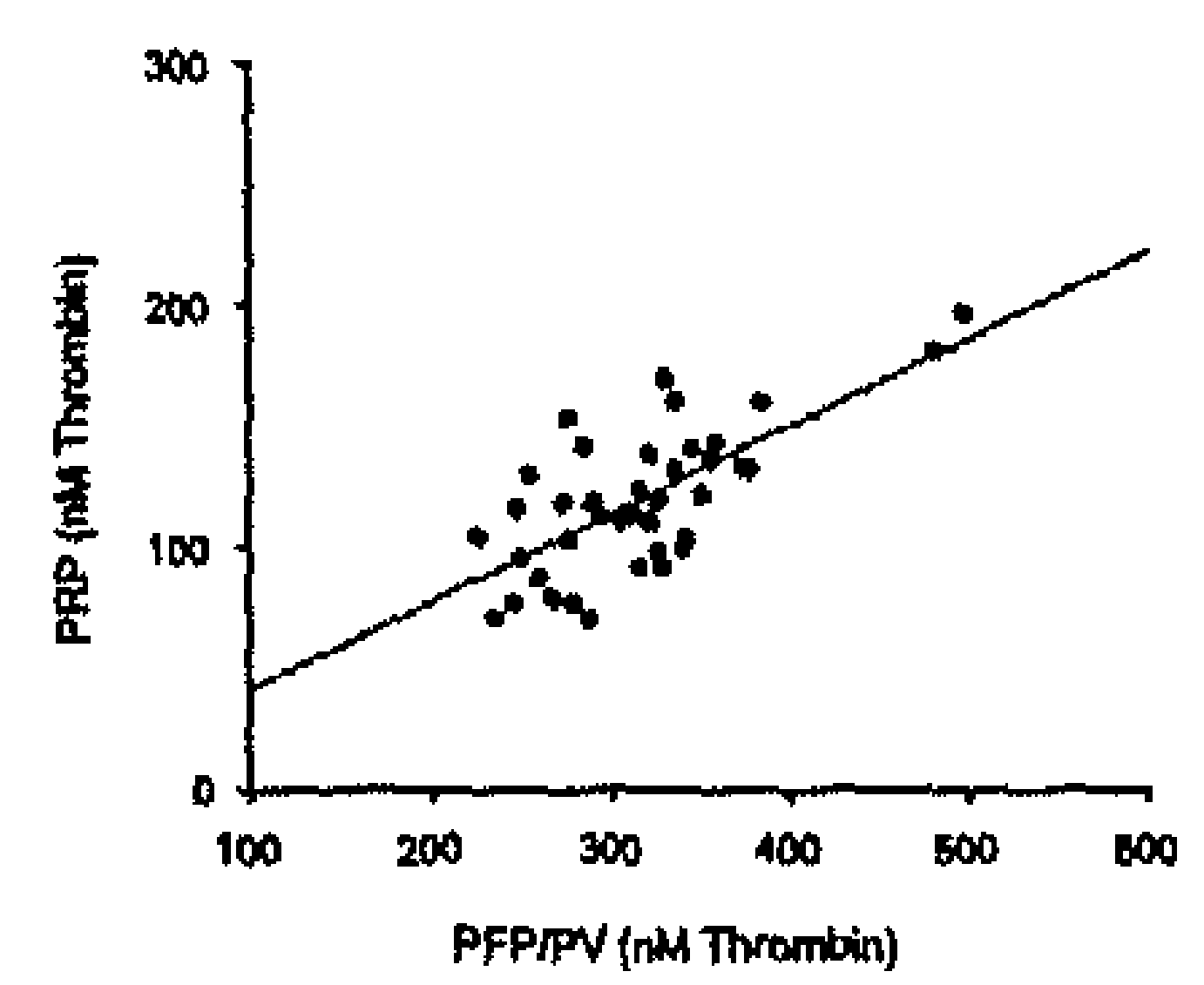

ETP

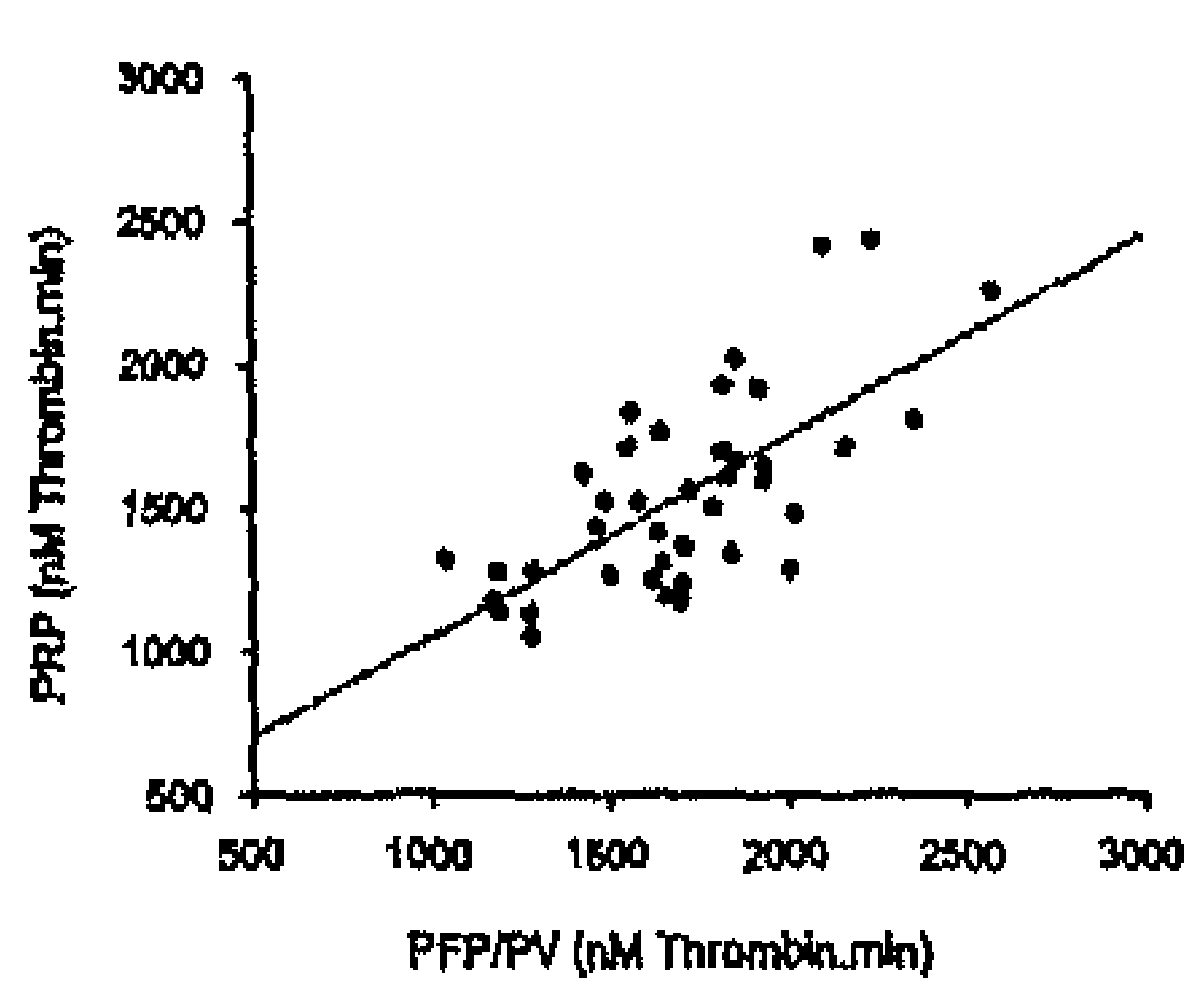

Figure 3. Inter-individual variation in thrombin generation is independent of the presence of platelets. Calibrated thrombograms measured with plasma from 41 healthy subjects under standard conditions (see Figure 2). Peak levels and ETP values obtained with PRP containing $100 \times 10^{9}$ platelets $\mathrm{L}^{-1}(\mathrm{~A}, \mathrm{C})$, or with PFP containing $4.0 \mu \mathrm{mol} \mathrm{L}{ }^{-1}$ phospholipid vesicles (PV) (B, D). Plots of peak levels (E) or ETP values (F) obtained with PFP/PV versus PRP from the same subjects.

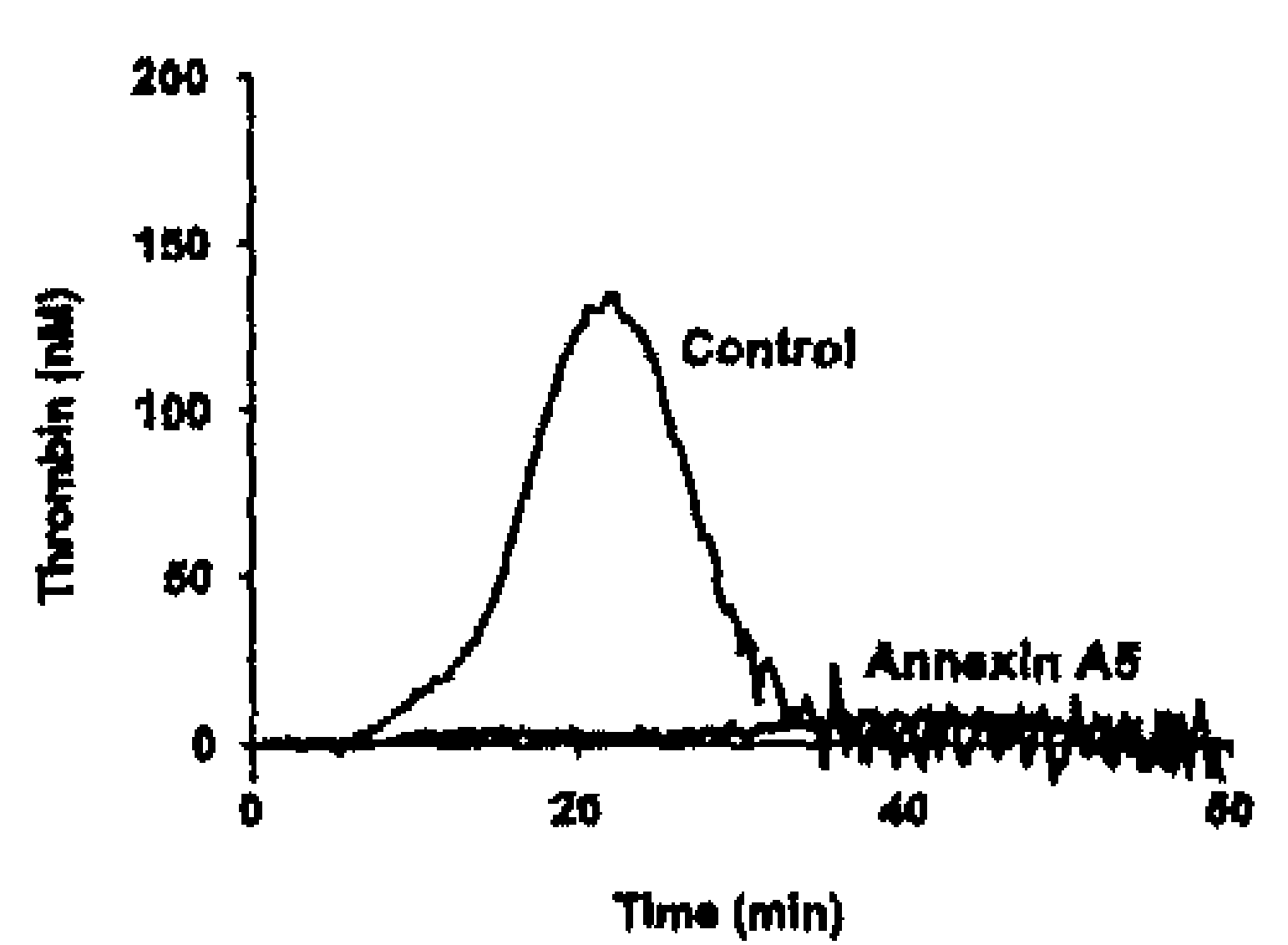

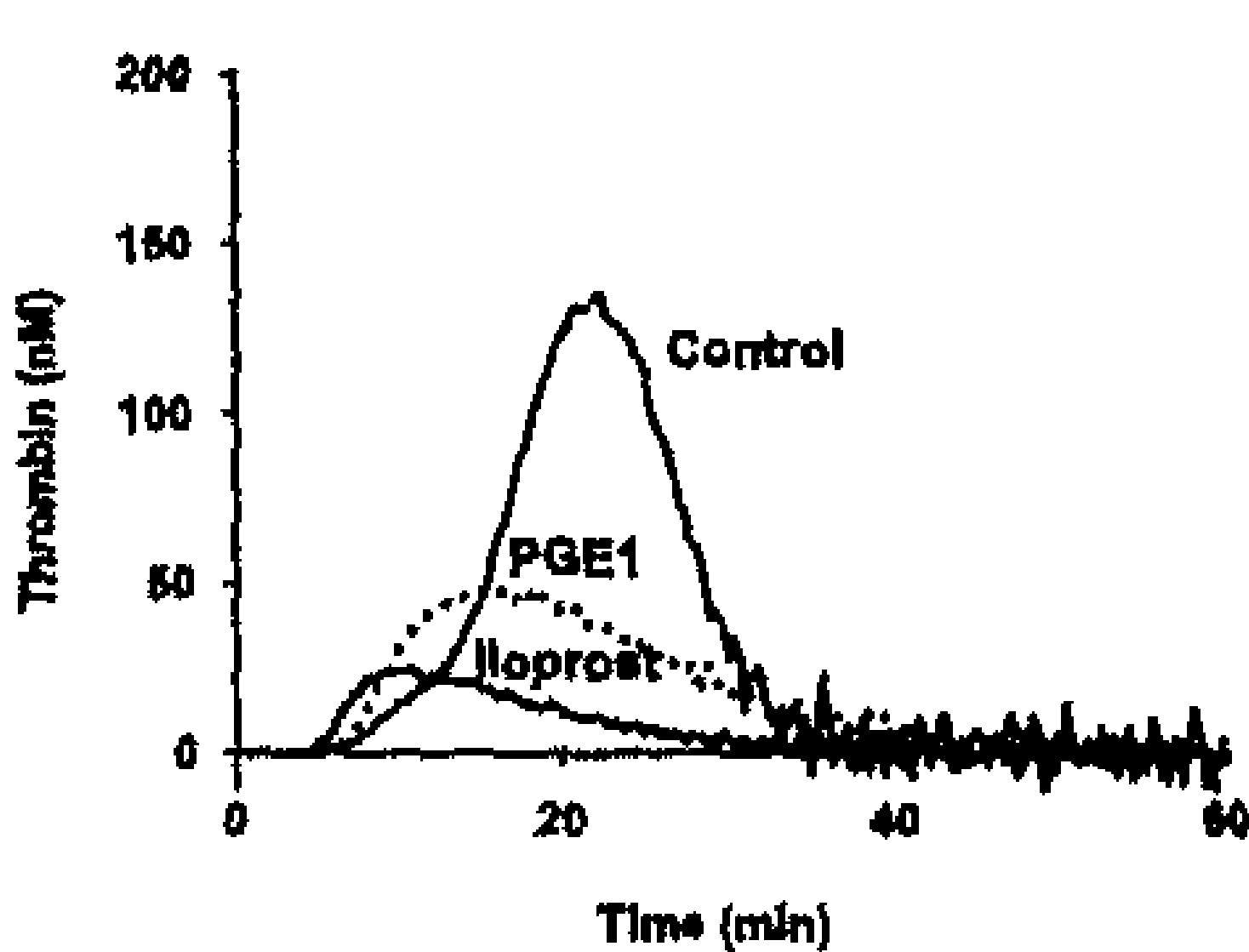

C

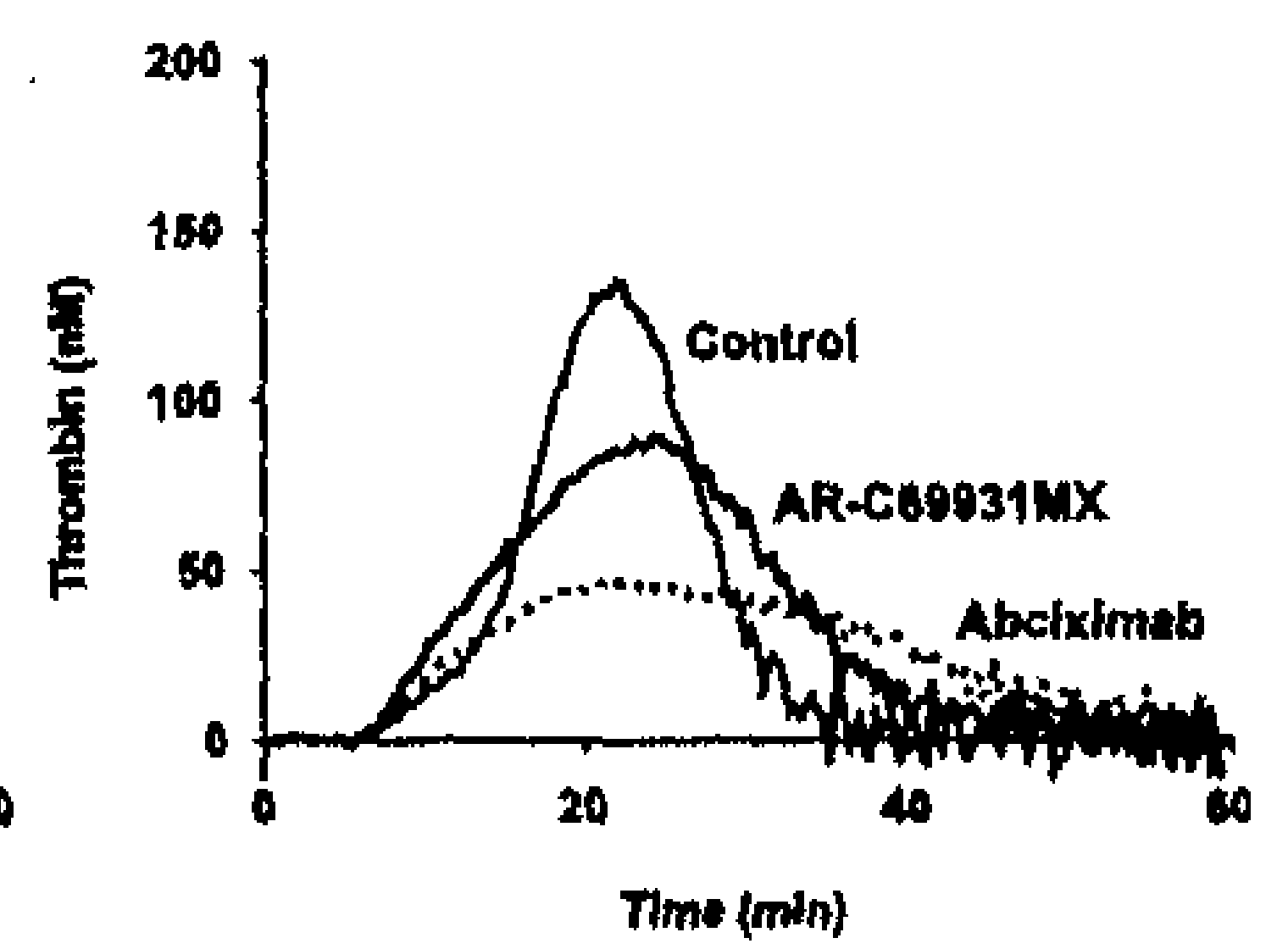

Figure 4. Effects of annexin $A 5$ and platelet inhibitors on thrombin generation in PRP. Conditions as in Figure 2. PRP was pre-incubated for $10 \mathrm{~min}$ with: (A) $1 \mu \mathrm{g} \mathrm{mL} \mathrm{m}^{-1}$ annexin A5; (B) $15 \mu \mathrm{mol} \mathrm{L} \mathrm{L}^{-1} \mathrm{PGE}_{1}$ or $1 \mu \mathrm{mol}$ $\mathrm{L}^{-1}$ iloprost; (C) $20 \mu \mathrm{mol} \mathrm{L} \mathrm{L}^{-1}$ AR-C69931MX or $30 \mathrm{mg} \mathrm{L}^{-1}$ abciximab. Calibrated traces are shown representative for 3-6 experiments.

Platelet integrin $\alpha$ IIb $\beta 3$ blockage also has a thrombin-inhibiting effect in various experimental systems $(8,11,25)$. We found that in PRP the $\alpha I I b \beta 3$ blocker abciximab, at maximally effective dose of $30 \mathrm{mg} \mathrm{L}^{-1}$, delayed the initial thrombin formation with $2.7 \pm 0.15 \mathrm{~min}$ (mean $\pm \mathrm{SE}, n=4$ ) and reduced the thrombin peak with $54 \%$ (Table 2). Abciximab, though, was less inhibitory on ETP level $(25 \%)$, as it prolonged the total 
duration of thrombin formation (Figure 4C). Similar, but less potent effects were obtained with AR-C69931MX, blocking the P2Y 12 ADP receptor (Table 2). In contrast, blocking of the P2Y ADP receptor with MRS2179 caused a small stimulation rather than reduction in thrombin peak level. Blocking of thromboxane production with aspirin decreased the peak level moderately with $9 \%$, leaving the ETP essentially unchanged (Table 2).

Table 2: Effects of platelet inhibitors and agonists on thrombin generation. PRP was pre-incubated with indicated inhibitor/agonist for $10 \mathrm{~min}$ (see Figure 4). Vehicle controls were run, as required. Thrombogram parameters are presented relative to the control condition without (ant)agonist (mean $\pm \mathrm{SE}, n=4-8$ ).

\begin{tabular}{|c|c|c|c|}
\hline $\begin{array}{l}\text { Inhibitor/activator } \\
\left(\mu \mathrm{mol} \mathrm{L} \mathrm{L}^{-1}\right)\end{array}$ & $\begin{array}{l}\text { Time to peak } \\
\text { (min relative to control) }\end{array}$ & $\begin{array}{l}\text { Peak level } \\
\text { (\% of control) }\end{array}$ & $\begin{array}{l}\text { ETP } \\
\text { (\% of control) }\end{array}$ \\
\hline Contral & $20 \pm 0.5$ & 100 & 100 \\
\hline Iloprost (1) & $-10 \pm 1.2$ & $24 \pm 2.6$ & $24 \pm 7.3$ \\
\hline $\mathrm{PGE}_{1}(10)$ & $-5 \pm 1.4$ & $29 \pm 9.3$ & $40 \pm 9.6$ \\
\hline Milrinone (40) & $-6 \pm 1.9$ & $31 \pm 7.7$ & $43 \pm 12.3$ \\
\hline Dipyridamole (40) & $+2 \pm 2.7$ & $103 \pm 3$ & $95 \pm 3.0$ \\
\hline Abciximab $\left(30 \mathrm{mg} \mathrm{L}^{-5}\right)$ & $+8 \pm 1.6$ & $46 \pm 6.4$ & $75 \pm 6.3$ \\
\hline AR-C69931MX (30) & $+3 \pm 1.0$ & $80 \pm 2.7$ & $96 \pm 1.5$ \\
\hline MRS2179 (50) & $+1 \pm 0.9$ & $118 \pm 3$ & $102 \pm 8$ \\
\hline Aspirin (100) & $-0.3 \pm 0.4$ & $91 \pm 0.8$ & $95 \pm 0.2$ \\
\hline Control & $21 \pm 1.3$ & 100 & 100 \\
\hline Adrenaline (10) & $-10 \pm 1.6$ & $138 \pm 14$ & $132 \pm 8$ \\
\hline $\operatorname{ADP}(20)$ & $-10 \pm 1.7$ & $138 \pm 12$ & $108 \pm 3$ \\
\hline SFLLRN (25) & $-9 \pm 1.3$ & $136 \pm 9$ & $111 \pm 2$ \\
\hline $\mathrm{U} 46619(0.1)$ & $-9 \pm 3.4$ & $159 \pm 21$ & $112 \pm 4$ \\
\hline Collagen $\left(5 \mathrm{mg} \mathrm{L}^{-1}\right)$ & $-10 \pm 2.0$ & $202 \pm 23$ & $117 \pm 5$ \\
\hline Convulxin $\left(50 \mu \mathrm{gL}^{-1}\right)$ & $-11 \pm 2.3$ & $201 \pm 6$ & $113 \pm 6$ \\
\hline Ionomycin (25) & $-18 \pm 0.4$ & $442 \pm 30$ & $114 \pm 4$ \\
\hline Sonicated platelets $(10 \%)$ & $-12 \pm 1.4$ & $262 \pm 19$ & $114 \pm 8$ \\
\hline
\end{tabular}

\section{Platelet agonists mainly shorten and accelerate thrombin generation in PRP}

To determine the effect of platelet activation on thrombin generation, platelets in PRP were pre-stimulated with various agonists before triggering of the coagulation with tissue factor. The weak agonist adrenaline, stimulating Gi-family proteins, shortened the onset of thrombin formation and time-to-peak with $2 \pm 0.2$ and $10 \pm 1.6 \mathrm{~min}$, respectively (mean $\pm \mathrm{SE}, \mathrm{n}=4$ ). Adrenaline increased the thrombin peak and ETP levels with about $35 \%$ (Table 2). Stimulation of Gq-protein coupled receptors with ADP, SFLLRN or 
U46619 - binding to P2Y, PAR-1 or TP $\alpha$ receptors, respectively - at maximally effective concentrations, also shortened the lag time with 1.7-2.7 min and the time-topeak with 9-10 min (Figure 5A). With these agonists, the peak level increased with 36$59 \%$, whereas ETP increased with only $8-12 \%$ (Table 2). Platelets in PRP were also stimulated with agonists known to give potent stimulation of PS exposure $(21,26)$. Glycoprotein VI activation with fibrillar collagen or convulxin also shortened the time to peak with 10-11 min and doubled the thrombin peak level (Figure 5B), while again the ETP value raised with only about $15 \%$ (Table 2). Prior sonication of the platelets gave similar results; $10 \%$ of sonicated platelets was sufficient to induce potent thrombin generation (Figure 5C). The $\mathrm{Ca}^{2+}$-ionophore ionomycin, causing nearly complete PS exposure, shortened the time to peak with $18 \mathrm{~min}$ and increased the thrombin peak more than fourfold (Table 2). As the peak level reflects the maximal rate of thrombin generation (23), these data indicate that platelet agonists - and especially established PS-exposing agonist - act by shortening and accelerating the thrombin-forming process. $^{2}$

We finally compared the effects of platelet (ant)agonists on thrombograms using PRP from various subjects. As illustrated in Figure 6, essentially the same curve shifts were obtained in PRP with high and low thrombin peak levels. Thus, platelet stimulation with collagen about doubled the peak leak in individuals with high and low plasma ETP value. For plasmas from 16 subjects, we extensively tested the effects of the clinically relevant platelet antagonists abciximab $\left(30 \mathrm{mg} \mathrm{L}^{-1}\right)$ and AR-C69931MX. For abciximab, neither the thrombin peak nor the ETP correlated significantly with the absolute level of the peak $(P=0.98)$ or ETP $(P=0.61)$ under control conditions. Similarly, the lowering effect of AR-C69931MX $\left(30 \mu \mathrm{mol} \mathrm{L}^{-1}\right)$ on peak or ETP did not correlate with the absolute peak $(P=0.82)$ or ETP $(P=0.19)$ level under control conditions. This supports the conclusion that inter-subject variation in thrombogram parameters is mainly determined by a variable coagulant activity.
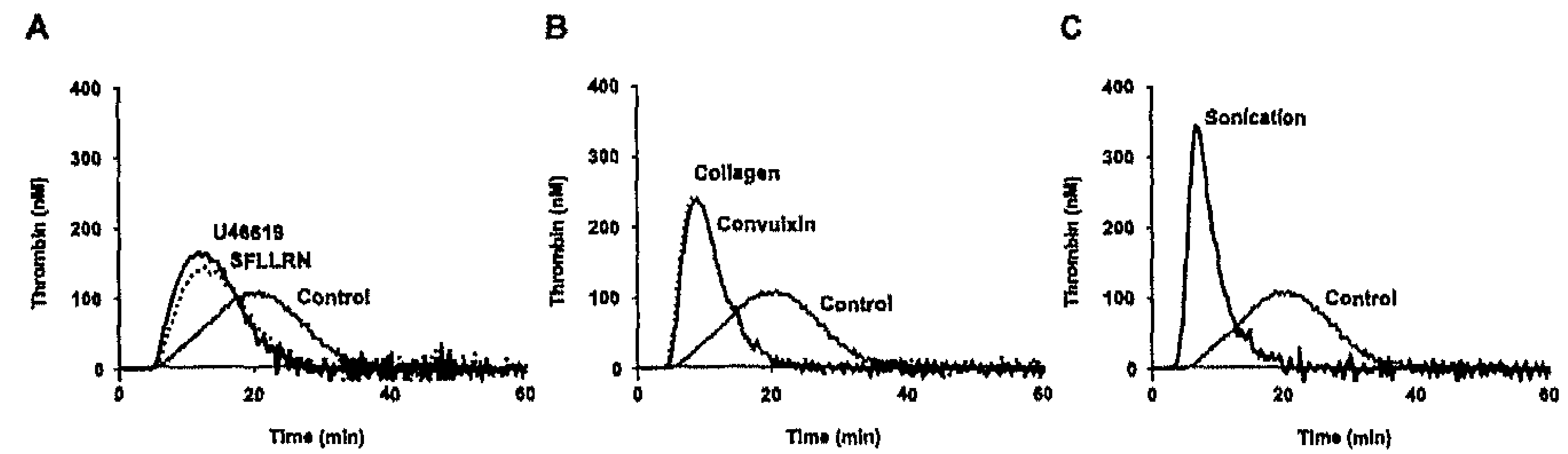

Figure 5. Effects of platelet activators on thrombin generation in PRP. Conditions as in Figure 2. PRP was pre-incubated for 10 min with: (A) $0.1 \mu \mathrm{mol} \mathrm{L} \mathrm{L}^{-1} \mathrm{U} 46619$ or $25 \mu \mathrm{mol} \mathrm{L}^{-1} \mathrm{SFLLRN}$; (B) $5 \mathrm{mg} \mathrm{L}^{-1}$ collagen or 50 $\mu \mathrm{g} \mathrm{L}^{-1}$ convulxin; $(\mathrm{C})$ or sonicated PRP $\left(10 \times 10^{9}\right.$ platelets $\left.\mathrm{L}^{-1}\right)$. Calibrated traces are shown representative for 4-8 experiments.

\footnotetext{
${ }^{2}$ At higher concentrations of tissue factors curves shifted to the left and effects of platelet agonists disappeared.
} 
A

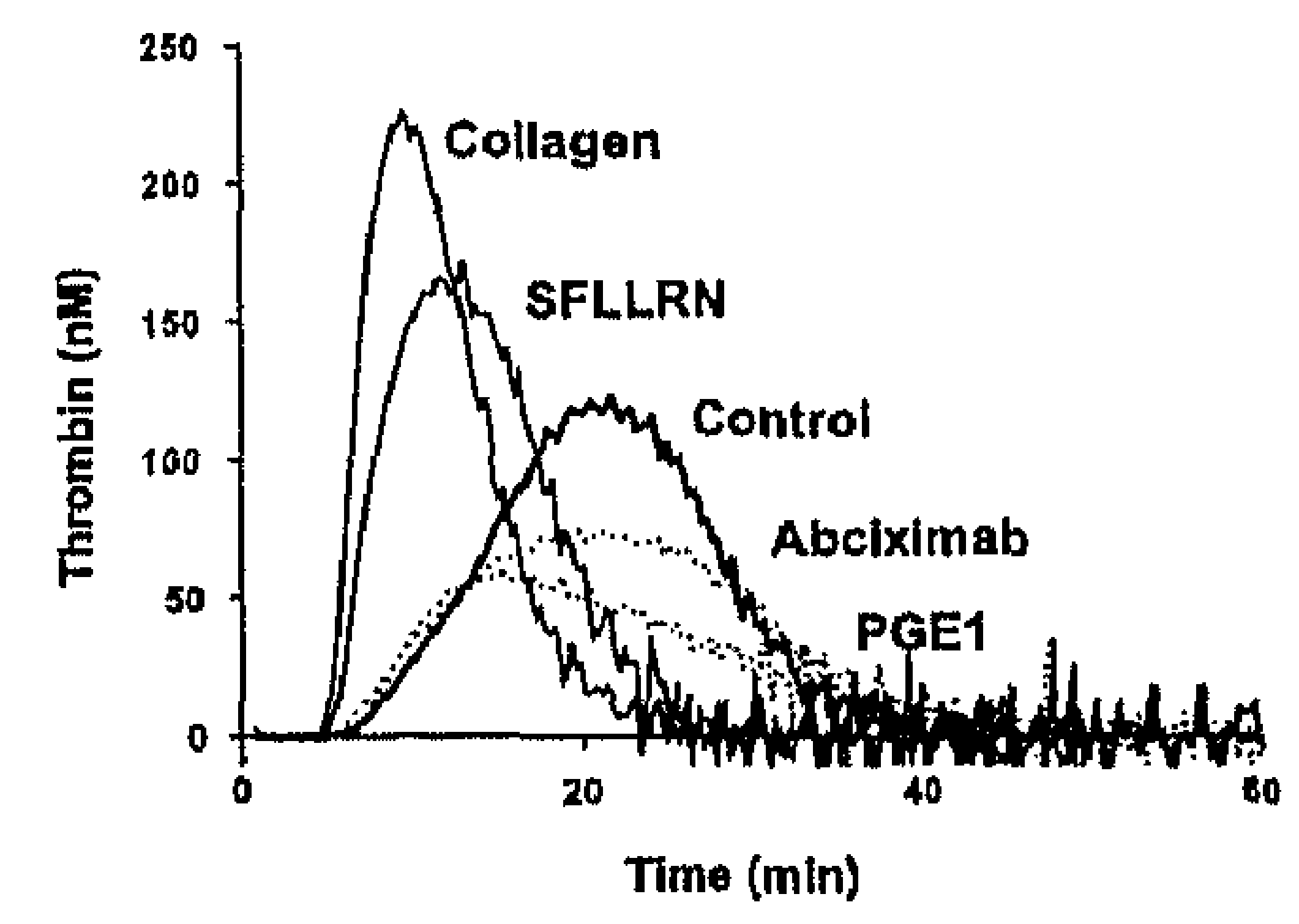

B

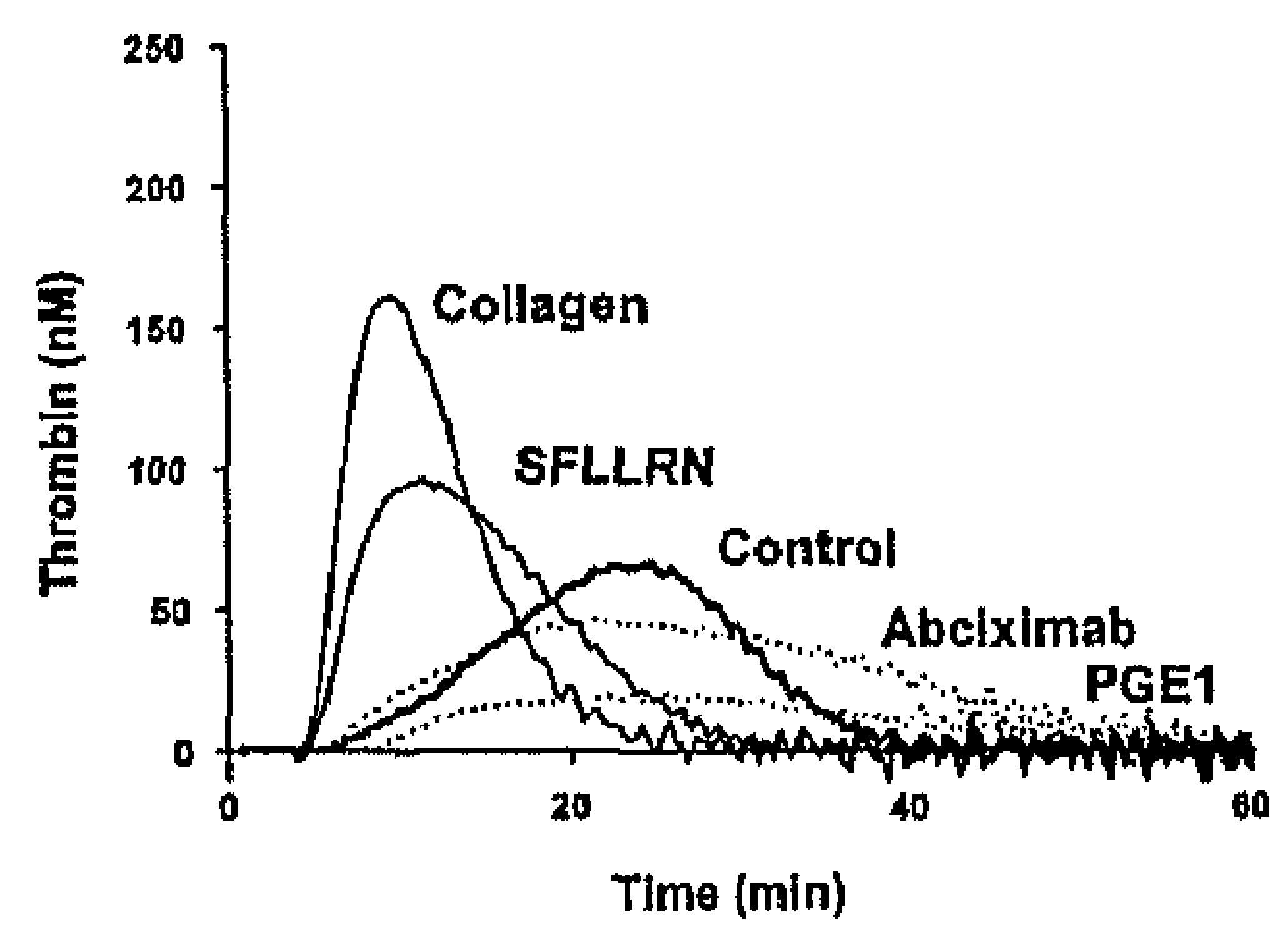

Figure 6. Effects of platelet inhibition or activation in plasma from subjects with high or low thrombin generation. PRP from subject 3 with relatively high (A) and from subject 4 with lower (B) thrombin generation was pre-incubated with inhibitor (see Figure 4) or agonist (see Figure 5), Representative calibrated traces are given.

\section{DISCUSSION}

The automated and calibrated thrombin measurements, using a low-affinity, fluorescent thrombin substrate, directly added to PRP, allowed precise measurements of initial effects of platelets in the thrombin-forming process. In PRP triggered with minute amounts of tissue factor, platelets dose-dependently contributed to thrombin generation. Typically, the rate of thrombin formation - which is reflected by the thrombin peak level (23) - increased up to $200 \times 10^{9}$ platelets $\mathrm{L}^{-1}$, while the total amount of thrombin formed (ETP) was already maximal around $35 \times 10^{9}$ platelets $\mathrm{L}^{-1}$. Thus, higher platelet counts mostly affected the rate rather than the total amount of thrombin generation.

The present thrombin generation curves differ to some extent from earlier published curves, where thrombin was measured by sampling from platelet-containing plasma $(8$, 20 ). Here we show a more delayed onset of thrombin formation, which most probably reflects the low activation state of platelets in freshly isolated PRP due to the absence of handling. Furthermore, we describe higher thrombin peak and ETP values in comparison to earlier work. This is explained by the presence of sub-millimolar concentration of low-affinity substrate Z-GGR-AMC, which competitively inhibits antithrombin activity and, thereby, markedly prolongs the thrombin half-life time in plasma. The assay still shows the required sensitivity to thrombin inactivation (27), as a low dose of $0.1 \mathrm{U} / \mathrm{mL}$ heparin abolished formation of thrombin. It should be remarked that any changes in plasma dilution and substrate concentration alter the actual values obtained in thrombin generation curves.

It has been shown for healthy subjects and stroke patients that platelets can vary among 
subjects in procoagulant activity, e.g. by different capability to PS exposure $(4,28)$. The present data however indicate that, with respect to thrombin generation in PRP, a considerable part of the inter-individual variability is independent of platelets and due to variant coagulant activity. Measurement of coagulation factors in plasma indicated that different levels of prothrombin, antithrombin, factor $\mathrm{V}$ and fibrinogen explain a significant part of this variation in thrombin formation (K. Vanschoonbeek, unpublished 2003). The sensitivity to fibrinogen is in agreement with earlier results (19).

The presence of PS-containing phospholipid vesicles in plasma (PFP) - at a similar low dose of tissue factor - led to a more rapid onset and peaking of thrombin generation than observed with platelets (PRP). This indicates that, under the experimental conditions used, the presence of procoagulant phospholipids greatly accelerate the thrombin-forming process. That PS exposure also plays a critical role in the thrombin generation in PRP appears from the fact that targeted blocking of PS with annexin A5 nearly completely abolished formation of thrombin (Figure 4A). Similar effects of annexin A5 were observed on thrombin generation in plasma with PS-containing vesicles or apoptotic Jurkat cells (H. Kenis, unpublished 2003). Together, this indicates that PS exposure by platelets and/or platelet-derived microvesicles limits both the rate and extent of the thrombin generation process in PRP. Others have proposed that PS exposure is necessary but perhaps not sufficient to account for platelet surface regulation of thrombin generation (4). Our data emphasize the necessity for procoagulant platelet phospholipids, but leave a possibility of additional regulatory effects by binding of coagulation factors to platelets. The present thrombogram assay with PRP mimics physiology of that part of the coagulation in which flow and shear do not play a major role, i.e. within formed aggregates and clots. We anticipate that this assay will be helpful to study other, poorly understood aspects of platelet-dependent coagulation, e.g. interaction with fibrin network, binding of coagulation factors to platelet glycoproteins (Ib-V-IX and $\alpha \mathrm{IIb} \beta 3)(12,29)$, coagulant function of platelet factor V (30), and COAT factor V (31).

Pre-activation of platelets in PRP shifted thrombogram curves to the left (Figure 5). Table 2 indicates the profound, stimulating effect of even weakly platelet-stimulating agents on the thrombin generation process. For instance, adrenaline and ADP, which are considered to be weak agonists unable to cause PS exposure in washed platelets, significantly shortened the onset of thrombin formation and increased thrombin peak levels. Most prominent curve shifts with two- or fourfold increases in peak level were seen after prior treatment of platelets with glycoprotein VI-stimulating agonists or ionomycin, respectively, i.e. conditions resulting in extensive PS exposure (32). The present data compare well to findings that collagen and convulxin potently stimulate platelet prothrombinase activity and, herein, are about half as effective as $\mathrm{Ca}^{2+}$ inophores $(21,31)$. Furthermore, we found that this stimulating effect was independent of the high or low ETP of the PRP (Figure 6). Taken together, the results thus indicate that, in coagulating PRP, PS exposure on activated platelets controls both the onset and rate of thrombin generation, although the total capacity of thrombin generation is restricted by variable, subject-dependent coagulant activity of the plasma. 
We also observed typical differences in effects of various platelet-function inhibitors. Aspirin had only limited anticoagulant effect on the thrombogram parameters. Agents elevating cAMP, i.e. prostaglandins and phosphodiesterase inhibitors, caused earlier start and peaking of thrombin formation but substantially reduced thrombin peak and ETP values. Recalling the high PS-dependency of thrombin formation, this may indicate that cAMP elevation does not retards initial PS exposure by platelets in coagulant plasma, but rather decreases its extent. In apparent deviation from the present results, Butenas et al. (11) report of delayed fibrin and thrombin-antithrombin complex formation in $\mathrm{PGE}_{1}$-treated whole blood.

On the other hand, integrin $\alpha I I b \beta 3$ blockage with abciximab strikingly reduced the rate of thrombin formation with less effect on the integrated thrombin potential. Antagonism of the $\mathrm{P} 2 \mathrm{Y}_{12}$ receptor, known to play a role in ADP-induced integrin activation, caused similar but less pronounced effects. This anti-integrin effect is compatible with the reported reduction of microvesicle formation (8) and PS exposure (30). It also agrees with the published reduction in rate of thrombin-antithrombin complex formation in coagulating whole blood (11). However, it is still unclear why integrin blockage and cAMP elevation have different effects particularly in the initial phase of thrombin generation.

\section{Acknowledgements}

We thank W. Beks and P. van der Meijden for technical assistance. Financial support was obtained from the Netherlands Organization for Scientific Research (NWO 980-10018). 


\section{REFERENCES}

1. Hemker HC. Thrombin generation, an essential step in haemostasis and thrombosis. In: Haemostasis and Thrombosis (Bloom AL, Forbes CD, Thomas DP, Tuddenham EGD, eds) Churchill Livingstone, Edinburgh. 1964; pp. 477-90.

2. Zwaal RFA, Schroit AJ. Pathophysiological implications of membrane phospholipid asymmetry in blood cells. Blood. 1997; 89: 1121-32.

3. Heemskerk JWM, Bevers EM, Lindhout T. Platelet activation and blood coagulation. Thromb Haemost. 2002; 88: 186-93.

4. Monroe DM, Hoffman M, Roberts HR. Platelets and thrombin generation. Arterioscler Thromb Vasc Biol, 2002; 22: 1381-9.

5. Baird TR, Walsh PN. The interaction of factor XIa with activated platelets but not endothelial cells promotes the activation of factor IX in the consolidation phase of blood coagulation. J Biol Chem. 2002; 277: $38462-7$.

6. Solum NO. Procoagulant expression in platelets and defects leading to clinical disorders. Arterioscl Thromb Vase Biol. 1999; 19: 2841-6.

7. Béguin S, Lindhout T, Hemker HC. The effect of trace amounts of tissue factor on thrombin generation in platelet rich plasma; its inhibition by heparin. Thromb Haemost. 1989; 61: 25-9.

8. Reverter JC, Béguin S, Kessels H, Kumar R, Hemker HC, Coller BS. Inhibition of platelet-mediated, tissue factor-induced thrombin generation by the mouse/human chimeric 7E3 antibody. J Clin Invest. 1996; 98: 863-74.

9. Hérault JP, Peyrou V, Savi P, Bernat A, Herbert JM. Effect of SR121566A, a potent GP IIb-IIIa antagonist on platelet-mediated thrombin generation in vitro and in vivo. Thromb Haemost. 1998; 79: 383-8.

10. Thomas S, Metcalfe P, Goodall AH, Gray E. Monoclonal antibodies against piatelet membrane glycoproteins IIb/IIIa and Iba inhibit platelet dependent thrombin generation by different mechanisms. Thromb Haemost. 2000; 84: 98-103.

11. Butenas S, Cawthern KM, van 't Veer C, DiLorenzo ME, Lock JB, Mann KG. Antiplatelet agents in tissue factor-induced blood coagulation. Blood. 2001; 97: 2314-22.

12. Dörmann D, Clemetson KJ, Kehrel BE. The GPIb thrombinubinding site is essential for thrombininduced platelet procoagulant activity. Blood. 2000; 96:2469.2478.

13. Dicker IB, Pedicord DL, Seiffert DA, Jamieson GA, Greco NJ. Both the high affinity thrombin receptor (GPIb-IX-V) and GPIIb/IIIa are implicated in expression of thrombin-induced platelet procoagulant activity. Thromb Haemost. 2001; 86: 1065-9.

14. Briedé JJ, Wielders SJH, Heemskerk JWM, Baruch D, Hemker HC, Lindhout T. Von Willebrand factor mediates thrombin-induced exposure of procoagulant phospholipids on the surface of fibrin-adherent platelets. J Thromb Haemost. 2003; 1 : 559-65.

15. Storey RF, Sanderson HM, White AE, May JA, Cameron KE, Heptinstall S. The central role of the $P 2 T$ receptor in amplification of human platelet activation, secretion and procoagulant activity. $\mathrm{Br} J$ Haematol. 2000; 110: 925-34.

16. Herault JP, Bono F, Avril C, Schaeffer P, Herbert JM. Activation of human vascular endolhelial cells by factor Xa, effect of specific inhibitors. Biochem Pharmacol. 1999; 57: 603-10.

17. Jacobsson F, Swahn E, Wallentin L, Ellborg M. Safety profile and tolerability of intravenous AR. C69931MX, a new antiplatelet drug, in unstable angina pectoris and non-Q-wave myocardial infarction. Clin Ther. 2002; 24: 752-65.

18. Hemker $\mathrm{HC}_{3}$ Giesen PLA, Ramjee M, Wagenvoord R, Béguin S. The thrombogram: monitoring thrombin generation in platelet-rich plasma. Thromb Haemost 2000; 83:589-91.

19. Hemker HC, Giesen P, Al Dieri R, Regnault V, de Smedt E, Wagenvoord R, Lecompte T, Béguin S. Calibrated automated thrombin generation measurement in clotting plasma. Pathophysiol Haemost Thromb. 2003; 33: 4-15.

20. Hemker $\mathrm{HC}$, Béguin $S$. Thrombin gencration in plasma: its assessment via the endogenous thrombin potential. Thromb Haemost. 1995; 74: 134-8.

21. Siljander P, Farndale RW, Feijge MAH, Comfurius P, Kos S, Bevers EM, Heernskerk JWM. Platelet adhesion enhances the glycoprotein VI-dependent procoagulant response: involvement of p38 MAP kinase and calpain. Arterioscler Thromb Vasc Biol. 2001; 21: 618-27. 
22. Heemskerk JWM, Feijge MAH, Henneman L, Rosing J, Hemker HC. The $\mathrm{Ca}^{2+}$-mobilizing potency of $\alpha$-thrombin and thrombin-receptor-activating peptide on human platelets. Eur J Biochem. 1997; 249: 547-55.

23. Nieuwenhuys CMA, Feijge MAH, Béguin S, Heemskerk JWM. Monitoring hypocoagulant conditions in rat plasma: factors determining the endogenous thrombin potential of tissue factor-activated plasma. Thromb Haemost. 2000; 84: 1045-51.

24. Feijge MAH, van Pampus ECM, Lacabaratz-Porret C, Hamulyák K, Lévy-Toledano S, Enouf J, Heemskerk JWM. Inter-individual variability in $\mathrm{Ca}^{2+}$ signalling in platelets from healthy volunteers. $\mathrm{Br} \mathrm{J}$ Haematol. 1998; 102: 850-9.

25. Mascelli MA, Lance ET, Damaraju L, Wagner CL, Weisman HF, Jordan RE. Pharmacodynamic profile of short-term abciximab treatment demonstrates prolonged platelet inhibition with gradual recovery from GPIIb/IIIa receptor blockade. Circulation. 1998; 97: 1680-8.

26. Heemskerk JWM, Vuist WMJ, Feijge MAH, Reıtelingsperger CPM, Lindhout T. Collagen but not fibrinogen surfaces induce bleb formation, exposure of phosphatidylserine and procoagulant activity of adherent platelets. Blood. 1997; 90: 2615-25.

27. Huntington JA, Baglin TP. Targeting thrombin: rational drug design from natural mechanisms. Trends Pharmacol Sci. 2003; 24: 589-95.

28. Vanschoonbeek K, Feijge MAH, Keuren JF, Hemker HC, Lodder JJ, Hamulyák K, van Pampus EC, Heemskerk JWM. Thrombin-induced hyperactivity of platelets of young stroke patients. Thromb Haemost. 2002; 88: 931-7.

29. Li N, Wallén NH, Savi P, Hérault JP, Herbert JM. Effects of a new platelet glycoprotein IIb/IIIa antagonist, SR 121566, on platelet activation, platelet-leukocyte interaction and thrombin generation. Blood Coagul Fibrinolys. 1998; 9: 507-15.

30. Furman MI, Krueger LA, Frelinger AL, Barnard MR, Mascelli MA, Nakada MT, Michelson AD. GPIIbIIla antagonist-induced reduction in platelet surface factor $\mathrm{V} / \mathrm{Va}$ binding and phosphatidylserine expression in whole blood. Thromb Haemost. 2000; 84: 492-8.

31. Alberio L, Safa O, Clemetson KJ, Esmon CT, Dale GL. Surface expression and functional characterization of $\alpha$-granule factor $V$ in human platelets: effects of ionophore A23187, thrombin, collagen, and convulxin. Blood. 2000; 95: 1694-702.

32. Bevers EM, Comfurius P, van Rijn JLML, Hemker HC, Zwaal RFA. Generation of prothrombinconverting activity and the exposure of phosphatidylserine at the outer surface of platelets. Eur $\mathrm{J}$ Biochem. 1982; 122: 429-36. 


\section{Chapter 5}

\section{Variable hypocoagulant effect of}

fish oil intake in man: modulation of fibrinogen level and thrombin generation

Kristof Vanschoonbeek, Marion A.H. Feijge, Martine Paquay, Jan Rosing, Wim H.M. Saris, Cornelis Kluft, Peter L.A. Giesen, Moniek P.M. de Maat and Johan W.M. Heemskerk

Arteriosclerosis, Thrombosis and Vascular Biology, 2004; 24: 1734-40 


\begin{abstract}
The beneficial effect of dietary fish oil, rich in n-3 polyunsaturated fatty acids (PUFAs) on cardiovascular disease is multi-factorial, and may partly rely on their anticoagulant action. We studied how fish oil intake influenced thrombin generation in plasma and which factors were involved herein. Therefore, twenty-five healthy males with borderline overweight received $3.0 \mathrm{~g} \mathrm{n}-3$ PUFAs daily during four weeks. Fish oil intake reduced plasma triglycerides and lowered platelet integrin activation as well as plasma levels of fibrinogen and factor $\mathrm{V}$, but had no effect on vitamin $\mathrm{K}$-dependent coagulation factors. Before fish oil intake, thrombin generation (reflecting the coagulant potential) considerably varied between plasmas from individual subjects, which was partly explained by variation in prothrombin, antithrombin, fibrinogen and factor $\mathrm{V}$ levels. Fish oil intake reduced thrombin generation both in the presence and absence of platelets. This reduction correlated with the fish oil effect on fibrinogen and factor $\mathrm{V}$ levels. Interestingly, the lowering effect of fish oil on both thrombin generation and fibrinogen clustered around subjects with high fibrinogen, carrying a structural fibrinogen $\alpha$-chain polymorphism. Taken together, these results indicate that dietary $n-3$ PUFAs provoke a hypocoagulant, vitamin $\mathrm{K}$-independent effect in man, the degree of which may depend on fibrinogen level.
\end{abstract}




\section{INTRODUCTION}

Since the 1970s, fish oil has been studied as a nutritional component with antithrombotic potential (1). The protective effect on thrombosis has been attributed to the $\mathrm{n}-3$ polyunsaturated fatty acids (PUFAs), eicosapentaenoic acid (EPA) and docosahexaenoic acid (DHA), which are abundantly present in fish oil. Early epidemiological and intervention studies pointed to a strong association between consumption of n-3 PUFAs and a reduced risk of coronary heart disease, even with only two fish dishes per week $(2,3)$. Currently, a daily intake of $0.3 \mathrm{~g}$ of $\mathrm{n}-3$ PUFAs is recommended for healthy adults and a daily dose up to $1-3 \mathrm{~g}$ for patients with coronary heart disease or hypertriglyceridemia (4).

In spite of thirty years of study, the precise mechanisms of action of n-3 PUFAs are still a matter of debate (5). Established effects include an altered heart and vessel function, a decreased risk for arrhythmias and lowering of blood pressure. Many reports also describe effects on plasma haemostatic variables, but usually with high inter-study variation. Best documented is that n-3 PUFA intake reduces plasma triglycerides levels, while plasma cholesterol is decreased in only few studies (6-8). Part of published studies show -often mild- lowering effects of n-3 PUFA on platelet activation and bleeding time (9).

With respect to coagulation, some trials point to a moderate reduction by fish oil of the plasma levels of fibrinogen and coagulation factors V, VII and X (10-12), whereas other studies fail to detect this $(5,9)$. Since some of these factors require vitamin K-dependent carboxylation for coagulant activity, it was suggested that fish oil interferes with the vitamin $\mathrm{K}$ action. Indeed, in rat, we and others have found that high amounts of dietary $\mathrm{n}-3$ PUFAs reduce the levels of the vitamin K-dependent factors $\mathrm{X}$ and prothrombin $(13,14)$. By continuous measurement of thrombin generation, which provides a highly sensitive method of measuring the coagulant potential of plasma $(15,16)$, we established that this lowering of coagulation factor levels resulted in hypocoagulant activity (14). However, because this hypocoagulant effect in rat was not enlarged by vitamin $\mathrm{K}$ depletion and was accompanied by a reduction in (vitamin $\mathrm{K}$-independent) factor $\mathrm{V}$, the hypocoagulant effect of fish oil has at least partially a vitamin $\mathrm{K}$ independent cause (17). How intake of n-3 PUFAs influences thrombin generation in man is still unknown.

Genetic variation in coagulation factors and adhesive platelet glycoprotein is likely to contribute to the risk for arterial and venous thrombosis $(18,19)$. There is limited evidence that genetic variety may also contribute to the antithrombotic response to nutrition. For instance, the reducing effect of dietary $n-6$ fatty acids on lipoprotein levels has been found to differ between carriers of polymorphisms of several genes encoding for apolipoproteins (20). It is therefore possible that the hypocoagulant effect of n-3 PUFAs is also sensitive to gene-environmental interactions which, in turn, contribute to the variable outcome of fish oil intervention studies.

In the present study, we investigated the effects of fish oil-derived n-3 PUFAs on thrombin generation (reflecting the coagulant potential) in a group of subjects with 
Chapter 5

borderline overweight and thereby slightly increased thrombotic risk. As thrombin generation in plasma is critically dependent on the presence of procoagulant phospholipids (21), this process was measured in the presence of either phospholipid vesicles or autologous platelets. It appeared that fish oil intervention decreased thrombin generation even in the absence of platelets, along with coagulation factors fibrinogen and factor V. Intriguingly, this hypocoagulant effect was clustered in a subgroup with relatively high baseline levels of fibrinogen, who were carrying the $312 \mathrm{~A}$ polymorphism in the fibrinogen- $\alpha$ gene.

\section{MATERIALS AND METHODS}

\section{Subjects and study design}

After full informed consent, 27 healthy males aged $48.5 \pm 9.8$ year (mean $\pm \mathrm{SD}$, median 51 year) enrolled in the study. The volunteers had a body weight of $92.4 \pm 9.9 \mathrm{~kg}$ and body mass index (BMI) of $29.0 \pm 2.5 \mathrm{~kg} / \mathrm{m}^{2}$. They did not suffer from clinical cardiovascular diseases, diabetes mellitus or hypertension, and they did not use cholesterol-lowering, antiplatelet or anticoagulant medication. During the trial, one of the subjects withdrew due to gastrointestinal discomfort, and one other for unknown reasons. Data from these two subjects were not used for analysis. Four subjects were smoking.

Volunteers completed a short dietary questionnaire, indicating that they maintained their normal nutritional, smoking and alcohol consumption pattern, and had not consumed fish or marine products before or during the intervention period. During 4 weeks, the subjects took, in addition to their normal diet, nine soft gelatin capsules per day. Each capsule contained $500 \mathrm{mg}$ fish oil, of which $475 \mathrm{mg}$ was free fatty acids (35\% EPA, $25 \%$ DHA and $10 \%$ other n-3 PUFAs). Total n-3 PUFA intake was $3.0 \mathrm{~g}$ daily. At three times, blood was drawn after overnight fasting: at 4 weeks and just before start of fish oil intake (no treatment values), and after 4-weeks of fish oil intervention. The study protocol was in agreement with the Helsinki declaration and was approved by the local medical ethics committee.

\section{Materials}

The fish oil supplement was a kind gift of Pharma Nord (Vejle, Denmark). Fluorescein isothiocyanate (FITC)-labeled monoclonal PAC-1 antibody came from BectonDickinson (San José, CA); FITC-labeled AK6 antibody against P-selectin (anti-CD62PFITC) was from CLB (Amsterdam, The Netherlands). SFLLRN and benzyloxycarbonyl-Gly-Gly-Arg 7-amido-4-methyl coumarin (Z-GGR-AMC) were purchased from Bachem (Bubendorf, Switzerland). Recombinant human tissue factor was from Dade (Miami, FL). Human thrombin calibrator and thrombogram software were supplied by Synapse (Maastricht, The Netherlands). Coagulation factor-deficient plasmas and kits to determine coagulant proteins were from sources described before. ${ }^{1,2}$ Test kits for determination of antithrombin and protein $\mathrm{C}$ came from Chromogenix 
(Mölndal, Sweden); kits to determine fibrinogen activity and free plasma glycerol were from Roche Diagnostics (Mannheim, Germany), as was high-pure kit for isolation of genomic DNA. An EIA-based kit to determine fibrinogen antigen levels was obtained from Gaubius-TNO (Leiden, The Netherlands). Reagents to determine plasma total cholesterol and high density lipoproteins were from ABX Diagnostics (Montpellier, France), while Sigma (St. Louis, MI) supplied a kit for measurement of total glycerol. DNA primers were synthesized by Eurogentec (Liège, Belgium). Taq DNA Polymerase, buffer and $\mathrm{MgCl}_{2}$ for polymerase chain reaction (PCR) were obtained from Amersham Pharmacia Biotech (Freiburg, Germany). Restriction enzymes with buffers were from the following sources: Hae III and Mnl I from New-England Biolabs (Beverly, MA); EcoR I from Gibco BRL (Breda, The Netherlands); Hind III and dNTP from Fermentas (St. Leon-Rot, Germany); Rsa I from Promega (Leiden, The Netherlands).

\section{Blood collection and preparation}

Blood was collected into open tubes with $129 \mathrm{mmol} / \mathrm{L}$ trisodium citrate (10 vol\%) and in $\mathrm{K}_{2}$ EDTA tubes (Vacutainer Systems, Plymouth, UK). Platelet-rich plasma (PRP) and buffy coats were immediately prepared from citrated blood by centrifugation at $260 \mathrm{~g}$ for 15 minutes. Platelet-free plasma (PFP) was obtained by centrifuging PRP at $870 \mathrm{~g}$ for 10 minutes, followed by two centrifugation steps at $18,000 \mathrm{~g}$ for 10 minutes. Platelet concentration in PRP was determined with a Beckman MicroDiff18 counter (Coulter Electronics, Luton, UK) and normalized to 30 or $150 \times 10^{9}$ platelets/L with autologous PFP. The PRP was used within 90 minutes. Buffy coats and PFP were snap-frozen in liquid nitrogen and stored at $-80^{\circ} \mathrm{C}$ for later coagulation measurements.

Standard hematological parameters were determined in EDTA-anticoagulated blood; remaining EDTA-anticoagulated blood was centrifuged twice at $870 \mathrm{~g}$ for 10 minutes. Collected plasma was stored at $-80^{\circ} \mathrm{C}$ for lipid analysis.

\section{Plasma lipids and coagulation factors}

In EDTA-anticoagulated plasma, total and free glycerol as well as total cholesterol and cholesterol in high density lipoproteins were measured using commercially available test kits. Triglycerides were determined by subtracting levels of free glycerol from total glycerol. Plasma levels of coagulation factors II and VII (14) and of factors V and X (17) were measured at two dilutions using factor-deficient plasmas, as described. Levels of protein $\mathrm{C}$ and antithrombin were determined with test kits from Chromogenix, following the manufacturer's instructions. Factor levels were expressed as percentages of activity compared to a 'normal' plasma pool of 40 healthy subjects (males and females). Basal levels of antithrombin in the subjects participating in the intervention study were below 'normal', probably because of their sex, age, and high BMI (22). Fibrinogen activity in plasma was determined according to Claus (test variability about $3 \%$ ) (23). In addition, total fibrinogen concentrations in plasma were measured with an in-house EIA that uses a pool of rabbit anti-human fibrinogen IgGs as catching 
antibodies (24), and a peroxidase-conjugated monoclonal antibody against fragment DD (DD13) as tagging antibody (25).

Plasma partially deficient in fibrinogen or factor $\mathrm{V}$ was prepared by mixing normal pooled plasma with the respective factor deficient plasma. Plasma enriched in fibrinogen or factor $\mathrm{V}$ was obtained by addition of respective purified human factor to normal pooled plasma. Levels of fibrinogen or factor $\mathrm{V}$ were checked after reconstitution of these plasma samples.

\section{Flow cytometry}

Activated integrin $\alpha I I b \beta 3$ and surface exposure of P-selectin on platelets was determined in duplicate using flow cytometry on an Epics-XL flow cytometer from Coulter Electronics (Luton, UK). For integrin activation, PRP containing $30 \times 10^{9}$ platelets/L was activated with sub-maximal SFLLRN $(5 \mu \mathrm{M}, 10 \mathrm{~min})$ in the presence of FITC-labeled PAC-1 antibody against activated $\alpha \operatorname{IIb} \beta 3$. To measure P-selectin exposure, PRP was stimulated with SFLLRN, diluted 30-times with phosphate-buffered saline, and incubated with FITC-labeled anti-CD62P antibody. Fractions of platelets expressing activated $\alpha \operatorname{IIb} \beta 3$ or P-selectin were determined from at least 10,000 events.

\section{Thrombin generation measurements}

Thrombin generation (thrombogram method) was measured in PRP and PFP, basically following described procedures (26). Contact activation of plasma was minimized by using hydrophobic materials. Briefly, triplicate samples of $80 \mu \mathrm{L}$ freshly isolated PRP $\left(150 \times 10^{9}\right.$ platelets $\left./ \mathrm{L}\right)$ were pipetted into a 96 -wells plate, containing $20 \mu \mathrm{L}$ recombinant tissue factor $(3 \mathrm{pmol} / \mathrm{L})$ in buffer A $(20 \mathrm{mmol} / \mathrm{L}$ Hepes, $140 \mathrm{mmol} / \mathrm{L} \mathrm{NaCl}, 5 \mathrm{mg} / \mathrm{mL}$ bovine serum albumin, $\mathrm{pH}$ 7.35). Polystyrene well plates (Immulon 2HB, Dynex Technologies, Chantilly, VA) were used, which were selected for minimal contact activation. The plate was inserted into a Fluoroskan Ascent well-plate reader (Thermo Labsystems, Helsinki, Finland), and pre-heated to $37^{\circ} \mathrm{C}$. Coagulation was started by automated addition of $20 \mu \mathrm{L}$ fluorescent thrombin substrate (Z-GGR-AMC, 2.5 $\mathrm{mmol} / \mathrm{L})$, suspended in buffer B $(20 \mathrm{mmol} / \mathrm{L}$ Hepes, $0.1 \mathrm{~mol} / \mathrm{L} \mathrm{CaCl}, 60 \mathrm{mg} / \mathrm{mL}$ bovine serum albumin, $\mathrm{pH}$ 7.35) under shaking. Final tissue factor concentration in experiments with PRP was $0.5 \mathrm{pmol} / \mathrm{L}$. When using PFP instead of PRP, $4 \mu \mathrm{mol} / \mathrm{L}$ phospholipids (phosphatidylserine : phosphatidylcholine : phosphatidylethanolamine, 1:3:1) were present, and coagulation was triggered with $5 \mathrm{pmol} / \mathrm{L}$ tissue factor (f.c.). In the absence of tissue factor, the lag-time of onset of thrombin generation was $>50 \mathrm{~min}$. Addition of corn trypsin inhibitor $(50 \mu \mathrm{g} / \mathrm{mL})$ to block the intrinsic coagulation system did not significantly alter the thrombin generation curves (data not shown). Thrombin generation curves with PRP had a long lag-time, which depended on the slow rate of phosphatidylserine exposure of platelets under these conditions (16).

Fluorescence accumulation was semi-continuously measured in time at excitation and emission wavelengths of 390 and $460 \mathrm{~nm}$, respectively $\left(37^{\circ} \mathrm{C}\right)$. First-derivative curves 
of accumulation of fluorescence intensity were converted into curves of nanomolar of thrombin using human thrombin calibrator and thrombinoscope software to correct for non-linearity of fluorescence with AMC concentration, depletion of fluorescent substrate, and fluorescence accumulation due to non-coagulant $\alpha_{2}$-macroglobulin-bound thrombin as described (26). The calibration samples contained the same plasma, to which a fixed amount of stable thrombin calibrator was added. In each analytical sample, deviation of fluorescence accumulation from linearity was corrected in one single step by comparing the fluorescence curve of the sample with the corresponding calibrator curve. Thrombograms were always run in triplicate, and analyzed on time to thrombin peak, peak height (indicative of maximal rate of thrombin formation), and area-under-the-curve or endogenous thrombin potential (ETP), reflecting the activity of thrombin during the total coagulation process. The assay variability of obtained thrombogram parameters, when measured repeatedly with the same plasma sample, was $<3 \%$ (26). Described intra-individual coefficients of variation of this assay with PFP/phospholipids were about $4.5 \%$ for time-to-peak, peak height and ETP. Variation coefficients of the assay with PRP were $5 \%$ for time-to-peak and $8-9 \%$ for peak height and ETP (16).

Activated protein $C$ (APC) resistance was measured with a modified thrombin generation test. A normalized APC sensitivity ratio (nAPCsr), indicative of APC resistance, was determined as the ratio of the amounts of $\alpha_{2}$-macroglobulin-thrombin complex present in plasma activated in the presence and absence of APC, divided by the same ratio determined in normal pooled plasma (27).

\section{Isolation of DNA and determination of genetic polymorphisms}

Leukocyte DNA was isolated from blood buffy coats using a high-pure kit according to instructions of the manufacturer (Roche). Polymorphisms were determined using PCR primers suitable for analysis by RFLP as described: factor V A4070G $\left(\mathrm{R}_{2} \mathrm{FV}\right)(28)$ and G1691A (FV Leiden $)$ (29); fibrinogen- $\alpha$ T312A (30); fibrinogen- $\beta$ C-148T and G-854A (31); fibrinogen- $\beta$ G-455A (32). PCR was for 30-35 cycles (temperature conditions according to characteristics of the primers) with $50 \mathrm{ng}$ isolated DNA, dNTPs (2 mmol/L of each), $1.5 \mathrm{mmol} / \mathrm{L} \mathrm{MgCl}_{2}$, forward and reverse primers $(10 \mu \mathrm{mol} / \mathrm{L})$, Taq polymerase $(5 \mathrm{U} / \mu \mathrm{L})$ and suitable PCR buffer. Housekeeping $\beta$-actin gene was co-amplified to control for quality of the isolated DNA. Generated PCR fragments and endonuclease digestion products were controlled for purity and fragment size by electrophoresis on ethidium bromide-stained agarose gels.

\section{Statistics}

To determine the effect of fish oil, per individual the values from two baseline blood samples were averaged and then subtracted from the value obtained after intake of fish oil. For statistical analysis, non-parametric tests were used, because some of the parameters were not distributed in a normal way. Per parameter, the differences between 
baseline samples were statistically compared to the effect of fish oil intake with the Wilcoxon signed rank-test. Correlation between individual parameters was determined with a Spearman test. Contribution of various coagulation factors to thrombin generation was evaluated by multivariate regression analysis. Mann-Whitney $U$ test was used to compare genotypic groups. Tests were carried out with the statistical package for the social sciences (SPSS, Chicago, IL).

\section{RESULTS}

\section{Effects of fish oil intervention on coagulation factor levels and on thrombin generation in the presence and absence of platelets}

Twenty-five healthy male subjects, aged $48.5 \pm 9.8$ years (mean \pm SD), with borderline overweight (BMI of $29.0 \pm 2.5 \mathrm{~kg} / \mathrm{m}^{2}$ ) participated in the fish oil study. The intervention consisted of intake of capsules with $3.0 \mathrm{~g} \mathrm{n}-3$ PUFAs per day during 4 weeks, which was equivalent to on average $32.8 \mathrm{mg} \mathrm{n}-3$ PUFAs per $\mathrm{kg}$ body weight daily. Blood samples were taken 4 weeks prior, immediately prior, and 4 weeks after of fish oil treatment. In baseline blood samples, all 25 subjects had normal counts of platelets $\left(215 \pm 9 \times 10^{9} / \mathrm{L}\right)$, erythrocytes $\left(5.2 \pm 0.1 \times 10^{12} / \mathrm{L}\right)$ and leukocytes $\left(6.6 \pm 0.4 \times 10^{9} / \mathrm{L}\right)$. Fish oil intake did not affect these parameters. The intervention resulted in significantly lower levels of plasma triglycerides, which is a common effect of fish oil. In contrast, cholesterol in LDL was tended to be increased (borderline significant, Table 1).

Table 1: Effect of fish oil on plasma lipid levels and haemostatic parameters. Levels or activities (\% of normal pooled plasma) were measured 4 weeks prior, immediately prior, and 4 weeks after of fish oil treatment. There were no systematic differences between the two baseline samples. Shown are averaged values before treatment and values after fish oil intake, further percent differences (calculated per subject) between pre-treatment values and fish oil effect ( $\Delta$ no treatment and $\triangle$ fish oil). Mean \pm SE $(n=25) .{ }^{*} P<0.1$ and ${ }^{* *} P<0.05$ (Wilcoxon).

\begin{tabular}{lllll}
\hline & No treatment & After fish oil & $\begin{array}{l}\Delta \text { No treatment } \\
(\%)\end{array}$ & $\begin{array}{l}\Delta \text { Fish oil } \\
(\%)\end{array}$ \\
\hline Lipids & & & & \\
$\quad$ Triglycerides (mmol/L) & $1.59 \pm 0.23$ & $1.33 \pm 0.16$ & $+2.6 \pm 8.3$ & $-10.4 \pm 5.0^{* *}$ \\
Total cholesterol (mmol/L) & $5.64 \pm 0.25$ & $5.70 \pm 0.27$ & $+2.5 \pm 1.7$ & $+1.1 \pm 1.6$ \\
LDL cholesterol (mmol/L) & $3.91 \pm 0.26$ & $4.07 \pm 0.27$ & $+2.2 \pm 2.9$ & $+5.7 \pm 3.4^{*}$ \\
Factors & & & & $-1.2 \pm 1.9$ \\
Fibrinogen (g/L) & $3.39 \pm 0.11$ & $3.29 \pm 0.13$ & $+1.6 \pm 0.7^{*}$ & $+0.4 \pm 0.9$ \\
Prothrombin (\%) & $101.6 \pm 1.9$ & $102.1 \pm 2.3$ & $-0.9 \pm 1.6$ & $-3.1 \pm 1.5^{* *}$ \\
Factor V (\%) & $100.8 \pm 3.7$ & $97.6 \pm 3.8$ & $-1.4 \pm 2.0$ & $-0.3 \pm 1.3$ \\
Factor VII (\%) & $102.7 \pm 3.0$ & $102.5 \pm 3.3$ & $+0.7 \pm 0.9$ & $-1.2 \pm 0.8$ \\
Factor X (\%) & $103.0 \pm 2.2$ & $101.8 \pm 2.4$ & $+2.0 \pm 1.0$ & $-0.4 \pm 1.2$ \\
Antithrombin (\%) & $84.1 \pm 1.3$ & $83.6 \pm 1.2$ & $+1.6 \pm 1.1$ & $+1.8 \pm 1.3$ \\
Protein C (\%) & $108.5 \pm 2.3$ & $110.4 \pm 2.7$ & + & \\
\hline
\end{tabular}


As a sensitive way to monitor the coagulant potential under hypocoagulant conditions, we measured thrombin generation in tissue factor-triggered plasma following the thrombogram method (15). To provide procoagulant phospholipids, plasma was supplied with platelets (PRP of standardized platelet count) or with a non-limiting concentration of $4 \mu \mathrm{mol} / \mathrm{L}$ phospholipids (PFP/phospholipids). Coagulation in PRP was initiated with a low concentration tissue factor $(0.5 \mathrm{pmol} / \mathrm{L})$, sufficient to start intrinsic coagulation and to detect platelet-dependent effects. Coagulation in PFP/phospholipids was triggered with optimal tissue factor $(5 \mathrm{pmol} / \mathrm{L})$. The thrombograms were analyzed on the following parameters: time to thrombin peak; peak height (indicative of maximal rate of thrombin formation); and area-under-the-curve or endogenous thrombin potential (ETP), reflecting total activity of thrombin during coagulation. Under these experimental conditions with PRP or PFP/phospholipids, thrombin generation relied on the extrinsic coagulation pathway and had an assay variability below $3 \%(26)$.

Table 2: Effect of fish oil on platelet activation and thrombin generation. Shown are averaged values before treatment and values after fish oil intake, as well as difference between these ( $\Delta$ no treatment and $\Delta$ fish oil). Platelets were stimulated with $5 \mu \mathrm{mol} / \mathrm{L}$ SFLLRN and exposure of activated $\alpha \mathrm{IIb} \beta 3$ integrin and of P-selectin was evaluated. Thrombin generation in plasma was measured as indicated for Figure 1. nAPCsr was determined from thrombin generation in the presence and absence of APC. Mean \pm SE $(n=25) . * P<0.1$ and $* * P<0.05$ (Wilcoxon).

\begin{tabular}{|c|c|c|c|c|}
\hline & No treatment & After fish oil & $\begin{array}{l}\Delta N_{0} \text { treatment } \\
(\%)\end{array}$ & $\begin{array}{l}\Delta \text { Fish oil } \\
(\%)\end{array}$ \\
\hline \multicolumn{5}{|l|}{ Platelet activation } \\
\hline$\alpha \operatorname{IIb} \beta 3$ (\% pos. cells) & $55.4 \pm 5.5$ & $45.6 \pm 6.2$ & $+8.0 \pm 12.2$ & $-18.4 \pm 10.6^{* *}$ \\
\hline P-selectin (\% pos. cells) & $48.1 \pm 2.9$ & $44.6 \pm 5.0$ & $+9.2 \pm 10.7$ & $-3.0 \pm 12.8$ \\
\hline \multicolumn{5}{|c|}{ Thrombin generation with platelets } \\
\hline Time-to-peak (min) & $25.7 \pm 0.6$ & $27.0 \pm 0.7$ & $+0.6 \pm 2.2$ & $+5.6 \pm 2.5^{*}$ \\
\hline Thrombin peak (nmol/L) & $118 \pm 5$ & $101 \pm 5$ & $+3.1 \pm 5.9$ & $-13.9 \pm 3.7^{* *}$ \\
\hline $\mathrm{ETP}(\mathrm{nmol} / \mathrm{L} \times \mathrm{min})$ & $1524 \pm 50$ & $1369 \pm 61$ & $+0.4 \pm 3.0$ & $-9.8 \pm 3.2^{* *}$ \\
\hline \multicolumn{5}{|c|}{ Thrombin generation with phospholipids } \\
\hline Time-to-peak (min) & $5.6 \pm 0.2$ & $5.8 \pm 0.2$ & $+1.6 \pm 2.0$ & $+4.2 \pm 1.7 * *$ \\
\hline Thrombin peak (nmol/L) & $305 \pm 9$ & $294 \pm 9$ & $+2.7 \pm 3.1$ & $-3.0 \pm 2.3^{*}$ \\
\hline $\operatorname{ETP}(\mathrm{nmol} / \mathrm{L} \times \mathrm{min})$ & $1847 \pm 48$ & $1805 \pm 50$ & $+3.3 \pm 1.6^{*}$ & $-2.1 \pm 1.6^{*}$ \\
\hline \multicolumn{5}{|l|}{$A P C$ resistance } \\
\hline nAPCsr & $1.17 \pm 0.16$ & $1.20 \pm 0.17$ & $+6.0 \pm 4.9$ & $+3.8 \pm 4.5$ \\
\hline
\end{tabular}


Before fish oil intervention, thrombin generation curves greatly differed between plasmas from the 25 subjects, as apparent from the high variation in thrombin peak heights and ETP levels (Figure 1A). The inter-subject variation coefficients of ETP with PRP and PFP/phospholipids ( $16.5 \%$ and $13.1 \%$, respectively) were much higher than intra-subject variation coefficients (about $4.5 \%$ ). Typically, ETP levels in the presence and absence of platelets were strongly correlated with $R^{2}=0.48$ and $P=0.001$ (Figure 1B). Thus, those subjects whose plasmas displayed relative high thrombin generation with platelets also had high thrombin generation with phospholipids present (Figure 1A). This indicated that much of the subject-dependent variability in thrombin generation with platelets was due to variant activity of the coagulation. No differences were seen in thrombogram parameters between two plasma samples taken before the intervention (Table 2).
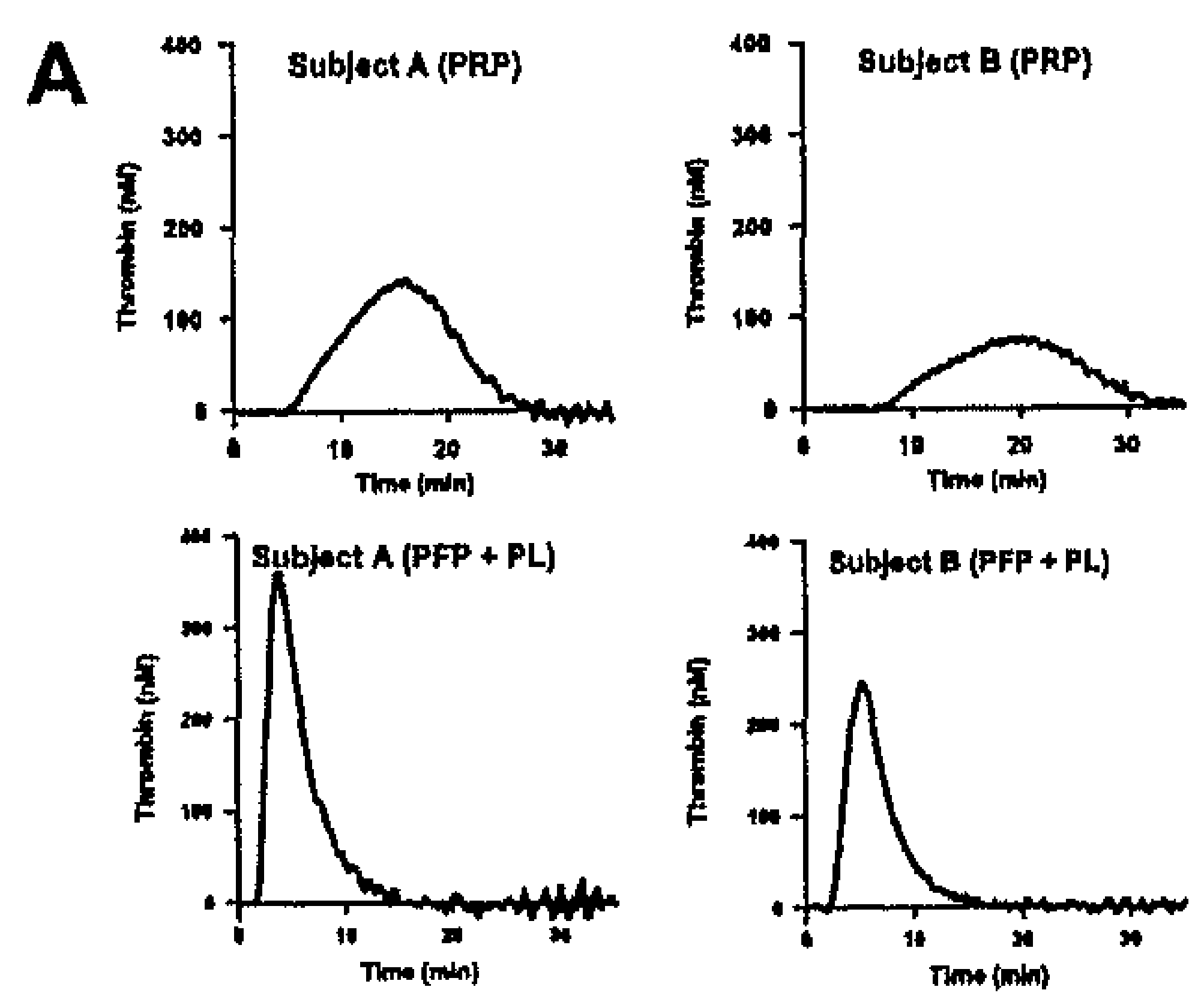

B

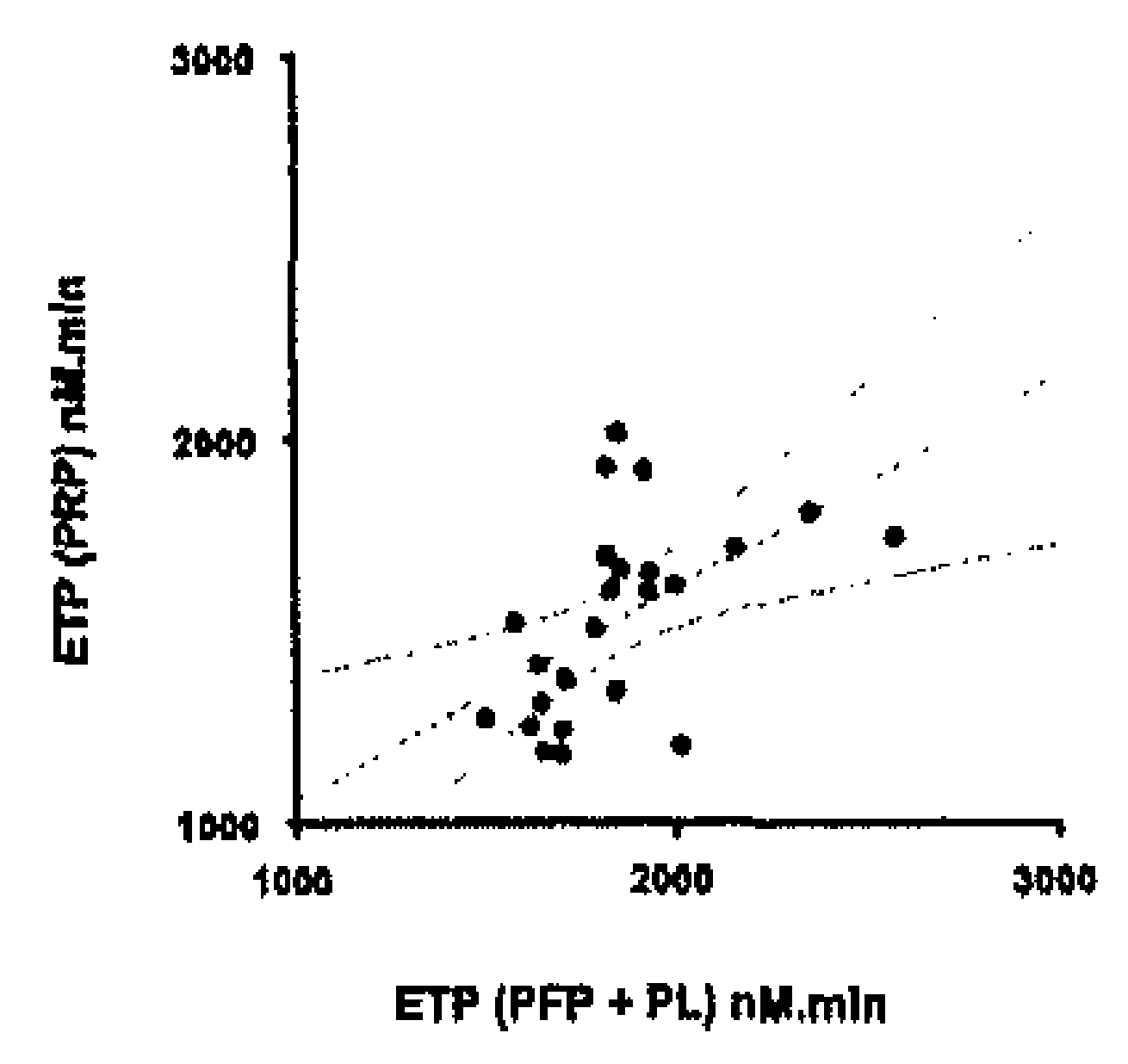

C

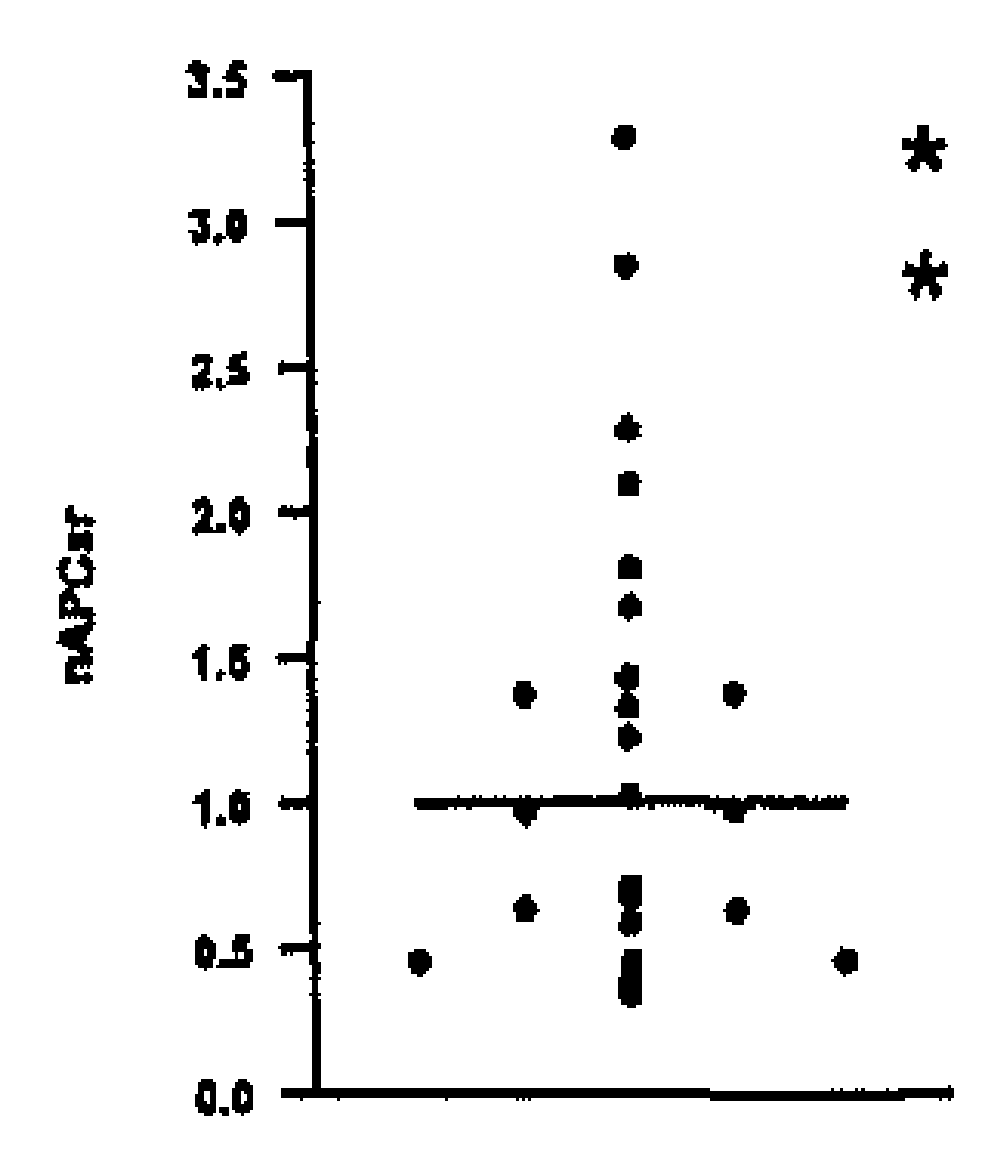

Figure 1. Inter-subject variation in thrombin generation. (A) Tissue factor-induced thrombin generation in plasma from 2 representative subjects with either $100 \times 10^{9}$ platelets/L (PRP) or $4 \mu \mathrm{mol} / \mathrm{L}$ phospholipids (PFP+PL). Note the high curves for subject A in comparison to subject B. (B) Correlation between ETP levels determined in plasma from all 25 subjects in the presence of platelets and with phospholipids $(95 \%$ confidence interval is shown, $R^{2}=0.48, P=0.001$ ). (C) Normalized APC sensitivity ratio (nAPCsr) determined in plasma from the 25 subjects. Heterozygous factor $\mathrm{V}^{\text {Leiden }}$ carriers are indicated by a $\operatorname{star}\left({ }^{*}\right)$. 
In addition, thrombin generation was measured in the presence and absence of activated protein C (APC) to determine the sensitivity of factor Va towards inactivation by APC. This reaction is sensitive to lipid (steroid) plasma components (27). The results were expressed as normalized APC sensitivity ratio (nAPCsr), which by definition has a value of 1.0 in normal pooled plasma (27). Before intervention, plasmas from the 25 subjects displayed variable nAPCsr values, with 2 subjects showing a nAPCsr $>2.5$ (Figure 1C).

When averaged for all 25 subjects, thrombogram parameters of PRP were significantly altered after 4 weeks of fish oil intake. The intervention significantly prolonged the time-to-peak, and decreased the peak height and the ETP by more than 10\% (Table 2). With PFP/phospholipids, fish oil prolonged the time-to-peak and had a smaller (borderline significant) effect on peak height and ETP of about 3\%. Typically, in some but not in all subjects, fish oil intake resulted in a decreased thrombin generation (Figure 2). The intervention did not significantly influence nAPCsr, indicating that factor $\mathrm{Va}$ inactivation remained unchanged. These data thus indicate that the reducing effect of fish oil on coagulant potential in the presence and absence of platelets is due to reduced thrombin formation, rather than to increased APC-dependent factor Va inactivation or increased thrombin inhibition.
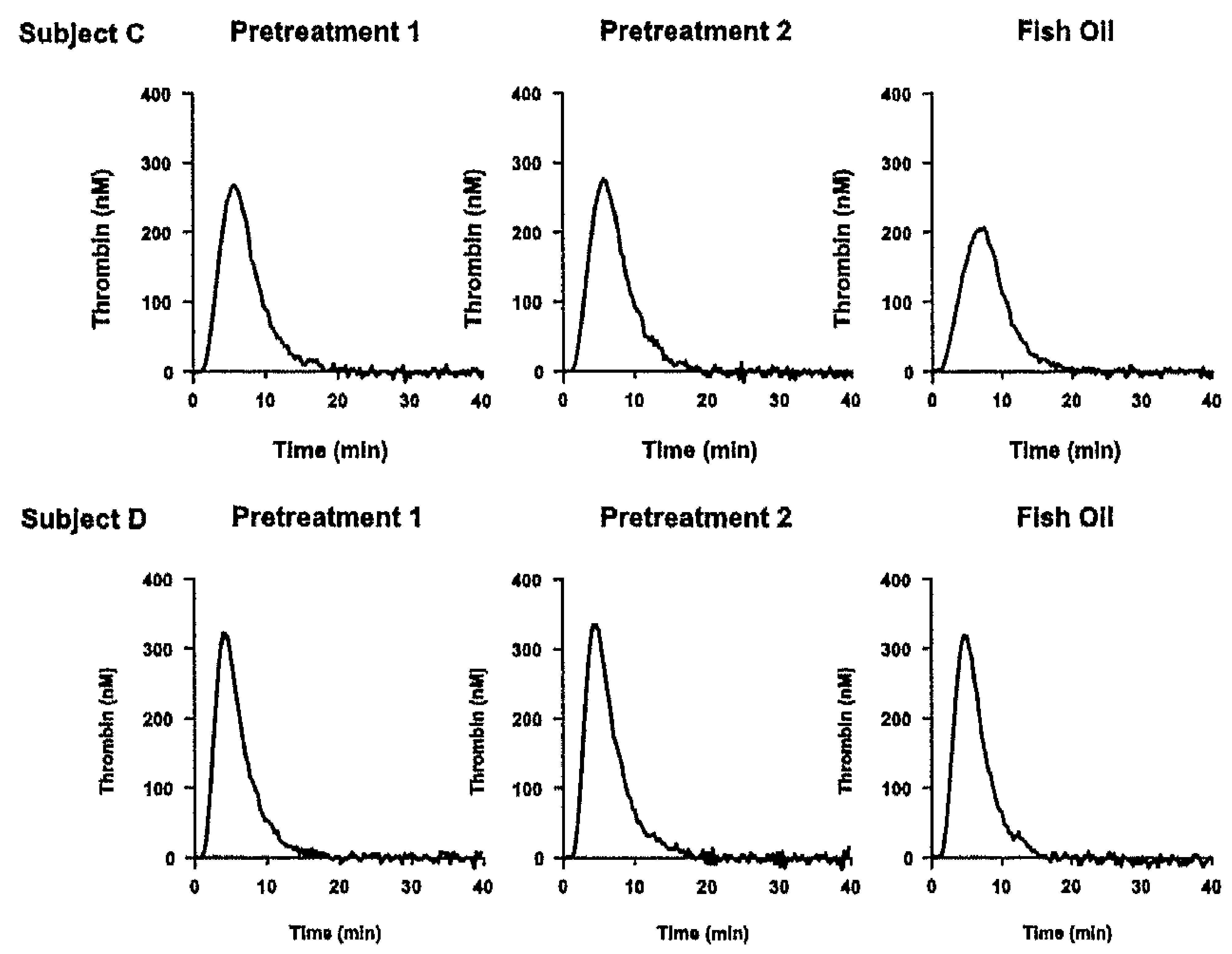

Fish Oll

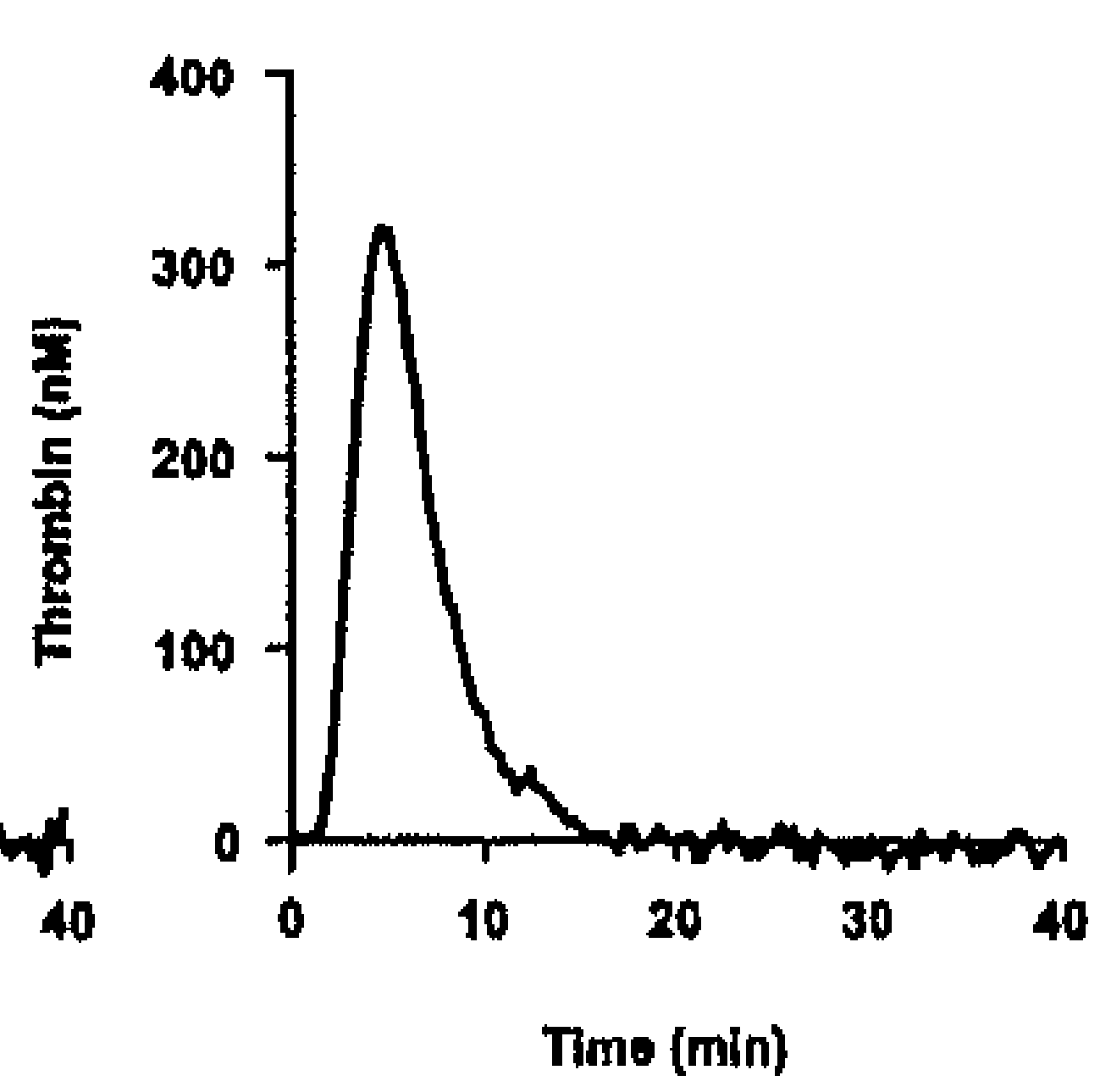

Figure 2. Variable effect of fish oil on thrombin generation. Thrombograms are given of plasma (PFP+PL) before and after fish oil intake from two representative subjects with different intervention responses (conditions as in Figure 1). For subject C, fish oil resulted in a $20 \%$ reduction in ETP, accompanied by a $7 \%$ reduction in fibrinogen. Fish oil did not alter ETP or fibrinogen in plasma from subject D. 


\section{Contribution of fibrinogen and factor V to fish oil effect on thrombin generation}

By multivariate regression analysis, the contribution of plasma (anti)coagulant factors to the large inter-subject variation in thrombin generation was evaluated. Comparison of pre-intervention values of the 25 subjects (Table 2) showed that levels of prothrombin and antithrombin were main determinants of ETP with PFP/phospholipids $\left(R^{2}=0.26\right.$, $P=0.042$ ). This is in agreement with published kinetic data (33). The levels of only fibrinogen and factor $V$ further contributed to the ETP variation. Together, these four factors explained about $30 \%$ of the variation of peak height and $\operatorname{ETP}\left(R^{2}=0.31\right.$, $P=0.036)$. The vitamin $\mathrm{K}$-dependent factor $\mathrm{VII}$, factor $\mathrm{X}$ and protein $\mathrm{C}$, which were covariants $(P<0.03)$, only determined the time-to-peak $(P<0.046)$, but did not further contribute to peak height and ETP level.
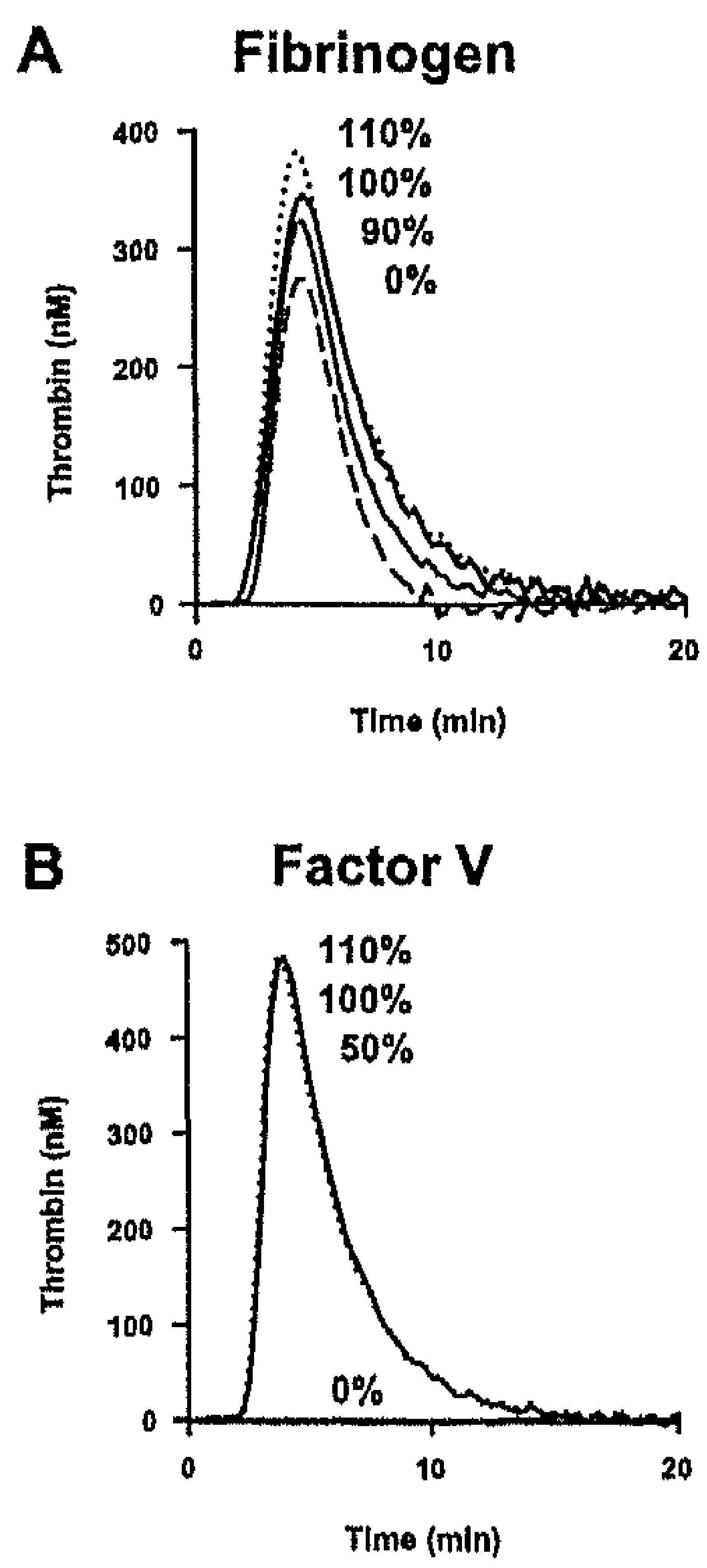

Figure 3. Effect of fibrinogen and factor $\mathrm{V}$ on thrombin generation. Normal pooled plasma was prepared with variable concentrations of human fibrinogen or factor $V$. Tissue factor-induced thrombin generation was measured with $4 \mu \mathrm{mol} / \mathrm{L}$ phospholipids at the following conditions: (A) $0-110 \%$ fibrinogen and $100 \%$ factor $\mathrm{V}$; (B) $0-110 \%$ factor $\mathrm{V}$ and $100 \%$ fibrinogen. Curves of nanomolar thrombin concentrations were obtained by using separate calibrator traces for each different sample, to eliminate differences in light scatter. Indicated factor levels (compared to normal pooled plasma) were always checked in the reconstituted plasma samples. Data are representative for 3 or more experiments. Thrombin generation curves with plasmas from carriers of 1299Arg and His 1299 factor $V$ gave the same factor V dependency. 
Multi-regression analysis of data from all subjects was also used to determine whether the fish oil effect on coagulation factor levels could explain its effect on thrombin generation. For PFP, the fish oil-evoked reduction in ETP significantly correlated with the reduction in fibrinogen or factor $\mathrm{V}$ level of $R=0.48(P=0.015)$ or $R=0.41(P=0.045)$, respectively. The variable decrease in thrombin peak-height also correlated with the reduction in factor $\mathrm{V}(P=0.041)$, while the increase in lag-time of thrombin formation correlated with the reduction in fibrinogen $(P=0.021)$. Also in PRP, the intervention effects on ETP and factor $V$ level were correlated $(P=0.016)$, but not those on ETP and fibrinogen level $(P=0.77)$. An indication that variable fibrinogen did contribute to thrombin generation in PRP came from reanalysis of calibrated curves; fish oil effects on thrombogram peak height were correlated with fibrinogen level $(P=0.048, n=11)$. On the other hand, there was no correlation between the fish oil effect on $\alpha I I b \beta 3$ integrin activation and on thrombin generation in PRP (Table 2).

Control experiments were carried out to determine whether changes in fibrinogen and factor $\mathrm{V}$ could indeed influence thrombogram characteristics. Figure 3 shows that addition of $10 \%$ human fibrinogen to normal pooled PFP/phospholipids resulted in increased thrombin generation, as indicated by higher thrombin peak and ETP levels. Partial depletion of fibrinogen but not factor $V$ led to decreased thrombin generation. Complete depletion of factor $\mathrm{V}$ but not of fibrinogen abolished thrombin generation.

\section{Genetic variation in fibrinogen and factor V to hypocoagulant fish oil effect}

Given the high variation in thrombograms between subjects, we explored the possibility that genetic variation in fibrinogen and factor $\mathrm{V}$ contributed to the variable effects of fish oil intervention on the coagulant potential. As a start, common polymorphisms in fibrinogen- $\alpha / \beta$ and factor $V$ genes were determined that have been associated with an increased risk of thrombosis. With respect to the fibrinogen $\beta$ gene, 11 subjects were carrying the less common allele of all the G-854A, G-455A and C-148T polymorphisms (1 homozygous), which are known to be in linkage disequilibrium. For these polymorphisms, we did not find associations with ETP or fish oil effects on ETP. In contrast, 10 subjects carrying the $312 \mathrm{Ala}$ allele of the fibrinogen$\alpha$ T312A polymorphism (30), had higher baseline levels of fibrinogen and a greater reduction in fibrinogen upon fish oil consumption ( $P=0.008$ and 0.021 , respectively) in comparison to the 15 non-carriers (Figure $4 \mathrm{~A}$ ). Fibrinogen reduction in the group of carriers correlated with the decrease in thrombin generation after fish oil $(P=0.048)$. Analysis of data from all subjects indicated that the 312Ala carriers were responsible for the fish oil effect on fibrinogen and thrombin generation. In the heterozygote TA group, the average decrease in fibrinogen was $8 \%$, while in the homozygote TT group fibrinogen increased with $0.5 \%$ (Figure 4B).

Five out of 25 subjects carried the less common 1299Arg allele of the A4070G polymorphism of factor $V$, which is invariably associated with the HR2 haplotype (28, 34). These carriers had lower factor $V$ levels than non-carriers both before and after the intervention period $(P=0.032$ and 0.035 , respectively). They had a tendency to greater 
factor $\mathrm{V}$ reduction with fish oil $(P=0.06)$ in comparison to non-carriers, which correlated with the reduced thrombin generation (Figure 4C-D). Two subjects carried the $\mathrm{Gln} 506$ (factor $\mathrm{V}_{\text {Leiden }}$ ) allele of the G1691A factor $\mathrm{V}$ polymorphism. They were responsible for the high nAPCsr levels $>2.5$ (Figure 1C), which is in agreement with expected APC resistance (35), but they did not show particular responses to fish oil.

With respect to platelet receptors, 12 subjects carried the high-risk 807T variant of integrin- $\alpha 2$, and 5 subjects the Leu33 $\left(\mathrm{Pl}^{\mathrm{A} 2}\right)$ variant of the $\mathrm{C} 1565 \mathrm{~T}$ integrin- $\beta 3$ polymorphism. Thrombograms of PRP with or without fish oil were not different between carriers and non-carriers $(P>0.073)$.

Fibrinogen- $\alpha$

312Thr (wildype)

A

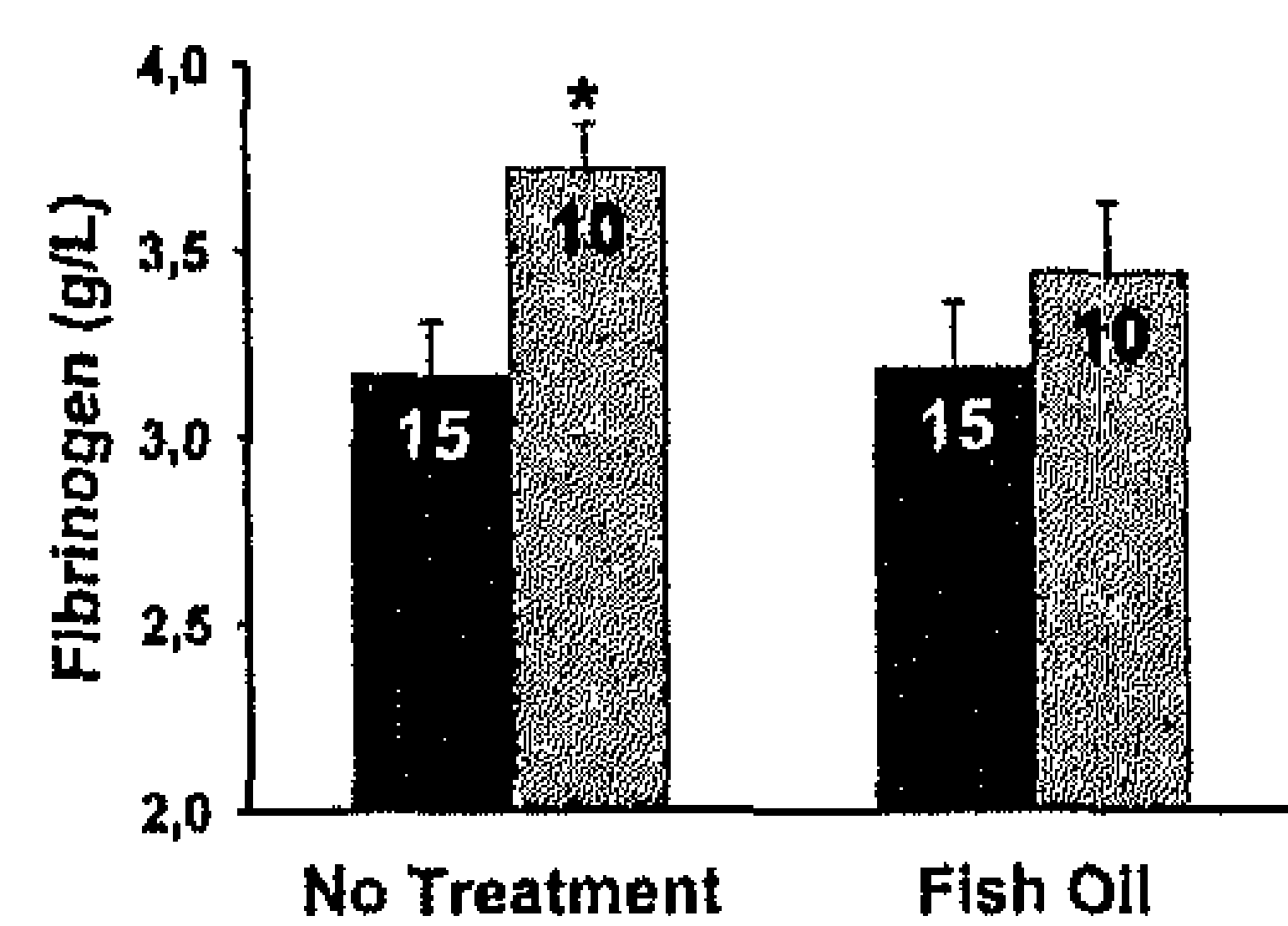

B

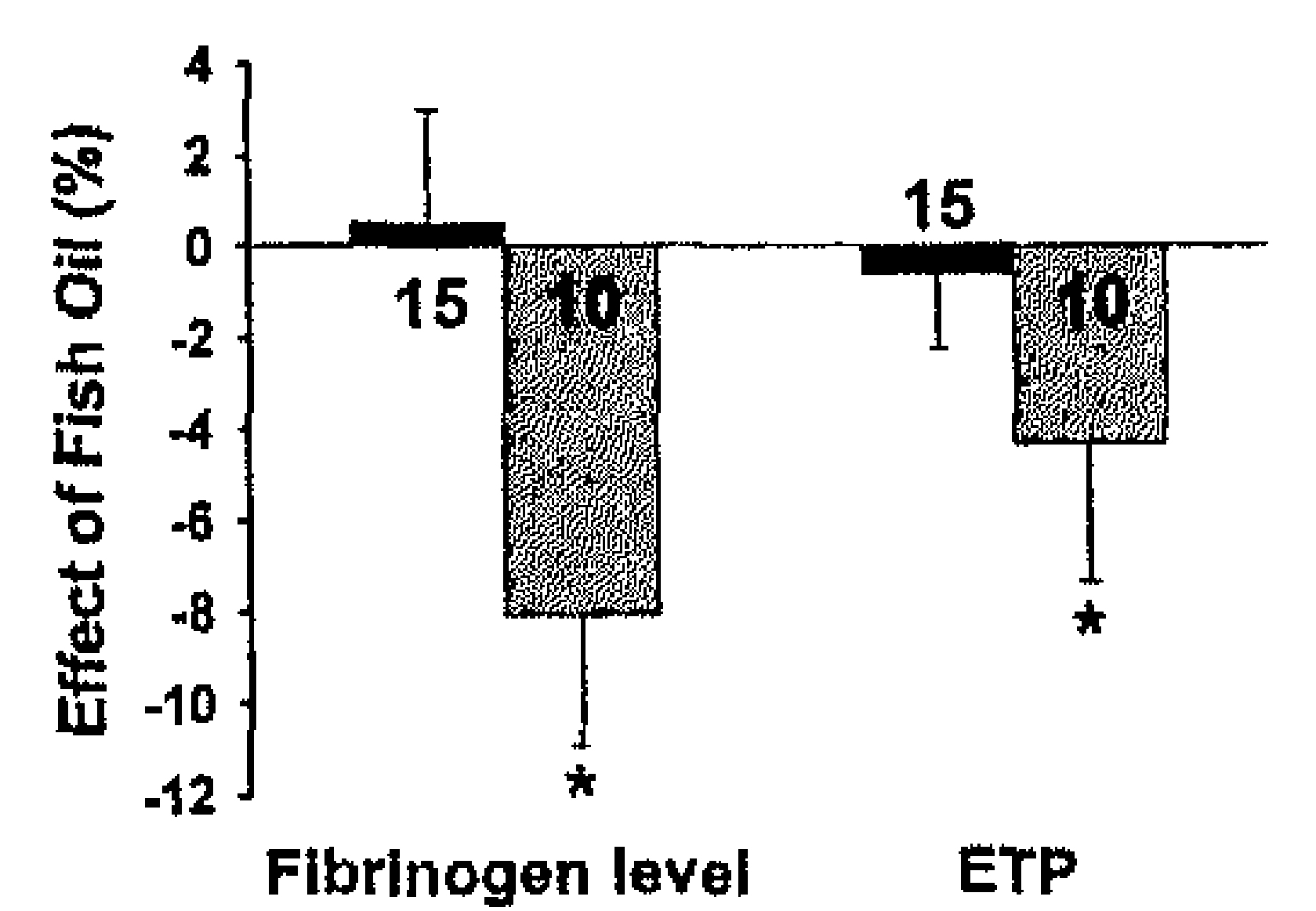

Factor $V$ 1299his (wildtype)

C

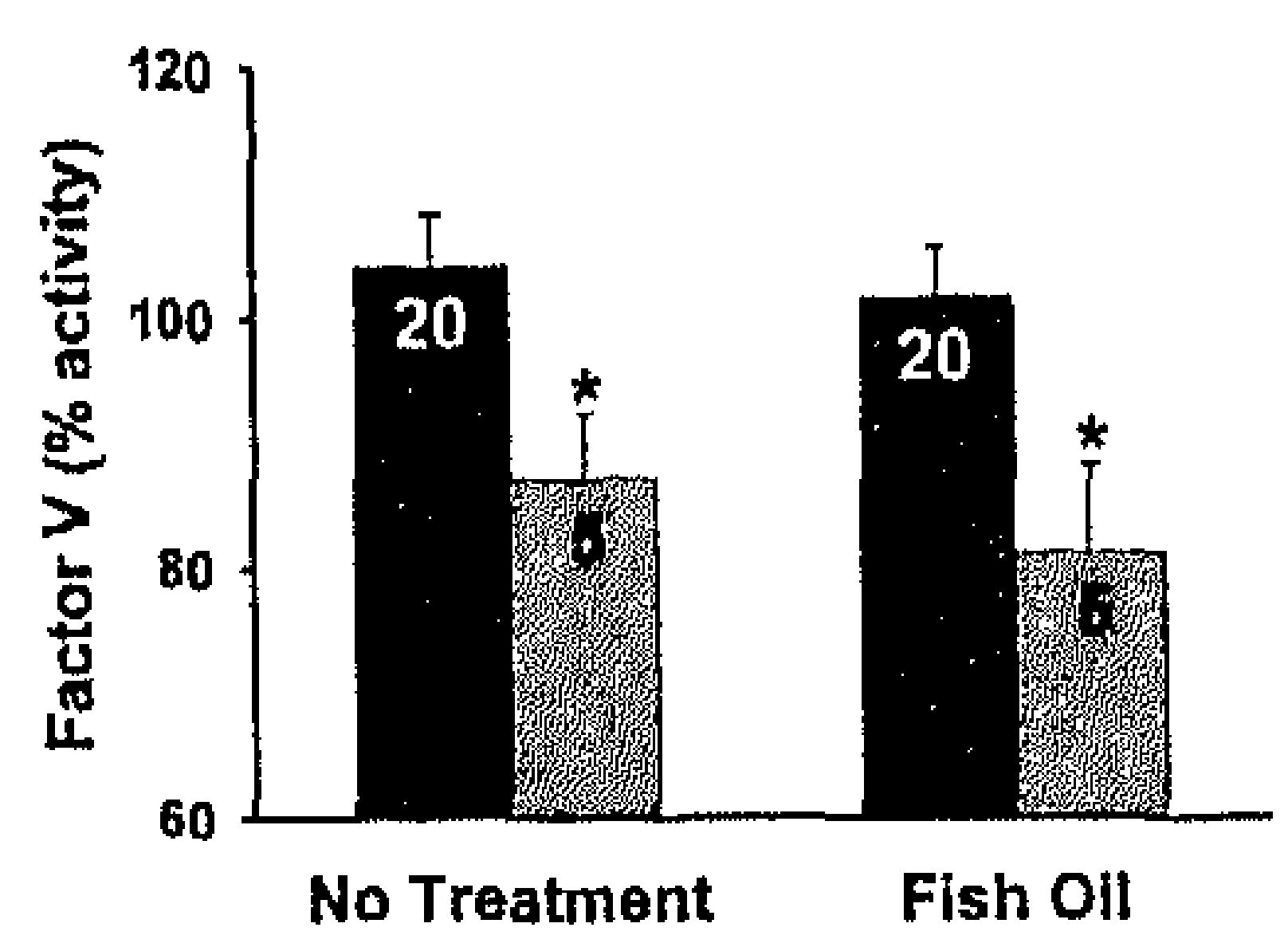

D

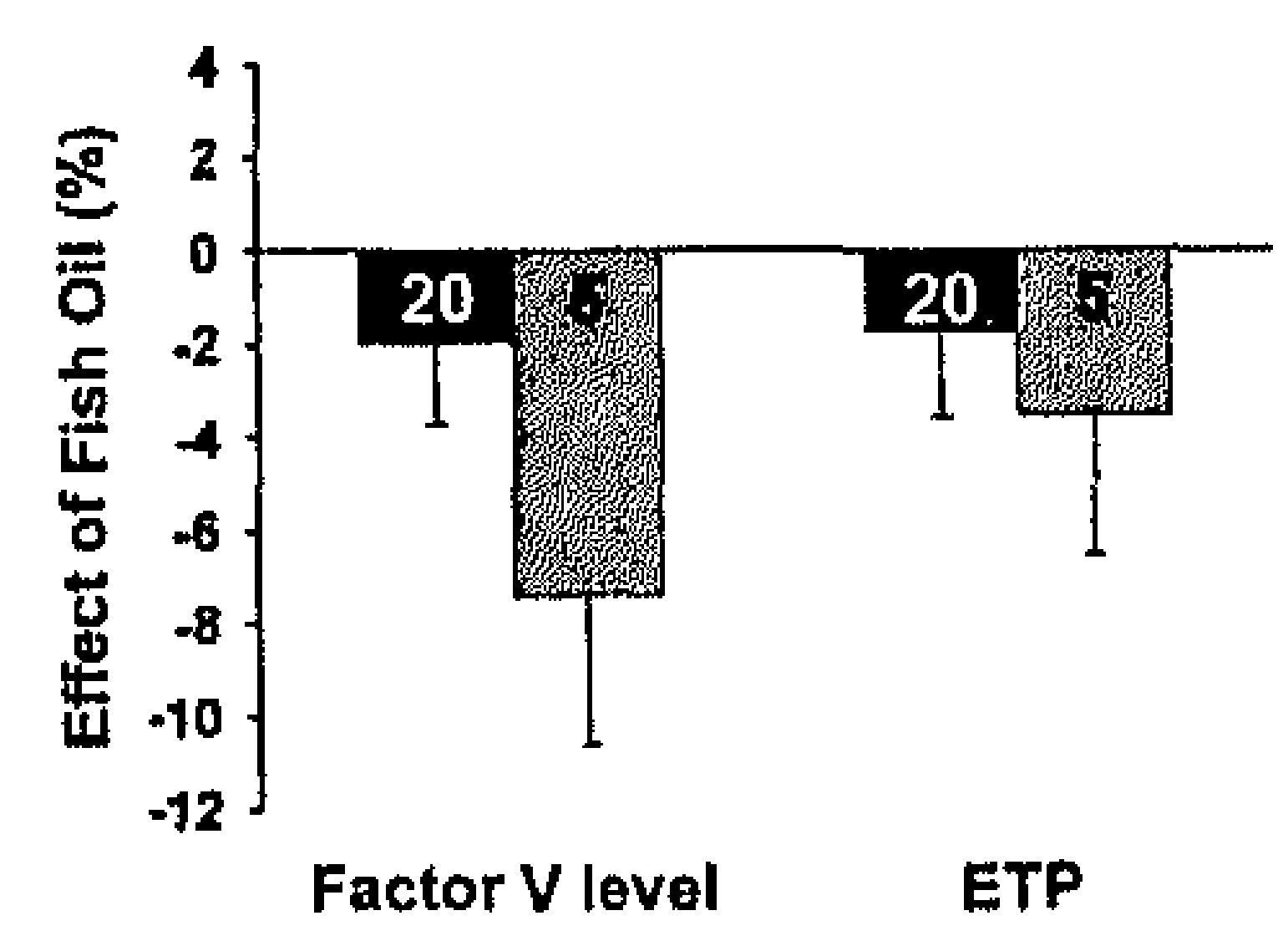

Figure 4. Effect of fish oil on fibrinogen and factor $V$ levels and thrombin generation in plasma/phospholipids. (A-B) Carriers of fibrinogen- $\alpha$ 312Ala allele ( $n=10$ heterozygotes/25); (C-D) carriers of factor V 1299Arg allele ( $n=5$ heterozygotes/25). Data (mean \pm SE) were obtained as described for Tables $1-$ 2. When fibrinogen was measured as antigen level, 312Ala carriers also had higher baseline levels than noncarriers $(3.70 \pm 0.20$ versus $2.57 \pm 0.19 \mathrm{~g} / \mathrm{L})$, and showed a greater reduction after fish oil $(P=0.016) . * P<0.05$ (Mann-Whitney).

\section{DISCUSSION}

The present data are a first report in man on reduced thrombin generation in response to fish oil intake. This effect was achieved in healthy male volunteers with borderline overweight, consuming $3.0 \mathrm{~g}$ fish oil-derived n-3 PUFAs daily during 4 weeks, and it was accompanied by a reduction in plasma levels of mainly fibrinogen and factor $V$. In agreement with other studies, fish oil intake lowered the plasma triglyceride concentrations (6-8). This latter effect pointed to efficacy of the n-3 PUFA intervention. The intervention led to a small increase in LDL cholesterol, an effect that is described earlier after fish oil intervention in normal and hyperlipoproteinemic subjects $(6,8)$. 
The data suggest that the reducing effects of fish oil on tissue factor-induced thrombin generation and on fibrinogen level are causally related. First, variability analysis shows that fibrinogen, in addition to prothrombin, antithrombin and factor $\mathrm{V}$, is a main coagulation factor contributing to the inter-subject variation in thrombogram parameters (peak height and ETP). The enhancing effect of fibrinogen on thrombin generation insitu has earlier been described by Hemker et al (26). Second, the intervention effect on thrombin generation in individuals significantly correlates with the effects on fibrinogen and factor $\mathrm{V}$ level. This holds for thrombograms obtained in the presence and absence of platelets. Third, in vitro modulation of fibrinogen in normal pooled plasma causes similar changes in thrombin generation as the fish oil intervention. Because artificial addition or depletion of factor $\mathrm{V}$ in normal plasma did not influence thrombin generation, it is likely that factor $\mathrm{V}$, in the thrombogram variation, is a confounder for another, related plasma factor that influences thrombin formation or inactivation. The lack of fish oil effect on nAPCsr suggests that this concerns a coagulant rather than anticoagulant factor.

Earlier studies often failed to measure anticoagulant effects of fish oil consumption (36), most probably because less sensitive coagulation assays like the prothrombin time were used (15). However, in some but not all human studies a reduction in plasma fibrinogen and/or factor $V$ activity was observed in response to fish oil $(9,11)$. In addition, in rats feeding of low doses of n-3 PUFAs lowered factor $V$ levels (17). With respect to fibrinogen, which is a likely independent cardiovascular risk factor when increased, fish oil has been shown to decrease this factor mainly in subjects with elevated baseline levels $(10,12)$. The present data agree with this.

At the applied dose of $3.0 \mathrm{~g} \mathrm{n}-3$ PUFAs/day, we did not find an intervention effect on vitamin $\mathrm{K}$-dependent coagulation factors, prothrombin, factor VII, factor $\mathrm{X}$ and protein C. This contradicts to the idea that fish oil can interfere with vitamin $\mathrm{K}$ action, as proposed from other studies where factor VII and factor $\mathrm{X}$ were moderately reduced by fish oil $(11,12,37)$. In rat plasma, we and others have indeed measured reduced levels of prothrombin and factor $\mathrm{X}$, an observation that was compatible with vitamin $\mathrm{K}$ antagonistic activity $(13,14)$. However, this was seen after relatively high doses of fish oil ( $\geq 3$ energy\%), and the hypocoagulant effect was not further affected by vitamin $\mathrm{K}$ depletion (17). This strongly suggests that the main fish oil effect, especially at lower doses, is independent of vitamin $\mathrm{K}$.

Quantitatively, the fish oil-induced decline in thrombin generation (peak level) was greater in the presence $(-15 \%)$ than in the absence $(-3 \%)$ of platelets. It is noted that relations between thrombin generation with platelets and, e.g., fibrinogen levels are more difficult to establish because of the high intra-subject variation in the assay with PRP. Fish oil reduced platelet integrin $\alpha \mathrm{IIb} \beta 3$ activation in response to thrombinreceptor stimulation. This is compatible with the notion that thrombin generation depends on the mutually stimulatory interactions of platelet activation and coagulation (21), and that integrin $\alpha \operatorname{IIb} \beta 3$ activation significantly contributes to platelet-dependent thrombin generation (38). Thus, as proposed earlier (9), moderate anti-platelet and hypocoagulant effects of fish oil may add in lowering the thrombogram curve. From the 
present results we can conclude that the fish oil effect on thrombin generation is enhanced by the presence of platelets, but that the contribution of integrin activation is still unclear.

As considerable inter-subject variation was observed in coagulation factor levels and size of the thrombogram, the 25 volunteers were evaluated on the presence of frequent polymorphisms in fibrinogen and factor $\mathrm{V}$ genes with reported increased thrombotic risk. Typically, carriers of fibrinogen $\alpha$-chain 312 Ala variant $(n=10 / 25)$ had a higher baseline fibrinogen level that was accompanied by stronger reduction in both thrombin generation (ETP) and fibrinogen level with fish oil than non-carriers. In fact, the fibrinogen reduction in carriers explained most of the effect on thrombin generation with or without platelets. In literature, the 312Ala allele influences clot stability (39) and predisposes clots to embolization (30), but the relation with fibrinogen expression is still unclear. This polymorphism is relatively abundant among Caucasians with an estimated frequency of $35-40 \%$ (30). On the other hand, there was no difference between carriers of common haplotypes in the promoter region of the $\beta$-fibrinogen gene $(-854 /-148)$, which in some but not all studies is linked to increased fibrinogen expression (31). The factor V His1299Arg (A4070G) polymorphism, associated with HR2 haplotype, is related with lower factor V levels (28). The 5 carriers of 1299Arg factor $\mathrm{V}$ had lower factor $\mathrm{V}$ levels than the non-carriers, both before and after fish oil supplementation. Carriers tended to respond better to fish oil, but group size was too small to validate this.

In general, limitation but also strength of this study is that the effect evaluation was analyzed in samples from a limited number of 25 individuals with borderline increased BMI. This limits the statistical power and precludes the finding of small effects but, when effects are found, these are likely to be biologically and medically significant. The small numbers make it difficult to draw strong conclusions on differences between the polymorphisms. Yet, this report provides a first indication that genetic variation can contribute to a variable hypocoagulant (thromboprotective) fish oil effect.

Considering that the hypocoagulant effect of in fish oil is vitamin $\mathrm{K}$-independent and has a genetic component, it is of interest to speculate on the mechanism of action. In mice, n-3 PUFAs can downregulate the hepatic expression of the sterol regulatory element-binding protein-1 (SREBP-1) (40) and of the peroxisome proliferator-activated receptor $\alpha$ (PPAR $\alpha$ ) system (41). Further, PPAR $\alpha$ controls fibrinogen levels in man (42). One possibility therefore is that n-3 PUFAs provoke hypocoagulant conditions by influencing transcription systems, in which genetic variation may play a modulatory role. However, fish oil may also act on the translation or post-translation level, e.g. altering hepatic secretion quantitatively or qualitatively.

\section{Acknowledgment}

We acknowledge financial support from the Netherlands Organization for Scientific Research (NWO 980-10-018). We thank Pharma Nord (Vejle, Denmark) for supply of fish oil capsules. 


\section{REFERENCES}

1. Bang HO, Dyerberg $\mathrm{J}$, Nielsen AB. Plasma lipid and lipoprotein pattern in Greenlandic west-coast Eskimos. Lancet. 1971; 1: 1143-5.

2. Burr ML, Fehily AM, Gilbert JF, Rogers S, Holliday RM, Sweetnam PM, Elwood PC, Deadman NM. Effects of changes in fat, fish, and fibre intakes on death and myocardial reinfarction: diet and reinfarction trial (DART). Lancet. 1989; 2: 757-61.

3. Kromhout D, Bosschieter EB, de Coulander CL. The inverse relation between fish consumption and 2year mortality from coronary heart disease. Lancet. 1987; i: 177-83.

4. Kris-Etherton PM, Harris WS, Appel LJ. Fish consumption, fish oil, omega-3 fatty acids, and cardiovascular disease (editorial). Arterioscler Thromb Vasc Biol. 2003; 23: 151-2.

5. Kris-Etherton PM, Harris WS, Appel LJ. Fish consumption, fish oil, omega-3 fatty acids, and cardiovascular disease. Circulation, 2002; 106: 2747-57.

6. Harris WS. N-3 fatty acids and serum lipoproteins: human studies. Am J Clin Nutr. 1997; 65: 1645S$54 \mathrm{~S}$.

7. Leaf A, Weber PC. Cardiovascular effects of n-3 fatty acids. N Engl J Med. 1988; 318: 549-57.

8. Malle E, Kostner GM. Effects of fish oil on lipid variables and platelet function indices. Prostagland Leukotr Essential Fatty Acids. 1993; 49: 645-63.

9. Vanschoonbeek $\mathrm{K}$, de Maat MP, Heemskerk JWM. Fish oil consumption and reduction of arterial disease. J Nutr. 2003; 133: 657-60.

10. Haglund O, Wallin R, Luostarinen R, Saldeen T. Effects of a new fluid fish oil concentrate, Eskimo-3, on triglycerides, cholesterol, fibrinogen and blood pressure. II Intern Med. 1990; 227: 347-53.

11. Oosthuizen W, Vorster HH, Jerling JC, Barnard HC, Smuts CM, Silvis N, Kruger A, Venter CS. Both fish oil and olive oil lowered plasma fibrinogen in women with high baseline fibrinogen levels. Thromb Haemost. 1994; 72: 557-62.

12. Shahar E, Folsom AR, Wu KK, Dennis BH, Shimakawa T, Conlan MG, Davis CE, Williams OD. Associations of fish intake and dietary $n-3$ polyunsaturated fatty acids with a hypocoagulable profile. The atherosclerosis risk in communities (ARIC) study. Arterioscler Thromb. 1993; 13: 1205-12.

13. Leray C, Wiesel ML, Freund M, Cazenave JP, Gachet C. Long-chain n-3 fatty acids specifically affect rat coagulation factors dependent on vitamin $\mathrm{K}$. Relation to peroxidative stress. Arterioscler Thromb Vasc Biol. 2001; 21: 459-65.

14. Nieuwenhuys CMA, Béguin S, Offermans RFM, Emeis JJ, Hornstra G, Heemskerk JWM. Hypocoagulant and lipid-lowering effects of dietary $n-3$ polyunsaturated fatty acids with unchanged platelet activation in rats. Arterioscler Thromb Vasc Biol. 1998; 18: 1480-9.

15. Hemker $\mathrm{HC}$, Béguin S. Thrombin gencration in plasma: its assessment via the endogenous thrombin potential. Thromb Haemost. 1995; 74; $134-8$.

16. Vanschoonbeek K, Feijge MAH, van Kampen RJW, Kenis H, Hemker HC, Giesen PLA, Heemskerk JWM. Initiating and potentiating roles of platelets in tissue factor-induced thrombin generation in the presence of plasma. J Thromb Haemost. 2004; 2: 476-484.

17. Nieuwenhuys CMA, Feijge MAH, Vermeer C, Hennissen AH, Béguin S, Heemskerk JWM. Vitamin Kdependent and vitamin $\mathrm{K}$-independent hypocoagulant effects of dietary fish oil in rats. Thromb Res. 2001; 104: 137-47.

18. Ardissino D, Mannucci PM, Merlini PA, Duca F, Fetiveau R, Tagliabue L, Tubaro M, Galvani M, Ottani $F$, et al. Prothrombotic genetic risk factors in young survivors of myocardial infarction. Blood. 1999; 94: 46-51.

19. Cadroy Y, Sakariassen KS, Charlet JP, Thalamas C, Boneu B, Sié P. Role of four platelet membrane glycoprotein polymorphisms on experimental arterial thrombus formation in men. Blood. 2001; 98: 3159-5161.

20. Wallace AJ, Humphries SE, Fisher RM, Mann JI, Chisholm A, Sutherland WHF. Genetic factors associated with response of LDL subfractions to change in the nature of dietary fat. Atherosclerosis. 2000; 149: 387-94.

21. Heemskerk JWM, Bevers EM, Lindhout T. Platelet activation and blood coagulation. Thromb Haemost. 2002; 88: 186-93

22. Conlan MG, Folsom AR, Finch A, Davis CE, Marcucci G, Sorlie P, Wu KK. Antithrombin III: associations with age, race, sex and cardiovascular disease risk factors. The Atherosclerosis Risk in Communities (ARIC) Study Investigators. Thromb Haemost. 1994; 72: 551-6. 
23. Clauss A. [Rapid physiological coagulation method in determination of fibrinogen.]. Acta Haematol. $1957 ; 17: 237-46$.

24. Koopman J, Haverkate F, Koppert P, Nieuwenhuizen W, Brommer EJ, Van der Werf WG. New enzyme immunoassay of fibrin-fibrinogen degradation products in plasma using a monoclonal antibody. J Lab Clin Med. 1987; 109: 75-84.

25. Koppert PW, Hoegee-de Nobel E, Nieuwenhuizen W. A monoclonal antibody-based enzyme immunoassay for fibrin degradation products in plasma. Thromb Haemost. 1988; 59: 310-5.

26. Hemker HC, Giesen P, Al Dieri R, Regnault V, De Smedt E, Wagenvoord R, Lecompte T, Beguin S. Calibrated automated thrombin generation measurement in clotting plasma. Pathophysiol Haemost Thromb. 2003; 33: 4-15.

27. Rosing J, Middeldorp S, Curvers J, Christella M, Thomassen LG, Nicolaes GA, Meijers JC, Bouma BN, Buller HR, et al. Low-dose oral contraceptives and acquired resistance to activated protein $\mathrm{C}$ : a randomised cross-over study. Lancet. 1999; 354: 2036-40.

28. Lunghi B, Iacoviello L, Gemmati D, Dilasio MG, Castoldi E, Pinotti M, Castaman G, Redaelli R, Mariani G, et al. Detection of new polymorphic markers in the factor $V$ gene: association with factor $V$ levels in plasma. Thromb Haemost. 1996; 75: 45-8.

29. Simioni P, Prandoni P, Lensing AW, Scudeller A, Sardella C, Prins MH, Villalta S, Dazzi F, Girolami A. The risk of recurrent venous thromboembolism in patients with an Arg506 $>$ Gln mutation in the gene for factor V (factor V Leiden). N Engl J Med. 1997; 336: 399-403.

30. Carter AM, Catto AJ, Kohler HP, Ariens RA, Stickland MH, Grant PJ. $\alpha$-Fibrinogen Thr312Ala polymorphism and venous thromboembolism. Blood. 2000; 96: 1177-9.

31. van 't Hooft FM, von Bahr SJ, Silveira A, Iliadou A, Eriksson P, Hamsten A. Two common, functional polymorphisms in the promoter region of the $\beta$-fibrinogen gene contribute to regulation of plasma fibrinogen concentration. Arterioscler Thromb Vasc Biol. 1999; 19: 3063-70.

32. Thomas AE, Green FR, Kelleher CH, Wilkes HC, Brennan PJ, Meade TW, Humphries SE. Variation in the promoter region of the $\beta$-fibrinogen gene is associated with plasma fibrinogen levels in smokers and non-smokers. Thromb Haemost. 1991; 65: 487-90.

33. Butenas S, van't Veer C, Mann KG. "Normal" thrombin generation. Blood. 1999; 94: 2169-78.

34. Castoldi E, Lunghi B, Mingozzi F, Ioannou P, Marchetti G, Bernardi F. New coagulation factor V gene polymorphisms define a single and infrequent haplotype underlying the factor $\mathrm{V}$ Leiden mutation in Mediterranean populations and Indians. Thromb Haemost. 1997; 78.

35. Curvers J, Thomassen MCLGD, Rimmer J, Hamulyak K, van der Meer J, Tans G, Preston FE, Rosing J. Effects of hereditary and acquired risk factors of venous thrombosis on a thrombin generation-based APC resistance test. Thromb Haemost. 2002; 88: 5-11.

36. Knapp HR. Dietary fatty acids in human thrombosis and hemostasis. Am J Clin Nutr. 1997; 65: 1687S98S.

37. Marckmann P, Bladbjerg EM, Jespersen J. Dietary fish oil (4 $\mathrm{g}$ daily) and cardiovascular risk markers in heaithy men. Arterioscler Thromb Vasc Biol. 1997; 17: 3384-91.

38. Reverter JC, Béguin S, Kessels H, Kumar R, Hemker HC, Coller BS. Inhibition of platelet-mediated, tissue-factor-induced thrombin generation by the mouse/human chimeric $7 \mathrm{E} 3$ antibody. Potential implications for the effect of $\mathrm{c} 7 \mathrm{E} 3 \mathrm{Fab}$ treatment on acute thrombosis and 'clinical restenosis'. J Clin Invest. 1996; 98: 863-74.

39. Curran JM, Fatah-Ardalani K, Tomvall P, Humphries SE, Green FR. A hypothesis to explain the reported association of the $\alpha$-fibrinogen A312 allele with thromboembolic disease. Thromb Haemost. $2001 ; 85: 1122-3$.

40. Nakatani T, Kim HJ, Kaburagi Y, Yasuda K, Ezaki O. A low fish oil inhibits SREBP-1 proteolytic cascade, while a high-fish-oil feeding decreases SREBP-1 mRNA in mice liver: relationship to antiobesity. J Lipid Res. 2003; 44; 369-79.

41. Takahashi M, Tsuboyama-Kasaoka N, Nakatani T, Ishii M, Tsutsumi S, Aburatani H, Ezaki O. Fish oil feeding alters liver gene expressions to defend against PPAR $\alpha$ activation and ROS production. Am J Physiol. 2002; 282: G338-G48.

42. Gervois P, Vu-Dac N, Kleemann R, Kockx M, Dubois G, Laine B, Kosykh V, Fruchart JC, Kooistra T, Staels $B$. Negative regulation of human fibrinogen gene expression by peroxisome proliferator-activated receptor $\alpha$ agonists via inhibition of CCAAT box/enhancer-binding protein $\beta$. J Biol Chem. 2001; 276: 33471-7. 


\section{Chapter 6}

\section{Plasma \\ triacylglycerol \\ and}

coagulation factor concentrations

predict the anticoagulant effect of

dietary fish oil in overweight subjects

Kristof Vanschoonbeek, Marion A.H. Feijge, Wim H.M. Saris, Moniek

P.M. de Maat and Johan W.M. Heemskerk

Journal of Nutrition, 2007; 137: 7-13 


\begin{abstract}
Fish oil, containing n-3 PUFAs, is associated with a moderate reduction in cardiovascular disease through a multi-factorial mechanism involving a decrease in plasma lipids and anticoagulant activity. Two intervention studies with subjects at risk were performed to determine the relation of these two fish-oil effects. In study 1, 54 overweight subjects consumed $3.1 \mathrm{~g}$ n-3 PUFA daily. In the second study, which involved 42 overweight patients with type 2 diabetes, 20 subjects consumed n-3 PUFA, while 22 others ingested a preparation rich in $n-6$ PUFA. Tissue factor-induced thrombin generation (thrombin potential) was determined as an integrated measure of plasma coagulant activity. In both studies, multivariate analysis indicated a strong clustering of fasting concentrations of triacylglycerols, prothrombin, factor $\mathrm{V}$, factor VII, and factor $\mathrm{X}$ with one another at baseline. This cluster of factors determined partly the inter-individual variation in thrombin generation, of which prothrombin and triacylglycerol concentrations were the main determinants. In both healthy subjects and diabetes patients, high triacylglycerol concentrations $(>1.69 \mathrm{mmol} / \mathrm{L})$ at baseline were closely linked to a strong fish oil-induced lowering of triacylglycerol and coagulation factor V, VII, and X concentrations, and thrombin generation. We conclude that high fasting triacylglycerol concentrations are predictive of high procoagulant activity and for a lowering in thrombin potential with dietary fish oil.
\end{abstract}




\section{INTRODUCTION}

Consumption of fish oil, which contains the n-3 PUFAs eicosapentaenoic acid (EPA) and docosahexaenoic acid (DHA), is consistently associated with a reduction in cardiovascular disease $(1,2)$. Since the early 1970 s, human observational studies and clinical trials have indicated that the cardioprotective effect of fish oil is multi-factorial in origin (3). Dietary n-3 PUFA can lead to an improvement in heart function $(4,5)$. Another key effect of fish oil is lowering of the plasma concentration of triacylglycerol, in contrast to that of cholesterol, which is only moderately influenced (6-8). The consistent triacylglycerol-lowering effect has led to the recent recommendation of a daily intake of n-3 PUFA to patients with hypertriglyceridemia (1).

Fish oil also has anti-platelet and anticoagulant activities, although these two effects vary considerably among published studies (9). In earlier work, we reported considerable inter-individual variation in the anticoagulant effect of fish oil (10). This variation became apparent by using a sensitive coagulation assay, which measures in an integrated way the kinetics and extent of tissue factor-induced thrombin generation in full plasma $(11,12)$. Part of the inter-subject variability could be explained by coagulation factor polymorphisms (10), but it is likely that other variables contribute to this as well.

The literature provides indications that the metabolism of coagulation factors and that of lipids in plasma are interrelated. For instance, concentrations of the vitamin Kdependent factors, prothrombin, factor VII and factor X, correlate with plasma lipid concentrations (13). Further, hypertriglyceridemia is a risk factor of thrombosis, and patients with high triacylglycerol concentrations also have high concentrations of factor VII (14). In the same patient group, postprandial hyperlipemia is accompanied by factor VII activation and increased coagulant activity (15). On the other hand, there is evidence that triacylglycerols do not directly influence factor VIIa activity or coagulation (16). Thus, whereas the plasma concentration of triacylglycerol seems to be related to coagulant activity, exactly how is unclear.

In the present paper, we investigated whether subjects' plasma triacylglycerol concentrations and hemostatic variables determine the lipid-lowering and hypocoagulant effects of dietary fish oil. For this purpose, we performed two n-3 PUFA intervention studies with two groups of overweight subjects: healthy volunteers and patients with type 2 diabetes and a tendency to hypertriglyceridemia.

\section{SUBJECTS AND METHODS}

\section{Subjects and study design}

Two intervention studies were undertaken to investigate the anticoagulant effect of fish oil in overweight subjects with increased thrombotic risk. Study protocols were in agreement with the Helsinki declaration and approved by the Medical Ethical Committee of the Academic Hospital Maastricht. Subjects were only included after they 
provided written informed consent. Study 1 was performed with 57 overweight but healthy Caucasian men. Inclusion criteria were body mass index (BMI) $>25 \mathrm{~kg} / \mathrm{m}^{2}$, and absence of lipid-lowering, antiplatelet or anticoagulant medication. The subjects did not suffer from clinical cardiovascular diseases or hypertension and had normal fasting blood glucose concentrations, indicating the absence of (type 2) diabetes. Nine of the subjects were smokers (Table $\mathbf{1}$ ).

Table 1: Baseline characteristics of overweight healthy subjects and type 2 diabetes patients.

\begin{tabular}{|c|c|c|}
\hline Variable & $\begin{array}{l}\text { Healthy subjects } \\
\text { (study 1) } \\
n=57\end{array}$ & $\begin{array}{l}\text { Type } 2 \text { diabetes patients } \\
\text { (study } 2 \text { ) } \\
n=42\end{array}$ \\
\hline Age, $y$ & $48.3(21-69)$ & $62.9(33-85)$ \\
\hline $\operatorname{Sex}(\mathrm{M} / \mathrm{F}), n$ & $57 / 0$ & $26 / 16$ \\
\hline Body mass index, $\mathrm{kg} / \mathrm{m}^{2}$ & $28.7(25-35)$ & $30.0(25-44)$ \\
\hline Plasma glucose, ${ }^{2} \mathrm{mmol} / \mathrm{L}$ & $5.3 \pm 0.1$ & $7.9 \pm 0.3$ \\
\hline Antidiabetic treatment (tablets/insulin/diet), $n$ & 0 & $20 / 25 / 3$ \\
\hline Lipid-lowering drugs, $n$ & 0 & 0 \\
\hline Other medication, $n$ & 0 & 0 \\
\hline Smoking, $n$ & 9 & 9 \\
\hline \multicolumn{3}{|l|}{ Plasma lipids, ${ }^{2} \mathrm{mmol} / \mathrm{L}$} \\
\hline Triacylglycerol & $1.48 \pm 0.14$ & $2.57 \pm 0.27$ \\
\hline Total cholesterol & $5.47 \pm 0.12$ & $5.72 \pm 0.16$ \\
\hline HDL cholesterol & $1.18 \pm 0.04$ & $1.17 \pm 0.04$ \\
\hline LDL cholesterol & $3.62 \pm 0.13$ & $3.02 \pm 0.12$ \\
\hline \multicolumn{3}{|l|}{ Coagulation factors ${ }^{2,3}$} \\
\hline Fibrinogen, $g / L$ & $3.21 \pm 0.06$ & $3.13 \pm 0.03$ \\
\hline Prothrombin, $\%$ & $99.9 \pm 1.2$ & $92.5 \pm 1.8$ \\
\hline Factor V, \% & $94.0 \pm 2.3$ & $95.0 \pm 3.9$ \\
\hline Factor VII, \% & $100.1 \pm 1.9$ & $100.0 \pm 3.2$ \\
\hline Factor $\mathrm{X}, \%$ & $100.3 \pm 1.6$ & $90.5 \pm 2.2$ \\
\hline Antithrombin, $\%$ & $88.8 \pm 1.0$ & $82.7 \pm 0.9$ \\
\hline \multicolumn{3}{|l|}{ Thrombin generation ${ }^{4}$} \\
\hline Time-to-peak, $\min$ & $6.6 \pm 0.2$ & $7.1 \pm 0.2$ \\
\hline Thrombin peak, nmol/L & $297 \pm 7$ & $282 \pm 8$ \\
\hline ETP, $n$ mol/L $\times \min$ & $1845 \pm 32$ & $1724 \pm 39$ \\
\hline
\end{tabular}

\footnotetext{
${ }^{1}$ Values are means \pm SEM or range.

${ }^{2}$ Fasting subjects were sampled.

${ }^{3}$ Coagulation factor concentrations are expressed as $\%$ of pooled, normal plasma.

${ }^{4}$ Thrombin generation data represent conventional thrombogram characteristics of tissue factor-triggered plasma.
} 
Blood samples were collected before the intervention (baseline) and after 4 wk of fish oil intake. This intervention period was chosen based on an earlier intervention study (10). During the intervention period, all subjects took 9 soft gelatin capsules (Pharma Nord, Vejle, Denmark) per day in addition to their normal diet. Each capsule contained $500 \mathrm{mg}$ fish oil ( $90 \%$ free fatty acids with $45 \% \mathrm{EPA}$ and $25 \%$ DHA - Table 2), giving a total n-3 PUFA intake of $3.1 \mathrm{~g}$ daily. Data from 3 of 57 subjects were excluded from analysis of intervention effects because they became ill during the intervention (2 influenza and 1 periodontal disease), which was also apparent from high plasma concentrations of C-reactive protein (>10 $\mathrm{mg} / \mathrm{L}$ ).

Study 2 was performed with 42 overweight Caucasian patients with confirmed type 2 diabetes; 26 males and 16 females. Nine of the patients were smokers. The patients had a fasting blood glucose concentration of $7.9 \pm 0.3 \mathrm{mmol} / \mathrm{L}$, while glycosylated hemoglobin $\left(\mathrm{HbA}_{\mathrm{fc}}\right)$ was $8.1 \pm 0.2 \%$. Most of the patients took antidiabetic medication and/or received other treatment (Table 1), which remained unchanged during the intervention study. Half of the individuals were assigned to take fish oil capsules $(90 \%$ free fatty acids with $40 \% \mathrm{EPA}$ and $25 \% \mathrm{DHA}$ - Table 2) and the other half to take corn oil capsules for $8 \mathrm{wk}$. Patients in the fish oil group received every day $3.1 \mathrm{~g} \mathrm{n}-3$ PUFA and $0.2 \mathrm{~g} \mathrm{n}-6$ PUFA; patients in the corn oil group received daily $<0.1 \mathrm{~g} \mathrm{n}-3$ PUFA and $2.2 \mathrm{~g} \mathrm{n}-6$ PUFA. The two groups were matched for sex, age and BMI. Plasma concentrations of C-reactive protein remained below $10 \mathrm{mg} / \mathrm{L}$.

Table 2: Fatty acid composition of dietary capsules used for intervention studies 1 and 2.

\begin{tabular}{|c|c|c|c|}
\hline \multirow{3}{*}{ Fatty acid } & \multirow{3}{*}{ 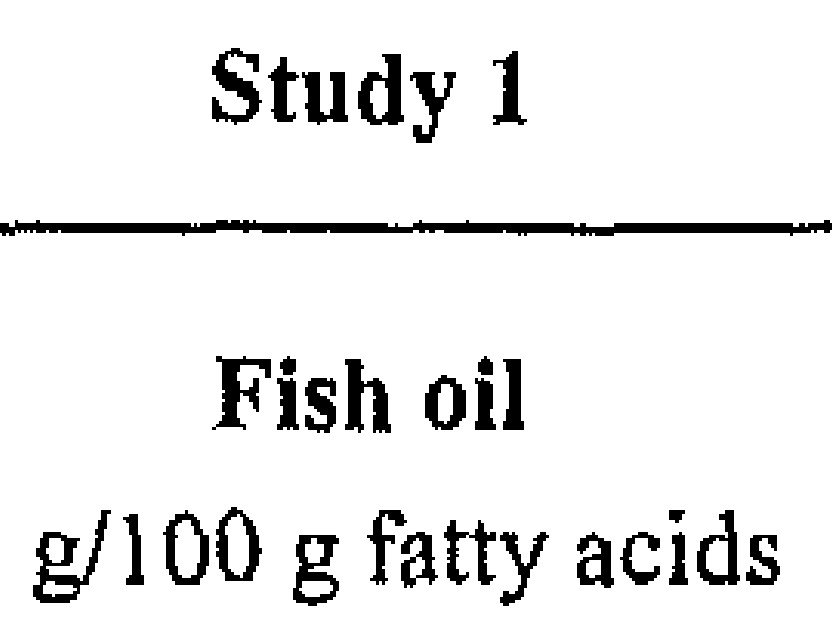 } & \multicolumn{2}{|c|}{ Study 2} \\
\hline & & Fish oil & Corn oil \\
\hline & & \multicolumn{2}{|c|}{$\mathrm{g} / 100 \mathrm{~g}$ fatty acids } \\
\hline$\Sigma \mathrm{SFA}^{1}$ & 5.2 & 8.2 & 14.3 \\
\hline $16: 0$ & 1.7 & 1.6 & 12.1 \\
\hline 18:0 & 2.0 & 2.5 & 1.8 \\
\hline $22: 0$ & 0.2 & 0.0 & 2.3 \\
\hline$\Sigma$ MUFA & 10.2 & 11.8 & 29.6 \\
\hline $18: 1 \mathrm{n}-9$ & 4.5 & 4.0 & 28.1 \\
\hline$\Sigma$ n-6 PUFA & 6.9 & 4.2 & 55.9 \\
\hline $18: 2 n-6$ & 2.2 & 0.8 & 55.9 \\
\hline$\sum n-3$ PUFA & 76.8 & 76.0 & 0.0 \\
\hline $20: 5 n-3$ & 44.5 & 40.2 & 0.0 \\
\hline $22: 6 n-3$ & 24.9 & 25.4 & 0.0 \\
\hline
\end{tabular}

${ }^{1}$ Abbreviations: MUFA, monounsaturated fatty acids; PUFA, polyunsaturated fatty acids; SFA, saturated fatty acids. 
The fatty acid composition of the capsules was as presented (Table 2). For both studies, the subjects were asked to maintain their normal dietary, smoking and alcohol consumption pattern, but not to take other fish or marine products $4 \mathrm{wk}$ before or during the intervention period. Subjects completed a short dietary questionnaire, in which this was verified. At $2 \mathrm{~d}$ prior to baseline blood sampling, dietary food intake records were obtained. These were used to standardize dietary intake prior to the post-intervention blood sampling. Food intake was recorded and details on energy intake and macronutrient composition of the diet before both blood samples were compared.

\section{Hematological measurements and plasma coagulation factor concentrations}

After an overnight fast, blood was collected into open tubes with $129 \mathrm{mmol} / \mathrm{L}$ trisodium citrate (10 vol\%) or with potassium EDTA. The citrate blood was immediately used to prepare platelet-free plasma (PFP) by centrifugation at $870 \mathrm{~g}$ for $10 \mathrm{~min}$, followed by two centrifugation steps at $18,000 \mathrm{~g}$ for $10 \mathrm{~min}$. PFP was snap-frozen in liquid nitrogen, and stored at $-80^{\circ} \mathrm{C}$ for coagulation measurements. The EDTA-anticoagulated blood was used for determination of standard hematological parameters. Remaining plasma samples, centrifuged twice at $870 \mathrm{~g}$ for $10 \mathrm{~min}$, were stored at $-80^{\circ} \mathrm{C}$, and later used to perform lipid analysis. Triacylglycerol in PFP was measured as total glycerol content (GPO-trinder 337B; Sigma, St. Louis, MO), subtracted with the free glycerol content (148270; Roche Diagnostics, Mannheim, Germany). Total cholesterol and HDL cholesterol were determined with reagents from ABX Diagnostics (Montpellier, France). Plasma LDL cholesterol was not directly measured, but calculated by LDL cholesterol $=$ total cholesterol $-\mathrm{HDL}$ cholesterol - triacylglycerol $/ 2.2$ (all in mmol/L). In citrate PFP, plasma concentrations of prothrombin and factors V, VII and X were measured at two dilutions using factor-deficient plasmas. Test kits were from Dade Behring (Marburg, Germany) and BioMérieux (Durham, NC). Concentrations of antithrombin were determined with a test kit from Chromogenix (Mölndal, Sweden). Fibrinogen activity in plasma (Claus method) and C-reactive protein were determined with reagents from Roche Diagnostics (Mannheim, Germany). Factor concentrations were measured using factor-deficient plasma and expressed as percentages of activity compared to a normal plasma pool from 40 healthy subjects (males and females).

\section{Thrombin generation measurements}

Thrombin generation was measured in PFP, using the automated thrombogram method $(12,17)$. Briefly, triplicate samples of $80 \mu \mathrm{L}$ freshly isolated PFP were pipetted into a 96-wells plate, containing per well $20 \mu \mathrm{L}$ recombinant human tissue factor $(30 \mathrm{pmol} / \mathrm{L}$ ) (Dade, Miami, FL) and $4 \mu \mathrm{mol} / \mathrm{L}$ phospholipids (phosphatidylserine : phosphatidylcholine : phosphatidylethanolamine, 1:3:1) in buffer A (20 mmol/L Hepes, $140 \mathrm{mmol} / \mathrm{L} \mathrm{NaCl}$ and $5 \mathrm{~g} / \mathrm{L}$ bovine serum albumin, $\mathrm{pH} 7.35$ ). This gave optimal final concentrations of procoagulant phospholipids and tissue factor. Polystyrene well plates (Immulon 2HB, Dynex Technologies, Chantilly, VA) were used with minimal contact 
activation. The plates were inserted into a Fluoroskan Ascent well-plate reader (Thermo Labsystems, Helsinki, Finland), and pre-heated to $37^{\circ} \mathrm{C}$. Coagulation was started by automated addition of $20 \mu \mathrm{L}$ fluorescent thrombin substrate Z-GGR-AMC $(2.5 \mathrm{mmol} / \mathrm{L}$, benzyloxycarbonyl Gly-Gly-Arg 7-amido-4-methyl coumarin, Bachem, Bubendorf, Switzerland), suspended in buffer B $\left(20 \mathrm{mmol} / \mathrm{L}\right.$ Hepes, $0.1 \mathrm{~mol} / \mathrm{L} \mathrm{CaCl} \mathrm{C}_{2}$ and $60 \mathrm{~g} / \mathrm{L}$ bovine serum albumin, $\mathrm{pH}$ 7.35) under shaking. Fluorescence accumulation was measured in time at excitation and emission wavelengths of 390 and $460 \mathrm{~nm}$, respectively $\left(37^{\circ} \mathrm{C}\right)$. First-derivative curves of accumulation of fluorescence intensity were converted into curves of nanomolar of thrombin using a human thrombin calibrator and thrombinoscope software (Synapse, Maastricht, The Netherlands) to correct for non-linearity of the fluorescence with AMC concentration, depletion of fluorescent substrate, and fluorescence accumulation due to non-coagulant $\alpha_{2^{-}}$ macroglobulin-bound thrombin (17).

Reference samples contained the same volume of plasma, to which a fixed amount of stable thrombin calibrator was added. Thrombograms were run in triplicate, and analyzed with respect to time to thrombin peak (equivalent to the clotting time), the thrombin peak height (indicative of the maximal rate of thrombin formation), and the area-under-the-curve or endogenous thrombin potential (ETP, representing total thrombin activity or the thrombin potential of plasma) (17). The assay variability of the thrombogram parameters is $<3 \%(18)$.

\section{Determination of genetic polymorphisms}

Leukocyte DNA was isolated from blood buffy coats using the high-pure kit from Roche Diagnostics (Mannheim, Germany), according to instructions of the manufacturer. Genetic polymorphisms were determined using PCR primers (Eurogentec, Liège, Belgium) suitable for analysis by RFLP as described: the T312A polymorphism of fibrinogen- $\alpha$ (19), the G20210A (20) and A19911G (21) variants of prothrombin, and the A4070G ( $R_{2}$ factor $V$ ) (22) and G1691A (factor $V_{\text {Leiden }}$ ) (23) variants of factor $\mathrm{V}$. PCR was for 30-35 cycles (temperature conditions according to characteristics of the primers) with $50 \mathrm{ng}$ isolated DNA, dNTPs ( $2 \mathrm{mmol} / \mathrm{L}$ of each), 1.5 $\mathrm{mmol} / \mathrm{L} \mathrm{MgCl}_{2}$, forward and reverse primers $(10 \mu \mathrm{mol} / \mathrm{L})$, Taq polymerase $(5 \mathrm{U} / \mu \mathrm{L})$ and suitable PCR buffer. Taq DNA polymerase, buffer and $\mathrm{MgCl} 2$ were obtained from Amersham Pharmacia Biotech (Freiburg, Germany). Restriction enzymes with buffers were from the following sources: Mnl I from New-England Biolabs (Beverly, MA); Rsa I from Promega (Leiden, The Netherlands); Hind III and dNTPs from Fermentas (St. Leon-Rot, Germany). Generated PCR fragments and endonuclease digestion products were controlled for purity and fragment size by electrophoresis on ethidium bromidestained agarose gels.

\section{Statistics}

Data are expressed as means $\pm S E M$, except when indicated otherwise. Principal 
component analysis was performed to determine the relation between plasma lipids and coagulation factors. The contribution of individual (coagulation) factors to the process of thrombin generation was evaluated with multivariate regression analysis. Within groups, effects of fish or corn oil on plasma variables were compared to baseline values with the paired t-test or, if parameters were not normally distributed, the non-parametric Wilcoxon signed rank-test. Baseline values of different groups were compared to one another with the Mann-Whitney U-test. The Pearson test was used to determine whether baseline concentrations and fish oil effects were correlated for individual variables. Statistical significance was set at $P<0.05$. All calculations were performed using the statistical package for the social sciences 12.0 (SPSS, Chicago, IL).

\section{RESULTS}

Relation between plasma concentrations of (anti)coagulant factors and lipids and thrombin generation at baseline

In study 1 , body weight was $92.1 \pm 10.9 \mathrm{~kg}$ and BMI was $28.7 \pm 2.6 \mathrm{~kg} / \mathrm{m}^{2}$ (mean \pm SD). Plasma concentrations of triacylglycerol, lipoproteins and coagulation factors were all in the normal range $(24,25)$ (Table 1 ). Principle component analysis was performed for all 57 subjects' baseline plasma samples to determine the relation between lipids and coagulation factors. This analysis showed a strong association among the concentrations of triacylglycerol, total cholesterol, prothrombin, factor VII and factor X (Figure 1A, component $1,29.6 \%$ ). Variables that clustered differently were fibrinogen/factor $\mathrm{V}$ (component 2, 18.7\%) and antithrombin/HDL (component 3, 16.0\%). Subsequent correlation analysis indicated that concentrations of triacylglycerol correlated with those of prothrombin $(R=0.33, P=0.011)$ and factor $\mathrm{X}(R=0.42, P=0.001)$ and tended to correlate with factor VII $(R=0.25, P=0.066)$. Calculated concentrations of LDL cholesterol correlated only with fibrinogen.

In study 2, body weight was $87.5 \pm 14.3 \mathrm{~kg}$ and BMI was $30.0 \pm 5.2 \mathrm{~kg} / \mathrm{m}^{2}$ (mean \pm $\mathrm{SD})$. At baseline, fasting plasma triacylglycerol concentrations from these overweight patients were typically high, compared to the study 1 group (Table 1). Principal component analysis pointed again to a clustering of triacylglycerol concentrations with those of total cholesterol, prothrombin, factor VII and factor X (Figure 1B, component $1,38.5 \%)$. Correlation analysis confirmed the relations of triacylglycerol with prothrombin $(R=0.29, P=0.060)$, factor VII $(R=0.51, P=0.001)$ and factor $\mathrm{X}(R=$ $0.44, P=0.004)$, but not with other factors. Again, calculated concentrations of LDL cholesterol correlated only with fibrinogen. Together, this points to a close link between the triacylglycerol concentration and those of various key coagulation factors in plasma. Tissue factor-triggered thrombin generation was used to measure the integrated coagulant activity of the plasmas. Plasma samples from all overweight subjects and diabetic patients had normal thrombin generation curves (Table 1). In both studies, multiple regression analysis indicated that plasma concentrations of triacylglycerol, total cholesterol, fibrinogen, prothrombin, factor $\mathrm{V}$, factor VII and factor X significantly 
determined the thrombin peak and/or ETP values, whereas the anti-coagulant factor antithrombin correlated inversely with the ETP. The variables of component 1 (triacylglycerol, total cholesterol, prothrombin, factor VII and factor X) predicted $32.9 \%$ and $42.7 \%$ of the ETP variation in overweight subjects and diabetic patients, respectively. Prothrombin and antithrombin were the main determinants of the ETP in the overweight subjects $(R=0.53, P<0.001)$ and diabetics $(R=0.68, P<0.001)$. In combination, the concentrations of triacylglycerol and total cholesterol significantly correlated with the ETP in overweight $(R=0.40, P=0.009)$ and diabetic $(R=0.42, P=$ $0.025)$ subjects. Only triacylglycerol contributed to the variation in study $1(P=0.019)$. Together, these results indicate that in both studies, plasma triacylglycerol and total cholesterol concentrations are associated with total thrombin generation, i.e. the integrated coagulant activity of plasma.
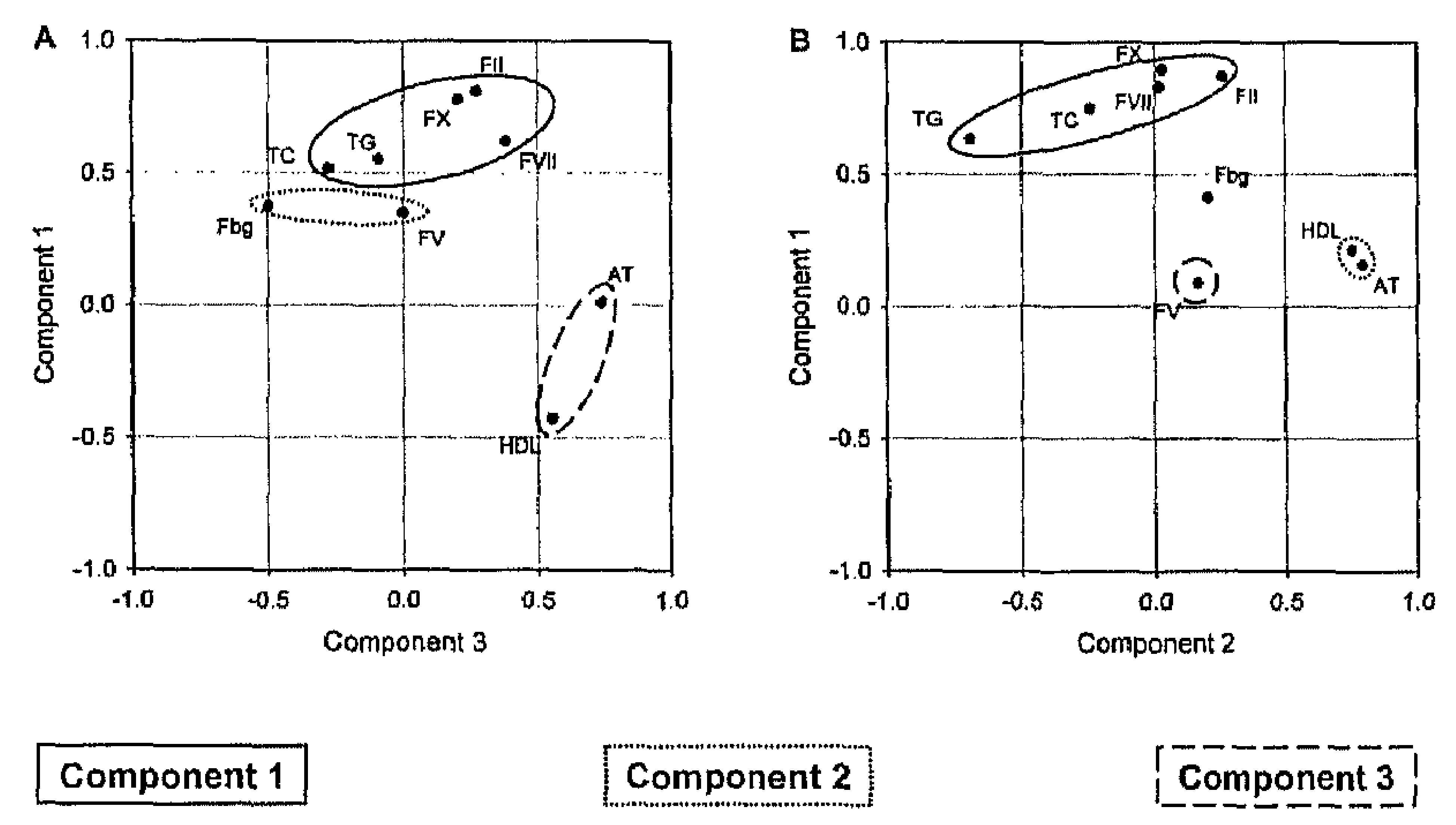

Figure 1. Principal component analysis of relations between baseline concentrations of lipids and coagulation factors in plasma from 57 overweight healthy men (study 1) (A) and 42 overweight type 2 diabetes patients (study 2) (B). In the component matrix, variables with values closer to 1.0 are contributing more to the clustered component. Abbreviations: AT, antithrombin; F, factor; Fbg, fibrinogen; HDL, HDL cholesterol; TC, total cholesterol; TG, triacylglycerol. LDL cholesterol was not included in the analysis, since this concentration was calculated from other variables.

\section{Intervention studies with fish oil}

Dietary questionnaires showed that none of the subjects had consumed fish (oil) during 4 wk prior to the start of the intervention. Accordingly, fish oil carry over effects were minimal. Furthermore, the habitual consumption pattern did not change prior to and during the intervention periods. Energy intake and macronutrient composition of the regular diet was similar before both blood samples. The recorded mean energy intake was $120.4 \pm 4.5 \mathrm{~kJ} / \mathrm{kg}$ body mass, with $35.7 \pm 0.8 \%$ of energy as carbohydrates, $43.9 \pm$ $1.0 \%$ of energy as fat, $17.5 \pm 0.4 \%$ of energy as protein and $2.4 \pm 0.4 \%$ of energy as alcohol. 
Chapter 6

\section{Effects of fish oil on thrombin generation}

In study 1, plasma concentrations of triacylglycerol were moderately reduced, while coagulation factors were not affected (Table 3). Overall, the fish oil intervention resulted in a prolonged time to thrombin peak. For the whole population of subjects (for subpopulations, see below), these results point to a slightly weaker anticoagulant effect than in an earlier fish oil intervention study (10).

Table 3: Effect of dietary fish and corn oil on fasting lipid concentrations, coagulation factor concentrations and thrombin generation profile in plasma of overweight healthy subjects and type 2 diabetes patients.'

\begin{tabular}{|c|c|c|c|c|c|c|}
\hline & \multicolumn{2}{|c|}{ Study 1} & \multicolumn{2}{|c|}{ Study 2} & \multicolumn{2}{|c|}{ Study 2} \\
\hline & Baseline & $\begin{array}{l}\Delta \text { Fish oil } \\
\%^{2}\end{array}$ & Baseline & $\begin{array}{l}\Delta \text { Fish oil } \\
\%^{2}\end{array}$ & Baseline & $\begin{array}{l}\Delta \text { Corn oil } \\
\%^{3}\end{array}$ \\
\hline \multicolumn{7}{|l|}{ Plasma lipids } \\
\hline $\begin{array}{l}\text { Triacylglycerol } \\
\mathrm{mmol} / \mathrm{L}\end{array}$ & $1.46 \pm 0.14$ & $-5.5 \pm 4.3^{*}$ & $2.36 \pm 0.27$ & $-20.9 \pm 3.4^{*}$ & $2.76 \pm 0.46$ & $-2.1 \pm 5.2$ \\
\hline $\begin{array}{l}\text { Total cholesterol } \\
\text { mmol/L }\end{array}$ & $5.46 \pm 0.13$ & $+1.3 \pm 1.2$ & $5.96 \pm 0.21$ & $-1.4 \pm 2.1$ & $5.51 \pm 0.23$ & $-0.9 \pm 1.6$ \\
\hline $\begin{array}{l}\text { HDL cholesterol } \\
\mathrm{mmol} / \mathrm{L}\end{array}$ & $1.19 \pm 0.04$ & $+2.8 \pm 1.9$ & $1.22 \pm 0.05$ & $+5.8 \pm 2.4$ & $1.12 \pm 0.05$ & $-1.0 \pm 2.5$ \\
\hline $\begin{array}{l}\text { LDL cholesterol } \\
\mathrm{mmol} / \mathrm{L}\end{array}$ & $3.60 \pm 0.14$ & $+5.3 \pm 2.4^{*}$ & $3.29 \pm 0.15$ & $+4.6 \pm 3.0$ & $2.79 \pm 0.16$ & $+4.3 \pm 3.2$ \\
\hline \multicolumn{7}{|c|}{ Coagulation factors } \\
\hline Fibrinogen, $g / L$ & $3.18 \pm 0.06$ & $-1.4 \pm 1.0$ & $3.13 \pm 0.04$ & $-1.6 \pm 1.4$ & $3.12 \pm 0.04$ & $+1.0 \pm 0.9$ \\
\hline Prothrombin, $\%$ & $99.6 \pm 1.2$ & $+0.8 \pm 0.6$ & $93.7 \pm 3.0$ & $-5.5 \pm 1.5^{*}$ & $91.5 \pm 2.2$ & $+0.4 \pm 1.9$ \\
\hline Factor $V, \%$ & $93.4 \pm 2.4$ & $-0.8 \pm 1.1$ & $97.7 \pm 6.7$ & $-9.6 \pm 4.5^{*}$ & $92.7 \pm 4.5$ & $+1.7 \pm 3.9$ \\
\hline Factor VII, $\%$ & $100.1 \pm 2.0$ & $-1.1 \pm 0.9$ & $96.6 \pm 3.1$ & $-6.3 \pm 2.0^{*}$ & $103.0 \pm 5.4$ & $-1.8 \pm 1.9$ \\
\hline Factor $\mathrm{X}, \%$ & $100.1 \pm 1.6$ & $-0.4 \pm 0.7$ & $92.2 \pm 3.4$ & $-5.9 \pm 1.7^{*}$ & $88.9 \pm 2.9$ & $-1.7 \pm 1.7$ \\
\hline Antithrombin, $\%$ & $88.7 \pm 1.0$ & $+1.5 \pm 0.9$ & $82.5 \pm 1.4$ & $+0.3 \pm 1.6$ & $82.9 \pm 1.1$ & $+0.1 \pm 1.1$ \\
\hline \multicolumn{7}{|c|}{ Thrombin generation } \\
\hline $\begin{array}{l}\text { Time-to-peak } \\
\min \end{array}$ & $6.6 \pm 0.2$ & $+3.7 \pm 1.5^{*}$ & $7.14 \pm 0.35$ & $-0.6 \pm 1.8$ & $7.09 \pm 0.24$ & $+2.0 \pm 2.1$ \\
\hline $\begin{array}{l}\text { Thrombin peak } \\
\text { nmol/L }\end{array}$ & $298 \pm 7$ & $-1.1 \pm 1.8$ & $294 \pm 12$ & $-1.6 \pm 3.7$ & $270 \pm 11$ & $+0.9 \pm 3.0$ \\
\hline $\begin{array}{l}\mathrm{ETP} \\
\mathrm{nmol} / \mathrm{L} \times \min \end{array}$ & $1838 \pm 32$ & $-0.3 \pm 1.0$ & $1799 \pm 59$ & $-3.1 \pm 1.9^{*}$ & $1656 \pm 49$ & $+1.7 \pm 1.2$ \\
\hline
\end{tabular}

1 Values are means \pm SEM.

${ }^{2}$ Fish oil effect, $n=54$ (study 1 ) or 20 (study 2 ). $* P<0.05$

${ }^{3}$ Corn oil effect, $n=22$ (study 2). There were no significant effects for any variable, $P>0.05$. 
After $8 \mathrm{wk}$, the 20 diabetic patients of study 2 who were assigned to take fish oil, had lower plasma concentrations of prothrombin, factor V, factor VII, factor $\mathrm{X}$ and of fibrinogen (borderline, $P=0.064$ ). In contrast, plasma coagulation factors did not change in the corn oil group (Table 3). Furthermore, in the fish oil group but not in the corn oil group, the plasma triacylglycerol concentration and tissue factor-induced thrombin generation (ETP) were significantly reduced. There were no differences in baseline plasma values between the fish oil and corn oil group. Overall, fish oil had stronger hypolipidemic and anticoagulant effects in the diabetic patients (study 2) than in the healthy subjects (study l).

\section{Increased anticoagulant effect of fish oil in subjects with high plasma triacylglycerol concentrations}

For the overweight subjects of study 1, correlation analysis showed that the fish oil effect on plasma triacylglycerol strongly correlated with the baseline triacylglycerol concentration $(R=-0.45, P=0.001)$, and also with the fish oil effect on factor VII $(R=$ $0.28, P=0.042)$ and factor $\mathrm{X}(R=0.25, P=0.070)$. Interestingly, such a relation was not found for the type 2 diabetes patients of study 2 , whom all had high triacylglycerol at baseline $(>1.50 \mathrm{mmol} / \mathrm{L})$ and a consistent lipid-lowering and anticoagulant response, as described above.

Since recent risk assessments indicate that fasting triacylglycerol concentrations of $>$ $150 \mathrm{mg} / \mathrm{dL}(>1.69 \mathrm{mmol} / \mathrm{L})$ are a matter of health concern (26), we used this as a cutoff point to distinguish between subjects with low and high triacylglycerol concentrations. For the overweight subjects of study 1 , this resulted in two subgroups, one of 39 subjects with low concentrations of triacylglycerol $(0.99 \pm 0.05 \mathrm{mmol} / \mathrm{L})$ and one of 15 subjects with moderately increased concentrations of triacylglycerol ( $2.68 \pm$ $0.32 \mathrm{mmol} / \mathrm{L}$ ). The BMI of the subgroups were $28.6 \pm 0.6$ and $28.4 \pm 0.4 \mathrm{~kg} / \mathrm{m}^{2}$, respectively.

At baseline, plasma concentrations of total and HDL cholesterol were not different between the subgroups (Figure 2A). However, the high-triacylglycerol subgroup had also higher concentrations of prothrombin $(P=0.024)$ and factor $\mathrm{X}(P=0.003)$, and tended to have a higher concentration of factor VII $(P=0.079)$, but not of factor V and antithrombin (Figure 2B). Thrombin generation was not different between the subgroups.

Fish oil greatly decreased triacylglycerol $(-24.2 \%, P=0.002)$ in the high- but not in the low-triacylglycerol subgroup (Figure 2C). Also, fish oil reduced factor VII $(-2.9 \%, P=$ 0.028 ) in the high-triacylglycerol subgroup (Figure 2D). Interestingly, thrombin generation was lowered (prolonged time-to-peak and decreased thrombin peak concentration, $P=0.017$ and 0.023 , respectively) again only in the high-triacylglycerol subgroup. Together with the data of study 2 , this pointed to a striking association of the triacylglycerol-lowering and anticoagulant effects of fish oil. Moreover, these effects were most apparent in plasma from individuals with high triacylglycerol concentrations. 

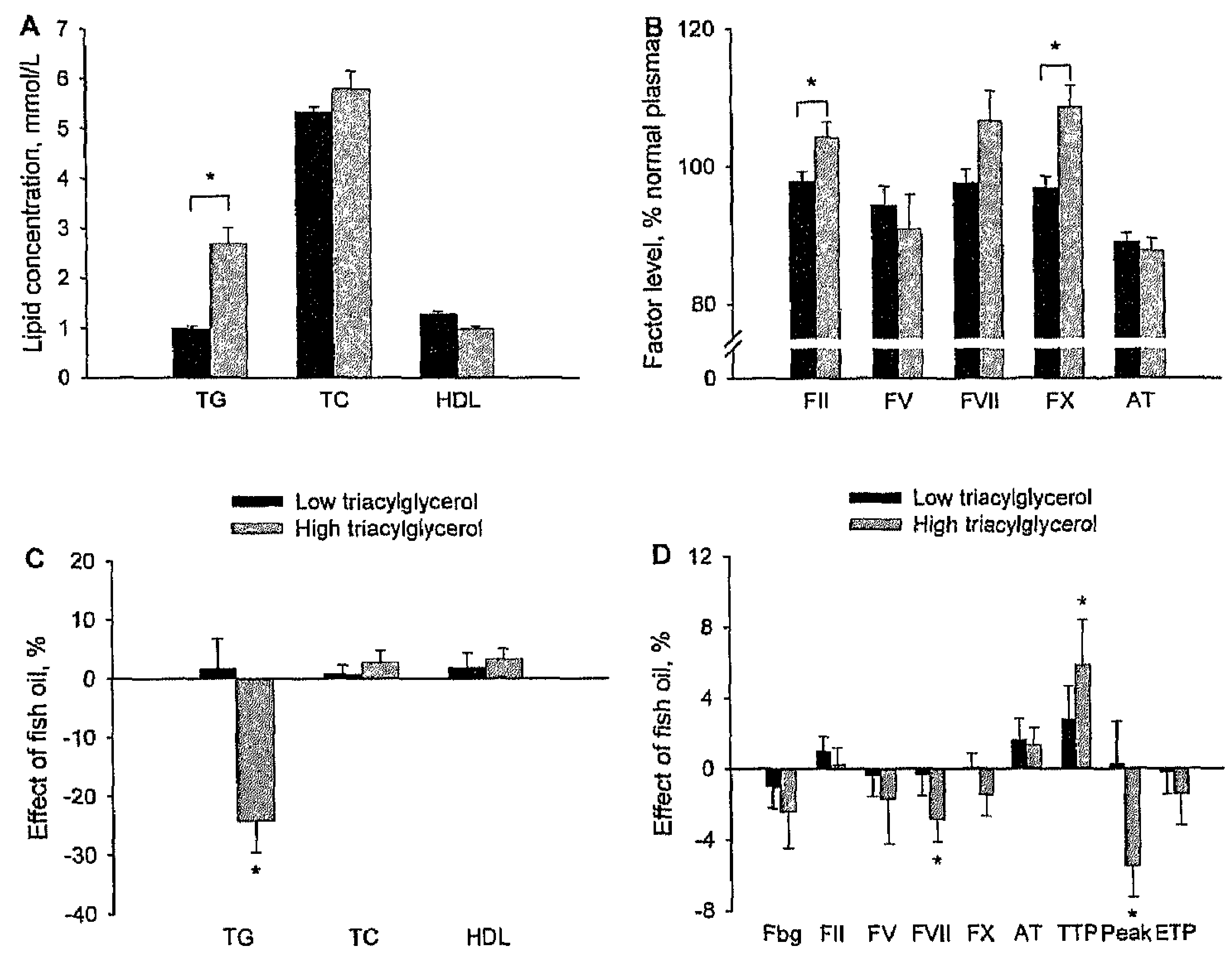

Figure 2. Effects of fish oil on plasma lipids, coagulation factors and thrombin generation in 54 overweight healthy subjects with low and high baseline triacylglycerol concentrations (study 1). Fasting concentrations triacyiglycerol at baseline were considered to be high at $>1.69 \mathrm{mmol} / \mathrm{L}$. Values are means $\pm \mathrm{SEM}$. Data presented from subjects with low $(n=39)$ and subjects with high $(n=15)$ triacylglycerol concentrations. (A, B) Baseline concentrations, ${ }^{*} P<0.05$ (Mann-Whitney U test). (C, D) Effects of fish oil intervention compared to baseline, $* P<0.05$ (paired t-test or Wilcoxon signed rank-test). Abbreviations: AT, antithrombin; ETP, endogenous thrombin potential; F, factor; Fbg, fibrinogen; HDL, HDL cholesterol; TC, total cholesterol; TG, triacylglycerol; TTP, time-to-peak.

\section{Increased anticoagulant effect of fish oil in subjects with high thrombin generation or fibrinogen}

We also evaluated whether high baseline concentrations of plasma components other than triacylglycerol could determine the fish oil effect on those components. This was the case for the thrombogram (thrombin generation curve) and for the fibrinogen concentration. In the overweight subjects of study 1 , thrombin peak height $(R=-0.35, P$ $=0.010)$ and $\operatorname{ETP}(R=-0.36, P=0.007)$ negatively correlated with the fish oil effect on these variables. Further, in study 1 and 2 baseline fibrinogen concentrations negatively correlated with the fish oil effect on fibrinogen $(R=-0.42, P=0.001$ and $R=-0.47, P=$ 0.037 , respectively). On the other hand, such a relation between baseline concentration 
and effect was not present for other coagulation factors (prothrombin, factor $\mathrm{V}$, factor VII, factor $X$ and antithrombin). This is of interest because it suggests that the anticoagulant effect of fish oil is typically highest in individuals with not only high triacylglycerol or fibrinogen concentrations but also with high coagulant activity.

\section{Genetic variation and effects of fish oil}

We have found that healthy carriers of the fibrinogen $\alpha$-chain 312Ala variant had relatively high fibrinogen concentrations and a strong reduction in thrombin generation in response to fish oil (10). For the overweight subjects of study 1, we determined a number of coagulation factor polymorphisms that have been associated with increased thrombotic risk, i.e. the fibrinogen $\alpha$-chain T312A polymorphism; the G20210A and A19911G polymorphisms of prothrombin; and the A4070G (HR2 haplotype) and G1691A (factor $V_{\text {Leiden }}$ ) polymorphisms of factor $V$. At baseline, data analysis confirmed the known linkage of G20210A carriers with a tendency to increased prothrombin concentrations $(n=3, P=0.138)$ and a linkage of A4070G carriers with decreased factor $\mathrm{V}$ concentrations $(n=8, P=0.019)$ (Table 4). Differences in fish oil effects between carriers and non-carriers were only observed for the fibrinogen $\alpha$ 312Ala carriers, which had a borderline decrease in thrombin peak concentration $(P=$ 0.082 ) and for the factor $V A 4070 G$ carriers, which had a tendency to decreased factor $\mathrm{V}$ concentrations $(P=0.058)$. However, correlation analysis indicated that the genetic variation was only a minor determinant of the subject-dependent fish-oil effects in comparison to the variation in triacylglycerol concentrations.

\section{DISCUSSION}

The present study provides a novel explanation for the earlier detected inter-subject differences in anticoagulant response to fish oil supplementation. We find that high concentrations of triacylglycerol in association with coagulation factors are predictive for the reducing effect of fish oil on the plasma concentrations of triacylglycerol and these coagulation factors. Furthermore, a high triacylglycerol concentration appears to be predictive for the fish-oil induced reduction in thrombin generation, i.e. in integrated coagulant activity. Similar results were obtained in both intervention studies, carried out with overweight healthy subjects and type 2 diabetes patients. In the first study, only those subjects with high fasting triacylglycerol concentrations responded to fish oil by a reduction in factor VII and other coagulation factors, along with a reduction in thrombin generation. Strikingly, these diet effects were associated with a reduction of plasma triacylglycerol, and not of cholesterol. In agreement with earlier results $(10,27)$, the intervention period of $4 \mathrm{wk}$ appeared to be sufficient to result in an overall anticoagulant effect of fish oil fatty acids.

In the second study, almost all diabetic patients had high triacylglycerol concentrations $(>1.50 \mathrm{mmol} / \mathrm{L}$ ) at baseline. Intake of fish oil, but not of corn oil (containing $\mathrm{n}-6$ PUFA), reduced plasma triacylglycerol concentration, accompanied by decreases in 
concentrations of prothrombin, factor V, factor VII and factor X, as well as by a potent reduction in thrombin generation. These findings likely are of clinical relevance since type 2 diabetes patients usually have an atherogenic lipoprotein profile with high triacylglycerol and LDL cholesterol, and show an increased risk of thrombosis $(28,29)$. It has been established that diabetic patients respond to fish oil by a partial correction of dyslipidemia $(30,31)$. We now provided evidence that the triacylglycerol-lowering effect in these patients is associated with an anticoagulant effect.

Table 4: Influence of genetic variation on baseline plasma concentrations and dietary fish oil effect in overweight healthy subjects. ${ }^{\prime}$

\begin{tabular}{|c|c|c|c|c|}
\hline & \multicolumn{2}{|c|}{ Non-carrier } & \multicolumn{2}{|c|}{ Carrier } \\
\hline & Baseline $^{2}$ & $\Delta$ Fish oil, $\%^{3}$ & Baseline $^{2}$ & $\Delta$ Fish oil, $\%^{3}$ \\
\hline \multicolumn{5}{|c|}{ Prothrombin G20210A $(51 / 3)^{4}$} \\
\hline Prothrombin, $\%$ & $99.0 \pm 1.2$ & $0.6 \pm 0.7$ & $110.3 \pm 7.2$ & $3.2 \pm 2.7$ \\
\hline Thrombin peak, nmol/L & $293 \pm 7$ & $-0.3 \pm 1.9$ & $363 \pm 66$ & $\cdot 1.4 \pm 2.5$ \\
\hline ETP, $n$ mol/L $\times \min$ & $1820 \pm 29$ & $-0.2 \pm 1.1$ & $2148 \pm 294$ & $-1.9 \pm 3.7$ \\
\hline \multicolumn{5}{|c|}{ Prothrombin A19911G (13/41) } \\
\hline Prothrombin, $\%$ & $98.0 \pm 2.8$ & $0.6 \pm 1.1$ & $100.1 \pm 1.4$ & $0.8 \pm 0.8$ \\
\hline Thrombin peak, nmol/L & $299 \pm 18$ & $1.8 \pm 3.5$ & $296 \pm 8$ & $-1.1 \pm 2.1$ \\
\hline $\mathrm{ETP}, n$ mol/L $\times \min$ & $1843 \pm 86$ & $-2.1 \pm 1.6$ & $1837 \pm 33$ & $0.3 \pm 1.3$ \\
\hline \multicolumn{5}{|l|}{ Factor V A4070G (46/8) } \\
\hline Factor $\mathrm{V}, \%$ & $95.8 \pm 2.5$ & $0.1 \pm 1.2$ & $79.5 \pm 4.9^{*}$ & $-5.9 \pm 2.5$ \\
\hline Thrombin peak, nmol/L & $291 \pm 7$ & $-1.1 \pm 2.1$ & $339 \pm 22$ & $-0.9 \pm 2.6$ \\
\hline $\mathrm{ETP}, n \mathrm{~mol} / L \times \mathrm{min}$ & $1822 \pm 31$ & $0.3 \pm 1.1$ & $1931 \pm 124$ & $-3.6 \pm 2.4$ \\
\hline \multicolumn{5}{|l|}{ Factor V G1691A (50/4) } \\
\hline Factor V, $\%$ & $93.8 \pm 2.5$ & $-0.8 \pm 1.2$ & $89.3 \pm 9.6$ & $-0.6 \pm 2.0$ \\
\hline Thrombin peak, nmol/L & $297 \pm 8$ & $-1.0 \pm 2.0$ & $316 \pm 21$ & $-2.8 \pm 1.5$ \\
\hline $\mathrm{ETP}, n \mathrm{~mol} / \mathrm{L} \times \mathrm{min}$ & $1843 \pm 34$ & $-0.4 \pm 1.1$ & $1775 \pm 115$ & $1.1 \pm 2.5$ \\
\hline \multicolumn{5}{|c|}{ Fibrinogen- $\alpha$ T312A (31/23) } \\
\hline Fibrinogen, $g / L$ & $3.12 \pm 0.07$ & $-0.5 \pm 1.3$ & $3.27 \pm 0.09$ & $-2.6 \pm 1.7$ \\
\hline Thrombin peak, nmol/L & $291 \pm 9$ & $0.0 \pm 2.2$ & $307 \pm 13$ & $-2.6 \pm 3.1$ \\
\hline ETP, $n$ mol/L $\times$ min & $1820 \pm 28$ & $0.2 \pm 1.2$ & $1864 \pm 65$ & $-0.8 \pm 1.9$ \\
\hline
\end{tabular}

'Values are means \pm SEM.

${ }^{2}$ Baseline values were compared between non-carriers and carriers, ${ }^{*} P<0.05$.

${ }^{3}$ Fish oil effect was compared to baseline. There were no significant effects for any variable, $P>0.05$.

${ }^{4}$ Polymorphism (non-carrier/carrier), $n$. 
It has been proposed that dietary fish oil may interfere with the production of vitamin $\mathrm{K}$-dependent coagulation factors (32). Earlier, this hypothesis was challenged in animal studies, indicating that fish oil also lowers the vitamin $\mathrm{K}$-independent factor $\mathrm{V}$ and further that the anticoagulant effect of fish oil is not sensitive to vitamin $\mathrm{K}$ depletion $(33,34)$. In the present human intervention studies, we again found a reduction in factor $\mathrm{V}$ by fish oil, particularly in subjects with high triacylglycerol concentrations. In spite of this, factor $V$ was not associated with the concentrations of vitamin K-dependent factors (prothrombin, factor VII and factor $\mathrm{X}$ ) at baseline, suggesting that its steady-state concentration in plasma is regulated separately. The physiological relevance of this becomes apparent from the clear correlation between the extent of thrombin generation (peak height and ETP) at baseline and the fish oil-provoked reduction in thrombin generation.

Other variables also appear to contribute to the subject-dependent response to fish oil. As we and others have observed before $(10,35,36)$, baseline fibrinogen concentrations correlated with the effect of fish oil on this plasma variable. In comparison to these likely determinants, statistical analysis indicates that genetic polymorphisms of prothrombin or factor $\mathrm{V}$ do not play an important role in the fish oil response, while the fibrinogen- $\alpha$ T312A polymorphism is of secondary importance. Together, this suggests that subjects with high concentrations of triacylglycerol, coagulation factors, coagulation activity and fibrinogen, and thus with increased risk of thrombosis, would benefit most from fish oil intake.

It has been reported by various groups that hyperlipidemic patients have elevated concentrations of factor VII $(13,15,37)$, and there is also evidence that these patients have elevated concentrations of prothrombin and factor X (38). This compares well with the present key observation that subjects with high triacylglycerol concentrations - both healthy subjects and patients - responded better to fish oil by a greater decrease in triacylglycerol, factor VII and thrombin generation, than those with lower triacylglycerol concentrations. Small changes in prothrombin are likely to contribute to this effect, as multivariate analysis showed that triacylglycerol together with prothrombin (and antithrombin) contribute to the variation in thrombin generation. Taken together, we conclude that the plasma triacylglycerol concentration is predictive of the (pro)coagulant state of plasma, likely by reflecting the overall activity of several coagulation factors. In fact, the present data suggest that measurement of overall thrombin generation (thrombin potential), or the triacylglycerol concentration as predictive value, gives a better indication of the (pro)coagulant state of plasma than measurement of individual hemostatic factors. High triacylglycerol concentrations also seem to predict the effect of dietary fish oil on plasma (pro)coagulant activity. Although these conclusions come from data obtained with 96 subjects, we note that larger epidemiological analyses are needed for confirmation. The intervention studies were carried out with relatively large amounts of n-3 PUFA $(3.1 \mathrm{~g} / \mathrm{d})$, which is equivalent to a daily intake of approximately $100-200 \mathrm{~g}$ fatty fish.

The present results indicate that the coagulation-lowering effect of fish oil is part of a broader mechanism that is not confined to coagulation factors alone, but also involves 
regulation of plasma lipids. One of the first reports to suggest a link between hypertriglyceridemia and hypercoagulability is the Northwick Park Heart Study, showing an overall correlation between plasma triglycerides and factor VII activity (39). In the present study with all together 99 subjects, principal component analysis indicated that fasting triacylglycerol clustered with the steady-state concentrations of a number of coagulation factors, namely prothrombin, factor VII and factor X. Covariance analysis confirmed that triacylglycerol correlated with these coagulation factors. This is likely to point to a common regulation by the liver, since the majority of triacylglycerol in fasting plasma comes from VLDL particles produced by the liver, which organ is also the source of most coagulation factors. The hepatic regulation of triacylglycerol in VLDL by fish oil is still a matter of debate. Mechanisms proposed include down-regulation of gene expression in the liver by the n-3 PUFAs delivered via chylomicron remnants $(40)$; suppression of VLDL apo B production $(41,42)$ or stimulation of apo B degradation (43); increased clearance of chylomicrons $(44,45)$; and higher conversion of VLDL into LDL in the peripheral tissues $(46,47)$. The present data argue for a common hepatic effect of n-3 PUFAs, e.g. jointly controlling the production and/or secretion of VLDL and vitamin $\mathrm{K}$ (in)dependent coagulation factors.

\section{Acknowledgments}

We acknowledge Dr. S. Loman (Pharma Nord, Vejle, Denmark) for the kind supply of capsules for intervention studies. We thank Dr. P. Marckmann and coworkers (Esbjerg, Denmark) for their help in the intervention studies and collection of patient data and samples. 
Predictors of anticoagulant effect of fish oil

\section{REFERENCES}

1. Kris-Etherton PM, Harris WS, Appel LJ. Fish consumption, fish oil, omega-3 fatty acids, and cardiovascular disease. Arterioscler Thromb Vasc Biol. 2003; 23: e20-30.

2. Hu FB, Cho E, Rexrode KM, Albert CM, Manson JE. Fish and long-chain omega-3 fatty acid intake and risk of coronary heart disease and total mortality in diabetic women. Circulation. 2003; 107: 1852-7.

3. Bang HO, Dyerberg J, Nielsen AB. Plasma lipid and lipoprotein pattern in Greenlandic west-coast Eskimos. Lancet. 1971; 1: 1143-5.

4. Dallongeville J, Yarnell J, Ducimetiere P, Arveiler D, Ferrieres J, Montaye M, Luc G, Evans A, Bingham $A$, et al. Fish consumption is associated with lower heart rates. Circulation. 2003; 108: 820-5.

5. Leaf A, Kang JX, Xiao YF, Billman GE. Clinical prevention of sudden cardiac death by $n-3$ polyunsaturated fatty acids and mechanism of prevention of arrhythmias by $\mathrm{n}-3$ fish oils. Circulation. 2003; 107: 2646-52.

6. Harris WS. N-3 fatty acids and serum lipoproteins: human studies. Am J Clin Nutr. 1997; 65: 1645S$54 \mathrm{~S}$.

7. Leaf A, Weber PC. Cardiovascular effects of n-3 fatty acids. N Engl J Med. 1988; 318: 549-57.

8. Malle E, Kostner GM. Effects of fish oil on lipid variables and platelet function indices. Prostagland Leukotr Essential Fatty Acids. 1993; 49: 645-63.

9. Vanschoonbeek K, de Maat MP, Heemskerk JWM. Fish oil consumption and reduction of arterial disease. J Nutr. 2003; 133: 657-60.

10. Vanschoonbeek K, Feijge MAH, Paquay M, Rosing J, Saris W, Kluft C, Giesen PL, de Maat MP, Heemskerk JWM. Variable hypocoagulant effect of fish oil intake in humans: modulation of fibrinogen level and thrombin generation. Arterioscler Thromb Vasc Biol. 2004; 24: 1734-40.

11. Hemker HC, Béguin S. Phenotyping the clotting system. Thromb Haemost. 2000; 84: 747-51.

12. Hemker HC, Al Dieri R, Béguin S. Thrombin generation assays: accruing clinical relevance. Curr Opin Hematol. 2004; 11: 170-5.

13. Hoffman CJ, Lawson WE, Miller RH, Hultin MB. Correlation of vitamin K-dependent clotting factors with cholesterol and triglycerides in healthy young adults. Arterioscler Thromb. 1994; 14: 1737-40.

14. Rosenson RS, Lowe GD. Effects of lipids and lipoproteins on thrombosis and theology. Atherosclerosis. $1998 ; 140: 271-80$

15. Nordoy A, Svensson B, Hansen JB. Atorvastatin and omega-3 fatty acids protect against activation of the coagulation system in patients with combined hyperlipemia. J Thromb Haemost. 2003; 1:690-7.

16. Bladbjerg EM, Munster AM, Marckmann P, Keller N, Jespersen J. Dietary factor VII activation does not increase plasma concentrations of prothrombin fragment $1+2$ in patients with stable angina pectoris and coronary atherosclerosis. Arterioscier Thromb Vasc Biol. 2000; 20: 2494-9.

17. Hemker HC, Giesen P, Al Dieri R, Regnault V, De Smedt E, Wagenvoord R, Lecompte T, Béguin S, Calibrated automated thrombin generation measurement in clotting plasma. Pathophysiol Haemost Thromb. 2003; 33: 4-15.

18. Vanschoonbeek K, Feijge MAH, van Kampen RJ, Kenis H, Hemker HC, Giesen PL, Heemskerk JWM. Initiating and potentiating role of platelets in tissue factor-induced thrombin generation in the presence of plasna: subject-dependent variation in thrombogram characteristics. J Thromb Haemost. 2004; 2: 476-84.

19. Carter AM, Catto AJ, Kohler HP, Ariens RA, Stickland MH, Grant PJ. $\alpha$-Fibrinogen Thr312Ala polymorphism and venous thromboembolism. Blood. 2000; 96: 1177-9.

20. Poort SR, Rosendaal FR, Reitsma PH, Bertina RM. A common genetic variation in the $3^{\prime}$-untranslated region of the prothrombin gene is associated with elevated plasma prothrombin levels and an increase in venous thrombosis. Blood. 1996; 88: 3698-703.

21. Ceelie H, Bertina RM, van Hylckama Vlieg A, Rosendaal FR, Vos HL. Polymorphisms in the prothrombin gene and their association with plasma prothrombin levels. Thromb Haemost. 2001; 85: $1066-70$.

22. Lunghi $B$, Iacoviello L, Gemmati D, Dilasio MG, Castoldi E, Pinotti M, Castaman G, Redaelli R, Mariani $G$, et al. Detection of new polymorphic markers in the factor $V$ gene: association with factor $V$ levels in plasna. Thromb Haemost. 1996; 75: 45-8.

23. Simioni P, Prandoni P, Lensing AW, Scudeller A, Sardella C, Prins MH, Villalta S, Dazzi F, Girolami A. The risk of recurrent venous thromboembolism in patients with an Arg506 $>$ Gln mutation in the gene for factor V (factor V Leiden). N Engl J Med. 1997; 336: 399-403. 
24. Third Report of the National Cholesterol Education Program (NCEP) Expert Panel on Detection, Evaluation, and Treatment of High Blood Cholesterol in Adults (Adult Treatment Panel III) final report. Circulation. 2002; 106: 3143-421.

25. Favaloro EJ, Soltani S, McDonald J, Grezchnik E, Easton L. Cross-laboratory audit of normal reference ranges and assessment of $\mathrm{ABO}$ blood group, gender and age on detected levels of plasma coagulation factors. Blood Coagul Fibrinolysis. 2005; 16: 597-605.

26. Kavey RE, Daniels SR, Lauer RM, Atkins DL, Hayman LL, Taubert K. American Heart Association guidelines for primary prevention of atherosclerotic cardiovascular disease beginning in childhood. Circulation. 2003; 107: 1562-6.

27. van Houwelingen AC, Hennissen AA, Verbeck-Schippers F, Simonsen T, Kester AD, Hornstra G. Effect of a moderate fish intake on platelet aggregation in human platelet-rich plasma. Thromb Haemost. $1988 ; 59: 507-13$.

28. Haffner SM, Lehto S, Ronnemaa T, Pyorala K, Laakso M. Mortality from coronary heart disease in subjects with type 2 diabetes and in nondiabetic subjects with and without prior myocardial infarction. $N$ Engl J Med. 1998; 339: 229-34.

29. Syvanne M, Taskinen MR. Lipids and lipoproteins as coronary risk factors in non-insulin-dependent diabetes mellitus. Lancet. 1997; 350: S120-3.

30. Petersen M, Pedersen H, Major-Pedersen A, Jensen T, Marckmann P. Effect of fish oil versus corn oil supplementation on LDL and HDL subclasses in type 2 diabetic patients. Diabetes Care. 2002; 25: 17048.

31. Pedersen H, Petersen M, Major-Pedersen A, Jensen T, Nielsen NS, Lauridsen ST, Marckmann P. Influence of fish oil supplementation on in vivo and in vitro oxidation resistance of low-density lipoprotein in type 2 diabetes. Eur J Clin Nutr. 2003; 57: 713-20.

32. Leray $C$, Wiesel ML, Freund M, Cazenave JP, Gachet C. Long-chain n-3 fatty acids specifically affect rat coagulation factors dependent on vitamin $K$. Relation to peroxidative stress. Arterioscler Thromb Vasc Biol. 2001; 21: 459-65.

33. Nieuwenhuys CMA, Béguin S, Offermans RF, Emeis JJ, Hornstra G, Heemskerk JWM. Hypocoagulant and lipid-lowering effects of dietary n-3 polyunsaturated fatty acids with unchanged platelet activation in rats. Arterioscler Thromb Vasc Biol. 1998; 18: 1480-9.

34. Nieuwenhuys CMA, Feijge MAH, Vermeer C, Hennissen AH, Béguin S, Heemskerk JWM. Vitamin Kdependent and vitamin $\mathrm{K}$-independent hypocoagulant effects of dietary fish oil in rats. Thromb Res. $2001 ; 104: 137-47$.

35. Haglund $O$, Wallin R, Luostarinen R, Saldeen T. Effects of a new fluid fish oil concentrate, Eskimo-3, on triglycerides, cholesterol, fibrinogen and blood pressure. J Intern Med. 1990; 227: 347-53.

36. Shahar E, Folsom AR, Wu KK, Dennis BH, Shimakawa T, Conlan MG, Davis CE, Williams OD. Associations of fish intake and dietary n-3 polyunsaturated fatty acids with a hypocoagulable profile. The Atherosclerosis Risk in Communities (ARIC) study. Arterioscler Thromb. 1993; 13: 1205-12.

37. Chan P, Tomlinsoin B, Tsai CW, Pan WH, Lee YS. Thrombophilia in patients with hypercholesterolemia. Metabolism. 1996; 45: 966-9.

38. Morishita E, Jokaji H, Matsuda T. Hyperlipidemia and hemostatic system. J Atheroscler Thromb. 1995; 2: $\mathrm{S} 36-40$.

39. Meade TW, Mellows S, Brozovic M, Miller GJ, Chakrabarti RR, North WR, Haines AP, Stirling Y, Imeson JD, Thompson SG. Haemostatic function and ischaemic heart disease: principal results of the Northwick Park Heart Study. Lancet. 1986; 2: 533-7.

40. Botham KM, Zheng X, Napolitano M, Avella M, Cavallari C, Rivabene R, Bravo E. The effects of dietary $n-3$ polyunsaturated fatty acids delivered in chylomicron remnants on the transcription of genes regulating synthesis and secretion of very-low-density lipoprotein by the liver: modulation by cellular oxidative state. Exp Biol Med. 2003; 228: 143-51.

41. Nestel PJ, Connor WE, Reardon MF, Connor S, Wong S, Boston R. Suppression by diets rich in fish oil of very low density lipoprotein production in man. J Clin Invest. 1984; 74: 82-9.

42. Bordin P, Bodamer OA, Venkatesan S, Gray RM, Bannister PA, Halliday D. Effects of fish oil supplementation on apolipoprotein B100 production and lipoprotein metabolism in normolipidaemic males. Eur J Clin Nutr. 1998; 52: 104-9.

43. Pan M, Cederbaum AI, Zhang YL, Ginsberg HN, Williams KJ, Fisher EA. Lipid peroxidation and oxidant stress regulate hepatic apolipoprotein B degradation and VLDL production. $J$ Clin Invest. 2004; 113: $1277-87$. 
44. Westphal S, Orth M, Ambrosch A, Osmundsen K, Luley C. Postprandial chylomicrons and VLDLs in severe hypertriacylglycerolemia are lowered more effectively than are chylomicron remnants after treatment with n-3 fatty acids. Am J Clin Nutr. 2000; 71: 914-20.

45. Park Y, Harris WS. Omega-3 fatty acid supplementation accelerates chylomicron triglyceride clearance. J Lipid Res. 2003; 44: 455-63.

46. Huff MW, Telford DE. Dietary fish oil increases conversion of very low density lipoprotein apoprotein B to low density lipoprotein. Arteriosclerosis. 1989; 9: 58-66.

47. Fisher WR, Zech LA, Stacpoole PW. Apolipoprotein B metabolism in hypertriglyceridemic diabetic patients administered either a fish oil- or vegetable oil-enriched diet. J Lipid Res. 1998; 39: 388-401. 


\section{Chapter 7}

\section{Anticoagulant effect of dietary fish}

oil in hyperlipidemia: a study of hepatic mRNA expression in

\section{APOE2 knock-in mice}

Kristof Vanschoonbeek, Kristiaan Wouters, Paola E.J. van der Meijden, Patrick J. van Gorp, Leon J. Schurgers, Marion A.H. Feijge, Marten H. Hofker, Moniek P.M. de Maat and Johan W.M. Heemskerk.

Submitted, 2007 


\begin{abstract}
In hyperlipidemia, a fish oil diet with n-3 polyunsaturated fatty acids (PUFA) provokes both lipid-lowering and hypocoagulant effects. In a transgenic APOE2 knock-in (ki) mouse model, we investigated how fish oil altered hepatic expression of genes controlling fat metabolism and (anti)coagulant factors. Adult male APOE ki mice, given a regular low-fat diet, developed hyperlipidemia and had high coagulation factor levels twice as high as wildtype mice. Both plasma lipids and coagulation factors normalized, after feeding a high-fat diet with fish oil ( $n-3$ PUFA), but not after a sunflower seed oil (n-6 PUFA) diet. The fish-oil gave a 40\% reduction in thrombin generation potential. Liver microarray and single gene expression analysis showed that fish oil, but not sunflower seed oil caused: up-regulation of genes involved in fatty acid degradation and oxidation; down-regulation of genes contributing to fatty acid synthesis and transport; lower gene expression of $\gamma$-glutamyl carboxylase, but not of (anti)coagulant factors. Immunohistochemical staining of liver sections indicated that only fish-oil diet increased coagulation factors in the liver. We conclude that the hyperlipidemic and hypercoagulant APOE2 ki mice respond to dietary $\mathrm{n}-3$ PUFA by reduced coagulant activity, which is not linked to altered hepatic expression of coagulation factor genes, but to restraint of these factors in the liver. The lipid-lowering effect of n-3 PUFA is linked to increased hepatic expression of genes regulating fatty acid degradation and decreased expression of genes regulating fatty acid synthesis.
\end{abstract}




\section{INTRODUCTION}

Both observational studies and clinical trials have pointed to a close association between consumption of fatty fish, rich in the n-3 polyunsaturated fatty acids (PUFA), eicosapentaenoic and docosahexaenoic acid, and a reduced risk of coronary heart disease. Together, these investigations have led to the recommendation of a daily intake of n-3 PUFA, particularly in case of hypertriglyceridemia (1). Fish oil has a lowering effect on plasma triacylglycerol levels, which effect is most prominent in subjects in whom these levels are elevated (2). In addition, we and others have found that the lipidlowering is accompanied by an clear anticoagulant effect, that involves various coagulation factors and results in a diminished coagulant potential of plasma (3-5). However, why and how these seemingly different action mechanisms of dietary $n-3$ PUFA are linked is not understood. In healthy subjects, there exists a marked relation between the plasma levels of triacylglycerol and of coagulation factors (6-8). It is therefore likely that both are regulated by a common factor or pathway. Knowing that the liver is the common source of these fats and proteins, an attractive hypothesis is that fish oil modulates one or more hepatic transcriptional or translational processes, that are involved in the production of triacylglycerol and coagulation factors.

Earlier intervention studies have indicated that dietary n-3 PUFA also reduce triglyceride and coagulation factor levels in experimental animals. In rats, it was suggested that fish oil reduces the vitamin $\mathrm{K}$ levels in the liver and, hence, the vitamin $\mathrm{K}$-dependent $\gamma$-carboxylation of coagulation factors $(9,10)$. However, this proposal was challenged by the observation that in rats also vitamin $\mathrm{K}$-independent factors, like factor $\mathrm{V}$ and fibrinogen, are reduced by $\mathrm{n}-3$ PUFA diet $(11,12)$. Because the ingestion of vitamin $\mathrm{K}$ is ample under normal nutritional conditions, it appeared unlikely the deficiency in this component explains the anticoagulant activity of fish oil.

In the present paper, we investigated whether n-3 PUFA in diet reduce lipids and coagulation factors in plasma by regulating a common (post)transcriptional mechanism in the liver. We therefore employed a murine model of type III hyperlipidemia, i.e. transgenic apolipoprotein E2 knock-in (APOE2 ki) mice, in which the endogenous mouse gene for apoE has been replaced by the human APOE2 gene (13). In man, the APOE2 polymorphism encodes for an Apo $\mathrm{E}$ protein form with a greatly reduced binding to low-density lipoprotein (LDL) receptors, when compared to the common APOE3 gene (14). Using the APOE2 ki mice, we determined the effects of dietary n-3 PUFA and n-6 PUFA on plasma lipid and coagulation parameters, and compared these with the dietary effects on hepatic mRNA expression patterns using microarray chip analysis.

\section{MATERIALS AND METHODS}

\section{Animals and diets}

Wildtype C57BL/6 mice were obtained from Charles River (Leiden, The Netherlands), 
and held on standard, low-fat chow diet, containing $9 \%$ of energy (en\%) as fat ( 38.9 $\mathrm{mg} / \mathrm{g}$ food), $58 \mathrm{en} \%$ as carbohydrates and $33 \mathrm{en} \%$ as protein (Ssniff, Soest, Germany). Homozygote, transgenic APOE2 ki mice, expressing the human APOE2 gene, were generated at a C57BL/6 background, as described (13). The mice, bred in-house, were used at the N6F1 and N5F3 generations (randomly mixed), and were pathogenic-free. For the diet study, thirty-two male APOE2 ki mice were grown with standard, low-fat chow diet. At an age of 16 weeks, the animals weighing 22-31 g were randomly divided into three groups, each receiving a different diet for 21 days. One group of 12 mice (low-fat group) continued on the standard diet. Two other groups of 10 mice received a diet, in which $8 \mathrm{en} \%$ of carbohydrates and $4 \mathrm{en} \%$ of protein was replaced by fat. The fat $(90.5 \mathrm{mg} / \mathrm{g}$ food, equivalent to $21 \mathrm{en} \%$ ) was provided by either $100 \%$ sunflower seed oil rich in n-6 PUFA (sunflower seed oil group), or 75\% fish oil rich in n-3 PUFA plus $25 \%$ sunflower seed oil (fish oil group). The fatty acid composition of the diets is given in Table 1. Other macro- and micronutrients were kept constant. Sunflower seed oil was obtained from Vandemoortele (Izegem, Belgium), and fish oil came from Hoffmann-La Roche (omega-3 oil, Basel, Switzerland); fatty acid composition of the oils was similar as described before (8). Oils were stored under oxygen-free conditions at $-80^{\circ} \mathrm{C}$, and checked for absence of peroxidation.

Table 1. Fatty acid composition of diets. Total fatty acid content ( $\mathrm{mg} / \mathrm{g}$ food) is given of the low-fat diet ( 9 en $\%$ as fat), and fat-enriched fish oil and sunflower seed oil diets (21 en\% as fat). Numbers in brackets indicate distribution of various fatty acids (weight percentages).

\begin{tabular}{clll}
\hline Fatty acid & $\begin{array}{l}\text { Low fat } \\
\mathrm{mg} / \mathrm{g}(\%)\end{array}$ & $\begin{array}{l}\text { Fish oil } \\
\mathrm{mg} / \mathrm{g}(\%)\end{array}$ & $\begin{array}{l}\text { Sunflower seed oil } \\
\mathrm{mg} / \mathrm{g}(\%)\end{array}$ \\
\hline Total $F A$ & $38.9(100 \%)$ & $90.5(100 \%)$ & $90.5(100 \%)$ \\
$\Sigma S F A^{1}$ & $7.7(19.7)$ & $3.8(4.2)$ & $11.8(13.0)$ \\
$<16: 0$ & $0.2(0.4)$ & $0.1(0.1)$ & $0.5(0.6)$ \\
$16: 0$ & $6.1(15.6)$ & $1.5(1.6)$ & $6.3(7.0)$ \\
$18: 0$ & $1.1(2.9)$ & $1.5(1.6)$ & $3.7(4.1)$ \\
$\Sigma M U F A$ & & & $27.6(30.5)$ \\
$18: 1 \mathrm{n}-9$ & $6.7(17.1)$ & $9.9(10.9)$ & $26.9(29.7)$ \\
& $6.4(16.5)$ & $7.6(8.4)$ & $50.7(56.0)$ \\
$\Sigma n-6 P U F A$ & $18.5(47.6)$ & $17.2(19.0)$ & $50.7(56.0)$ \\
$18: 2 \mathrm{n}-6$ & $18.5(47.5)$ & $13.9(15.4)$ & $0.3(0.3)$ \\
$\sum n-3 P U F A$ & $5.3(13.5)$ & $59.2(65.4)$ & $0.1(0.1)$ \\
$20: 5 \mathrm{n}-3$ & $0.0(0.0)$ & $32.9(36.3)$ & $0.0(0.0)$ \\
$22: 6 \mathrm{n}-3$ & $0.0(0.0)$ & $21.5(23.7)$ & \\
\hline
\end{tabular}

'Abbreviations: SFA, saturated fatty acids, MUFA, mono-unsaturated fatty acids. 
Diets were stored in aliquots at $-80^{\circ} \mathrm{C}$, and daily thawed before administration to the animals. Food was presented in stainless steel cups ( $5 \mathrm{~g} /$ mouse/day), and uneaten food was discarded daily. Tap water was provided in unlimited quantities. After 3 weeks of diet, mean weight was similar for each group of mice. The experiments were approved by the local Animal Ethics Committee.

\section{Collection of blood and liver}

Before blood collection, mice were deprived from food for about $4 \mathrm{~h}$. The animals were then anaesthetized with ketamine/xylazine, and injected with $180 \mu \mathrm{L}$ of $129 \mathrm{mmol} / \mathrm{L}$ trisodium citrate via the posterior vena cava. About $1 \mathrm{~mL}$ blood was collected via this vein, and the animal was sacrificed. Platelet-free plasma was prepared by centrifuging the blood twice at $18,000 \mathrm{~g}$ for $10 \mathrm{~min}$, and then snap-frozen in liquid nitrogen and stored at $-80^{\circ} \mathrm{C}$. The liver was immediately dissected according to a standard protocol, adherent connective tissue was removed and the organ was rinsed with ice-cold saline to remove all blood (15). Parts of the livers were snap-frozen and stored at $-80^{\circ} \mathrm{C}$, while other parts were fixed in $4 \%$ formaldehyde/PBS (15).

\section{Lipids and coagulation parameters}

Lipids were extracted from diets, fatty acids were transmethylated, and fatty acid profiles were analyzed by gas chromatography, as described (12). The triacylglycerol content in plasma was quantified, as described elsewhere (15). Levels of prothrombin and factors V, VII and X were measured using factor-deficient plasmas (11). Antithrombin was determined with a kit from Chromogenix (Mölndal, Sweden). Factor levels were expressed as percentages of activity of normal pooled plasma (male C57BL/6 wildtype mice). Fibrinogen was determined with the Claus method (11). Recombinant tissue factor, thromboplastin and thrombin reagent were from DadeBehring (Leusden, The Netherlands).

\section{Thrombin generation}

Thrombin generation was measured according to the automated thrombogram method $(5,16)$, adapted for mouse plasma. Briefly, duplicate (triplicate if sufficient plasma was available) samples of $40 \mu \mathrm{L}$ plasma containing $4 \mu \mathrm{mol} / \mathrm{L}$ (f.c.) procoagulant phospholipids were pipetted into a 96-wells plate. Each well contained $10 \mu \mathrm{L}$ recombinant tissue factor $(6 \mathrm{pmol} / \mathrm{L})$ in buffer $\mathrm{pH} 7.35(20 \mathrm{mmol} / \mathrm{L}$ Hepes, $140 \mathrm{mmol} / \mathrm{L}$ $\mathrm{NaCl}, 5 \mathrm{mg} / \mathrm{mL}$ bovine serum albumin). After pre-heating to $37^{\circ} \mathrm{C}$, coagulation was started by addition per well of $10 \mu \mathrm{L}$ fluorescent thrombin substrate (Z-Gly-Gly-Arg aminomethyl coumarin, $2.5 \mathrm{mmol} / \mathrm{L}$ ) suspended in $20 \mathrm{mmol} / \mathrm{L}$ Hepes, $0.2 \mathrm{~mol} / \mathrm{L} \mathrm{CaCl}_{2}$ plus $60 \mathrm{mg} / \mathrm{mL}$ bovine serum albumin (pH 7.35) under shaking. First-derivative curves of accumulation of fluorescence intensity in time were converted into curves of nanomolar thrombin, using human thrombin calibrator (17). Thrombograms were 
analyzed for thrombin peak height (indicative of maximal rate of thrombin formation), and area-under-the-curve or endogenous thrombin potential (thrombin activity during the total coagulation process).

\section{Preparation and pooling of tissue RNA}

Total RNA from liver tissue was isolated, and rigorously checked for quantity and quality, as described (15). For gene expression analysis, pools of high-quality total RNA were created; per pool it was checked that the concerning mice had on average representative values of plasma triglycerides and thrombin generation. The five pools consisted of $7.5 \mu \mathrm{g}$ total RNA from each of 4 livers: low-fat pools 1 and 2 (LF1 and LF2), sunflower seed oil pool (SSO), fish oil pools 1 and 2 (FO1 and FO2).

\section{Gene expression analysis using Affymetrix Gene Chips}

Liver RNA pools were converted into biotinylated cRNA, hybridized onto an Affymetrix GeneChip mouse expression array 430A cartridge (Affymetrix, Santa Clara, CA, USA), and then stained and quantified by confocal laser scanning microscopy (15). The cartridges contained 22,690 probe sets, corresponding to about 14,000 transcripts and variants. Arrays were run with cRNA material from the pools LF1, LF2, SSO, FO1 and FO2. Array data were quantified and analyzed with MAS 5.1 and NetAffx software (Affymetrix). Data from SSO and FO arrays were compared to those of both LF arrays (baseline). Per expressed sequence, the signal log ratio of expression was calculated for each combination of experimental (SSO, FO1 and FO2) and baseline (LF1 and LF2) arrays. Averaging resulted in a mean signal log ratio, from which a mean fold-change was calculated. Fold-changes $\geq 1.40$ were considered to be significant.

\section{Real-time quantitative PCR}

Non-pooled RNA samples from individual livers were subjected to real-time quantitative PCR (RT-PCR) to determine expression of specific genes. Total RNA (1 $\mu \mathrm{g}$ ) was converted into first strand cDNA, and used for RT-PCR with an ABI Prism 7000 (Applied Biosystems, Foster City, CA, USA) (15). Primers (5'-3', Eurogentec, Liège, Belgium) used were: for fibrinogen $\beta$ (Affymetrix ID: 1428079_at) CAGTGGTGTCTGGGAAAGAGTGT and CGGCTTGATGGAGGTGTCA; for prothrombin (1418897_at) GAGACATGGACAACCAACATCAAT and GTCATTCA CCTTGAAGCCAGCA; for lipoprotein lipase (1415904_at) AAAGCCGGAGAGACT CAGAAAA and TTTGTTTGTCCAGTGTCAGCC; for acyl-CoA dehydrogenase (142 4184_at) AGACGGAGGACAGGAATCGG and ACCACGGTGGCAAATTGATC; for carnitine palmitoyl transferase 1 (1460409_at) 5'-ACCCCACAACAACGGCAG and GCCAGCGCCCGTCAT. Standard $\beta$-actin cDNA was used as a reference for calibration and normalization. Per sample, chromogenic curves were generated in duplicate, and analyzed using SDS 1.0 software (Applied Biosystems). 


\section{Histology and immunohistochemistry}

Paraffin-embedded hepatic sections $(3 \mu \mathrm{m})$ were mounted on slides, deparaffinized in xylene, and rehydrated through a graded alcohol series and distilled water. Sections were stained with hematoxylin and eosin for general histological evaluation. Other sections were stained with polyclonal antibodies (dilution 1:50), raised against prothrombin (goat anti-human), factor VII (goat anti-mouse) and factor X (goat antihuman) from Santa Cruz (Santa Cruz, CA, USA). Sections were also stained with a monoclonal antibody against human $\gamma$-carboxy glutamate (Gla) residues $(1: 250)$ from American Diagnostica (Breda, The Netherlands). After washing, the sections were incubated with 1:250 diluted secondary polyclonal biotinylated rabbit anti-goat antibody (Dako, Heverlee, Belgium). Color development was with a streptavidin biotinylated alkaline phosphatase complex (Dako) and an alkaline phosphatase kit (Vector Laboratories, Burlingame, CA, USA). The sections were counterstained with hematoxylin and mounted on coverslips. Antibodies were tested for murine coagulation factors; negative control stainings were performed, omitting incubation with primary antibody. For each liver section, the red staining was quantified in representative adjacent microscopic images, using Lucia 4.8 software for immunohistochemistry (Nikon, Düsseldorf, Germany). Staining was expressed as integrated pixel intensity of positively stained tissue area over total tissue area.

\section{Statistics}

Data are expressed as mean \pm SEM. Differences between diet groups were compared with the Mann-Whitney U-test. Signal data from array sequences were compared with the Pearson test. The statistical package for the social sciences 12.0 was used (SPSS, Chicago, IL, USA).

\section{RESULTS}

Effects of fish and sunflower seed oil diets on plasma lipids and coagulation in APOE2 ki mice

When maintained on a standard low-fat diet, male APOE2 ki mice on a C57BL/6 background had relatively high fasting plasma levels of triacylglycerol, reaching $143 \pm 19 \mathrm{mg} / \mathrm{dL}$ (mean $\pm \mathrm{SEM}, n=7$ ), in agreement with earlier studies $(13,15)$. In comparison, plasma triacylglycerol levels in male wildtype C57BL/6 mice, held on the same diet, are considerably lower, i.e. $82.6 \pm 5.7 \mathrm{mg} / \mathrm{dL}(n=10)$, thus confirming the suitability of APOE2 transgenes as a model for hypertriglyceridemia. Strikingly, the APOE2 ki mice showed about two-fold increased levels of vitamin $\mathrm{K}$-dependent coagulation factors (prothrombin and factors VII and X), of vitamin $\mathrm{K}$-independent factors (factor $\mathrm{V}$ and, insignificantly, fibrinogen), and of the anticoagulant factor, antithrombin (Figure 1A). As a sensitive method of coagulant activity (16), the 
thrombin generation potential of plasma was measured, using optimal concentrations of tissue factor and phospholipids. Markedly, thrombin generation curves with plasma of APOE2 ki mice were about twice as high as curves with wildtype plasma (Figure 1B). Together, this points to increased coagulant activity associated with hyperlipidemia in the APOE2 ki genotype.

Earlier studies with rats have indicated that dietary n-3 PUFA influences plasma parameters and arterial thrombosis tendency in a dose-dependent way with the amount of fish oil $(12,18)$. We thus designed an intervention study, where inbred, male adult APOE2 ki mice were fed with high amounts of n-3 PUFA (fish oil diet) or, as a high-fat comparison, n-6 PUFA (sunflower seed diet). Part of the mice were maintained on the standard low-fat diet, and other mice received fish-oil diet (with $59 \mathrm{mg} / \mathrm{g}$ eicosapentaenoic plus docosahexaenoic acid, and $14 \mathrm{mg} / \mathrm{g}$ of the essential fatty acid linoleic acid), or sunflower seed oil diet (with $51 \mathrm{mg} / \mathrm{g}$ linoleic acid) (Table 1). The diets were given for 21 days, i.e. for a period sufficiently long for reaching steady-state changes in plasma lipids and coagulation factors (not shown).
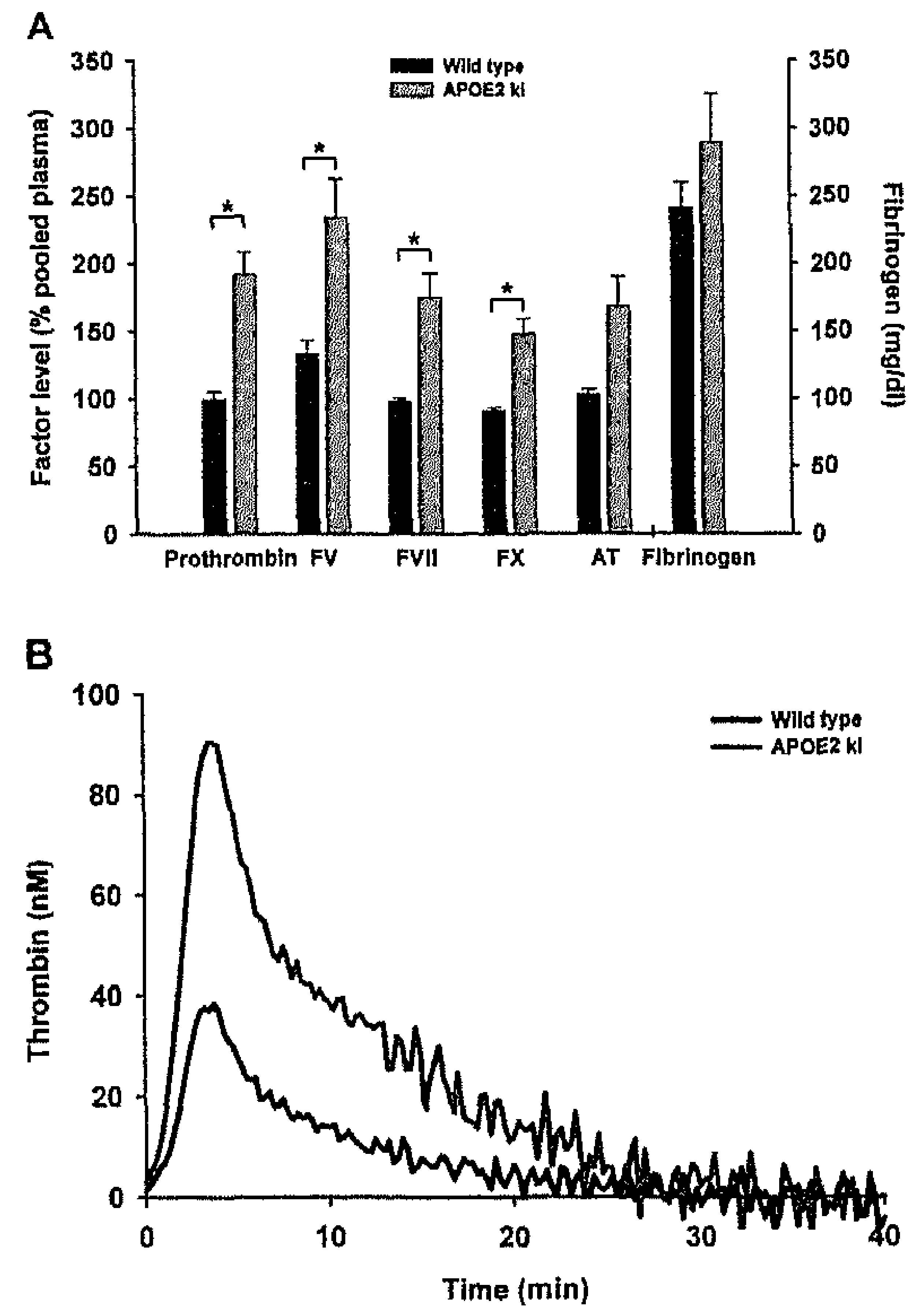

Figure 1. Coagulation and plasma lipid profile of APOE2 ki mice. (A) Levels of coagulation factors and lipids determined in plasmas from male wildtype and APOE2 ki C57BL/6 mice. Factor $(\mathrm{F})$ and antithrombin (AT) levels are expressed as percentages of normal murine pool plasma activity. (B) Representative thrombin generation curves of plasmas supplemented with $4 \mu \mathrm{mol} / \mathrm{L}$ phospholipids and triggered with $1 \mathrm{pmol} / \mathrm{L}$ tissue factor. Data are means $\pm \operatorname{SEM}(n=5-10) ;{ }^{*} P<0.05$ compared to low-fat group (Mann-Whitney $\mathrm{U}$ test). 
Fish oil, but not the sunflower seed oil diet led to a $30 \%$ reduction in plasma triglycerides, in comparison to the low-fat group (Table 2). Fish oil also caused a 30$40 \%$ reduction of vitamin K-dependent factors (prothrombin, factors VII, X) and of vitamin $\mathrm{K}$-independent factors (factor $\mathrm{V}$, antithrombin), while it reduced the fibrinogen level only borderline (Table 2). As results, after the fish oil intervention, plasma levels of most coagulation factors tended to approach those of pooled plasma from wildtype C57BL/6 mice. Sunflower seed oil diet, on the other hand, caused only smaller, insignificant reductions in triglyceride and coagulation factor levels (Table 2).

Table 2. Effect of fatty acid diets on plasma parameters.' APOE2 ki mice were fed during 3 weeks with low fat, fish oil or sunflower seed oil diet.

\begin{tabular}{|c|c|c|c|c|c|}
\hline Plasma component & $\begin{array}{l}\text { Low-fat } \\
\text { group }\end{array}$ & $\begin{array}{l}\text { Fish oil } \\
\text { group }\end{array}$ & $\begin{array}{l}\Delta \\
(\%)\end{array}$ & $\begin{array}{l}\text { Sunflower seed } \\
\text { oil group }\end{array}$ & $\begin{array}{l}\Delta \\
(\%)\end{array}$ \\
\hline Triacylglycerol (mg/dL) & $143 \pm 19$ & $101 \pm 10$ & $-29.9^{*}$ & $134 \pm 26$ & -6.7 \\
\hline Fibrinogen $(\mathrm{mg} / \mathrm{dL})$ & $289 \pm 35$ & $189 \pm 29$ & $-34.7^{+}$ & $238 \pm 23$ & -17.6 \\
\hline Prothrombin $(\%)^{2}$ & $191 \pm 17$ & $128 \pm 11$ & $-33.3^{*}$ & $172 \pm 8$ & -10.1 \\
\hline Factor V $(\%)$ & $234 \pm 28$ & $148 \pm 27$ & $-36.6^{*}$ & $189 \pm 16$ & -19.4 \\
\hline Factor VII $(\%)$ & $174 \pm 18$ & $114 \pm 9$ & $-34.4^{*}$ & $147 \pm 6$ & -15.6 \\
\hline Factor X $(\%)$ & $147 \pm 12$ & $105 \pm 6$ & $-28.7^{*}$ & $127 \pm 6$ & -14.0 \\
\hline Antithrombin $(\%)$ & $168 \pm 22$ & $104 \pm 7$ & $-38.2^{*}$ & $104 \pm 5$ & $-7.8^{+}$ \\
\hline
\end{tabular}

${ }^{1}$ Data are means $\pm \operatorname{SEM}(n=7-10)$.

${ }^{2}$ Coagulation factor activities are expressed as percentages of normal murine pooled plasma.

* $P<0.05$ and ${ }^{*} P<0.10$, compared to low-fat group (Mann-Whitney U test).

Tissue factor-induced thrombin generation was measured as an overall test of dietary effects on the coagulant potential of plasma (5). Thrombin generation curves showed a large, $40-45 \%$ reduction in thrombin peak height and endogenous thrombin potential (area-under-the-curve) in the fish oil group, but an insignificant reduction in the sunflower seed oil group, when compared to the low-fat group (Figure 2). Accordingly, the high coagulant activity of APOE2 ki mice was strongly reversed by the high-fat fish oil diet, but not the sunflower seed oil diet, suggesting a specific result of the n-3 PUFA intervention.

\section{Effects of fish oil and sunflower seed oil diets on gene expression in liver}

Since the liver is the principal source of plasma triglycerides and most (anti)coagulation factors, we were interested to see how the diets influenced the expression of relevant genes in the liver. Per diet group, pools of mRNA from 4 livers were prepared in order to limit individual variation between animals. For logistic and economic reasons, two pools were made from livers of low-fat mice (LF1 and LF2), two pools of mice fed fish oil (FO1 and FO2), and one pool of the sunflower seed oil group (SSO). The pools were 

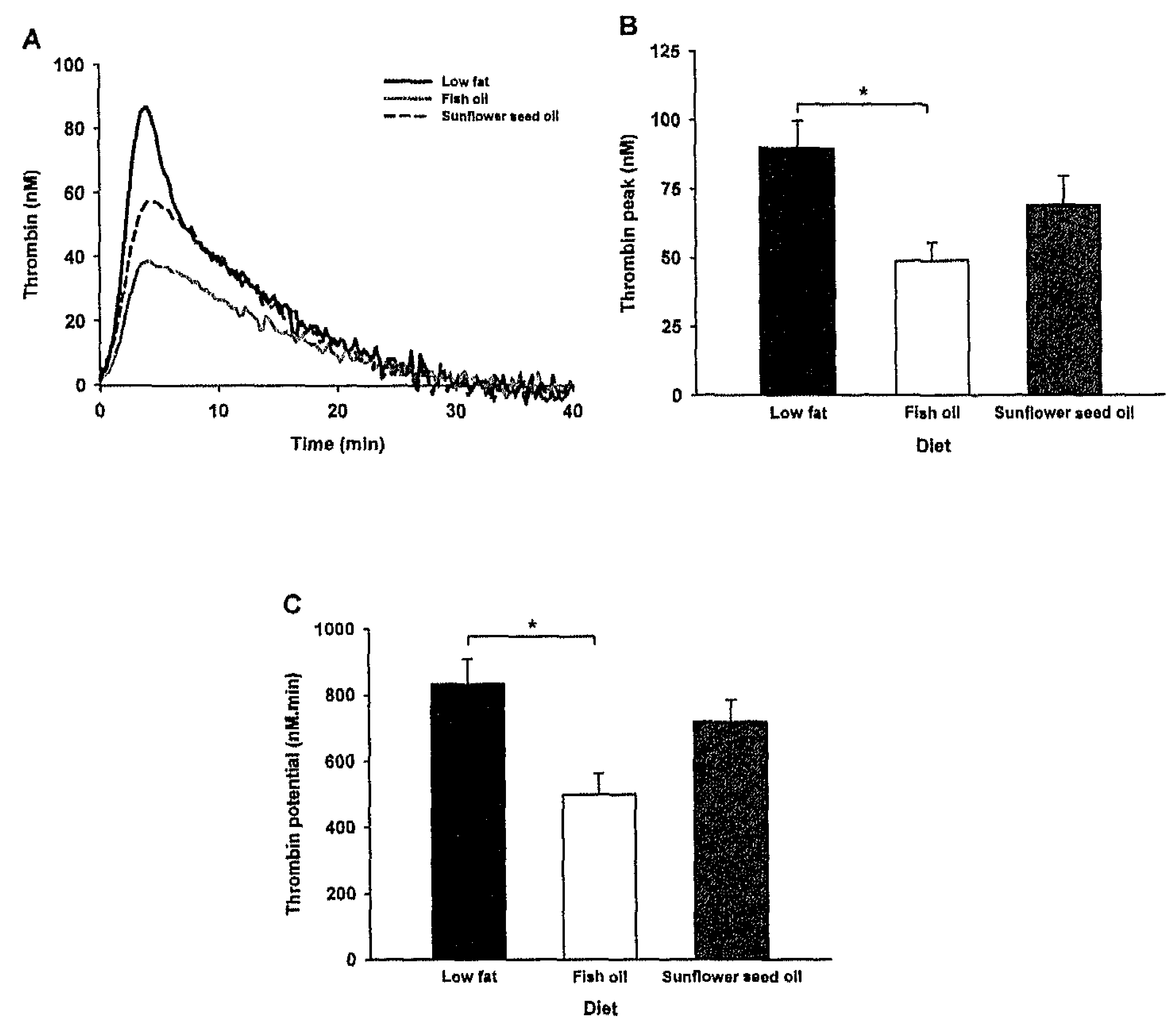

Figure 2. Effect of diets on thrombin generation in APOE2 $\mathrm{ki}$ mice. Tissue factor-induced thrombin generation was measured in plasmas from male APOE2 ki mice, after feeding for 3 weeks with low-fat, fish oil or sunflower seed oil diet. (A) Representative thrombin generation curves. (B) Thrombin peak height and (C) endogenous thrombin potential per diet group. Data are means $\pm \mathrm{SEM} ; * P<0.05$ compared to low-fat group (Mann-Whitney).

used for microchip analysis. Pair-wise comparisons of the signal data of all 22,690 sequences per chip indicated that duplicate arrays gave highly similar results, for both the two LF and the two FO microarrays ( $R=0.99$ and 0.98 , respectively), demonstrating reproducibility of procedure and analysis (Figure 3A). Per microarray, 7891-8610 sequences $(35-38 \%)$ were expressed at significant intensity $(P<0.05)$, and hence could be used for further evaluation (Figure 3B). Pair-wise comparisons of expression results indicated differences for 537-737 sequences, when FO was compared to LF, and of a lower number of 398-425 differences, when SSO was compared to LF (Figure 3C). Averaged results from duplicate chips showed that $401 / 7973$ (5.0\%) of the sequences differed between FO and LF chips, while only 250/7973 (3.1\%) of the sequences differed between SSO and LF chips (Figure 3C). 


\section{A}

Low-fat diet

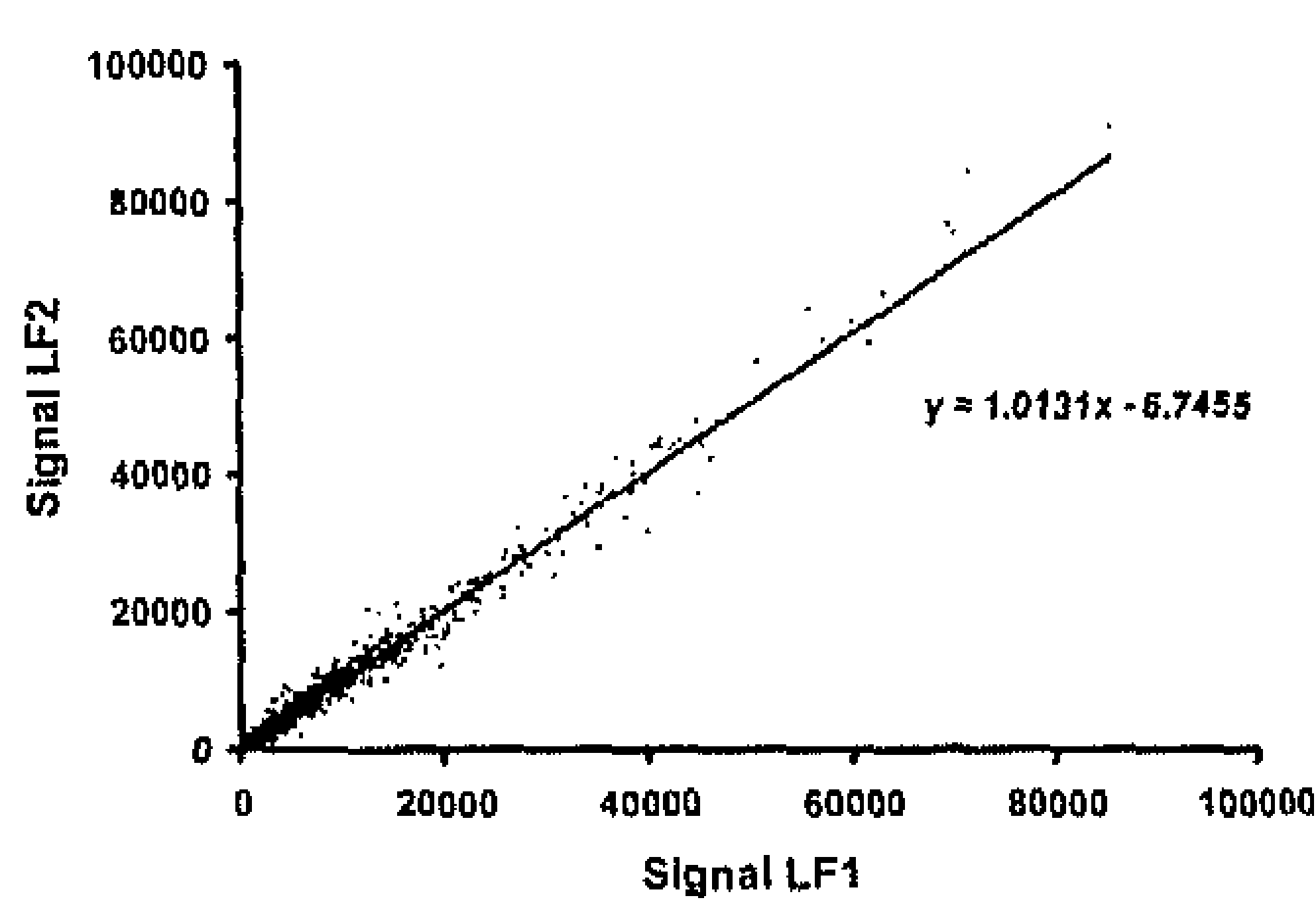

Fish oil diet

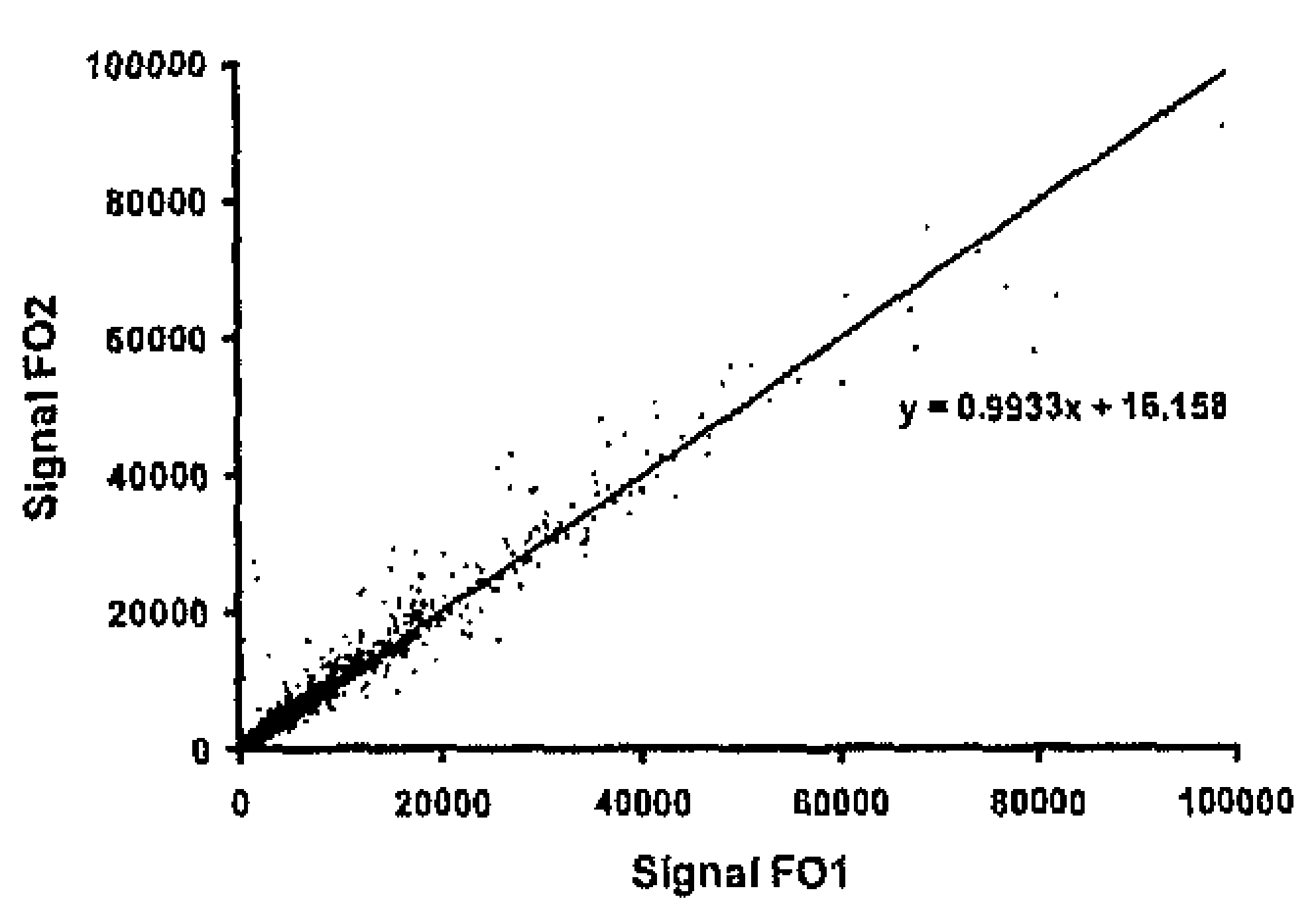

B
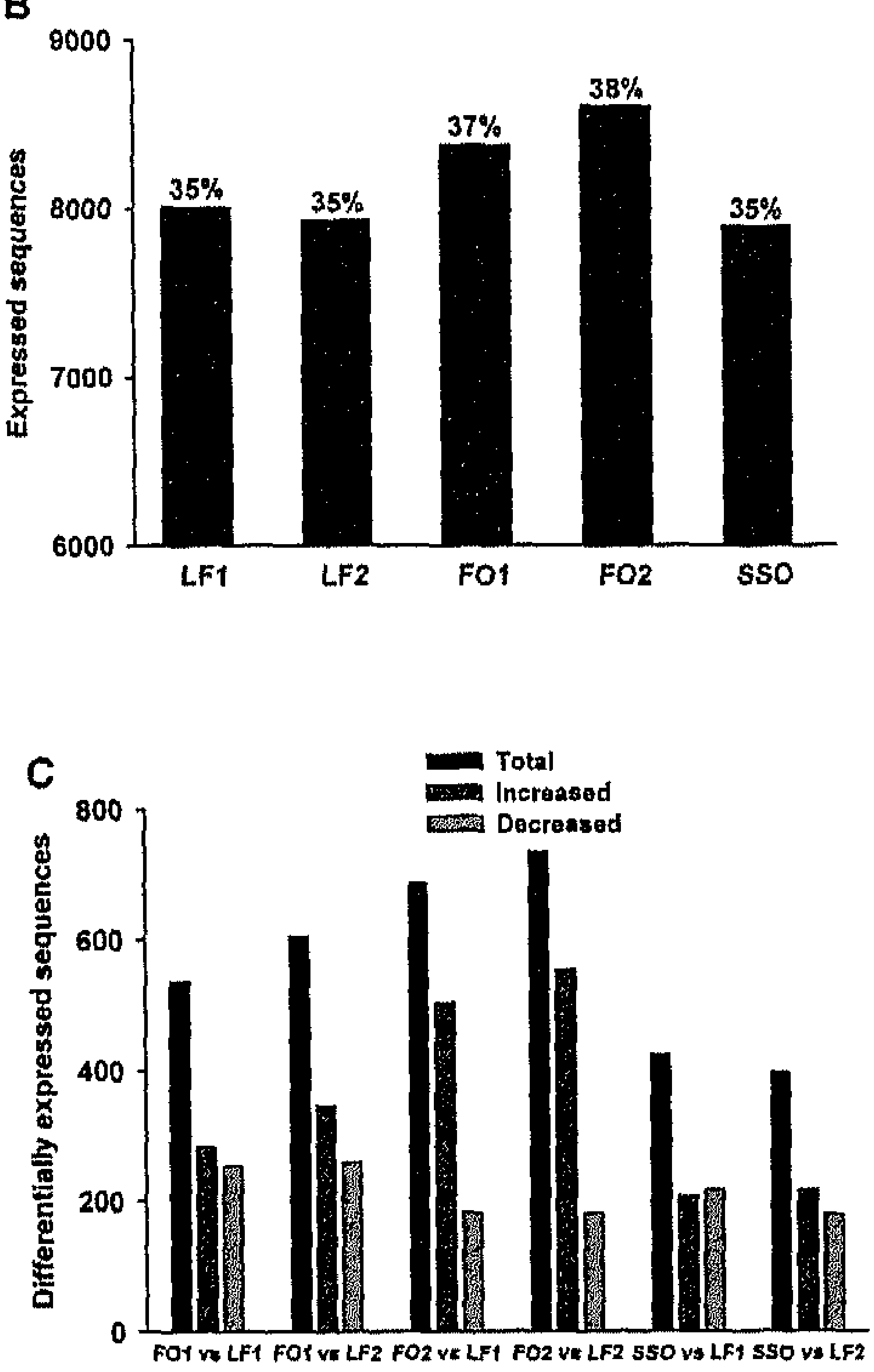

Figure 3. Effect of diets on hepatic mRNA expression profiles. Gene expression was determined in livers from APOE2 ki mice fed with various diets. The Affymetrix gene chip $430 \mathrm{~A}$ was used for microarray analysis of five mRNA pools (4 livers/pool): low-fat pools 1 and 2 (LF1 and LF2), fish oil pools 1 and 2 (FO1 and FO2), and sunflower seed oil pool (SSO). (A) Pair-wise comparison of signal data of all 22,690 hybridized sequences from the duplicate LF $1 / 2$ and FO1/2 microarrays; $R^{2}$ values are 0.986 and 0.968 , respectively $(P<0.001$, Pearson test). (B) Numbers of sequences with a reliable signal with $P<0.05$ in each of the five microarrays. Percentages indicate expressed sequences compared to all 22,690 hybridized sequences. (C) Numbers of sequences with significantly increased or decreased expression in pair-wise comparisons of microarray data $(P<0.05)$; total $=$ increased plus decreased. 
Chapter 7

Affymetrix software was then used to relate expressed sequences to specific metabolic pathways or biological functions. A total of 1,596 differentially expressed sequences could be classified to proteins with known functions. Listings of FO/LF and SSO/LF signal ratios showed that particularly the fish oil effected expression of genes involved in fatty acid degradation and oxidation, electron transport and fatty acid synthesis (Table 3). Table 4 gives a summary of the microarray results, by showing the principal effects of fish oil and sunflower seed oil diets on mRNA expression, in comparison to the low-fat diet. A number of genes of key enzymes regulating fatty acid degradation and oxidation were higher expressed in only the fish oil arrays (e.g., lipoprotein lipase, carnitine palmitoyl transferase 1 and fatty acid CoA ligase). This was also the case for some but not all genes of electron transport proteins involved in fatty acid combustion. In contrast, key genes involved in fatty acid synthesis and transport were downregulated (e.g., fatty acid synthase, stearoyl-CoA desaturase and fatty acid elongase). Surprisingly, most genes encoding for (anti)coagulation proteins were not influenced with fish oil, or were even increased (factor $\mathrm{V}$, factor $\mathrm{X}$, protein $\mathrm{Z}$; prothrombin and factor VII, at borderline). Yet, gene expression of $\gamma$-glutamyl carboxylase was reduced. Of the transcription factors linked to lipid metabolism, only the genes of peroxisome proliferator-activated receptor- $\alpha$ (PPAR $\alpha$, increased), nuclear factor I/X (NF I/X, increased), and erythroid-derived nuclear factor 2 (decreased) were differentially regulated by fish oil, whereas those of PPAR $\delta$ and $\gamma$ and of sterol regulatory element binding factor were unchanged. The sunflower seed oil diet, in general, had less marked effects on gene expression, with as exception down-regulation of genes for fatty acid synthesis and transport, in a similar way as fish oil.

Table 3. Full overview of dietary effects on hepatic mRNA expression in APOE2 ki mice fed with low-fat, fish oil or sunflower seed oil. Microarray expression was determined with mRNA pools LF1/2, FO1/2 and SSO (see Figure 3). Positive signals from the FO and SSO microarrays were compared against those of the LF microarrays. Differential expression was deduced from signal log ratios of FO/LF and SSO/ LF. Signal log ratios of the combinations were averaged and converted into averaged fold changes of each sequence; positive or negative changes $\geq 1.40$ were considered to be relevant. Upregulated genes are indicated in dark gray, downregulated genes in light gray. Shown are data from known genes regulating: fatty acid degradation and oxidation; fatty acid synthesis; as well as genes of (anti)coagulation factors; relevant transcription factors; or involved in electron transport. Abbreviation: ${ }^{*}$ nc, not changed.

\begin{tabular}{llcccc}
\hline Code Name & Genbank & LF & $\Delta$ FO & $\Delta$ SSO \\
& accession & mean & fold & fold \\
& number & signal change change \\
\hline
\end{tabular}

Fatty acid degradation and oxidation

1416946_a at acetyl-CoA acyltransferase 1

1415984_at acetyl-CoA dehydrogenase, medium chain

1448987_at acetyl-CoA dehydrogenase, long chaín

1424184_at acyl-CoA dehydrogenase, very long chain

1416408_at acyl-CoA oxidase 1

$\begin{array}{lcccc}\text { Acaal } & \text { NM_130864 } & 6425 & & \text { and } \\ \text { Acadm } & \text { NM_007382 } & 5770 & & n c^{*} \\ \text { Acadl } & \text { NM_007381 } & 4599 & 1.3 & \mathrm{nc} \\ \text { Acadvl } & \text { BC026559 } & 4588 & 1.3 & \mathrm{nc} \\ \text { Acoxl } & \text { NM_015729 } & 13892 & & -1.3\end{array}$


Anticoagulant effect of fish oil: an mRNA expression study

\begin{tabular}{|c|c|}
\hline 1456728_x_at & aconitase 1 \\
\hline 1460409_at & carnitine palmitoyltransferase 1 \\
\hline 1416772_at & camitine palmitoyltransferase 2 \\
\hline $1416727_{-} a_{-}$at & cytochrome b-5 \\
\hline 1422526 at & fatty acid CoA ligase, long chain 2 \\
\hline 1433531_at & fatty acid CoA ligase, long chain 4 \\
\hline $1428082_{m}^{\text {at }}$ & fatty acid $C O A$ ligase, long chain 5 \\
\hline 1422703 at & glycerol kinase \\
\hline 1460184 at & 3-hydroxyacyl-Co $A$ dehydrogenase, short chain \\
\hline 1415904 at & lipoprotein lipase \\
\hline 1416316_at & solute carrier family 27 (fatty acid transporter) 2 \\
\hline
\end{tabular}

\begin{tabular}{|c|c|c|c|c|}
\hline Acol & BB504570 & 5826 & 1.2 & ne \\
\hline Cplla & Al987925 & 4749 & & 1.3 \\
\hline Cpt 2 & NM_009949 & 1715 & & $\mathrm{nc}$ \\
\hline Cyb5 & NM_02.5797 & 20248 & & 1.3 \\
\hline Facl2 & NM_007981 & 6160 & & $n c$ \\
\hline Facl4 & BQ174545 & 653 & & ne \\
\hline Facls & AK006541 & 4815 & & 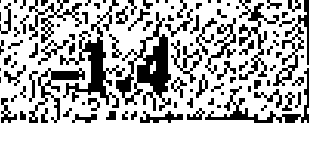 \\
\hline Gyk & NM_008194 & 715 & & ne \\
\hline Hadhsc & $N M_{-} 008212$ & 4308 & $x$ & ne \\
\hline Lpl & NM_008509 & 545 & & $n c$ \\
\hline Slc27a2 & $\mathrm{BCO} 13442$ & 19867 & & 1.3 \\
\hline
\end{tabular}

\section{Fatty acid synthesis and transport}

\begin{tabular}{|c|c|}
\hline 1415964_at & stearoyl-CoA desaturase 1 \\
\hline 1451666_at & ATP citrate lyase \\
\hline 1455994_x_al & elongase of very long chain fatty acids, I \\
\hline 1420722_at & elongase of very long chain fatty acids, 3 \\
\hline 1417023_a_at & fatty acid binding protein 4 , adipocyte \\
\hline 1416022_at & fatty acid binding protein 5 , epidermal \\
\hline 1449325_at & fatty acid desaturase 2 \\
\hline 1423828 at & fatty acid synthase \\
\hline 1427229 at & hydroxymethyl glutaryl CoA reductase \\
\hline $1421262_{\text {and }}$ & lipase, endothelial \\
\hline 1421821_at & low density lipoprotein receptor \\
\hline 1416383_aat at & pyruvate carboxylase \\
\hline
\end{tabular}

\begin{tabular}{|c|c|c|c|c|}
\hline Scdl & BC007474 & 36152 & 106 & $17 x_{2}$ \\
\hline Acly & BI456232 & 3572 & (2) & -1.3 \\
\hline Elovll & BB145065 & 1038 & -1.3 & ne \\
\hline Elovl3 & $\mathrm{BC} 016468$ & 5023 & W & 4 \\
\hline Fabp4 & NM_024406 & 237 & & $\mathrm{IiC}$ \\
\hline Fabp5 & $\mathrm{BC} 002008$ & 1582 & 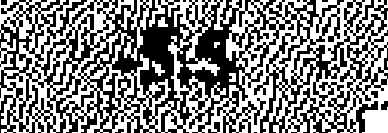 & $x_{2}$ \\
\hline Fads2 & NM_019699 & 1962 & 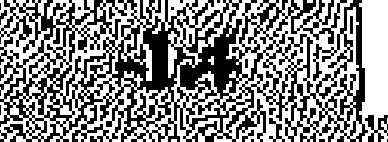 & nc \\
\hline Fasn & AF 127033 & 3761 & rat & 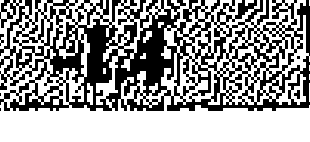 \\
\hline Hmger & BB 123978 & 594 & 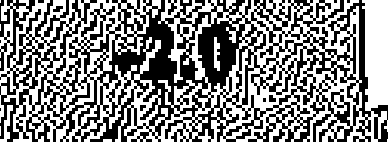 & nc \\
\hline Lipg & $\mathrm{BC} 020991$ & 595 & y & 1) \\
\hline Ldir & BM207920 & 1711 & 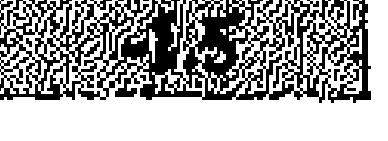 & nc \\
\hline Pcx & $N M_{-} 008797$ & 3404 & 1.2 & ne \\
\hline
\end{tabular}

\section{Coagulation and anticoagulation}

\begin{tabular}{|c|c|}
\hline 1424279_at & fibrinogen, alpha chain \\
\hline 1428079 at & fibrinogen, beta chain \\
\hline 1416025_at & fibrinogen, gamma chain \\
\hline $1418897_{\text {and }}$ at & prothrombin \\
\hline 1449269_at & factor $V$ \\
\hline 1418907_at & factor $V$ \\
\hline 1419321_at & factor VII \\
\hline 1418992_at & factor $X$ \\
\hline 1449305_at & factor $\mathrm{X}$ \\
\hline 1451788_at & factor XI \\
\hline 1420496_at & factor XII \\
\hline 1419131_at & factor XIII, beta chain \\
\hline 1423554_at & gamma-glutamyl carboxylase \\
\hline 1449034_at & kallikrein B, plasma ! \\
\hline $1416676_{-}$at & kininogen \\
\hline 1416729_at & plasminogen \\
\hline 1418845_at & protein C \\
\hline
\end{tabular}

\begin{tabular}{|c|c|c|c|c|}
\hline Fga & $\mathrm{BC} 005467$ & 36849 & $\mathrm{nc}$ & $n c$ \\
\hline $\mathrm{Fgb}$ & AK011118 & 35389 & ne & nc \\
\hline Fgg & NM_133862 & 40216 & $\pi \mathfrak{c}$ & $n \mathfrak{c}$ \\
\hline $\mathrm{F} 2$ & NM_010168 & 16654 & 1.2 & nc \\
\hline $\mathrm{FS}$ & NM_007976 & 4615 & . & 1.3 \\
\hline F5 & BB799410 & 7029 & 1.3 & ne \\
\hline F7 & NM_010172 & 1863 & 1.2 & $n c$ \\
\hline F10 & AJ506285 & 400 & & $\mathrm{nc}$ \\
\hline F10 & NM_007972 & 6345 & $\mathrm{nc}$ & nc \\
\hline F11 & AF356627 & 1637 & $\mathrm{nc}$ & 1.3 \\
\hline F12 & $N M \_021489$ & 5149 & $\mathfrak{n e}$ & nc \\
\hline F13b & NM_031164 & 4133 & $\mathfrak{n c}$ & $n c$ \\
\hline Ggcx & AV370848 & 637 & 4 & $\mathrm{nc}$ \\
\hline Klkbi & $\mathrm{BC} 026555$ & 3245 & 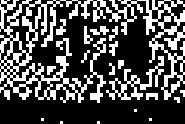 & ne \\
\hline Kng & NM_023125 & 15133 & & $\mathrm{nc}$ \\
\hline Pig & NM_008877 & 26030 & 1.2 & $\mathrm{nc}$ \\
\hline Proc & NM_008934 & 6280 & $\mathrm{nc}$ & ne \\
\hline
\end{tabular}


Chapter 7

$\begin{array}{ll}1426246 \text { _at } & \text { protein S, alpha chain } \\ 1450201 \text { at } & \text { protein Z } \\ 1417909 \text { at } & \text { antithrombin (SERPINC1) } \\ 1418547_{\text {_at }} & \text { tissue factor pathway inhibitor } 2 \\ 1426642_{\text {at }} & \text { fibronectin 1 } \\ 1420484 \text { a at } & \text { vitronectin }\end{array}$

\section{Transeription factors}

\begin{tabular}{|c|c|}
\hline 1427680_a_at & nuclear factor $\mathrm{V} / \mathrm{B}$ \\
\hline 1436363_a_at & nuclear factor $\mathrm{V} X$ \\
\hline 1416543_at & nuclear factor erythroid derived 2 , like 2 \\
\hline 1449051_at & peroxisome proliferator activated receptor alpha \\
\hline 1425703_at & peroxisome proliferator activated receptor delta \\
\hline 1420715_a_at & peroxisome proliferator activated receptor gamma \\
\hline 1454875_a_at & retinoblastoma binding protein 4 \\
\hline 1426690 & sterol regulatory element binding factor $I$ \\
\hline
\end{tabular}

\section{Electron transport}

\begin{tabular}{|c|c|c|c|c|c|c|}
\hline 1416727_a_at & cytochrome b-S & Cyb5 & NM_025797 & 20248 & 1.3 & 1.3 \\
\hline 1448844 at & cytochrome b5 outer mitochondrial membr. precursor & Cyb5m & NM_025558 & 1230 & $x+2$ & 28 \\
\hline 1432263_a at & cytochrome $\mathrm{c}$ oxidase subunit VIIa polypeptide 2-like & $\operatorname{Cox} 7 \mathrm{a} 21$ & AK009614 & 2006 & 1.2 & ne \\
\hline 1448322_a_at & cytochrome c oxidase, subunit IVa & $\operatorname{Cox} 4 a$ & NM_009941 & 8118 & 1.3 & nc \\
\hline 1415933_a_at & cytoclurome c oxidase, subunit Va & $\operatorname{Cox} 5 a$ & NM_007747 & 9102 & 1.2 & nc \\
\hline 1454716_x_at & cytochrome c oxidase, subunit $\mathrm{Vb}$ & Cox $5 b$ & AA960638 & 5747 & 1.3 & $\mathrm{nc}$ \\
\hline 1415970_at & cytochrome c oxidase, subunit VIc & $\operatorname{Cox} 6 \mathrm{c}$ & NM_053071 & 11404 & 1.3 & ne \\
\hline 1448112_at & cytochrome $\mathrm{c}$ oxidase, subunit VIIc & $\operatorname{Cox} 7 \mathrm{c}$ & NM_007749 & 8548 & 1.3 & ne \\
\hline 1416604_at & cytochrome c-1 & Cyci & NM_025567 & 7536 & nc & -1.1 \\
\hline $1450646 \_$at & cytochrome P450, 51 & Cyp51 & NM_020010 & 1061 & 24 & 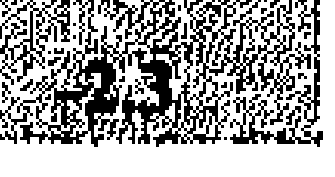 \\
\hline 1450715_at & cytochrome $P 450$, family 1 , subfamily a, polypeptide 2 & Cypla2 & NM_009993 & 7781 & nc & 1.2 \\
\hline $1418821_{-}$at & cytochrome P450, family 2 , subfamily a, polypeptide 12 & Cyp2al2 & NM_133657 & 11680 & 1.2 & ne \\
\hline $1422230 \_$s_at & cytochrome P450, family 2 , subfamily a, polypeptide 5 & Сур2а5 & NM_007812 & 8549 & & \\
\hline 1422257_s_at & cytochrome $\mathrm{P} 450$, family 2 , subfamily b, polypeptide 10 & Сур2b10 & NM_009998 & 243 & ne & \\
\hline 1425645_s_at & cytochrome $\mathrm{P} 450$, family 2 , subfamily b, polypeptide 20 & Cyp2b20 & AF 128849 & 296 & ne & \\
\hline 1417651_at & cytochrome P450, family 2 , subfamily c, polypeptide 29 & Сур $2 \mathrm{c} 29$ & NM_. 007815 & 17468 & nc & \\
\hline 1452501_at & cytochrome P450, family 2, subfamily c, polypeptide 38 & Сур2c38 & AF047725 & 1706 & ne & -1.9 \\
\hline 1423244_at & cytochrome P450, family 2 , subfamily c, polypeptide 40 & Cyp2c40 & AI 265721 & 7956 & -1.3 & nc \\
\hline 1424273_at & cytochrome P450, family 2 , subfamily c, polypeptide 70 & Сур2с70 & BC025822 & 15805 & -1.1 & ne \\
\hline 1418113_at & cytochrome P450, family 2 , subfamily d, polypeptide 10 & Cyp2d10 & $\mathrm{BC} 010989$ & 13752 & 1.3 & 1.3 \\
\hline 1448683_at & cytochrome P450, family 2, subramily d, polypeptide 26 & Cyp2d26 & NM_029562 & 14410 & & ne \\
\hline 1419349_a_at & cytochrome $\mathrm{P} 450$, family 2 , subfamily $\mathrm{d}_{\text {, polypeptide } 9}$ & Cyp2d 9 & BC010593 & 17354 & & 1.2 \\
\hline 1415994_at & cytochrome $\mathrm{P} 450$, family 2 , subfamily e, polypeptide 1 & Cyp2el & NM_021282 & 43479 & 1.2 & 1.3 \\
\hline 1419094_at & cytochrome P450, family 2. subfumily c, polypeptide 37 & Cyp2c37 & NM_010001 & 5391 & 1.3 & \\
\hline 1419430_at & cytochrome $\mathrm{P} 450$, family 26 , subfamily a, polypeptide 1 & Cyp26al & NM_00781t & 288 & & \\
\hline $1417590 \_$at & cytochrome P450, family 27 , subfamily a, polypeptide 1 & Cyp27al & $\mathrm{NM}_{0} 024264$ & 10296 & $\mu$ & -1.2 \\
\hline
\end{tabular}

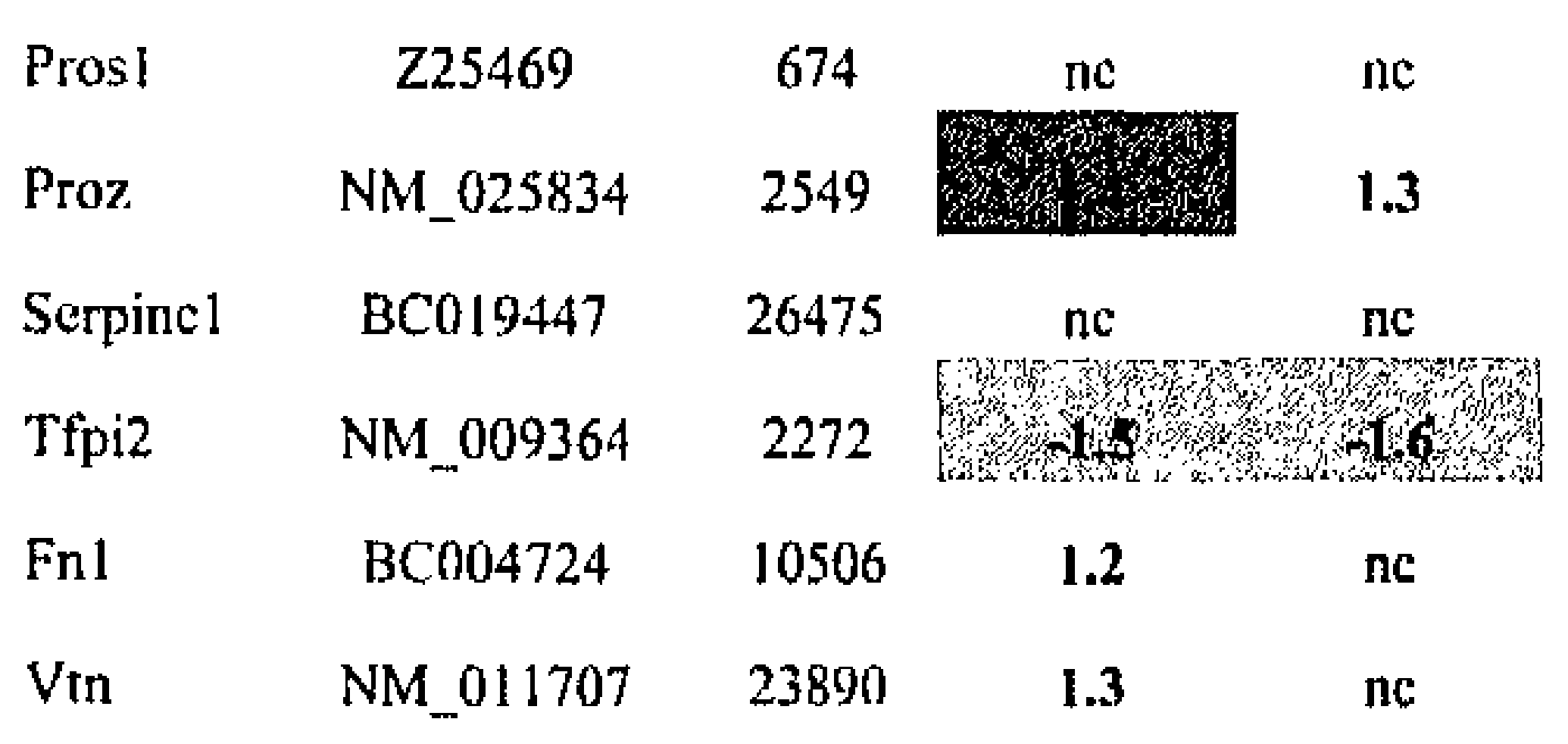

\begin{tabular}{|c|c|c|c|c|}
\hline Nfib & Y07687 & 473 & 1,3 & ne \\
\hline Nfix & AW049660 & 1528 & & \\
\hline $\mathrm{Nfe} 212$ & NM_010902 & 1167 & 4 & nc \\
\hline Ppara & $\mathrm{BC} 016892$ & 4369 & & -1.2 \\
\hline Ppard & L28116 & - & $\mathrm{nc}$ & nc \\
\hline Pparg & $\mathrm{NM}_{-} 011146$ & - & $n \mathrm{c}$ & $\mathrm{ne}$ \\
\hline Rbbp4 & BF011461 & 858 & $\mathrm{nc}$ & \\
\hline rebfl & $\mathrm{A} 1326423$ & 2132 & $\mathrm{nc}$ & \\
\hline
\end{tabular}

Srebfl A1326423 2132 


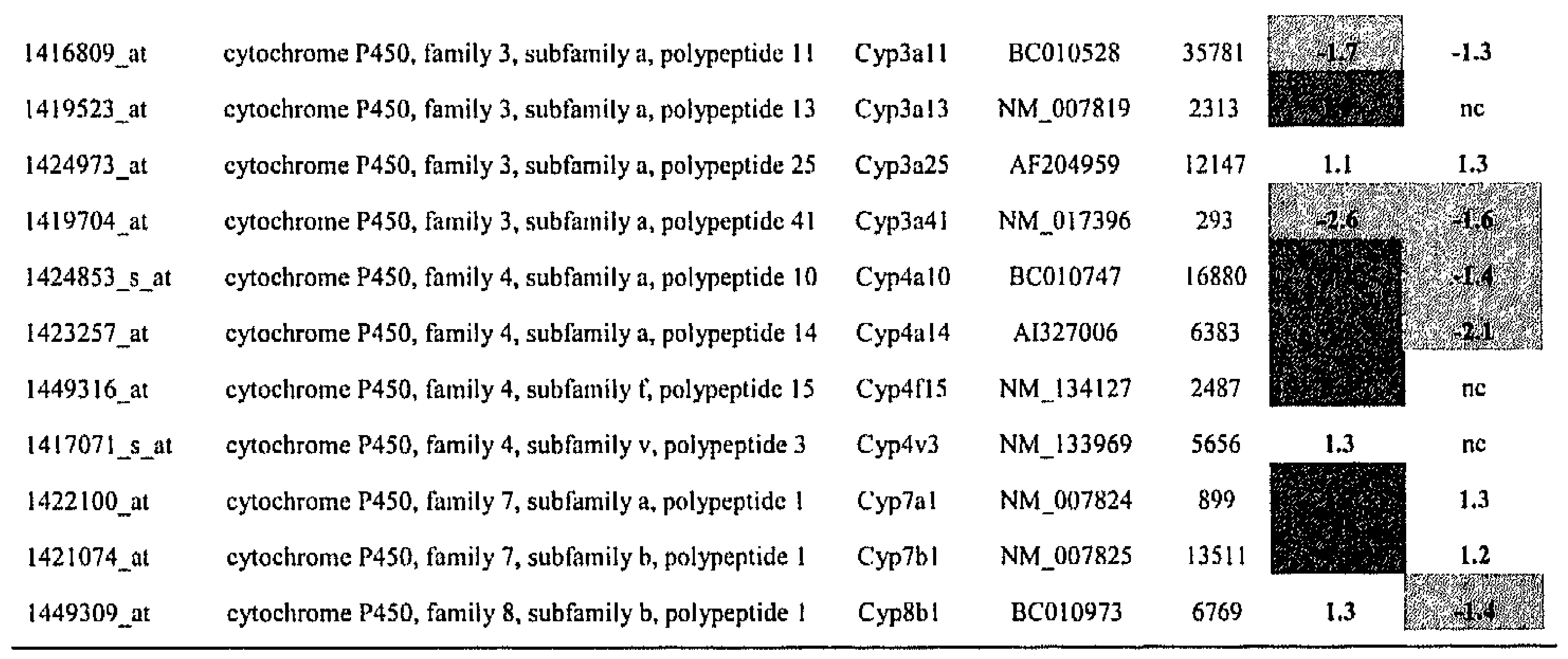

Table 4. Overview of fish oil (FO) and sunflower seed oil (SSO) effects on hepatic mRNA expression in APOE2 ki mice. Listings are given of genes, where expression is increased, unchanged or decreased after FO diet in comparison to low-fat diet. Overall results from microarray chips are given (see Table 3 for details). Effects on expression are sorted for the following categories: $(A)$ fatty acid oxidation and degradation, $(B)$ electron transport, $(C)$ fatty acid synthesis and transport, $(D)$ (anti)coagulation, $(E)$ transcription factors.

Increased by FO diet \& unchanged/decreased by SSO diet:

(A) lipoprotein lipase; carnitine palmitoyltransferase 1; fatty acid CoA ligase; acetyl-CoA acyltransferase;

acetyl-CoA dehydrogenase; acetyl-CoA oxidase; glycerol kinase

(B) cyt $\mathrm{P}-450$ family $2,3,4,7$ polypeptides

(C) FABP 4

(D) factor $\mathrm{V}, \mathrm{X}$; protcin $\mathrm{Z}$; kininogen

(E) $\operatorname{PPAR} \alpha, \mathrm{NF} \mathrm{I} / \mathrm{X}^{*}$

Unchanged by FO diet \& unchanged/increased by SSO diet:
(A) acyl-CoA dehydrogenase very long chain**; aconitase 1
(B) cyt c oxidase; cyt P-450 several families
(C) pyruvate carboxylase
(D) fibrinogen $\alpha, \beta, \gamma ;$ prothrombin**; factor VII**, XI, XII, XIII; protein C, S; antithrombin
(E) PPAR $\delta, \gamma$; RBP; SREBF

Decreased by FO diet \& unchanged/decreased by SSO diet:
$(A)$ fatty acid $\mathrm{CoA}$ ligase long chain
(B) cyt b5; cyt P-450 family 2, 3, 27 polypeptides
(C) fatty acid synthase; stearoyl-CoA desaturase, fatty acid elongase; LDL receptor; FABP 5
(D) $\gamma$-glutamyl carboxylase; kallikrein B; TFPI
(E) NF 2

Abbreviations: cyt, cytochrome; FABP, fatty acid binding protein; NF, nuclear factor; PPAR, peroxisome proliferator-activated receptor; RBP, retinoblastoma binding protein; SREBF, sterol regulatory elementbinding factor; TFPI, tissue-factor pathway inhibitor. ${ }^{*}$ Increased with SSO diet. ${ }^{* *}$ Borderline increase. 
To confirm the microarray expression results, quantitative real-time PRC analysis was performed for a number of key genes, using mRNA samples of individual livers. The results confirmed that mRNA levels of lipoprotein lipase, acyl-CoA dehydrogenase very long-chain and carnitine palmitoyl transferase 1 (the last one not significant) were increased in livers from animals fed fish oil, but not sunflower seed oil (Figure 4A). While mRNA for fibrinogen- $\beta$ was unchanged, the level for prothrombin was slightly higher with fish oil but not sunflower seed oil. In general a strong correlation was obtained between the (duplicate) microarray analysis and the real-time PCR results (Figure 4B, $R=0.734, P=0.016$ ). Taken together, the fish oil diet - much more than the sunflower seed oil diet - altered the hepatic expression of genes involved in fatty acid metabolism. Fish oil did not reduce, but rather increased, the expression of major coagulation factor genes, with $\gamma$-glutamyl carboxylase as an exception.

A

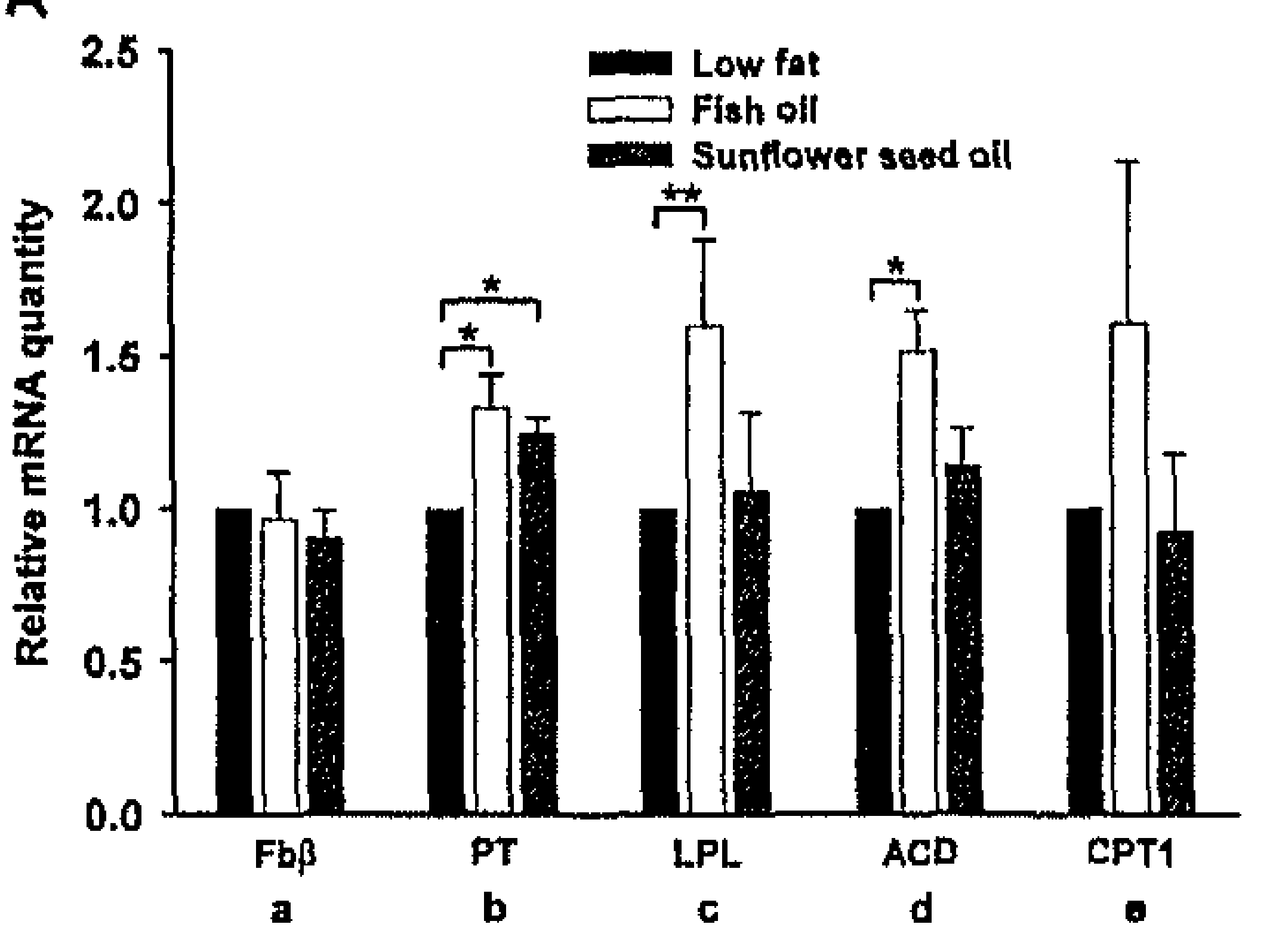

B

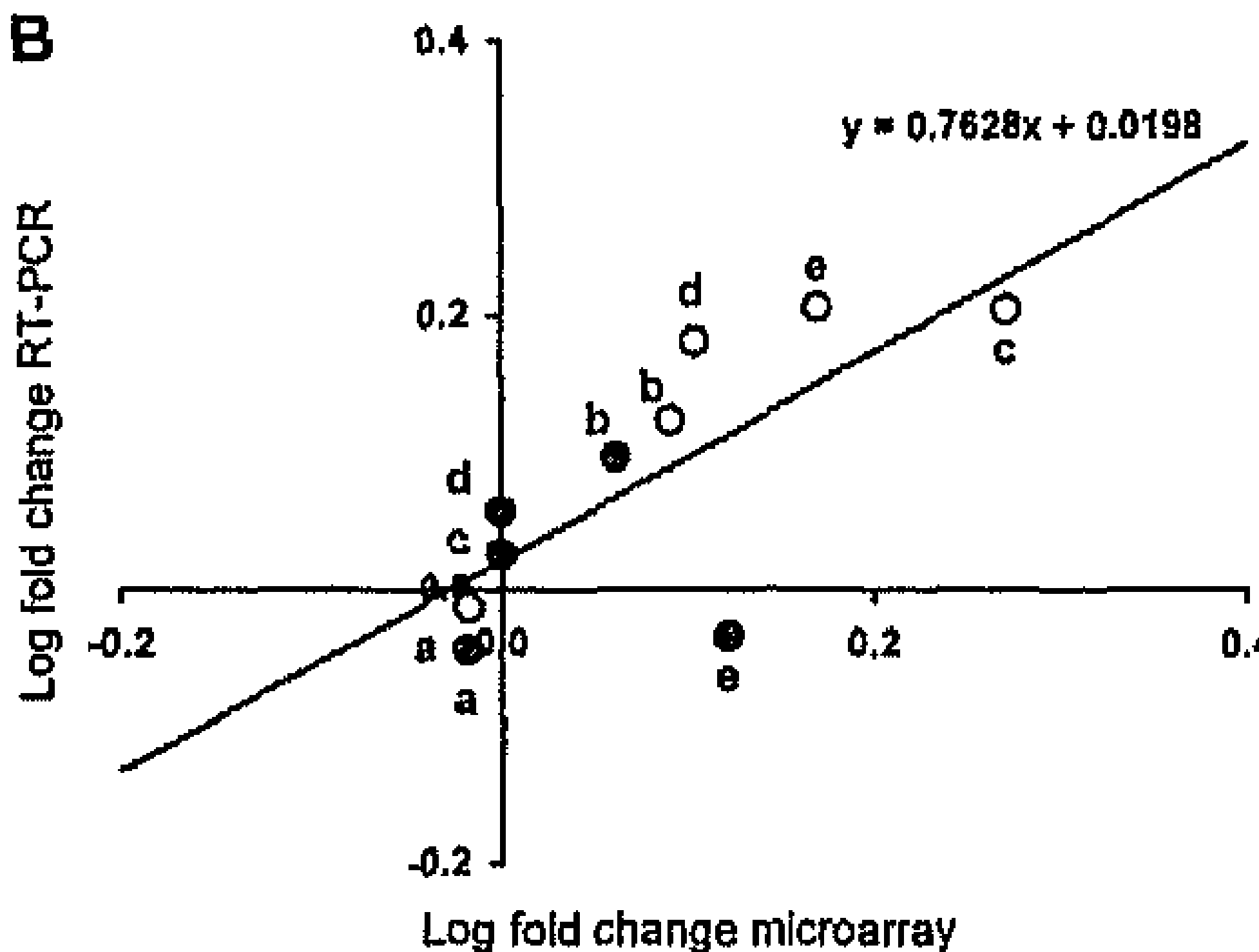

Figure 4. Effect of diets on hepatic mRNA expression of individual genes. (A) Gene expression of fibrinogen- $\beta(\mathrm{Fb} \beta)$, prothrombin $(\mathrm{PT})$, lipoprotein lipase (LPL), acyl-CoA dehydrogenase very long-chain (ACD) and carnitine palmitoyltransferase 1 (CPT1) was determined by quantitative real-time PCR, and normalized to $\beta$-actin expression. Data are expressed as fold differences relative to $\beta$-actin mRNA. Values are means $\pm \mathrm{SEM} ;{ }^{*} P<0.05$ and ${ }^{* *} P<0.01$, compared to low-fat group. (B) Correlation of logarithmic values of fold (log-fold) changes of mRNA expression of fish oil (open symbols) and sunflower seed oil (gray symbols) obtained from microarray and real-time PCR analyses $(R=0.734, P=0.016)$.

\section{Effects of fish and sunflower seed oil diets on coagulation factors in liver}

Histological examination of liver slices did not reveal fat deposition or pathological abnormalities in any of the diet groups (data not shown). This confirmed the earlier conclusion that high-fat intervention in APOE2 ki mice does not lead to abnormal liver function (13). Slices were stained immunohistochemically for the key coagulation factors, prothrombin, factor VII and factor X. Typically, liver slices from fish-oil fed mice showed clear focal accumulation sites of prothrombin (Figure $5 \mathbf{A}$ ) and factors VII and $X$ (not shown), which in most cases were concentrated around blood vessels. Such a focal staining pattern was only incidentally seen in livers from mice fed sunflower seed oil, and not at all in livers from mice fed low-fat (Figure 5A). Quantification of the 
overall staining showed a significant increase in protein expression of prothrombin, factor VII as well as factor X after the fish oil diet (Figure 5B). To evaluate the activity $\gamma$-glutamyl carboxylase, liver slices were also stained for the presence of its product, i.e. $\gamma$-carboxy glutamate (Gla) residues. Staining was with a monoclonal antibody, which has been used to monitor the overall vitamin $\mathrm{K}$-dependent processing of coagulation factors and matrix Gla protein in tissues (19). Livers from all three diet groups stained equally well with this antibody (Figure 5B); focal staining spots were not detected. Thus, the focal increased protein expression of coagulation factors in fish oil-fed animals was not accompanied by increased staining for Gla residues.
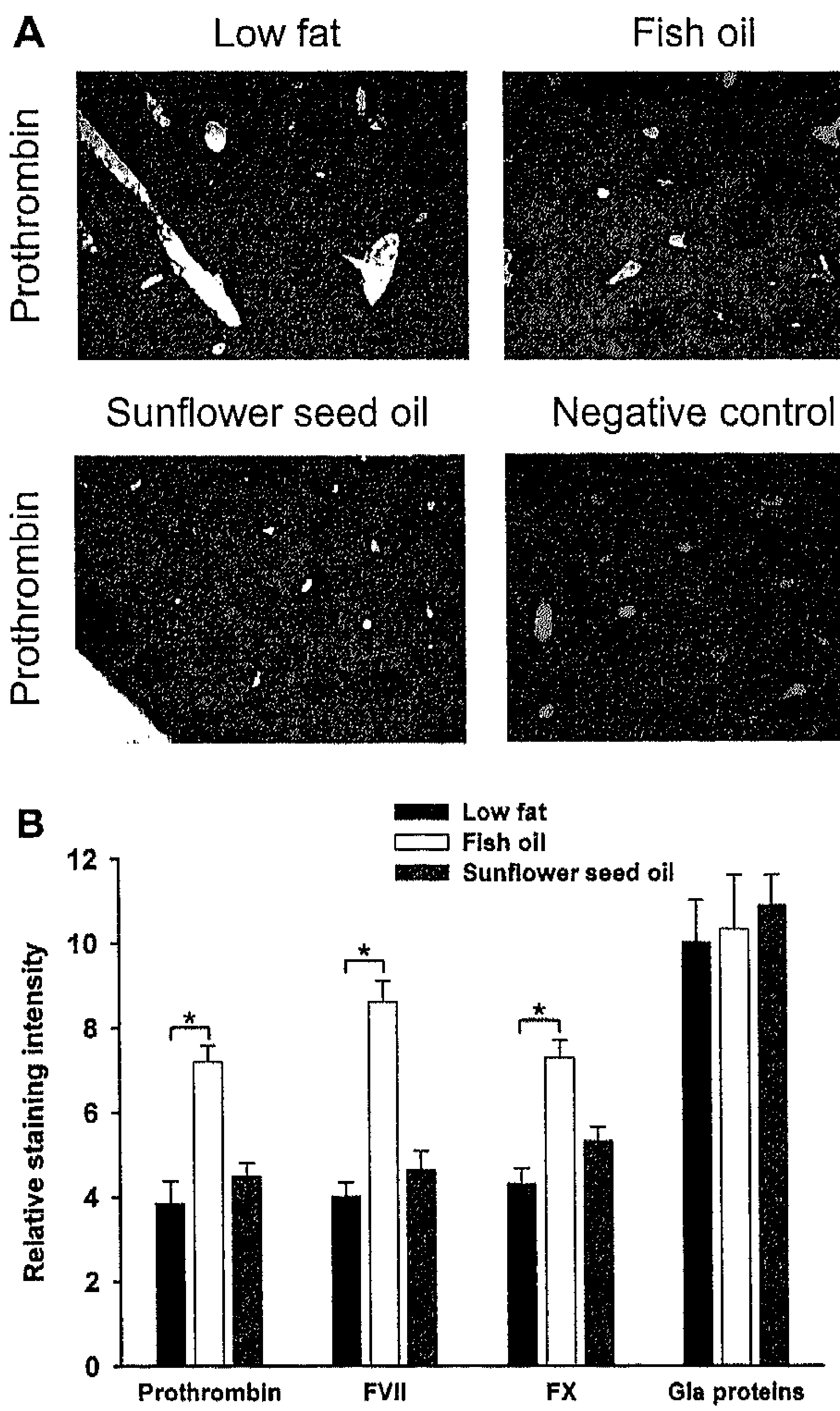

Fish oil

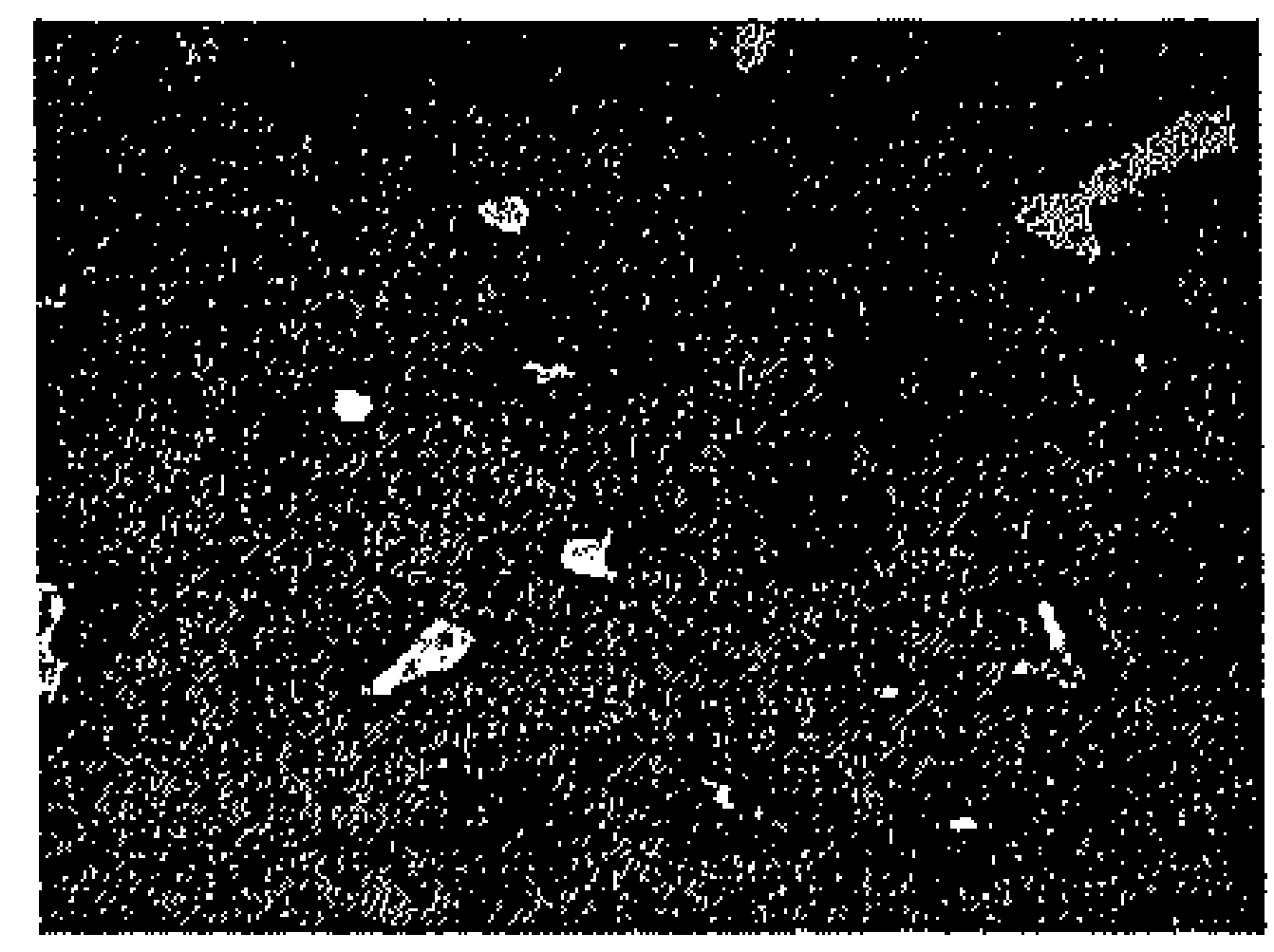

Negative control
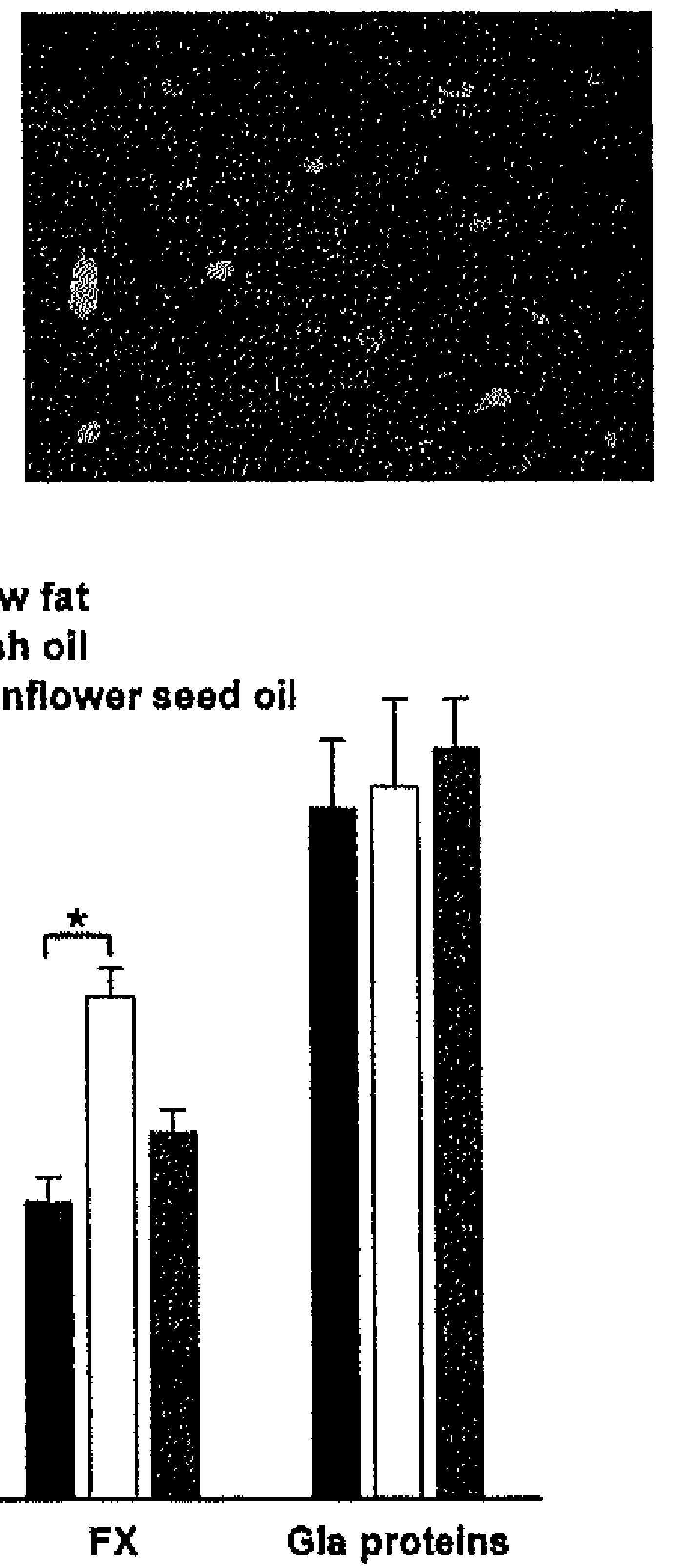

Figure 5. Effect of diets on presence of coagulation factors in liver. APOE2 ki mice were fed with low-fat, fish oil or sunflower seed oil diet. Liver slices from different mice were immuno-histochemically stained using antibodies against prothrombin, factor VII (FVII), factor X (FX) or Gla proteins. (A) Representative microscopic images of liver sections stained for prothrombin $(b a r=100 \mu \mathrm{m})$. In the negative control, primary anti-thrombin antibody was omitted. (B) Relative staining intensity with different antibodies per diet group (means $\pm \mathrm{SEM}, n=10$ ), ${ }^{*} P<0.05$ compared to low-fat group (Mann-Whitney). 


\section{DISCUSSION}

Here, we studied the lipid-lowering and anticoagulant effects of dietary fish oil, using hyperlipidemic and pro-atherogenic APOE2 ki mice, in which the endogenous murine apoE gene is replaced by the human APOE2 gene. The human APOE2 genotype (frequency of 7\%) carries a $\mathrm{Arg}^{158} \rightarrow$ Cys variant, which impedes binding of ApoE to the LDL receptor $(14,20)$. It is one of the main causes of type III hyperlipoproteinemia, causing diminished clearance of chylomicrons and VLDL and, hence, elevated plasma lipid levels. In transgenic APOE2 mice, the high plasma triglyceride levels appear to be accompanied by up-to two-fold higher levels of coagulation factors and antithrombin, when compared with wildtype mice of the same genetic background (C57BL/6), sex (male) and dietary regime. This likely results in a procoagulant phenotype, as demonstrated by the greatly increased thrombin generation potential, which is an integrated measure of coagulant and anticoagulant activity of the plasma. The relevance of this may appear from the recent finding that, in man, concentrations of triacylglycerol are strongly correlated with coagulation factors levels like prothrombin, factor VII and $X(8)$. Several coagulation factors are also known to be increased in hyperlipidemia (6, $21,22)$.

An important finding is that feeding of APOE2 ki mice with a high-fat diet rich in fish oil (with n-3 PUFA) markedly reduced - and thus normalized - not only plasma triglycerides but also coagulation factor levels. The lipid-lowering effect of fish oil is also described in other hyperlipidemic murine APOE models (23-25). Strikingly, in APOE2 ki mice, the reduction by fish oil concerned both vitamin K-dependent (prothrombin, factor VII, X) and vitamin $\mathrm{K}$-independent (factor $\mathrm{V}$, antithrombin) coagulation factors, and was not seen in response to a diet rich in sunflower seed oil (with n-6 PUFA). The anticoagulant effect of fish oil was quantified as a $40 \%$ diminished thrombin generation. Conclusively, fish oil can correct for dyslipidemia in mice and, at the same time, normalize elevated coagulant activity. It is therefore possible that reduced coagulation contributes to the recently described atherosclerosissuppressive effect of fish oil in hyperlipidemic mice $(24,25)$.

Microarray analysis of hepatic mRNA profiles, confirmed by real-time PCR analysis, indicated that fish oil diet increased the expression of several genes involved in fatty acid degradation and combustion and decreased that of genes involved in fatty acid synthesis. Herein, fish oil was much more effective than the n-6 PUFA diet. These results point to a net decrease in hepatic lipid synthesis in response to n-3 PUFA, which is likely to be responsible for the lipid-lowering effect. This conclusion is supported by a recent proteomics analysis of APOE3-Leiden transgenic mice, where also, partly similar, enzymes involved in fatty acid degradation were found to be increased by fishoil diet (23). On the enzymatic level, there is earlier evidence of increased activity, in response to n-3 PUFA, of a number of enzymes of fatty acid oxidation and degradation (26), among which acetyl-CoA oxidase.

It is likely that the modulating effect of fish oil on gene expression in fatty acid metabolism involves common factors. Microarray analysis showed clear fish-oil effects 
of only few nuclear receptors of fat-induced gene regulation. Upregulated were PPAR $\alpha$ and NF I/X, while erythroid-derived nuclear factor-2 was down-regulated. Of interest is the increased expression of PPAR $\alpha$ mRNA, although there are indications from others that the activity of PPAR $\alpha$ is not rate-limiting in the hypolipidemic action of fish oil (27).

Surprisingly, genes encoding for (anti)coagulant proteins were not decreased in expression after fish oil diet. Instead, we measured moderate increases in mRNA of prothrombin (real-time PCR), factor V, factor VII (borderline), factor X and protein Z. On the protein level, this was reflected by increased immunohistochemical staining of liver sections for prothrombin, factor VII and factor $\mathrm{X}$ in mice fed with n-3 PUFA, but not with n-6 PUFA.

Hepatic retention of coagulation factors is likely to be caused by impaired secretion, for instance due to altered post-translational modification. Staining of the livers for Gla residues, which are formed by vitamin $\mathrm{K}$-dependent modification of coagulation factors, was not increased after fish oil. However, gene expression of vitamin K-dependent $\gamma$ glutamyl carboxylase was down-regulated, suggesting that part of the stored coagulation factors are reduced in $\gamma$-carboxylation. Accordingly, decreased carboxylase activity can explain the anticoagulant effect of fish oil, as far as concerning the vitamin $\mathrm{K}$-dependent coagulation factors. Note that earlier diet studies with rats did not provide evidence for a reduced vitamin $\mathrm{K}$ uptake $(11,12)$, as was suggested by others (9). Yet, the anticoagulant effect of fish oil must involve other mechanisms, because also levels of non-Gla containing factor $\mathrm{V}$ and antithrombin are reduced. The present results argue against a common regulatory mechanism of lipid metabolism and coagulation factor expression in the liver. Fish oil is likely to lower plasma lipid levels via controlled gene expression of lipid degradation and synthesis, but it reduces plasma coagulation factors not via direct expression regulation of the factor genes.

\section{Acknowledgments}

We thank dr. R. Shiri-Sverdlov, dr. C. Evelo and dr. T. Ayoubi for expert assistance in microarray analysis and stimulating discussions. We acknowledge funding from the Netherlands Organization for Scientific Research (NWO 980-10-018). 


\section{REFERENCES}

1. Kris-Etherton PM, Harris WS, Appel LJ. Fish consumption, fish oil, omega-3 fatty acids, and cardiovascular disease. Arterioscler Thromb Vasc Biol. 2003; 23: e20-30.

2. Vanschoonbeek K, de Maat MP, Heemskerk JWM. Fish oil consumption and reduction of arterial disease. J Nutr. 2003; 133: 657-660.

3. Grundt H, Nilsen DW, Hetland O, Mansoor MA, Aarsland T, Woie L. Atherothrombogenic risk modulation by $n-3$ fatty acids was not associated with changes in homocysteine in subjects with combined hyperlipidaemia. Thromb Haemost. 1999; 81: 561-565.

4. Porreca E, Di Febbo C, Amore C, Di Castelnuovo A, Baccante G, Donati MB, Cuccurullo F, Iacoviello L. Effect of lipid-lowering treatment on factor VII profile in hyperlipidemic patients. Thromb Haemost. 2000; 84: 789-793.

5. Vanschoonbeek K, Feijge MAH, Paquay M, Rosing J, Saris W, Kluft C, Giesen PLA, de Maat MPM, Heemskerk JWM. Variable hypocoagulant effect of fish oil intake in humans: modulation of fibrinogen level and thrombin generation. Arterioscler Thromb Vasc Biol. 2004; 24: 1734-1740.

6. Hoffman CJ, Lawson WE, Miller RH, Hultin MB. Correlation of vitamin K-dependent clotting factors with cholesterol and triglycerides in healthy young adults. Arterioscler Thromb. 1994; 14: 1737-1740.

7. Rosenson RS, Lowe GD. Effects of lipids and lipoproteins on thrombosis and rheology. Atherosclerosis. 1998; 140: 271-280.

8. Vanschoonbeek K, Feijge MAH, Saris WH, de Maat MP, Heemskerk JWM. Plasma triacylglycerol and coagulation factor concentrations predict the anticoagulant effect of dietary fish oil in overweight subjects. J Nutr. 2007; 137: 7-13.

9. Andriamampandry M, Freund M, Wiesel ML, Rhinn S, Ravanat C, Cazenave JP, Leray C, Gachet C. Diets enriched in (n-3) fatty acids affect rat coagulation factors dependent on vitamin K. C R Acad Sci III. 1998; 321: 415-421.

10. Leray C, Wiesel ML, Freund M, Cazenave JP, Gachet C. Long-chain n-3 fatty acids specifically affect rat coagulation factors dependent on vitamin $\mathrm{K}$ : relation to peroxidative stress. Arterioscler Thromb Vasc Biol. 2001; 21: 459-465.

11. Nieuwenhuys CMA, Béguin $S$, Offermans RFG, Emeis Jj, Hornstra G, Heemskerk JWM. Hypocoagulant and lipid-lowering effects of dietary $n-3$ polyunsaturated fatty acids with unchanged platelet activation in rat. Arterioscler Thromb Vasc Biol. 1998; 18: 1480-1489.

12. Nieuwenhuys CMA, Feijge MAH, Vermeer C, Hennissen AH, Beguin S, Heemskerk JWM. Vitamin Kdependent and vitamin $\mathrm{K}$-independent hypocoagulant effects of dietary tish oil in rats. Thromb Res. 2001; 104: 137-147.

13. Sullivan PM, Mezdour H, Quarfordt SH, Maeda N. Type III hyperlipoproteinemia and spontaneous atherosclerosis in mice resulting from gene replacement of mouse apoE with human APOE*2. J Clin Invest. 1998; 102: 130-135.

14. Weisgraber KH, Innerarity TL, Mahley RW. Abnormal lipoprotein receptor-binding activity of the human $\mathrm{E}$ apoprotein due to cysteine-arginine interchange at a single site. J Biol Chem. 1982; 257: 2518 2521.

15. Shiri-Sverdlov R, Wouters K, van Gorp PJ, Gijbels MJ, Noel B, Buffat L, Staels B, Maeda N, van Bilsen M, Hofker MH. Early diet-induced non-alcoholic steatohepatitis in APOE2 knock-in mice and its prevention by fibrates. J Hepatol. 2006; 44: 732-741.

16. Hemker $\mathrm{HC}, \mathrm{Al}$ Dieri $\mathrm{R}$, Béguin $\mathrm{S}$. Thrombin generation assays: accruing clinical relevance. Curr Opin Hematol. 2004; 11:170-175.

17. Hemker HC, Giesen P, Al Dieri R, Regnault V, De Smedt E, Wagenvoord R, Lecompte T, Béguin S. Calibrated automated thrombin generation measurement in clotting plasna. Pathophysiol Haemost Thromb. 2003; 33: 4-15.

18. Nieuwenhuys CMA, Hornstra $G$. The effects of purified eicosapentaenoic and docosahexaenoic acids on arterial thrombosis tendency and platelet function in rats. Biochim Biophys Acta. 1998; 1390: 313-322.

19. Schurgers LJ, Teunissen KJ, Knapen MH, Kwaijtaal M, van Diest R, Appels A, Reutelingsperger CP, Cleutjens JP, Vermeer $C$. Novel conformation-specific antibodies against matrix gammacarboxyglutamic acid (Gla) protein: undercarboxylated matrix Gla protein as marker for vascular calcification. Arterioscler Thromb Vasc Biol. 2005; 25: 1629-1633.

20. Rall SC, Weisgraber KH, Mahley RW. Human apolipoprotein E. The complete amino acid sequence. J Biol Chem. 1982; 257: 4171-4178. 
21. Chan P, Tomlinsoin B, Tsai CW, Pan WH, Lee YS. Thrombophilia in patients with hypercholesterolemia. Metabolism. 1996; 45: 966-969.

22. Morishita E, Jokaji H, Matsuda T. Hyperlipidemia and hemostatic system. J Atheroscler Thromb. 1995; 2: \$36-40.

23. De Roos B, Duivenvoorden I, Rucklidge G, Reid M, Ross K, Lamers RJ, Voshol PJ, Havekes LM, Teusink B. Response of apolipoprotein E*3-Leiden transgenic mice to dietary fatty acids: combining proteomics with physiological data. FASEB J. 2005; 19: 813-815.

24. Yamashita T, Oda E, Yamashita T, Ijiru Y, Giddings JC, Yamamoto J. Varying the ratio of dietary n6/n-3 polyunsaturated fatty acids alters the tendency to thrombosis and progression of atherosclerosis in ApoE -/- LDR -/- double knockout mice. Thromb Res. 2005; 116: 393-401.

25. Zampolli A, Bysted A, Leth T, Mortensen A, De Caterina R, Falk E. Contrasting effect of fish oil supplementation on the development of atherosclerosis in murine models. Atherosclerosis. 2005; 184: $78-85$.

26. Jump DB, Clarke SD. Regulation of gene expression by dietary fat. Annu Rev Nutr. 1999; 19: 63-90.

27. Dallongeville J, Baugé E, Tailleux A, Peters JM, Gonzalez FJ, Fruchart JC, Staels B. Peroxisome proliferator-activating receptor alpha is not rate-limiting for the lipoprotein-lowering action of fish oil. J Biol Chem. $2001 ; 276: 4634-4639$. 
Chapter 8

\section{General discussion}


Given the high prevalence and impact of arterial thrombosis in the Western world and the likely multi-factorial cause of this disease, much effort has been made in finding the genetic and environmental factors involved and, in particular, the interactions between these factors. The studies of this thesis approached this topic by investigating the interindividual variation in the processes of platelet activation and blood coagulation, by determining whether this variation is explained by common genetic variation in haemostatic factors, and evaluating whether nutrition (fish oil) alters these processes in a subject-dependent way.

\section{SUBJECT-DEPENDENT PLASMA LEVELS OF HAEMOSTATIC FACTORS}

It has been suggested that inter-individual variability in haemostatic factors (e.g., platelets and coagulation factors) contributes to the predisposition for thrombosis (1-3). Activated platelets are involved in the thrombotic process by providing a surface, at which coagulation factors assemble and become activated (4). The platelet procoagulant activity relies on receptor-stimulated increase in the cytosolic free $\mathrm{Ca}^{2+}$ concentration. This $\mathrm{Ca}^{2+}$ response was shown to have a persistent subject-dependent component, which is unaltered after aspirin intake $(5,6)$. In chapter 3 , we elucidated the causes of the inter-individual variability in $\mathrm{Ca}^{2+}$ responses using platelets from healthy subjects, young patients recuperating from stroke, and patients with symptomatic peripheral arterial disease. A considerable number of the stroke patients had platelets with increased $\mathrm{Ca}^{2+}$ responses to thrombin, when the patients were in the convalescent phase of at least three months after the ischemic event. The high $\mathrm{Ca}^{2+}$ responses were not due to thromboxane production and were, in about half of the cases, accompanied by increased thrombin-mediated procoagulant activity, i.e. activation of coagulation factors. Furthermore, in healthy subjects, the high $\mathrm{Ca}^{2+}$ responses appeared to be specifically due to activation of the protease-activated receptor 1 (PAR1) for thrombin. This variable, PAR1-dependent $\mathrm{Ca}^{2+}$ responsiveness agrees with the evidence that also receptor-evoked platelet dense granule release - i.e. a $\mathrm{Ca}^{2+}$-dependent process - is subjected to inter-individual variability (7), and that PAR1 is the principal thrombin receptor involved in platelet procoagulant activity (8). We have not investigated whether PAR1 or signalling molecules downstream of PAR1 are increased in expression in the high $\mathrm{Ca}^{2+}$ responders. However, the results suggest that in a considerable part of the young stroke patients the PAR1 signalling pathway is increased in activity.

Based on evidence in literature that the PAR1-dependent variability in platelet activation can extend to integrin activation and platelet aggregation (7), we determined in chapter 3 also the relation between PAR1-induced $\mathrm{Ca}^{2+}$ signalling and genetic variation in two major platelet integrins, $\alpha I \mathrm{Il} \beta 3$ and $\alpha 2 \beta 1$. We focussed on the $\mathrm{Pl}^{\mathrm{A} 2}$ allele of the integrin $\beta 3$ chain and the 807T allele of the $\alpha 2$ chain (chapter 1), both of which are polymorphisms linked to increased platelet activation and proposed as risk factors for stroke (9-11). However, comparison of the $\mathrm{Ca}^{2+}$ responses with thrombin (receptor peptide), ADP or the glycoprotein VI (GPVI) agonist, convulxin, pointed to a 
similar thrombin-evoked $\mathrm{Ca}^{2+}$ signal generation in the platelets from carriers and noncarriers. Interestingly, platelets from $807 \mathrm{~T}$ carriers had a lower response to convulxin than those from non-carriers. It is known that the (silent) $807 \mathrm{~T}$ allele correlates with increased platelet surface density of the $\alpha 2 \beta 1$ collagen receptor and a corresponding increase in adhesion to collagen $(9,12,13)$. We therefore speculate that in $807 \mathrm{~T}$ carriers increased $\alpha 2 \beta 1$ expression can interfere with signalling via the other collagen receptor, GPVI, as induced by convulxin. However, it is noted that the power of the present study was too low to draw far-reaching conclusions.

Since haemostasis relies on both platelet activation and coagulation, it is expected that assays in which these processes are simultaneously measured provide important information on the haemostatic and, hence, prothrombotic state of the blood. A useful test in this respect is the automated and calibrated thrombogram method, in which thrombin generation in plasma is continuously measured after triggering with tissue factor $(14,15)$. In this assay, phosphatidylserine (PS)-containing vesicles or platelets are used as procoagulant membrane surface, thus meaning that the coagulation process can be studied in the absence or presence of platelet activation. Chapter 4 presents a study with healthy subjects, aiming to reveal factors contributing to the inter-individual variation in thrombin generation with phospholipid vesicles or platelets present. When comparing plasma from different subjects, we found that platelets contribute relatively little to the variation in thrombin-generating capacity (endogenous thrombin potential or ETP). In other words, individuals, who showed high thrombin generation curves in the presence of platelets, in general also gave high curves with phospholipid vesicles. This was confirmed in a study with another group of subjects, described in chapter $\mathbf{5}$. In conclusion, the inter-individual variation in plasma thrombin generation is mostly determined by variable, subject-dependent factors in coagulant activity rather than by variable platelet-related properties. Nevertheless, in assays with platelets, the activation of platelets and PS exposure appeared to be of key importance for the process of thrombin generation per se. Thus, these studies showed that the thrombin generation in platelet-rich plasma is fully dependent on the activation of platelets, but is also restricted in rate and extent by variable, subject-dependent coagulant activity of the plasma.

In which way plasma levels of coagulation factors contribute to the subject-dependent variation in thrombin generation was considered in chapters 5 and 6 . Chapter 5 describes a study with overweight male subjects, in which multivariate regression analysis was used to determine the contribution of principal (anti)coagulant factors to the large inter-subject variation in thrombin generation. In agreement with kinetic data $(16,17)$, we found that plasma levels of prothrombin and antithrombin were the main determinants of the endogenous thrombin potential with phospholipids. Only the plasma levels of fibrinogen and factor $\mathrm{V}$ had a small additional contribution to the variation in thrombin generation. Since moderate manipulation of the factor $\mathrm{V}$ concentration in plasma did not influence the thrombin generation, it is likely that in the thrombogram variation, factor $\mathrm{V}$ is a confounder for another plasma factor. Together, these four factors explained about $30 \%$ of the variation of the thrombin generation parameters. When extended to the in vivo situation, this implies that changes in these factors 
accomplish variation in the local rate of thrombin generation, e.g., at thrombotic sites, and hence may determine the extent of thrombosis.

Some reports describe that hyperlipidemic patients have elevated plasma levels of prothrombin, factor VII and factor X (18-21). In chapter 6, we studied two groups of subjects with a tendency of hypertriglyceridemia and thrombosis, i.e. overweight healthy volunteers and overweight patients with type 2 diabetes. Again, the variation in thrombin generation was determined and related to the levels/activities of individual (anti)coagulation factors. Principal component analysis indicated that for both study groups the fasting levels of triacylglycerol clustered with those of prothrombin, factor VII and factor X. Accordingly, although triacylglycerol is not involved in the thrombin generation process itself, the plasma levels of triacylglycerol significantly contribute to the variation in thrombin generation curves, together with the levels of prothrombin and antithrombin.

Presently, there is no clear, mechanistic explanation for the covariance of triacylglycerol and coagulation factor levels. In fasting plasma, the majority of the triacylglycerol is present in very-low density lipoproteins (VLDL). These particles are produced by the liver, similarly as most coagulation factors. It is therefore possible that one or more hepatic regulation processes control the production or secretion of both VLDL and these coagulation factors.

\section{HYPOLIPIDEMIC AND HYPOCOAGULANT EFFECTS OF DIETARY FISH} OIL

Fish oil is rich in n-3 polyunsaturated fatty acids (n-3 PUFA). Although epidemiological observations point to a strong association between fish oil consumption and reduced risk of atherothrombosis $(22,23)$, the molecular mechanism of this health-promoting effect of fish oil has is still unclear. The data presented in chapter 5 are a first report showing that in man fish-oil intake reduces the tissue factor-triggered thrombin generation. This assay is very sensitive in detecting hypocoagulant conditions (17), which explains why many earlier studies failed to detect a hypocoagulant effects of fish-oil consumption, as these relied on less sensitive coagulation assays like the prothrombin time. In the study of this thesis, 25 males with overweight received a high dose of $3.0 \mathrm{~g} \mathrm{n}-3$ PUFA per day during 4 weeks. An interesting observation was that the fish oil-induced decrease in thrombin peak level was greater in the presence than in the absence of platelets. Since fish oil also reduced platelet integrin $\alpha \operatorname{IIb} \beta 3$ activation in response to thrombin receptor stimulation, these data confirm the notion that thrombin generation depends on the mutually stimulatory interactions of platelet activation and coagulation (24).

The fish oil-induced decrease in thrombin generation was accompanied by a reduction in plasma levels of coagulation factors, which in this study was only significant for fibrinogen and factor $\mathrm{V}$. The reduction in plasma levels of fibrinogen and factor $\mathrm{V}$ correlated with the reduced thrombin generation, although these factors are only week predictors of the endogenous thrombin potential. On the other hand, experimental manipulation of the plasma fibrinogen level altered the thrombin generation curves as 
predicted. Some, but not all earlier intervention studies did also show that fibrinogen and/or factor $\mathrm{V}$ levels decrease in response to fish oil. As reviewed in chapter 2, this inter-study variation may not only be due to differences in design of the studies, but also to inter-subjects differences in responsiveness to the dietary intervention.

In the fish-oil study of chapter $\mathbf{5}$, we observed a reducing of plasma triacylglycerol, but did not find a significant intervention effect on the vitamin $\mathrm{K}$-dependent coagulation factors, prothrombin, factor VII, factor X and protein C, in spite of the clear reduction in thrombin generation of the plasma. In chapter 6 , this prompted us to new intervention studies, again with subjects at increased atherothrombotic risk: 54 overweight but healthy volunteers and 20 patients with type 2 diabetes and a tendency to hypertriglyceridemia. These subjects again received $3.1 \mathrm{~g} \mathrm{n}-3$ PUFA per day during 4 and 8 weeks, respectively. Although the decrease in levels of fibrinogen and factor $\mathrm{V}$ was not significant in study groups as a whole, we still found that the fish-oil effects on fibrinogen correlated with the baseline fibrinogen levels. This observation is in agreement with earlier published findings $(25,26)$.

For both study groups of chapter 6 , it also appeared that individuals with high fasting levels of triacylglycerol at baseline show the largest reduction of triacylglycerol after intake of fish oil. In the overweight subjects, this lowering in triacylglycerol was strikingly correlated with a reduction in thrombin generation and in coagulation factors VII and X. All diabetic patients had relatively high triacylglycerol levels at baseline. Here, intake of fish oil gave a very strong reduction in triacylglycerol (-21\%), which was accompanied by a potent reduction in thrombin generation and greatly reduced levels of prothrombin and factors V, VII and X (decreasing by 6-10\%). These effects were not seen in a control group of patients receiving n-6 PUFA-enriched corn oil. From these and other correlation analyses, we conclude that in particular the plasma triacylglycerol concentration acts as a predictive parameter for the (pro)coagulant state of plasma, likely by reflecting the overall activity of several coagulation factors. In other words, the above discussed clustering (or interaction) of plasma levels of triacylglycerol and the coagulation factors, prothrombin, factor VII and factor X, is maintained upon fish-oil intervention. This conclusion also agrees with the observation that the diet-induced reduction in thrombin generation curve was strongest for subjects with high baseline levels of thrombin generation.

The results of these intervention studies are of interest, because they suggest that the anticoagulant effect of fish oil is typically highest in individuals with not only high triacylglycerol or fibrinogen levels, but also with high coagulant activity. Or stated differently, those subjects with an increased risk of thrombosis - as exemplified by a high triacylglycerol or coagulation profile - would profit most of fish oil intake. This particularly concerns type 2 diabetes patients, who often show an atherogenic lipoprotein profile with high triacylglycerol and LDL cholesterol $(27,28)$. Other investigators have documented that diabetes patients respond to fish oil by partial correction of dyslipidemia $(29,30)$. Here we provide evidence that the triacylglycerollowering effect in these patients also associates with an anticoagulant effect.

Considering that the liver is the main source of the fasting levels of VLDL 
triacylglycerol and of most coagulation factors, the results seem to suggest that the n-3 PUFA in fish oil influence a common hepatic controlling the production and/or secretion of VLDL and coagulation factors. Various mechanisms have been proposed to explain how n-3 PUFA in fish oil can reduce the triacylglycerol in VLDL: n-3 PUFAinduced down-regulation of specific gene expression in the liver (31); suppression of VLDL apo B production $(32,33)$ or stimulation of apo B degradation (34); increased clearance of chylomicrons $(35,36)$; and higher conversion of VLDL into LDL in peripheral tissues $(37,38)$. If there indeed is a common regulatory mechanism in the control of plasma triacylglycerol and coagulation factor levels, n-3 PUFA-induced regulation of gene expression is an attractive possibility.

\section{FROM MAN TO MOUSE}

To elucidate the mechanism responsible for the lipid-lowering and hypocoagulant effects of fish oil, chapter 7 focuses on the mouse liver. We used a hyperlipidemic and pro-atherogenic model, i.e. APOE2 knock-in mice, in which the endogenous murine apoE gene is replaced by the human APOE2 gene. The human ApoE2 variant protein has impeded binding to the LDL receptor, causing diminished clearance of chylomicrons and VLDL and, hence, elevated plasma levels of triacylglycerol $(39,40)$. The human APOE2 polymorphism is one of the main causes of type III hyperlipoproteinemia. When comparing to wildtype mice of the same genetic background, a first interesting observation was that APOE2 knock-in mice, held on a standard low-fat diet, showed quite high plasma levels of not only triacylglycerol, but also of several coagulation factors, including fibrinogen (borderline), prothrombin and factors V, VII and X. Thus, the earlier observed association between high plasma levels of triacylglycerol and coagulation factors was also present in these mice. Furthermore, the APOE2 knock-in mice showed markedly increased thrombin generation curves in comparison to wildtypes, such in line with the high coagulation factor concentrations.

Feeding of the APOE2 knock-in mice for 3 weeks with a high-fat diet, rich in n-3 PUFA-containing fish oil, substantially decreased the plasma levels of triacylglycerol and coagulation factors, almost normalizing these concentrations to those of wildtype mice on low-fat diet. The fish oil simultaneously reduced the thrombin generation. These dietary intervention effects appeared to be specific for n-3 PUFA, as they were not seen with a n-6 PUFA diet rich in sunflower seed oil.

Microarray analysis of mRNA profiles in the livers of the APOE2 knock-in mice, indicated a number of interesting differences after feeding with standard low-fat diet and with high-fed diet, containing fish oil or sunflower seed oil. In mice fed with $\mathrm{n}-3$ PUFA, gene expression was reduced of several key enzymes involved in the synthesis of fatty acids and lipids, while the expression was increased of several genes involved in the oxidation and degradation of fatty acids as well as in electron transport reactions. Less marked and often different dietary effects were seen in livers from mice fed with the n-6 PUFA. Accordingly, it is likely that the lipid-lowering effect of n-3 PUFA in these mice is the consequence of a net reduced fatty acid and lipid synthesis in the liver. 
This notion is in agreement with earlier data of increased activity of a number of enzymes of fatty acid oxidation and degradation in response to dietary n-3 PUFA (41). From the data it is unclear whether a common regulatory factor is implicated in the n-3 PUFA-induced changes in mRNA expression of lipid-metabolizing enzymes. Differentially upregulated, in comparison to n-6 PUFA-fed mice, was the gene of the transcription factor, PPAR $\alpha$, and downregulated was the gene of the erythroid-derived nuclear factor-2. However, so far the literature does not provide strong indications that these transcription factors are rate-limiting in controlling lipid synthesis in the liver and lipid levels in plasma.

An unexpected finding was that genes encoding for (anti)coagulant proteins were not decreased in expression in the APOE2 mice fed with fish oil diet. This was concluded from the microarray analysis and also from quantitative real-time PCR tests. Instead, mRNA levels of prothrombin and factors V, VII and X and protein $Z$ were moderately increased after feeding fish oil but not sunflower seed oil. In the first group of mice, this was reflected on the protein level by immunohistochemical staining of liver sections, showing topical accumulation of prothrombin, factor VII and factor X.

Retention of coagulation factors after altered post-translational modification may cause hepatic accumulation and reduce their secretion. Staining of the livers for Gla residues, which are formed by vitamin $\mathrm{K}$-dependent carboxylation of the coagulation factors, prothrombin and factors VII and X, was not increased after fish oil. On the other hand, gene expression of the vitamin $\mathrm{K}$-dependent $\gamma$-glutamyl carboxylase was downregulated, which suggested that part of the accumulated coagulation factors are reduced in $\gamma$-carboxylation. This is reminiscent of the action of vitamin $\mathrm{K}$-dependent carboxylase inhibitors like coumarins, which also provoke accumulation of 'proteins induced by vitamin $\mathrm{K}$ absence or antagonists' (PIVKAs) (42). A decreased carboxylase activity partly explains the anticoagulant effect of fish oil, as far as concerning the vitamin K-dependent coagulation factors (prothrombin, factors VII, IX and X, and protein $\mathrm{C}, \mathrm{S}$ and $\mathrm{Z}$ ). However, as the present studies indicate that also vitamin $\mathrm{K}$ independent (anti)coagulant factors can be affected by n-3 PUFA diet, i.e. fibrinogen, factor $\mathrm{V}$ and antithrombin, the fish oil effect should also rely on a different mechanism. This has also been concluded in earlier dietary intervention studies with rats, which also showed that fish decreased levels of both vitamin $\mathrm{K}$-dependent and -independent factors and, further, that fish oil did not interfere in the hepatic vitamin $K$ uptake $(43,44)$.

Taken together, the results presented in chapter 7 argue against a common regulatory mechanism of lipid metabolism and coagulation factor synthesis in the murine liver. Fish oil is likely to lower plasma lipid levels via altered expression of genes controlling fatty acid and lipid degradation and synthesis, while its effect on plasma coagulation factors is not directly by expression regulation of the factor genes.

\section{WEAK CONTRUBUTION OF COAGULATION FACTOR POLYMORPHISMS}

A number of genetic polymorphisms of coagulation factors, e.g. of fibrinogen, prothrombin and factor $V(45,46)$, have been described that correlate with altered 
plasma levels and/or function of these factors. Hence, it was of interest to examine whether inter-subject variation in the response of fish oil on the factor levels and thrombin generation related to the presence of such polymorphisms. In the small study of chapter 5, carriers of the fibrinogen $\alpha$-chain 312Ala variant appeared to have a higher baseline fibrinogen level, which was accompanied by a stronger reduction with fish oil in both fibrinogen concentration and thrombin generation in comparison to noncarriers of this polymorphism. The fibrinogen reduction in carriers could explain most of the effect on thrombin generation with or without platelets. However, in the large group of subjects of chapter 6 , the fibrinogen- $\alpha$ T312A polymorphism only played a non-significant role in the prediction of the anticoagulant effect of fish oil. While the 312Ala allele influences clot stability (47) and predisposes clots to embolization (48), other authors also indicate that the relation of this polymorphism with fibrinogen expression is unclear. There was no difference in fish-oil responses between carriers and non-carriers of a common haplotype in the promoter region of the $\beta$-fibrinogen gene ($854 /-148$ ). Also in this case, it is unclear how the polymorphism relates to fibrinogen expression (49-51).

With respect to factor $\mathrm{V}$, there is evidence that the His1299Arg (A4070G) polymorphism, being associated with HR2 haplotype, is related to the level of factor $\mathrm{V}$ in plasma (45). In the study described in chapter 5, carriers of the 1299Arg allele of factor $\mathrm{V}$ had lower factor $\mathrm{V}$ levels than the non-carriers, both before and after fish-oil supplementation. Carriers also tended to respond better to fish oil, which was also confirmed in the larger study of chapter 6. For prothrombin, we could confirm the known linkage of G20210A carriers with higher prothrombin levels. However, both the G20210A and A19911G polymorphisms of prothrombin were not related to the prothrombin-lowering effect of fish oil. Furthermore, for all these polymorphisms, correlation analysis indicated that the genetic variation was at best a minor determinant of the subject-dependent fish-oil effects, certainly when compared to the variation in triacylglycerol level. Therefore, although we realize that population sizes in the present diet studies were small, it can be concluded that these common genetic variations of coagulation factors - which predispose for disease - do not play a major role in the variable anticoagulant response of subjects to dietary fish oil. It remains to be investigated whether genetic variation in apolipoproteins, e.g. ApoE, is a predictive variable for the anticoagulant of fish oil.

\section{CONCLUSIONS}

The studies of this thesis confirm the know linkage of common genetic variations of haemostatic factors with altered plasma levels of these factors. Furthermore, the thrombogram method determines the variable, subject-dependent haemostatic state of plasma, which is fully dependent on the activation of platelets, but is restricted in rate and extend by the coagulant activity of the plasma. Plasma levels of prothrombin, antithrombin and triacylglycerol significantly contribute to the inter-individual variation in thrombin generation, although triacylglycerol is not involved in the thrombin 
generation process itself.

Genetic variation does not play a major role in the subject-dependent response to dietary fish oil, but the associated lipid-lowering and hypocoagulant effects of dietary fish oil are highest in subjects with a high triacylglycerol or coagulation profile - i.e. subjects with an increased risk of thrombosis. Despite this association, there is no common regulatory mechanism of lipid metabolism and coagulation factor expression in the murine liver. Fish oil alters hepatic expression of genes controlling fatty acid and lipid degradation and synthesis, while it reduces hepatic secretion of plasma coagulation factors, probably after altered post-translational modification. 


\section{REFERENCES}

1. Grant PJ. The genetics of atherothrombotic disorders: a clinician's view. J Thromb Haemost. 2003; 1: 1381-90.

2. Humphries SE, Henry JA, Montgomery HE. Gene-environment interaction in the determination of levels of haemostatic variables involved in thrombosis and fibrinolysis. Blood Coagul Fibrinolysis. 1999; 10: S17-21.

3. Puddu P, Cravero E, Puddu GM, Muscari A. Genes and atherosclerosis: at the origin of the predisposition. Int J Clin Pract. 2005; 59: 462-72.

4. Heemskerk JW, Kuijpers MJ, Munnix IC, Siljander PR. Platelet collagen receptors and coagulation. A characteristic platelet response as possible target for antithrombotic treatment. Trends Cardiovasc Med. $2005 ; 15: 86-92$.

5. Feijge MA, van Pampus EC, Lacabaratz-Porret C, Hamulyak K, Levy-Toledano S, Enouf J, Heemskerk JW. Inter-individual variability in $\mathrm{Ca}^{2+}$ signalling in platelets from healthy volunteers: effects of aspirin and relationship with expression of endomembrane $\mathrm{Ca}^{2+}$-ATPases. $\mathrm{Br}$ J Haematol. 1998; 102: 850-9.

6. Feijge MAH, Lacabaratz-Porret $C$, van Pampus ECM, Hamulyak K, Lévy-Toledano S, Enouf $J$, Heemskerk JWM. Contribution of thromboxane and endomembrane $\mathrm{Ca}^{2+}-$ ATPases to variability in $\left[\mathrm{Ca}^{2+}\right]_{\mathrm{i}}$ signalling of platelets from healthy volunteers. Platelets. 1998; 9: 179-83.

7. Lasne D, Krenn M, Pingault V, Arnaud E, Fiessinger JN, Aiach M, Rendu F. Interdonor variability of platelet response to thrombin receptor activation: influence of PlA2 polymorphism. $\mathrm{Br} J$ Haematol. 1997; 99: 801-7.

8. Keuren JFW, Wielders SJ, Ulrichts H, Hackeng T, Deckmyn H, Heemskerk JWM, Bevers E, Lindhout T. Synergistic effect of thrombin on collagen-induced platelet procoagulant activity is mediated through protease-activated receptor-1. Arterioscler Thromb Vasc Biol. 2005; 25: 1499-505.

9. Carlsson LE, Santoso S, Spitzer C, Kessler C, Greinacher A. The $\alpha 2$ gene coding sequence T807/A873 of the platelet collagen receptor integrin $\alpha 2 \beta 1$ might be a genetic risk factor for the development of stroke in younger patients. Blood. 1999; 93: 3583-6.

10. Hassan A, Markus HS. Genetics and ischaemic stroke. Brain. 2000; 123 ( Pt 9): 1784-812.

11. Michelson AD, Furman MI, Goldschmidt-Clermont P, Mascelli MA, Hendrix C, Coleman $L$, Hamlington J, Barnard MR, Kickler T, et al. Platelet GP IIIa PI(A) polymorphisms display different sensitivities to agonists. Circulation. 2000; 101: 1013-8.

12. Kritzik M, Savage B, Nugent DJ, Santoso S, Ruggeri ZM, Kunicki TJ. Nucleotide polymorphisms in the $\alpha 2$ gene define multiple alleles that are associated with differences in platelet alpha2 beta1 density. Blood. 1998; 92: 2382-8.

13. Kunicki TJ, Kritzik M, Annis DS, Nugent DJ. Hereditary variation in platelet integrin $\alpha 2 \beta 1$ density is associated with two silent polymorphisms in the $\alpha 2$ gene coding sequence. Blood. 1997; 89: 1939-43.

14. Hemker HC, Giesen P, Al Dieri R, Regnault V, de Smedt E, Wagenvoord R, Lecompte T, Béguin S. Calibrated automated thrombin generation measurement in clotting plasma. Pathophysiol Haemost Thromb. 2003; 33: 4-15.

15. Hemker HC, Giesen PLA, Ramjee M, Wagenvoord R, Béguin S. The thrombogram: monitoring thrombin generation in platelet rich plasma. Thromb Haemost. 2000; 83: 589-91.

16. Butenas S, van't Veer C, Mann KG. "Normal" thrombin generation. Blood. 1999; 94; 2169-78.

17. Hemker HC, Béguin S. Thrombin generation in plasma: its assessment via the endogenous thrombin potential. Thromb Haemost. 1995; 74: 134-8.

18. Chan P, Tomlinsoin B, Tsai CW, Pan WH, Lee YS. Thrombophilia in patients with hypercholesterolemia. Metabolism. 1996; 45: 966-9.

19. Hoffman CJ, Lawson WE, Miller RH, Hultin MB. Correlation of vitamin K-dependent clotting factors with cholesterol and triglycerides in healthy young adults. Arterioscler Thromb. 1994; 14: 1737-40.

20. Morishita E, Jokaji H, Matsuda T. Hyperlipidemia and hemostatic system. J Atheroscler Thromb. 1995; 2: $\$ 36-40$.

21. Rosenson RS, Lowe GD. Effects of lipids and lipoproteins on thrombosis and rheology. Atherosclerosis. 1998; 140: $271-80$.

22. Hu FB, Cho E, Rexrode KM, Albert CM, Manson JE. Fish and long-chain w3 fatty acid intake and risk of coronary heart disease and total mortality in diabetic women. Circulation. 2003; 107: 1852-7.

23. Kris-Etherton PM, Harris WS, Appel LJ. Fish consumption, fish oil, omega-3 fatty acids, and cardiovascular disease. Circulation. 2002; 106: 2747-57. 
24. Heemskerk JW, Bevers EM, Lindhout T. Platelet activation and blood coagulation. Thromb Haemost. 2002; 88: 186-93.

25. Haglund $O$, Wallin R, Luostarinen R, Saldeen T. Effects of a new fluid fish oil concentrate, Eskimo-3, on triglycerides, cholesterol, fibrinogen and blood pressure. J Intern Med. 1990; 227: 347-53.

26. Shahar E, Folsom AR, Wu KK, Dennis BH, Shimakawa T, Conlan MG, Davis CE, Williams OD. Associations of fish intake and dietary n-3 polyunsaturated fatty acids with a hypocoagulable profile. The atherosclerosis risk in communities (ARIC) study. Arterioscler Thromb. 1993; 13: 1205-12.

27. Syvanne M, Taskinen MR. Lipids and lipoproteins as coronary risk factors in non-insulin-dependent diabetes mellitus. Lancet. 1997; 350: S120-3.

28. Haffner SM, Lehto S, Ronnemaa T, Pyorala K, Laakso M. Mortality from coronary heart disease in subjects with type 2 diabetes and in nondiabetic subjects with and without prior myocardial infarction. $N$ Eng! J Med. 1998; 339: 229-34.

29. Pedersen H, Petersen M, Major-Pedersen A, Jensen T, Nielsen NS, Lauridsen ST, Marckmann P. Influence of fish oil supplementation on in vivo and in vitro oxidation resistance of low-density lipoprotein in type 2 diabetes. Eur J Clin Nutr. 2003; 57: 713-20.

30. Petersen M, Pedersen H, Major-Pedersen A, Jensen T, Marckmann P. Effect of fish oil versus corn oil supplementation on LDL and HDL subclasses in type 2 diabetic patients. Diabetes Care. 2002; 25: 17048.

31. Botham KM, Zheng X, Napolitano M, Avella M, Cavallari C, Rivabene R, Bravo E. The effects of dietary $n-3$ polyunsaturated fatty acids delivered in chylomicron remnants on the transcription of genes regulating synthesis and secretion of very-low-density lipoprotein by the liver: modulation by cellular oxidative state. Exp Biol Med. 2003; 228: 143-51.

32. Bordin P, Bodamer OA, Venkatesan S, Gray RM, Bannister PA, Halliday D. Effects of fish oil supplementation on apolipoprotein B100 production and lipoprotein metabolism in normolipidaemic males. Eur J Clin Nutr. 1998; 52: 104-9.

33. Nestel PJ, Connor WE, Reardon MF, Connor S, Wong S, Boston R. Suppression by diets rich in fish oil of very low density lipoprotein production in man. J Clin Invest. 1984; 74: 82-9.

34. Pan M, Cederbaum AI, Zhang YL, Ginsberg HN, Williams KJ, Fisher EA. Lipid peroxidation and oxidant stress regulate hepatic apolipoprotein B degradation and VLDL production. J Clin Invest. 2004; 113: $1277-87$.

35. Park Y, Harris WS. Omega-3 fatty acid supplementation accelerates chylomicron triglyceride clearance. J Lipid Res. 2003; 44: 455-63.

36. Westphal S, Orth M, Ambrosch A, Osmundsen K, Luley C. Postprandial chylomicrons and VLDLs in severe hypertriacylglycerolemia are lowered more effectively than are chylomicron remnants after treatment with n-3 fatty acids. Am J Clin Nutr. 2000; 71: 914-20.

37. Fisher WR, Zech LA, Stacpoole PW. Apolipoprotein B metabolism in hypertriglyceridemic diabetic patients administered either a fish oil- or vegetable oil-enriched diet. J Lipid Res. 1998; 39: 388-401.

38. Huff MW, Telford DE. Dietary fish oil increases conversion of very low density lipoprotein apoprotein B to low density lipoprotein. Arteriosclerosis. 1989; 9: 58-66.

39. Rall SC, Weisgraber KH, Mahley RW. Human apolipoprotein E. The complete amino acid sequence. J Biol Chem. 1982; 257: 4171-8.

40. Weisgraber $\mathrm{KH}$, Innerarity TL, Mahley RW. Abnormal lipoprotein receptor-binding activity of the human $E$ apoprotein due to cysteine-arginine interchange at a single site. J Biol Chem. 1982; 257: 251821.

41. Jump DB, Clarke SD. Regulation of gene expression by dietary fat. Annu Rev Nutr. 1999; 19: 63-90.

42. Vermeer $\mathrm{C}$, Schurgers LJ. A comprehensive review of vitamin $\mathrm{K}$ and vitamin $\mathrm{K}$ antagonists. Hematol Oncol Clin North Am. 2000; 14:339-53.

43. Nieuwenhuys CM, Béguin S, Offermans RF, Emeis JJ, Hornstra G, Heemskerk JW. Hypocoagulant and lipid-lowering effects of dietary n-3 polyunsaturated fatty acids with unchanged platelet activation in rat. Arterioscler Thromb Vasc Biol. 1998; 18: 1480-9.

44. Nieuwenhuys CM, Feijge MA, Vermeer C, Hennissen AA, Béguin S, Heemskerk JW. Vitamin Kdependent and vitamin $\mathrm{K}$-independent hypocoagulant effects of dietary fish oil in rats. Thromb Res. 2001; 104: 137-47.

45. Lunghi B, Iacoviello L, Gemmati D, Dilasio MG, Castoldi E, Pinotti M, Castaman G, Redaelli $R$, Mariani $G$, et al. Detection of new polymorphic markers in the factor $V$ gene: association with factor $V$ levels in plasma. Thromb Haemost. 1996; 75; 45-8. 
46. Castoldi E, Simioni P, Kalafatis M, Lunghi B, Tormene D, Girelli D, Girolami A, Bernardi F. Combinations of 4 mutations (FV R506Q, FV H1299R, FV Y1702C, PT 20210G/A) affecting the prothrombinase complex in a thrombophilic family. Blood. 2000; 96: 1443-8.

47. Curran JM, Fatah-Ardalani K, Tornvall P, Humphries SE, Green FR. A hypothesis to explain the reported association of the alpha-fibrinogen $\mathrm{A} 312$ allele with thromboembolic disease. Thromb Haemost. 2001; 85: 1122-3.

48. Carter AM, Catto AJ, Kohler HP, Ariens RA, Stickland MH, Grant PJ, alpha-fibrinogen Thr312Ala polymorphism and venous thromboembolism. Blood. 2000; 96: 1177-9.

49. Behague I, Poirier O, Nicaud V, Evans A, Arveiler D, Luc G, Cambou JP, Scarabin PY, Bara L, et al. Beta fibrinogen gene polymorphisms are associated with plasma fibrinogen and coronary artery disease in patients with myocardial infarction. The ECTIM Study. Circulation. 1996; 93: 440-9.

50. Humphries SE, Ye S, Talmud P, Bara L, Wilhelmsen L, Tiret L. European Atherosclerosis Research Study: genotype at the fibrinogen locus (G-455-A beta-gene) is associated with differences in plasma fibrinogen levels in young men and women from different regions in Europe. Evidence for gendergenotype-environment interaction. Arterioscler Thromb Vasc Biol. 1995; 15: 96-104.

51. Van 't Hooft FM, von Bahr SJ, Silveira A, Iliadou A, Eriksson P, Hamsten A. Two common, functional polymorphisms in the promoter region of the beta-fibrinogen gene contribute to regulation of plasma fibrinogen concentration. Arterioscler Thromb Vasc Biol. 1999; 19: 3063-70. 
Summary 
Atherothrombosis, defined as atherosclerotic plaque disruption with superimposed thrombosis, is the leading cause of mortality in the Western world. Because individuals are known to vary considerably in their susceptibility for developing atherothrombosis, much effort has been made in finding the genetic and environmental factors involved in this subject-dependent variation and, in particular, the interactions between these factors. The studies of this thesis investigated the inter-individual variation in the processes of platelet activation and blood coagulation, determined whether this variation is explained by common genetic variation in haemostatic factors, and evaluated whether fish oil alters these processes in a subject-dependent way. A brief introduction to relevant basic mechanisms of activation of blood platelets and the coagulation system is given in chapter 1. Furthermore, relevant genetic polymorphisms of platelets and coagulation factors and a brief introduction to the transport of blood lipids are presented.

The interest in fish oil as a possible antithrombotic nutritional component arose in the mid-1970s, when it was observed that Greenland Inuits, consuming high amounts of fatty fish, had a tendency of prolonged bleeding and a low incidence of cardiovascular disease. The main responsible nutritional components for this effect were soon considered to be the n-3 polyunsaturated fatty acids ( $n-3$ PUFA) of fish oil. Since then, epidemiological observations have pointed to a clear association between fish oil consumption and reduced risk of coronary heart disease. In chapter 2 , an extensive literature overview to the risk-reducing and potentially harmful effects of fish oil is described. It is concluded that earlier reports on the risk-reducing effects of dietary fish oil with regards to haemostatic parameters are highly variable in outcome. This high inter-study variation may not only be due to differences in the experimental set-up of the studies, but also to differences between the subjects participating in the studies. We therefore postulated that inter-individual variability in haemostatic factors - particularly platelet and coagulation factors - may contribute to the risk of atherothrombosis, and that dietary fish oil may change these haemostatic factors in a subject-dependent way. A subject-dependent response to dietary fish oil may help to explain to the variable outcome of fish oil intervention studies.

Undisturbed flow of blood through the vascular system is based on balanced interactions between blood cells, plasma proteins and the endothelial-coated vessel wall. Following vessel wall injury, platelets become activated via multiple signalling pathways, in particular leading to a receptor-stimulated increase in cytosolic free $\mathrm{Ca}^{2+}$ concentration. This $\mathrm{Ca}^{2+}$ response can lead to platelet procoagulant activity due to surface exposure of phosphatidylserine, after which coagulation factors can assemble at this surface and the coagulation cascade becomes activated. In chapter 3, we studied whether the platelet procoagulant response has a subject-dependent component. Therefore, we compared agonist-induced $\mathrm{Ca}^{2+}$ signal generation in the platelets from a group of healthy volunteers, of young patients recuperating from stroke, and of patients with symptomatic peripheral arterial disease. In the presence of aspirin, the average thrombin-induced $\mathrm{Ca}^{2+}$ response of platelets was significantly higher in either patient group compared to healthy subjects. Stroke patients more often had highly responsive 
platelets than patients with peripheral arterial disease or healthy subjects. In about half of the subjects with identified high thrombin-induced $\mathrm{Ca}^{2+}$ responses, this was accompanied by an increased procoagulant activity of the platelets after stimulation with thrombin. In a follow-up study using platelets from healthy subjects, we then found that the subject-dependent variation in thrombin-induced $\mathrm{Ca}^{2+}$ responses was at least partially due to variation in protease-activated receptor 1 (PAR1)-mediated platelet activation. Since PAR1-dependent variability in platelet activation can extend to integrin activation and platelet aggregation, we also studied the relation between PAR1induced $\mathrm{Ca}^{2+}$ signalling and the genetic variation in two major platelet integrins, $\alpha \operatorname{IIb} \beta 3$ and $\alpha 2 \beta 1$. Both the $\mathrm{PI}^{\mathrm{A} 2}$ allele of the $\beta 3$ chain and the 807T allele of the $\alpha 2$ chain have been associated to increased platelet activation and therefore might act as risk factors for stroke. However, the $\mathrm{Ca}^{2+}$ responses were not associated with these platelet integrin polymorphisms.

Assays in which the mutually stimulatory processes of platelet activation and coagulation are simultaneously measured, can provide important information on the haemostatic and, hence, prothrombotic state of the blood. In chapter 4 , we studied such an assay, the calibrated automated thrombogram method, with the aim to establish the inter-relationship of platelet activation and coagulation in platelet-rich plasma (PRP) from healthy subjects. In this assay, thrombin generation is continuously measured after triggering the plasma with tissue factor, while phosphatidylserine-containing platelets or phospholipid vesicles provide the procoagulant membrane surface. In PRP from all subjects, platelets agonists like ADP, thrombin and collagen stimulated the rate of thrombin generation. Conversely, integrin aIIb $\beta 3$ antagonists and ADP receptor blockage, but not aspirin, decreased the rate of thrombin generation and extended the time of onset of the process. Platelet inhibition with cyclic AMP-elevating agents also decreased the thrombin generation, but surprisingly shortened the onset time.

Comparison of the plasmas from various subjects showed considerable inter-individual variation in the total amount of thrombin generation, regardless of whether platelets or phospholipids were present. This variation persisted in time. In PRP from donors with low or high thrombin generation, platelet inhibitors and activators were similarly effective. The findings together demonstrate that, in tissue factor-triggered PRP, phosphatidylserine exposure on activated platelets regulates both onset and rate of thrombin generation. While the kinetics of thrombin generation in PRP are controlled by platelet agonists and inhibitors, this process appears to be restricted in amount by a variable, subject-dependent coagulant activity of the plasma.

This knowledge has been used in the two following chapters, where dietary intervention studies with fish oil-derived n-3 PUFA were performed in subjects at increased atherothrombotic risk. We determined the contribution of principal (anti)coagulant factors to the large inter-subject variation in thrombin generation, and studied the effect of n-3 PUFA on plasma lipids, coagulation factors and the thrombin generation profile. We also checked for candidate genetic polymorphisms of platelet and coagulation factor proteins, which had been associated with an increases thrombotic risk, thus hypothesizing that the antithrombotic effect of dietary n-3 PUFA has a genetic 
component.

In chapter 5, the results are described of a dietary intervention study, in which 25 overweight but healthy male volunteers received $3.0 \mathrm{~g} \mathrm{n}-3$ PUFA daily during four weeks. Before the fish oil intake, thrombin generation considerably varied between the plasmas of the individual subjects. This variation could for a significant part be explained by variation in the plasma levels of prothrombin, antithrombin, fibrinogen and factor V. Fish oil intake reduced the level of triacylglycerol in plasma as well as the levels of fibrinogen and factor $\mathrm{V}$, and lowered platelet integrin activation. Although this intervention did not affect the vitamin $\mathrm{K}$-dependent coagulation factors, it reduced thrombin generation both in the presence and absence of platelets. This reduction correlated with the reducing effect of fish oil on fibrinogen and factor $V$ levels. In this small study population, the lowering effect of fish oil on thrombin generation and fibrinogen clustered around subjects with high fibrinogen levels at baseline, who often carried the 312Ala variant of the fibrinogen- $\alpha$ T312A polymorphism. Furthermore, carriers of the 1299Arg variant of the factor V His1299Arg (A4070G) polymorphism had lower factor $V$ levels than non-carriers, both before and after fish oil supplementation. The 1299Arg carriers also tended to respond better to fish oil.

To extend this work and to establish how fish oil influences the plasma levels of vitamin $\mathrm{K}$-dependent and -independent coagulation factors, two other studies were performed with subjects at increased atherothrombotic risk. Chapter 6 describes the results of these studies, carried out with 57 overweight but healthy volunteers (4 weeks intervention), and 42 patients with type 2 diabetes and a tendency to hypertriglyceridemia ( 8 weeks intervention). All subjects received $3.1 \mathrm{~g} \mathrm{n}$-3 PUFA per day. In both studies, multivariate analysis demonstrated a strong clustering of the fasting plasma concentrations of triacylglycerol, prothrombin, factor V, factor VII, and factor X at baseline. This cluster significantly contributed to the inter-individual variation in thrombin generation. Intriguingly, the triacylglycerol and prothrombin concentrations were main determinants of the amount of thrombin generation, even though triacylglycerol by itself is not involved in this process. Furthermore, in the overweight subjects and the type 2 diabetes patients, high triacylglycerol concentrations at baseline were closely linked to a stronger fish oil-induced lowering of triacylglycerol and factor $\mathrm{V}, \mathrm{VII}$, and $\mathrm{X}$ concentrations, along with a reduction in thrombin generation.

In this larger study population, the fibrinogen- $\alpha$ T312A polymorphism was no longer associated with the effect of fish oil on thrombin generation. Similar as in chapter 5 , 1299Arg carriers of the factor V His 1299Arg (A4070G) polymorphism tended to respond better to fish oil. However, correlation analysis indicated that genetic variation of the coagulation factors was not a major determinant of the subject-dependent fish oil effects. We did not find a mechanistic explanation for the covariance in levels of triacylglycerol and coagulation factors. However, in fasting plasma most of the triacylglycerol is present in very-low density lipoproteins (VLDL), produced by the liver. Since the liver also is the largest source of coagulation factors, it is postulated that one or more hepatic processes jointly control the production or secretion of VLDL and coagulation factors. 
To elucidate a possible mechanism for the lipid-lowering and hypocoagulant effects of fish oil, we then moved to the mouse in chapter 7. We used hyperlipidemic and proatherogenic APOE2 knock-in mice, in which the endogenous murine apoE gene is replaced by the human, higher-risk APOE2 gene. Adult male APOE2 knock-in mice, when fed with a low-fat diet, developed hyperlipidemia and had high plasma coagulation factor levels. Both plasma lipids and coagulation factors normalized, when these mice received a high-fat diet containing fish oil (n-3 PUFA), but not after a comparable diet with sunflower seed oil ( $n-6$ PUFA). Fish oil diet also gave a considerable reduction in thrombin generation potential. Microarray and quantitative single gene expression analysis of liver mRNA showed that fish oil, but not sunflower seed oil diet caused an up-regulation of genes involved in fatty acid degradation and oxidation, a down-regulation of genes contributing to fatty acid synthesis and transport, and a lower gene expression of $\gamma$-glutamyl carboxylase. However, no major changes in genes of (anti)coagulant factors were detected. Immunohistochemical staining of liver sections indicated that only the fish oil diet increased the presence of vitamin Kdependent coagulation factors in the liver. We concluded that the hyperlipidemic and hypercoagulant APOE2 knock-in mice respond to dietary n-3 PUFA by reduced coagulant activity, which is not linked to altered hepatic expression of coagulation factor genes, but to restraint of these factors in the liver and/or altered post-translational modification. The lipid-lowering effect of n-3 PUFA is linked to increased hepatic expression of genes regulating fatty acid degradation and decreased expression of genes regulating fatty acid synthesis. These results do not support a common regulatory mechanism of lipid metabolism and coagulation factor synthesis in the murine liver.

Chapter 8 places key results of this thesis into a broader perspective. It is argued that the calibrated automated thrombogram method senses a variable, subject-dependent haemostatic state of plasma, which in PRP is fully dependent on the activation of platelets, but is restricted in rate and extent by the coagulant activity of the plasma. Plasma levels of prothrombin, antithrombin and triacylglycerol significantly contribute to the inter-individual variation in thrombin generation, although triacylglycerol is not involved in the thrombin generation process per se. An important finding is that the lipid-lowering and hypocoagulant effects of dietary fish oil are highest in subjects with a high baseline level of triacylglycerol or thrombin generation. This suggests that subjects at risk with a hyperlipidemic and hypercoagulant profile will mostly benefit from fish oil intake. Genetic variation on the other hand, as far as investigated, does not seem to play a major role in the subject-dependent response to dietary fish oil. 
Samenvatting 
Atherotrombose wordt gedefinieerd als de afscheuring van een atherosclerotische plaque gevolgd door trombose, en is doodsoorzaak nummer 1 in de Westerse wereld. Omdat mensen aanzienlijk verschillen in hun vatbaarheid voor de ontwikkeling van atherotrombose, wordt er veel aandacht besteed aan de zoektocht naar de genetische en omgevingsfactoren betrokken in deze persoonsafhankelijke variatie, en meer bepaald de interactie tussen deze factoren. De studies beschreven in deze thesis onderzochten de persoonsafhankelijke variatie in de processen van bloedplaatjesactivatie en bloedstolling, bepaalden of deze variatie verklaard kan worden door gekende kleine genetische variaties (polymorfismen) in hemostatische factoren, en controleerden of visolie bloedplaatjesactivatie en bloedstolling op een persoonsafhankelijke wijze beïnvloedt. Een korte introductie over relevante mechanismen betrokken bij de activering van bloedplaatjes en het stollingssysteem staat weergegeven in hoofdstuk 1. In hetzelfde hoofdstuk worden voorts relevante genetische polymorfismen in bloedplaatjes en stollingsfactoren beschreven, alsook een korte inleiding over het transport van bloedlipiden.

De interesse in visolie als een mogelijk antitrombotische voedingscomponent ontstond midden de jaren '70, toen ontdekt werd dat Inuïts in Groenland, die grote hoeveelheden vette vis consumeerden, een neiging tot verlengde bloedingen hadden en tevens een laag voorkomen van hart- en vaatziekten. De $\mathrm{n}-3$ meervoudig onverzadigde vetzuren ( $\mathrm{n}-3$ PUFA) uit visolie werden al snel beschouwd als de voornaamste voedingscomponenten verantwoordelijk voor dit effect. Vanaf toen hebben epidemiologische studies een duidelijk verband aangetoond tussen visolieconsumptie en een verminderd risico op coronair hartlijden. In hoofdstuk 2 wordt een uitgebreide literatuurstudie over de risicoverlagende en mogelijk schadelijke effecten van visolie gepresenteerd. Eerdere rapporten over de risicoverlagende effecten van visolie met betrekking tot hemostatische factoren blijken zeer verschillende resultaten weer te geven. Deze hoge variatie tussen studies onderling is mogelijk niet enkel te wijten aan verschillen in de experimentele opzet van de studies, maar ook aan verschillen tussen de proefpersonen die deelnemen aan de betreffende studies. We stelden daarom dat de persoonsafhankelijke variabiliteit in hemostatische factoren - meer bepaald bloedplaatjes en stollingsfactoren - kan bijdragen tot het risico op atherotrombose, en dat visolie deze hemostatische factoren op een persoonsafhankelijke wijze kan veranderen. Een persoonsafhankelijke reactie op visolie zou de verschillen in uitkomst van visolie interventiestudies kunnen verklaren.

Een ongestoorde bloedstroom door de bloedvaten is gebaseerd op een evenwicht in de reacties tussen bloedcellen, plasmaeiwitten en de met endotheel beklede vaatwand. Ten gevolge van een beschadiging van de vaatwand, worden bloedplaatjes geactiveerd via meerdere signaleringswegen, die in het bijzonder leiden tot een receptorgestimuleerde toename van de vrije $\mathrm{Ca}^{2+}$-concentratie in het cytosol van het bloedplaatje. Deze $\mathrm{Ca}^{2+}$ reactie kan vervolgens leiden tot een stollingsbevorderende (procoagulante) respons van bloedplaatjes wegens het verschijnen van fosfatidylserine aan hun buitenzijde. Hierop kunnen stollingsfactoren samenkomen, gevolgd door een activatie van de stollingscascade. In hoofdstuk 3 bestudeerden we of de procoagulante respons van 
bloedplaatjes een persoonsafhankelijke component heeft. Hiertoe vergeleken we agonist-geïnduceerde $\mathrm{Ca}^{2+}$ signaalgeneratie in de bloedplaatjes van gezonde vrijwilligers, jonge patiënten recupererend van een herseninfarct, en patiënten met symptomatisch perifeer vaatlijden. In de aanwezigheid van aspirine was de gemiddelde trombine-geïnduceerde $\mathrm{Ca}^{2+}$-respons van bloedplaatjes significant hoger in beide groepen patiënten, vergeleken met de gezonde proefpersonen. Patiënten met een herseninfarct hadden vaker bloedplaatjes met een hoge respons dan patiënten met perifeer vaatlijden of gezonde proefpersonen. In zowat de helft van de proefpersonen met een gekende hoge trombine-geinduceerde $\mathrm{Ca}^{2+}$-respons, was dit fenomeen vergezeld door een verhoogde procoagulante activiteit van de bloedplaatjes na stimulatie met trombine. In een vervolgstudie met bloedplaatjes van gezonde proefpersonen vonden we vervolgens dat de persoonsafhankelijke variatie in trombinegeïnduceerde $\mathrm{Ca}^{2+}$-respons ten minste gedeeltelijk het gevolg was van variatie in bloedplaatjesactivatie door de protease-geactiveerde receptor 1 (PAR1). Omdat PAR1afhankelijke variabiliteit in bloedplaatjesactivatie kan leiden tot integrineactivatie en bloedplaatjesaggregatie, bestudeerden we tevens de relatie tussen PAR1-geïnduceerde $\mathrm{Ca}^{2+}$-signalering en de genetische variatie in twee belangrijke integrines, $\alpha \mathrm{IIb} \beta 3$ and $\alpha 2 \beta 1$. Zowel het $\mathrm{Pl}^{\mathrm{A} 2}$ allel van de $\beta 3$ keten en het $807 \mathrm{~T}$ allel van de $\alpha 2$ keten zijn gelinkt met een verhoogde bloedplaatjesactivatie en kunnen daarom risicofactoren zijn voor een herseninfarct. De $\mathrm{Ca}^{2+}$-respons stond echter niet in verband met deze polymorfismen in bloedplaatjesintegrines.

Testen waarin de wederzijds stimulerende processen van bloedplaatjesactivatie en bloedstolling tegelijkertijd gemeten worden, kunnen belangrijke informatie opleveren over de hemostatische en daardoor protrombotische eigenschappen van het bloed. In hoofdstuk 4 bestudeerden we zulk een test, de gecalibreerde automatische trombogram methode, met als doel de relatie tussen bloedplaatjesactivatie en bloedstolling te bepalen in bloedplaatjes-rijk plasma (PRP) van gezonde proefpersonen. In deze test wordt de vorming van trombine voortdurend gemeten na triggering van het plasma met weefselfactor, terwijl fosfatidylserine-bevattende bloedplaatjes of fosfolipidenvesikels een procoagulant membraanoppervlak beschikbaar stellen. In PRP van alle proefpersonen stimuleerden bloedplaatjesagonisten zoals ADP, trombine en collageen de snelheid van trombinevorming. Omgekeerd vertraagden integrine allb $\beta 3$ antagonisten en ADP-receptor blokkering, maar niet aspirine, de vorming van trombine en verlengden de aanvangstijd van het proces. Remming van bloedplaatjes met cyclisch AMP-verhogende stoffen verminderde de trombinevorming, maar verkortte onverwacht de aanvangstijd.

Vergelijking van het plasma van verschillende proefpersonen gaf een belangrijke persoonsafhankelijke variatie in de totale hoeveelheid gevormd trombine, losstaand van de aanwezigheid van bloedplaatjes of fosfolipiden. Deze variatie duurde voort in de tijd. In PRP van donoren met lage of hoge trombinegeneratie waren bloedplaatjesstimulatoren en -remmers soortgelijk doeltreffend. Samenvattend tonen deze bevindingen aan dat in PRP gestimuleerd met weefselfactor, de expositie van fosfatidylserine door geactiveerde bloedplaatjes zowel de aanvangstijd als de snelheid 
van trombinevorming bepaalt. Terwijl de kinetiek van trombinevorming in het PRP gecontroleerd wordt door bloedplaatjesstimulatoren en -remmers, wordt de hoeveelheid tijdens dit proces gevormd trombine beperkt door de variabele, persoonsafhankelijke stollingsactiviteit van het plasma.

Deze kennis werd in de twee volgende hoofdstukken gebruikt, waar voedingsinterventies met n-3 PUFA afkomstig van visolie werden uitgevoerd bij proefpersonen met een verhoogd risico op atherotrombose. We bepaalden de bijdrage van de voornaamste (anti)stollingsfactoren aan de grote persoonsafhankelijke variatie in trombinegeneratie, en bestudeerden het effect van n-3 PUFA inname op plasmalipiden, stollingsfactoren en op het trombinegeneratieprofiel. We controleerden ook voor kandidaat genetische polymorfismen van bloedplaatjes en stollingsfactoreiwitten, welke gerelateerd zijn aan een verhoogd tromboserisico, hierbij de hypothese stellende dat het antitrombotisch effect van n-3 PUFA een genetische component heeft.

In hoofdstuk 5 worden de resultaten beschreven van een voedingsinterventiestudie, waarin 25 gezonde mannelijke proefpersonen met overgewicht dagelijks $3.0 \mathrm{~g} \mathrm{n}-3$ PUFA innamen gedurende vier weken. Voor de inname van visolie was er een aanzienlijke variatie in de trombinegeneratie tussen de plasmas van de individuele proefpersonen. Deze variatie kon voor een belangrijk deel verklaard worden door variatie in de plasmaconcentraties van protrombine, antitrombine, fibrinogeen en factor V. Inname van visolie verminderde de plasma triglyceridenconcentratie, alsook de concentraties van fibrinogeen en factor $\mathrm{V}$, en verlaagde de activatie van bloedplaatjesintegrines. Hoewel deze interventie geen effect had op de vitamine Kafhankelijke stollingsfactoren, was de trombinegeneratie zowel in aan- als afwezigheid van bloedplaatjes verlaagd. Deze verlaging correleerde met het verlagend effect van visolie op de plasmaconcentraties van fibrinogeen en factor $V$. In deze kleine studiepopulatie groepeerde het verlagend effect van visolie op trombinegeneratie en fibrinogeenconcentratie zich rond proefpersonen met hoge baseline fibrinogeenconcentraties, die vaak de 312Ala variant van het fibrinogeen- $\alpha$ T312A polymorfisme bezaten. Verder hadden dragers van de 1299Arg variant van het factor $\mathrm{V}$ His 1299Arg (A4070G) polymorfisme lagere factor V concentraties dan niet-dragers, en dit zowel voor als na visolie supplementatie. De 1299Arg dragers hadden ook de neiging beter te reageren op visolie.

Om dit werk uit te bereiden en te bepalen hoe visolie de plasmaconcentraties van vitamine $\mathrm{K}$-afhankelijke en -onafhankelijke stollingsfactoren beïnvloedt, werden twee andere studies uitgevoerd met proefpersonen met een verhoogd risico op atherotrombose. Hoofdstuk 6 beschrijft de resultaten van deze studies, uitgevoerd met 57 gezonde proefpersonen met overgewicht (4 weken interventie), en 42 patiënten met type 2 diabetes en een neiging tot verhoging van de triglyceridenconcentratie ( 8 weken interventie). Alle proefpersonen namen dagelijks $3.1 \mathrm{~g} \mathrm{n}-3$ PUFA in. In beide studies toonde multivariantie-analyse een sterke groepering van de plasmaconcentraties van triglyceriden, protrombine, factor $\mathrm{V}$, factor VII, en factor $\mathrm{X}$ voor de aanvang van de studie. Dit cluster droeg significant bij tot de persoonsafhankelijke variatie in trombinegeneratie. De plasmaconcentraties van vooral triglyceriden en protrombine 
waren bepalend voor de hoeveelheid gevormd trombine, ook al zijn triglyceriden zelf niet betrokken bij de trombinevorming. Verder waren zowel bij de proefpersonen met overgewicht als bij de type 2 diabetes patiënten, hoge anvangsconcentraties van triglyceriden nauw verbonden met een sterkere visolie-geïnduceerde verlaging van de concentraties van triglyceriden en factoren V, VII, en X, tesamen met een vermindering in trombinegeneratie.

In deze grotere studie populatie was het fibrinogeen- $\alpha$ T312A polymorfisme niet langer gerelateerd aan een effect van visolie op de trombinegeneratie. Zoals in de studie van hoofdstuk 5 hadden 1299Arg dragers van het factor V His1299Arg (A4070G) polymorfisme de neiging om beter te reageren op visolie. Correlatie-analyse toonde echter aan dat genetische variatie in stollingsfactoren geen bepalende factor was in de individuele visolie-effecten. We vonden geen verklaring voor de covariantie in concentraties van triglyceriden en stollingsfactoren. In het nuchtere plasma is het grootste deel van de triglyceriden aanwezig in very-low density lipoproteïnen (VLDL), geproduceerd door de lever. Omdat de lever tevens de grootste bron van stollingsfactoren is, veronderstellen we dat één of meer processen in de lever samen de productie of secretie van VLDL en stollingsfactoren controleert.

Om een mogelijk mechanisme voor de gepaarde lipidenverlagende en stollingsverminderende effecten van visolie te vinden, stapten we over op de muis in de studie beschreven in hoofdstuk 7. We gebruikten hyperlipidemische en pro-atherogene APOE2 knock-in muizen, waarin het eigen muizen apoE gen is vervangen door het humane, hoge-risico APOE2 gen. Volwassen mannelijke APOE2 knock-in muizen ontwikkelden hyperlipidemie en hadden hogere plasmaconcentraties van stollingsfactoren dan wildtype muizen, wanneer ze gevoed werden met een laag-vet dieet. Zowel de plasmalipiden als de stollingsfactoren normaliseerden wanneer de APOE2 knock-in muizen gevoed werden met een hoog-vet dieet dat rijk was aan visolie ( $n-3$ PUFA), maar niet met een vergelijkbaar dieet met zonnebloemzaadolie ( $n-6$ PUFA). Voedingsinterventie met visolie resulteerde ook in een aanmerkelijke reductie in trombinegeneratie. Genexpressie analyse, onder meer middels micorarrays van het lever mRNA, toonde aan dat visolie, maar niet zonnebloemzaadolie, leidde tot een opregulatie van de genen betrokken bij vetzuurdegradatie en -oxidatie, en een afname van expressie van genen betrokken bij vetzuursynthese en -transport. Er werden echter geen grote veranderingen in genen van (anti)stollingsfactoren gevonden, behalve een verlaagde genexpressie van het $\gamma$-glutamyl carboxylase. Immunohistochemische kleuring van leversecties toonde aan dat enkel het dieet met visolie de aanwezigheid van vitamine K-afhankelijke stollingsfactoren in de lever verhoogde. We concluderen dat de hyperlipidemische en hypercoagulante APOE2 knock-in muizen op een voedingsinterventie met $n-3$ PUFA reageren door een verminderde stollingsactiviteit, die niet veroorzaakt wordt door een veranderde hepatische expressie van stollingsfactorgenen, maar door het weerhouden van deze stollingsfactoren in de lever, ten dele door veranderde post-translationele modificatie. Het lipidenverlagende effect van n-3 PUFA wordt verklaard door een verhoogde hepatische expressie van genen die de vetzuurdegradatie regelen en een verminderde expressie van genen die de 
vetzuursynthese regelen. Deze resultaten wijzen niet op een gemeenschappelijk regelmechanisme van lipidenmetabolisme en synthese van stollingsfactoren.

Hoofdstuk 8 plaatst de belangrijkste resultaten van dit proefschrift in een breder perspectief. De gecalibreerde automatische trombogrammethode uitgevoerd met PRP blijkt een variabele, persoonsafhankelijke activiteit van het plasma te detecteren, die afhankelijk is van de aanwezigheid en activatie van de bloedplaatjes, maar beperkt is in snelheid en omvang door de stollingsactiviteit van het plasma. Plasmaconcentraties van protrombine, antitrombine en triglyceriden dragen significant bij tot de persoonsafhankelijke variatie in trombinegeneratie, hoewel triglyceriden per se niet betrokken zijn bij het trombinegeneratieproces. Een belangrijke bevinding is dat de lipiden- en stollingsverlagende effecten van visolie het grootst zijn bij proefpersonen met een hoge triglyceridenspiegel in plasma of een hoge trombinegeneratie. Dit geeft aan dat personen met een risicovol hyperlipidemisch en hypercoagulant profiel wellicht het meeste voordeel zullen hebben bij het innemen van visolie. Genetische variatie echter, voor zover onderzocht, blijkt geen belangrijke rol te spelen in de persoonsafhankelijke reactie op een dieet rijk aan visolie. 
Dankwoord 
Het dankwoord van een proefschrift bevat meestal enkele clichés, die ik al schrijvende enkel maar kan bevestigen. Eén daarvan is dat een dankwoord (meestal) als allerlaatste hoofdstuk van het proefschrift wordt geschreven door de betreffende promovendus, terwijl het door de meerderheid van de lezers als eerste (en vaak ook enige) hoofdstuk volledig wordt gelezen. Een ander cliché is dat een proefschrift enkel tot stand kan komen door de samenwerking van een heel team. Vandaar dat ik dan ook begin met iedereen, die doorheen de jaren - van hél ver tot héél dichtbij - betrokken was met het onderzoek beschreven in dit proefschrift, te bedanken voor de geleverde tijd en/of moeite. Aan iedereen die dit leest, en die van zichzelf weet dat hij/zij een wezenlijke bijdrage geleverd heeft, bedankt voor alles.

Hetgeen hierboven beschreven staat verhindert me echter niet een aantal personen extra in de schijnwerpers te plaatsen. In de eerste plaats de leden van mijn promotieteam, die ieder op hun manier betrokken waren bij mijn promotietraject en de totstandkoming van dit proefschrift. Johan, als mijn dagelijkse begeleider en co-promotor was je de drijvende kracht achter het werk beschreven in de voorgaande hoofdstukken. Ondanks de schijnbaar ontelbare projecten waarbij je tegelijkertijd betrokken bent, was je er altijd wanneer nodig. Bedankt voor je geduld en het vertrouwen dat je in mij stelde bij het opzetten en uitvoeren van de experimenten en de (klinische) studies, en de kritische beoordeling van de resultaten en manuscripten die ik inleverde. Moniek, als copromotor bedankt voor de begeleiding op afstand en de frisse kijk op het hele gebeuren in Maastricht. Voor uitleg over statistiek en genetica kon ik steeds bij jou terecht, en jouw connecties waren bepalend voor de resultaten beschreven in hoofdstuk 6 . Wim, als promotor was je meer op de achtergrond aanwezig, maar je wist wel altijd waar ik mee bezig was. Bedankt voor de motiverende gesprekken en de geboden kansen, ook na mijn promotietraject.

De leden van de beoordelingscommissie, bestaande uit Prof. dr. C.D.A. Stehouwer, Prof. dr. H. ten Cate, Dr. C. Kluft, Prof. dr. E.C.M. Mariman en Prof. dr. ir. R.P. Mensink, wil ik bedanken voor het kritisch evalueren van dit proefschrift.

Voorts wil ik de medeauteurs vermelden van de manuscripten waarop de uiteindelijke hoofdstukken van dit proefschrift gebaseerd zijn. Prof. Hemker en Peter Giesen, bedankt om me in te wijden in de thrombine generatie test, die mede aan de basis lag van een groot deel van de resultaten beschreven in de voorgaande hoofdstukken. Jan Rosing, bedankt voor je bijdrage aan hoofdstuk 5 en de kritische vragen tijdens de werkbesprekingen. Marten Hofker, Patrick van Gorp, Kristiaan Wouters en Leon Schurgers, bedankt voor jullie tijd, vakkundige uitleg en verstrekte hulp bij de experimenten beschreven in hoofdstuk 7. Leon, extra dank voor de aangename gesprekken en succes nog met het verder uitbouwen van VitaK. Matthijs Blankesteijn, bedankt voor het verlenen van de benodigde lab faciliteiten.

I would like to thank Dr. Stoffer Loman (Pharma Nord, Vejle, Denmark) for the kind supply of capsules for the described intervention studies, and Dr. Peter Marckmann and coworkers (Esbjerg, Denmark) for their help in the intervention study presented in chapter 6 , and the collection of patient data and samples.

Een speciaal woord van dank gaat naar de oud-collega's van beide onderzoeksgroepen 
waarin ik werkzaam was gedurende mijn jaren aan de Universiteit van Maastricht. Allereerst de leden van de 'plaatjes' groep met wie ik in de jaren van mijn promotietraject nauw samengewerkt heb. Marion, je hebt me met raad en daad bijgestaan tijdens mijn eerste (schuifelende) passen van dit traject en ook daarna was je altijd bereid een luisterend oor te verlenen. Bedankt, ik ben het niet vergeten. Voorts Jeffrey, Marijke, Imke, Sandra en Judith, bedankt voor de leuk tijd binnen en buiten het lab, in al zijn facetten. Veel succes allemaal met jullie verdere carrière. Paola, voor jou natuurlijk hetzelfde als hierboven beschreven en een extra woord van dank omdat je de rol van paranimf wil vervullen. Het cocktailjurkje zal je trouwens beeldig staan.

Ook een woord van dank aan Theo en Simone, voor de kritische opmerkingen met betrekking tot respectievelijk wetenschappelijk onderzoek en het hele gebeuren er omheen. Mieke, bedankt voor de (h)eerlijke uitspraken tijdens en na het werk (Chroesjtsjov - ik heb het even opgezocht), en succes met je nieuwe carrière als piano lerares.

Voorts alle leden van de $3 \mathrm{M} \mathrm{M} \mathrm{M}^{3}$ groep, waarin ik werkzaam was na mijn promotietraject. Luc, bedankt voor alle geboden mogelijkheden - onze samenwerking heeft me voor een deel gevormd tot de wetenschapper die ik nu ben. Je bent 24/7 aan het werk, zelfs als je dat niet bent, en alleen al daarom nog veel succes met alles wat je verder onderneemt. Zorg er echter voor dat het de moeite waard blijft om je dromen waar te maken. René, terwijl onze kamergenoten (Erwin, Kaatje, Hanneke, Githa en Anneke - een blijvertje) kwamen en gingen, bleven wij gezellig zitten op ons eilandje op de derde verdieping. Gelukkig voor ons bleek het uiteindelijk geen halitose, maar een gebrek aan zonlicht te zijn. Bedankt voor alle gesprekken over werk en leven algemeen, en de stiltes wanneer nodig. Samen met Anouk veel succes toegewenst met jullie oversteek naar het grootste eiland van allemaal. Anouk, omdat ik weet dat je dit leest, nogmaals bedankt voor de Q-tip - Q is good for you. Ralph, officieel gehuisvest op de tweede verdieping, maar vaak derde man op onze kamer en nooit te beroerd om een helpende hand toe te steken. Nog veel succes met het afronden van je eigen proefschrift en ook jij bedankt omdat je de rol van paranimf wil vervullen. Antoine, Bart, Hanneke, Joan, Lex, Maurice, Michael, Milou, Richard en Stephan, bedankt voor jullie kleine en grote bijdragen aan mijn aangename tijd in Maastricht, en nog veel succes met jullie carrières. Jos - kunnen we niet, hebben we niet, beginnen we niet aan - schitterend hoe menig beginnend promovendus beteuterd terug aanklopte bij zijn/haar begeleider. Bregje en Ruth, dames die bewezen hun mannetje te staan, succes met jullie promotietraject en tot binnenkort. Katrien van Laere en het team van Numico Research B.V., bedankt voor de samenwerking, ik heb er het nodige van opgestoken. Buurvrouw Kristel, bedankt voor je hulp bij de laatste loodjes.

Iedereen werkzaam op de afdelingen Humane Biologie en Biochemie, gaande van secretariaat over analisten tot collega promovendi, bedankt voor de leuke tijd van de voorbije jaren, en dit zowel tijdens als na de uren op de afdeling. Zonder proefpersonen en helpende handen staat een (klinisch) onderzoeker nergens, vandaar mijn dank aan alle mannen en vrouwen die gedurende de voorbije jaren vrijwillig deelnamen aan de in dit proefschrift beschreven studies, en aan alle nog niet eerder vermelde stagestudenten 
die me assisteerden bij deze onderzoeken. Ook een woord van dank aan de medewerkers van de Centrale Proefdier Voorzieningen.

Veerle, eerst collega en vervolgens lotgenoot die een stap zette in de vriendenkring, bedankt voor alle vakkundige uitleg en hulp bij de genetische en histologische experimenten beschreven in hoofdstuk 7. Ook al was je zelf druk bezig, steeds wist je tijd en antwoorden op mijn vragen te vinden. Je weet ondertussen ook wat het betekent een proefschrift af te ronden in combinatie met een nieuwe baan en het (ver)bouwen van een huis. Nog even doorbijten, binnenkort begin je aan je eigen dankwoord.

Rest me enkel nog het thuisfront te bedanken voor de jarenlange trouwe steun en interesse. Alle vrienden en familieleden die zich momenteel nog steeds afvragen wat een promotietraject inhoudt, raad ik aan het boek 'Lab' van Miquel Bulnes (Vassallucci Amsterdam 2005) te lezen. Naast enkele vermakelijke uurtjes biedt dit boek ook alle antwoorden op jullie vragen. Voorts hopen we binnenkort eindelijk ons steentje bij te dragen aan de snel uitbreidende sierbende.

Een bijzonder woord van dank ook aan mijn ouders en zusje. Ik ben soms een man van (te) weinig woorden en tijd, maar ik besef maar al te goed dat ik zonder de door jullie aangeboden steun en mogelijkheden niet zou staan waar ik nu sta. Jullie blijven rotsvast in Anneleen en mij geloven, in welk avontuur we ons ook storten. Alleen al daarom is jullie hulp onbetaalbaar - ik draag dit proefschrift dan ook op aan jullie. Lig er voor de rest niet (meer) van wakker, alles komt uiteindelijk op zijn pootjes terecht.

De laatste woorden die ik schrijf in het kader van dit proefschrift zijn bestemd voor jou, Daisy. In al die jaren ben je nooit in het voetlicht getreden, maar toch ben je de belangrijkste persoon betrokken bij het tot standkomen van dit proefschrift. Bedankt voor alle liefde en steun, en om me alle benodigde tijd en ruimte te geven. Je weet dat het wederzijds is. Ik ben dan ook enorm trots op wat we beiden zowel privé als professioneel tot nog toe verwezenlijkt hebben - we zijn goed bezig...

Been there, done that. 


\section{Curriculum Vitae}


Kristof Vanschoonbeek was born on January 3rd 1973 in Hasselt, Belgium. After completing secondary school at the Amandinacollege in Herk-de-Stad, he obtained his bachelor's degree in Medical Laboratory Technology (1996, Katholieke Hogeschool Leuven) and his master's degree in Biomedical Sciences (1999, Vrije Universiteit Brussel). In the summer months from 1996 until 1999, he was employed as biomedical laboratory technician at the Haemostasis Laboratory of the University Hospital of Leuven (Campus Gasthuisberg). From September 1998 until June 1999, he was trained in the Centre of Molecular and Vascular Biology (Katholieke Universiteit Leuven) under supervision of Dr. ir. J. Arnout. He continued to work there as scientific researcher until June 2000. From August 2000 until September 2004, he was employed as $\mathrm{PhD}$ student at the Department of Human Biology, Nutrition and Toxicology Research Institute Maastricht (NUTRIM) of the University of Maastricht. In this period, he performed the research described in this thesis under supervision of Dr. J.W.M. Heemskerk, together with Dr. M.P. de Maat and Prof. dr. ir. W.H.M. Saris. This work was supported by the Netherlands Organization for Scientific Research (ZonMw, programme Nutrition and Chronic Diseases). From October 2004 until May 2007, he worked as scientific researcher in the same department. In this period, he studied the effect of nutritional components on blood glucose concentration and body composition in type 2 diabetes patients and healthy elderly, in collaborative projects with Numico Research B.V. and the Virga Jesse Hospital of Hasselt. In June 2007, he obtained a position as Clinical Research Associate at Quintiles Belgium, a Contract Research Organization. 


\section{Publications}




\section{Full papers:}

- Vanschoonbeek K, Feijge MAH, Keuren JFW, Hemker HC, Lodder JJ, Hamulyàk $\mathrm{K}$, van Pampus ECM, Heemskerk JWM. Thrombin-induced hyperactivity of platelets of young stroke patients. Thromb Haemost. 2002; 88: 931-37.

- Vanschoonbeek K, de Maat MPM, Heemskerk JWM. Fish oil consumption and reduction of arterial disease. J Nutr. 2003; 133: 657-60.

- Vanschoonbeek K, Feijge MAH, van Kampen R, Kenis H, Hemker HC, Giesen PLA, Heemskerk JWM. Initiating and potentiating role of platelets in tissue factorinduced thrombin generation in the presence of plasma: subject-dependent variation in thrombogram characteristics. J Thromb Haemost. 2004; 2: 476-84.

- Feijge MAH, Ansink K, Vanschoonbeek K, Heemskerk JWM. Control of platelet activation by cyclic AMP turnover and cyclic nucleotide phosphodiesterase type-3. Biochem Pharmacol. 2004; 67: 1559-67.

- Vanschoonbeek K, Feijge MAH, Paquay M, Rosing J, Saris WHM, Kluft C, Giesen PLA, de Maat MPM, Heemskerk JWM. Variable hypocoagulant effect of fish oil intake in man: modulation of fibrinogen level and thrombin generation. Arterioscler Thromb Vasc Biol. 2004; 24: 1734-40.

- Vanschoonbeek K, Thomassen BJW, Senden JM, Wodzig WKWH, van Loon LJC. Cinnamon supplementation does not improve glycemic control in post-menopausal type 2 diabetes patients. J Nutr. 2006; 136: 977-80.

- Vanschoonbeek K, Feijge MAH, Saris WHM, de Maat MPM, Heemskerk JWM. Plasma triacylglycerol and coagulation factor concentrations predict the anticoagulant effect of dietary fish oil in overweight subjects. J Nutr. 2007; 137: 713.

- Vanschoonbeek K, Wouters K, van der Meijden PEJ, van Gorp PJ, Schurgers LJ, Feijge MAH, Hofker MH, de Maat MPM, Heemskerk JWM. Anticoagulant effect of dietary fish oil in hyperlipidemia: a study of hepatic mRNA expression in APOE2 knock-in mice (Submitted, 2007).

\section{Abstracts:}

- Vanschoonbeek K, van Pampus ECM, Feijge MAH, Keuren JFW, Ansink K, Hemker HC, Hamulyàk K, Lodder JJ, Heemskerk JWM. Thromboxane-independent hyperactivity of platelets from patients with arterial vascular disease. Thromb Haemost. 2001; 86 (Suppl. July). 
- Vanschoonbeek K, van Pampus ECM, Feijge MAH, Keuren JFW, Ansink K, Hemker HC, Hamulyàk K, Lodder JJ, Heemskerk JWM. Hyperactive platelets in young patients with stroke. Platelets. 2002; 13: 61.

- Feijge MAH, Ansink K, Vanschoonbeek K, Giesen PLA, Heemskerk JWM. Differential platelet-stimulatory effects of cAMP- and cGMP phosphodiesterases. Platelets. 2002; 13: 334-35.

- Vanschoonbeek K, van Kampen R, Feijge MAH, Hemker HC, Giesen PLA, de Maat MPM, Heemskerk JWM. Platelets and thrombin formation: effects of fish oil supplementation. Platelets. 2002; 13: 511.

- Vanschoonbeck K, Feijge MAH, van Kampen R, Hemker HC, Giesen PLA, Heemskerk JWM. Effects of platelet agonists and antiplatelet agents on thrombin formation in human plasma. J Thromb Haemost. 2003; 1 (Suppl. July).

- Vanschoonbeek K, Feijge MAH, Paquay M, de Maat MPM, Heemskerk JWM. Effects of dietary fish oil on coagulation and platelets. J Thromb Haemost. 2003; 1 (Suppl. July). 